



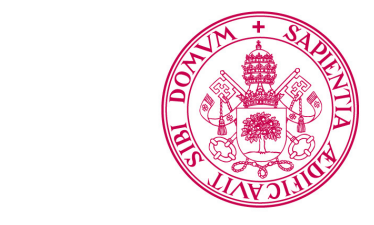

Universidad deValladolid

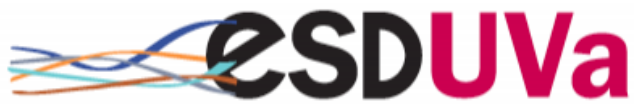

Escuela de Doctorado Universidad de Valladolid

PROGRAMA DE DOCTORADO EN INVESTIGACIÓN

TRANSDISCIPLINAR EN EDUCACIÓN

TESIS DOCTORAL:

\section{APROXIMACIÓN A UN MODELO QUE \\ EXPLIQUE LA TRANSFERENCIA EN EL APRENDIZAJE ESCOLAR}

Presentada por $\mathrm{M}^{\mathrm{a}}$ Henar Reca Fernández

para optar al grado de

doctora por la Universidad de Valladolid

Dirigida por:

Dr. Benito Arias Martínez

Dra. Henar Rodríguez Navarro 



\section{TABLA DE CONTENIDOS}

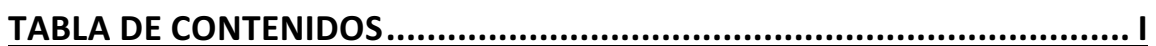

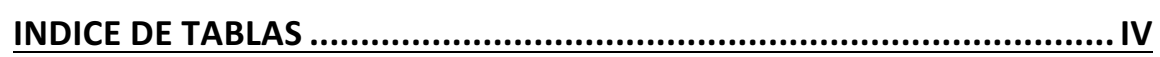

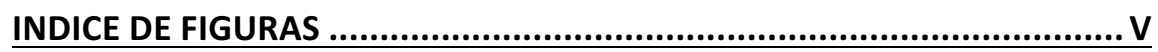

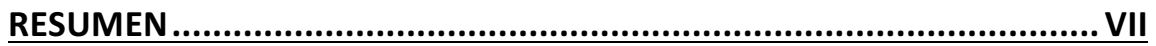

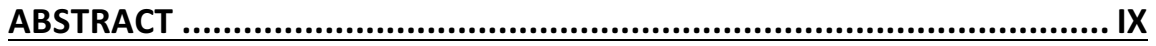

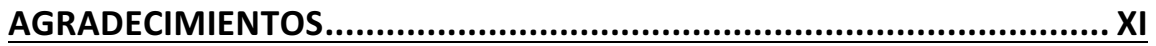

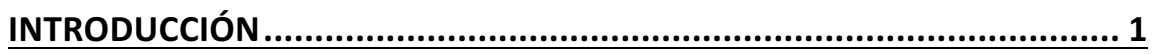

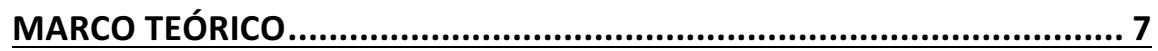

1. DEFINICIÓN DE LA TRANSFERENCIA EN LOS ENTORNOS

COMUNICATIVOS DE APRENDIZAJE ............................................... 8

1.1 ENTORNOS COMUNICATIVOS DE APRENDIZAJE ........................................... 8

1.2 PROPUESTAS DE ENTORNOS COMUNICATIVOS DE APRENDIZAJE.................... 12

1.3 CONCEPTUALIZACIÓN DE LA TRANSFERENCIA EN EL APRENDIZAJE ESCOLAR ..... 14

1.4 TRANSFERENCIA EN ENTORNOS COMUNICATIVOS DE APRENDIZAJE ................ 17

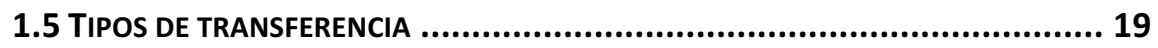

2. ESTADO DE LA CUESTIÓN: ANTECEDENTES Y ESTUDIOS PREVIOS QUE

ANALIZAN LA TRANSFERENCIA ............................................................ 24

2.1 ANALOGÍAS EN TAREAS Y RESOLUCIÓN DE PROBLEMAS ............................. 24

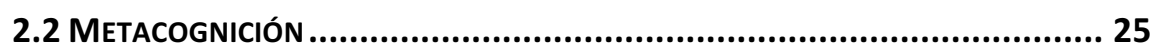

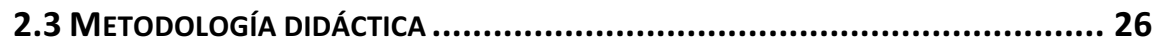

3. DIMENSIONES Y VARIABLES QUE DEFINEN LA TRANSFERENCIA

EDUCATIVA …................................................................................... 27

3.1 ASPECTOS DE TIPO COGNITIVO Y METACOGNITIVO .................................... 29

3.2 ASPECTOS EMOCIONALES Y MOTIVACIONALES QUE IMPLICAN LA TRANSFERENCIA

33

3.3 ASPECTOS CONTEXTUALES ................................................... 35

$$
-1-
$$


4. ENFOQUE DE LA TRANSFERENCIA APORTADO ................................ 38

5. ANÁLISIS DEL DISCURSO EN EL AULA …...................................... 39

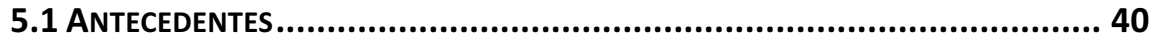

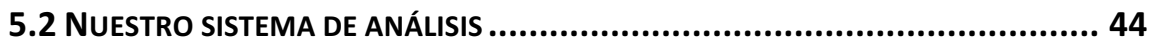

5.3 RELACIÓN DEL ANÁLISIS DE LA PRÁCTICA EDUCATIVA Y LA TRANSFERENCIA ..... 45

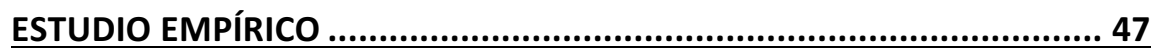

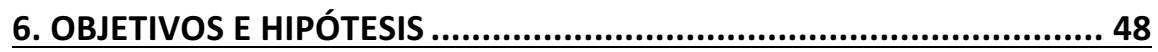

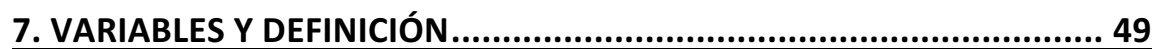

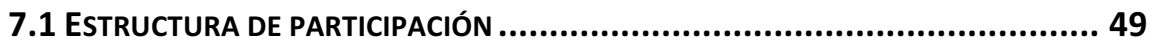

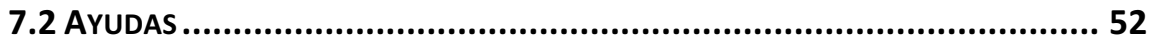

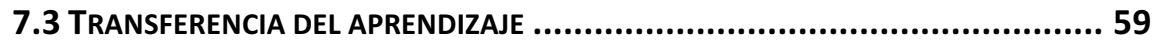

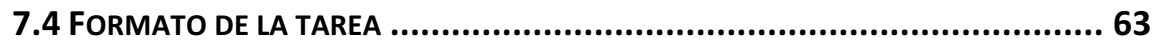

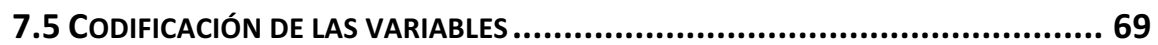

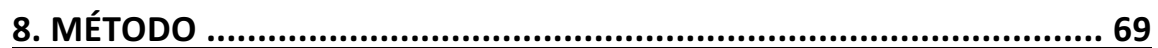

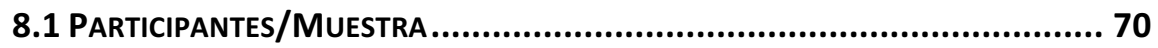

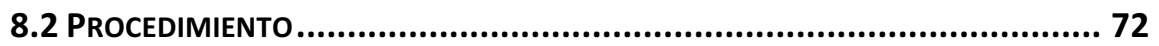

CREACIÓN DE UNA ESTRUCTURA DE APRENDIZAJE COMÚN ...................................74

IMPLEMENTACIÓN EN LAS CLASES DE LENGUA Y EDUCACIÓN FÍSICA ........................77

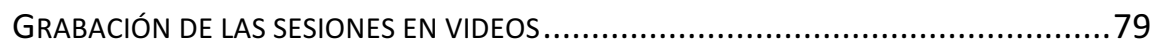

SISTEMA DE CATEGORIZACIÓN DE ANÁLISIS (CRITERIOS) .....................................8

EXPLICACIÓN DEL PROCESO DE ANÁLISIS DE LAS INTERACCIONES EN NUESTRA

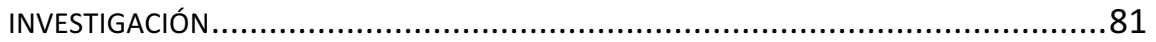

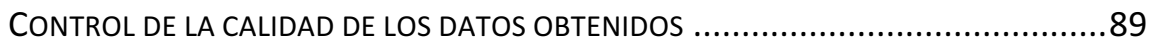

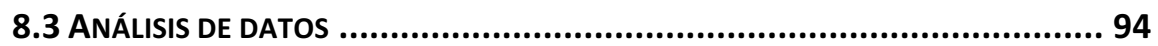

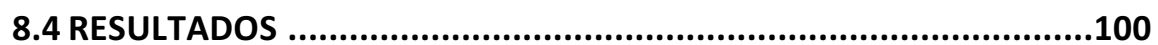

8.4.1 RESULTADOS DE LOS ANÁLISIS DESCRIPTIVOS .....................................100

8.4.2 ANÁLISIS LOG-LINEAL ....................................................... 127

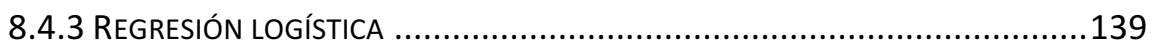

8.4.4 GRADO DE CUMPLIMIENTO O VERIFICACIÓN DE LAS HIPÓTESIS.....................157

$$
-\mathrm{II}-
$$


9. DISCUSIÓN, LIMITACIONES E IMPLICACIONES PARA INVESTIGACIONES FUTURAS.............................................................159

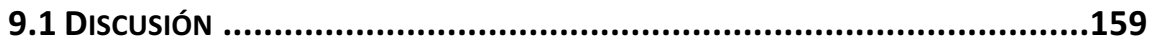

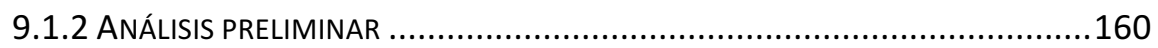

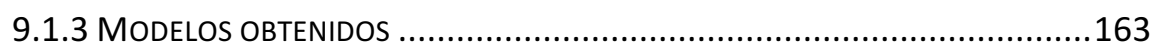

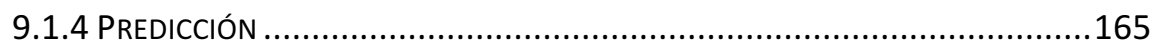

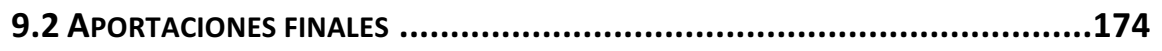

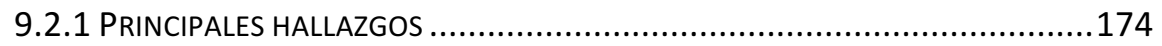

9.2.2 INTERACCIÓN ENTRE ASPECTOS CUANTITATIVOS Y CUALITATIVOS .................178

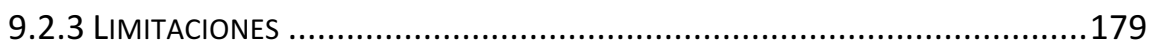

9.3 VÍAS FUTURAS DE INVESTIGACIÓN ....................................................180

REFERENCIAS BIBLIOGRÁFICAS ..............................................183

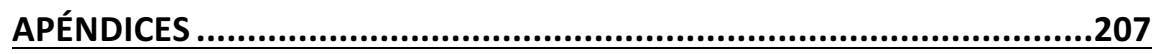

APÉNDICE A: CATEGORÍAS INICIALES........................................208

APÉNDICE B: TRANSCRIPCIONES Y CATEGORIZACIÓN .......................209

APÉNDICE C: SINTAXIS DE LOS ANÁLISIS EXPLORATORIOS (R) ...........236

APÉNDICE D: SINTAXIS DEL ANÁLISIS LOGARÍTMICO-LINEAL (R) ........239

APÉNDICE E: SINTAXIS DEL ANÁLISIS DE REGRESIÓN LOGÍSTICA (SAS)245

APÉNDICE F: CÓDIGO DE OTROS ANÁLISIS (R)..............................250

APÉNDICE G: CÓDIGO DE OTROS ANÁLISIS (STATA) ........................252 


\section{INDICE DE TABLAS}

TABLA 1 UNIDADES DE ANÁLISIS (SÁNCHEZ ET AL., 2010) ............................................. 42

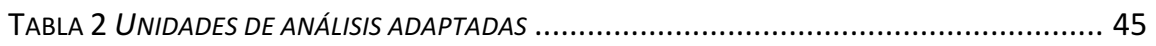

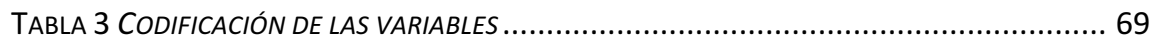

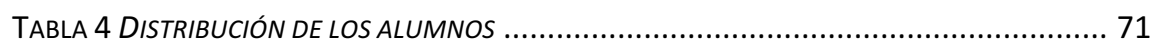

TABLA 5 ELEMENTOS DE TRANSFERENCIA ENTRE ÁREAS ............................................... 76

TABLA 6 CATEGORIZACIÓN OBSERVACIONES ALEATORIAS JUECES ....................................... 91

TABLA 7 INTERPRETACIÓN DE LOS VALORES DE LOS COEFICIENTES DE CONCORDANCIA B ${ }_{N}^{W} \ldots . . .94$

TABLA 8 FRECUENCIA ESTRUCTURA DE PARTICIPACIÓN .............................................. 102

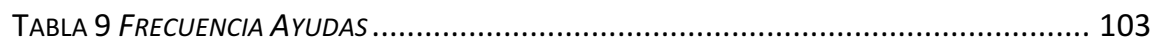

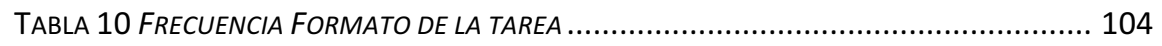

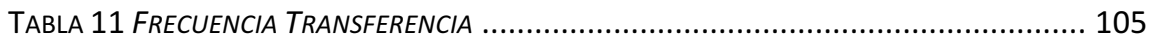

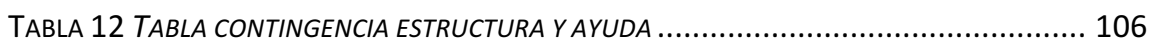

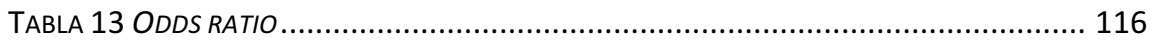

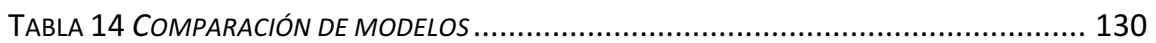

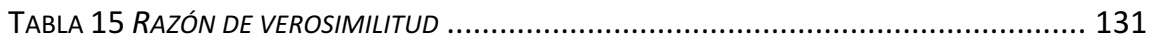

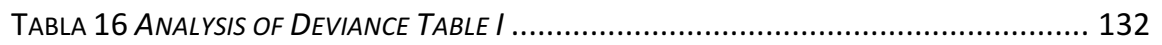

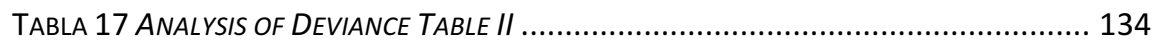

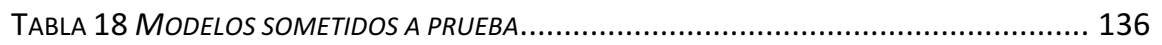

TABLA 19 DESCRIPTIVOS POR CATEGORÍA DE PREDICTORES ......................................... 140

TABLA 20 ANÁLISIS DE LOS ESTIMADORES DE MÁXIMA VEROSIMILITUD .............................. 143

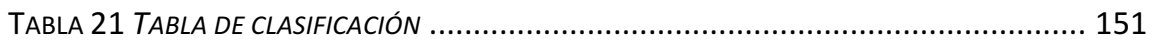

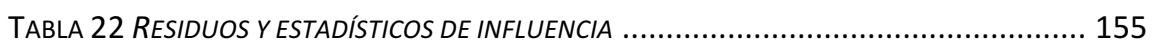




\section{INDICE DE FIGURAS}

FIGURA 1. APORTACIONES A LOS ENTORNOS COMUNICATIVOS DE APRENDIZAJE ................... 12

FIGURA 2. DIVERSIDAD DE TIPOLOGÍAS DE TRANSFERENCIA ........................................... 23

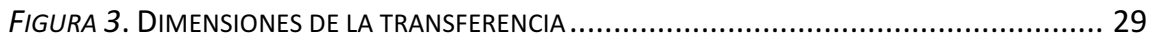

FIGURA 4. MOdELO COMPLETO DE LAS VARIABLES DE ESTUDIO. .....................................6 68

FIGURA 5. SÍNTESIS DEL PROCEDIMIENTO LLEVADO A CABO ........................................... 73

FIGURA 6. RESULTADOS DE LA CONCORDANCIA ENTRE JUECES. ..................................... 93

FIGURA 7. GRÁFICO DE BALÓN ESTRUCTURA DE PARTICIPACIÓN Y AYUDA........................... 107

FiguRa 8. GRÁFICO de BALÓN ESTRUCTURA de PARTICIPACIÓN Y FORMATO DE LA TAREA..... 109

FIGURA 9. GRÁFICO DE BALÓN ESTRUCTURA DE PARTICIPACIÓN Y TRANSFERENCIA. ............. 110

FIGURA 10. GRÁFICO DE BALÓN FORMATO DE LA TAREA Y AYUDA................................ 112

FIGURA 11. GRÁFICO DE BALÓN TRANSFERENCIA Y AYUDA.......................................... 113

FIGURA 12. GRÁFICO DE BALÓN FORMATO DE LA TAREA Y TRANSFERENCIA. ..................... 114

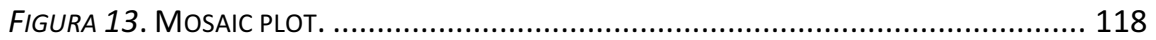

FIGURA 14. ASSOCIATION PLOT. .................................................................... 120

FIGURA 15. ANÁLISIS DE CORRESPONDENCIAS ENTRE ESTRUCTURA DE PARTICIPACIÓN Y FORMATO

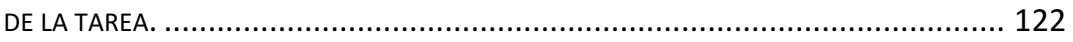

FIGURA 16. ANÁLISIS DE CORRESPONDENCIAS ENTE ESTRUCTURA DE PARTICIPACIÓN Y

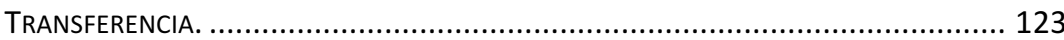

FIGURA 17. ANÁLISIS DE CORRESPONDENCIAS ENTRE FORMATO DE LA TAREA Y TRANSFERENCIA.

124

FIGURA 18. ANÁlISIS DE CORRESPONDENCIAS ENTRE AYUDA Y FORMATO DE LA TAREA. ....... 125

FIGURA 19. ANÁLISIS DE CORRESPONDENCIAS ENTRE ESTRUCTURA DE PARTICIPACIÓN Y AYUDA.

FIGURA 20. ANÁLISIS DE CORRESPONDENCIAS ENTE TRANSFERENCIA Y AYUDA. ................. 127

FIGURA 21. REPRESENTACIÓN GRÁFICA DE LOS MODELOS SOMETIDOS A PRUEBA. ............... 139

FIGURA 22. COMPARACIÓN DE CURVAS ROC CON DISTINTAS COMBINACIONES DE PREDICTORES.

FIGURA 23. OdDS RATIOS CON LÍMITES DE CONFIANZA (95\%) DE WALD. ....................... 149

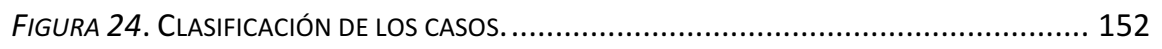

FIGURA 25. DIAGNÓSTICO DE LOS RESIDUOS Y ESTADÍSTICOS DE INFLUENCIA..................... 153 



\section{Resumen}

$\mathrm{E}$ 1 objetivo de la tesis ha consistido en: (1) identificar si existe relación entre las variables estructura de participación (EST), ayuda (AYU), formato de la tarea (FOR) y transferencia (TRA); (2) establecer el mejor modelo que se ajuste a los datos empíricos y (3) constituir las relaciones entre las variables independientes estructura de participación, ayuda y formato de la tarea y la variable dependiente transferencia. Para lograr este fin, se planteó una aproximación a los métodos mixtos donde se realizó un análisis de contenido para transcribir las secuencias de aprendizaje, análisis multivariado para identificar relaciones entre las variables, análisis log-lineal con el fin de establecer el mejor modelo y el análisis de regresión logística para establecer relaciones entre las VI y la VD. La muestra constó de 1506 secuencias de aprendizaje observadas en las sesiones de grupos interactivos en las áreas de Lengua Castellana y Literatura y Educación Física en alumnos de $5^{\circ}$ y $6^{\circ}$ de Educación Primaria. Los principales resultados mostraron que: (a) el mejor modelo que se ajusta con los datos recogidos es EST*AYU*FOR+EST*FOR*TRA+AYU*FOR*TRA, (b) la variable predictora estructura de participación presentó el mejor poder clasificatorio de las tres en la transferencia del aprendizaje seguido de formato en la tarea y ayuda, (c) la estructura de participación dialógica contribuyó en mayor medida al proceso de transferencia, (d) el formato en la tarea que contenía solo explicación contribuyó en mayor medida al proceso de transferencia y (e) la ayuda de tipo regulatoria contribuyó en mayor medida al proceso de transferencia. Como aspectos a destacar de este estudio caben mencionar: (1) la novedad en cuanto al tipo de análisis en el campo educativo, (2) la relación entre la 
estructura dialógica del aprendizaje con la transferencia, (3) utilización del sistema de clasificación de la Interacción Social en el aula aunándolo a la transferencia del aprendizaje en entornos comunicativos de aprendizaje y (4) aproximación teórica que introduce los postulados ofrecidos por la psicología socio cultural al concepto de transferencia de aprendizaje.

Palabras clave: Entornos comunicativos de aprendizaje, transferencia, análisis multivariado, log-lineal, regresión logística 


\begin{abstract}
The aim of this study was to: (1) identify the correlation between the variables "structure of participation" (STR), "help" (HLP), "support in the task" (SUP) and transference (TRA); (2) establish the best model that fits the empirical data and (3) found the relationships between the independent variables "structure of participation", "help" and "support in the task" and the dependent variable transference. To achieve this goal, a mixed methodology (content analysis, multivariate analysis, log-linear and logistic regression) was used. The sample consisted of 1506 learning sequences observed in interactive group sessions in the areas of Spanish Language and Literature and Physical Education students from 5th and 6th grades of primary education. The main results showed ( $\mathrm{a}$ ) as the best model that fits with the data collected is STR $*$ HLP $*$ SUP + STR $*$ SUP $*$ TRA + HLP $*$ SUP $*$ TRA (b) the predictor variable structure of participation presented the best classificatory power in the transfer of learning followed by support in the task and help, (c) the structure of dialogic participation contributed most to the transfer process, (d) support in the task containing only explanation contributed more as the process of transfer and $(e)$ regulatory help contributed most to the transfer process. As highlights of the study it is worth mentioning (1) novelty in the type of mixed analysis educational research (2) the relationship between the dialogic structure of learning transfer, (3) use the classification system of social interaction in the classroom along with the transfer of learning in communicative learning environments and (4) theoretical approach that introduces the postulates by socio-cultural psychology to the concept of learning transference.
\end{abstract}


Abstract

Key words: communicative learning environments, transference, multivariate analysis, log-linear, logistic regression 


\section{Agradecimientos}

uiero agradecer a mi tutor y director el Dr. Arias Martínez toda su
implicación durante el largo proceso de esta tesis. Gracias por todas
las cosas que he podido aprender a tu lado, tanto de análisis de datos como formalidades varias. Gracias por tu paciencia y dedicación.

También quiero mostrar mis agradecimientos a mi directora la Dra. Rodríguez Navarro por toda su confianza y apoyo a lo largo de todo este proceso. Gracias por compartir tu saber y tu entusiasmo.

Gracias a los dos he podido conjugar lo mejor de cada uno y plasmarlo en esta investigación. Gracias por todos los aprendizajes conjuntos.

En segundo lugar, quería agradecer a Carmen Rois, parte imprescindible en todo este proceso, por ser voluntaria en centro y partícipe en esta investigación conjunta. Gracias por todo el trabajo compartido durante estos cuatro años así ha sido mucho más fácil todo este proceso. Gracias por llevarme y dejarte llevar, hacemos un buen equipo.

A toda la comunidad educativa del CEIP Miguel Iscar (alumnos, profesores, voluntarios, familiares y alumnos de la Universidad de Valladolid), protagonistas principales de todo esto, sin ellos esta tesis no hubiera tenido cabida. Cabe mencionar en especial a Sebastián, César y Silvia que han sido mucho más que alumnos en prácticas. Gracias por querer formar parte de todo este proyecto, habéis participado de una manera muy importante. Gracias por hacer y dejar hacer. 
Gracias a todos los que de cierta manera habéis estado presentes tanto en los Proyectos de Innovación Docente, seminarios y tanto del Grupo Acoge como del GAIS (grupo de análisis de la interacción social).

A mi familia, a la que he dedicado poco tiempo durante este proceso. En especial a José Luis, que ha sido un ejemplo de lucha y fortaleza, va por ti.

A Luis Ángel, que me ha soportado sobre todo en los momentos más difíciles y amargos de estos años, sin tu aliento esto no hubiera salido adelante.

A todos aquellos que forman o han formado parte de mi durante este tiempo. 
Introducción

\section{INTRODUCCIÓN}

$\mathrm{L}$

a escuela de hoy se enfrenta a nuevos retos, está cambiando y cada vez la toma de decisiones se enmarca en entornos comunicativos, el

papel del docente se descentraliza y se comparte con toda la comunidad educativa el reto de enseñar. Sin embargo, sigue existiendo una preocupación en el entorno escolar y es el referido a cómo se produce la transferencia de aprendizaje de un área a otra. Por ello esta tesis que se centra en profundizar y buscar evidencias científicas que soporten la idea de que los entornos comunicativos de aprendizaje (ECA en adelante) son entornos favorecedores de la transferencia en el aprendizaje escolar. Para tal fin tratamos de identificar la existencia de relación entre los tipos de transferencia del conocimiento, las estructuras de participación dentro del aula, la ayuda entre los participantes de situaciones educativas y el formato de tarea que se presenta a los alumnos. Por otro lado, estableceremos un modelo de interacción entre dichas variables con el fin de establecer pautas metodológicas que nos permitan llevar a cabo una educación de calidad. Además, pretendemos encontrar las relaciones existentes entre la estructura de participación del aula, las ayudas ofrecidas por los participantes y el formato de las tareas a resolver con la transferencia. Hemos empleado una aproximación a los métodos mixtos integrando los beneficios de ambos, por un lado, realizamos un análisis de contenido de las sesiones llevadas a la práctica y por otro lado análisis cuantitativos tales como el análisis multivariado, análisis log-lineal y regresión logística. 
El impacto social que adquiere este estudio se centra en un mayor conocimiento de los entornos dialógicos de aprendizaje y cómo estos entonos se erigen como favorecedores de la transferencia del aprendizaje al dotar tanto a docentes como alumnos de mecanismos que permitan un aprendizaje más eficaz al demostrar que variables como la ayuda o el formato de la tarea influyen de una manera directa en dicho proceso. Los entornos basados en el diálogo permiten abrir las puertas del proceso de enseñanza-aprendizaje, creando un clima libre de intercambio de ideas y opiniones que enriquecen tanto el proceso de aprendizaje como el proceso de transferencia del conocimiento. La eficacia de esos procesos pasa por manejar adecuadamente variables como las ayudas que se ofrecen tanto por parte de los docentes como del resto de personas partícipes en dicho proceso como los apoyos que se establecen en la formulación de la tarea a realizar.

Desde esta perspectiva basada en la comunicación e interacción es necesario desarrollar modelos educativos que hagan accesible a todas las personas las habilidades y competencias necesarias para enfrentarse de forma crítica a los continuos cambios sociales (Elboj \& Oliver, 2003). En nuestro estudio hemos introducido un enfoque interactivo en la escuela a partir de la puesta en marcha de una organización del aula basado en grupos interactivos, donde los objetivos educativos incluían principalmente resolver las tareas con calidad a partir de la mejora de las relaciones sociales entre los estudiantes.

Las orientaciones prácticas de intervención educativa que se desprenden (ver sección 9.2. Aportaciones finales) pretenden ser una base sólida para que los docentes replanteen sus actuaciones dentro de aula y desde la teoría surgida pongan en práctica actividades facilitadoras de la transferencia.

La novedad en la temática, así como los análisis llevados a cabo dentro de la investigación ponen de manifiesto su relevancia. Los análisis empleados 
Introducción

(log-lineal y regresión logística) no se han empleado hasta ahora en el campo educativo con este fin.

Existe poca literatura al respecto y la relación entre los ECA y la transferencia es algo inédito y que no ha sido encontrado a pesar de la exhaustiva búsqueda bibliográfica en las principales bases de datos tales como ERIC, WOS, Scopus, SciELO, TESEO, Dialnet, Taylor \& Francis o Elsevier.

El sistema de clasificación de la Interacción Social en el aula (Sánchez, García \& Rosales, 2010) se ha empleado como base en el análisis de contenido ya que de todos los revisados (Coll, Colomina, Onrubia, \& Rochera, 1992; Edwards \& Mercer, 1988; Lemke, 1997; Sánchez et al., 2010) es el único que ofrecía la estructura de participación dialógica dentro de su clasificación de estructuras. Hasta ahora este sistema se había empleado para analizar clases de corte tradicional analizando sesiones en las que la lectura era el eje principal. Sin embargo, en este estudio se emplea en las clases donde la estructura de participación principal está basada en la interacción y el diálogo siendo el objetivo central identificar el proceso de la transferencia de aprendizaje. Sintetizamos las aportaciones inéditas de este trabajo en las siguientes ideas: (a) La adaptación del sistema de clasificación de las interacciones sociales para relacionarlo con el concepto de la transferencia en el aprendizaje, (b) introducción de los referentes socioculturales basados en la interacción y el diálogo en el tema de la transferencia y (c) relación entre dos áreas de conocimiento que tradicionalmente han sido consideradas como "contrapuestas", la Lengua y la Educación Física, ofreciendo una visión integradora del desarrollo madurativo del niño, donde cuerpo y mente forman una unidad.

\section{Cómo ha sido el procedimiento del trabajo realizado}

El surgir de la tesis se basa en la colaboración con el Grupo Acoge durante el desarrollo de mi Trabajo de Fin de Máster, mi llegada al CEIP Miguel Iscar 
como maestra especialista en Educación Física y las colaboraciones con Henar Rodríguez. La Biblioteca tutorizada como tema central de mi TFM abre las puertas a nuevas propuestas en los entornos comunicativos de aprendizaje. Al finalizar este trabajo observamos la necesidad de profundizar en aspectos relacionados con el aprendizaje. Queríamos tener un conocimiento centrado en cuestiones "micro", donde, por un lado, siguiéramos aplicando la visión comunicativa de la enseñanza, a través de los ECAs, y por otro, analizáramos los procesos psicológicos del aprendizaje a través del concepto de transferencia de un área a otra.

La relevancia del tema, la facilidad de acceder al campo de estudio y el interés desde el punto de vista docente e investigador hacen que tome fuerza el objeto de estudio. Dicho tema dará pie a diversas investigaciones. Por un lado, el TFM de Carmen Rois (Rois, 2014) en el cual analizamos los tipos de ayudas que se ofrecen los iguales en procesos interactivos de aprendizaje, esta misma tesis y posteriormente la tesis de Carmen, en la cual se analiza el proceso de la transferencia a través de los procesos cualitativos, surge así el autodenominado Transfer Team.

Respecto a las decisiones metodológicas tenidas en cuenta, optamos por unificar las dos tradiciones cualitativa y cuantitativa para ofrecer una descripción más amplia del fenómeno, usamos por tanto los métodos mixtos, para ello contamos con el enfoque cuantitativo, ofrecido por el profesor Benito Arias y el cualitativo de la profesora Henar Rodríguez.

\section{Estructura del documento}

El presente documento se vertebra sobre dos partes que unifican los ejes principales que sirven de guía para dar globalidad a esta tesis.

El primer eje vertebrador se centra en el marco teórico en el cual se imbrica todo el proceso investigador, sirve de base teórica para establecer los fun- 
damentos sobre los que se sustenta el problema de investigación. Este eje a su vez se divide en tres aspectos importantes que dan sentido teórico a este estudio. Un apartado que establecerá las líneas base para entender los Entornos Comunicativos de Aprendizaje y las actuaciones que en ellos se llevan a cabo. Un segundo apartado ahondará sobre el concepto de la transferencia del aprendizaje que dará soporte teórico a todo el estudio y un tercer apartado que se encargará de explicar y desarrollar el sistema de clasificación de las interacciones en el aula empleado que permite entender el proceso de análisis del discurso del aula. El apartado concluirá con la definición de las variables objeto de estudio.

Una vez desarrollado las bases teóricas fundamentales de este estudio, el segundo eje vertebrador se centra en el estudio empírico propiamente dicho. Dentro de este capítulo se plantean los objetivos e hipótesis, así como el trazado del método empleado incluyendo los análisis llevados a cabo y los principales resultados, aspectos centrales que nos permiten entender mejor el estudio. Para finalizar este capítulo se lleva a cabo una discusión de los principales resultados, se presentan los principales hallazgos, así como las futuras vías de investigación. 



\section{MARCO TEÓRICO}

\section{CAPÍTULO 1}




\section{Definición de la transferencia en los entornos comunicativos de aprendizaje}

Una de las grandes preocupaciones de los docentes es que sus alumnos no transfieren los aprendizajes de una situación a otra o de una materia a otra, por lo tanto, uno de los principales objetivos de la enseñanza formal es preparar a los alumnos para que empleen conocimientos y habilidades aprendidas en distintos ámbitos a los de su aprendizaje. Los criterios de evaluación marcados por la Organización para la Cooperación y el Desarrollo Económicos (Schleicher, Zimmer, Evans, \& Clements, 2009), tienen en consideración la capacidad que posee el alumnado para aplicar el conocimiento adquirido en la escuela a otros escenarios de la vida cotidiana. De este modo, el Programa la Evaluación Internacional de Alumnos (PISA) evalúa a los alumnos mediante ítems que pretenden observar si los escolares son capaces o no de transferir el conocimiento. Sin embargo, sigue habiendo una desconexión entre la forma de enseñar de los docentes y la forma de aprender de los alumnos.

\subsection{Entornos comunicativos de aprendizaje}

La sociedad actual está cambiando, se desarrolla y se reinventa, dando un giro hacia una perspectiva donde la interacción y el diálogo juegan un papel clave en el aprendizaje. Este enfoque se ha conceptualizado como el giro dialógico en la comprensión de los procesos de aprendizaje (Carrión, Roldán, López, \& Valdez, 2016; Racionero \& Padrós, 2010). Este giro dialógico da lugar a una nueva concepción educativa en la que prima lo social, donde el aprendizaje se basa en la cultura, la inteligencia se presenta de forma distribuida y el aprendizaje se consolida a través de fondos de conocimiento. Sobre estos pilares surgen los entornos comunicativos de aprendizaje una pro- 
puesta que trata de romper con la visión más tradicionalista de la educación y acercarla a las demandas de la sociedad actual.

A lo largo de la historia tanto de la psicología como de la pedagogía se han sucedido distintas corrientes que han llevado a tener distintas concepciones del aprendizaje, esa evolución del concepto de aprendizaje se ha ido sucediendo a medida que las investigaciones han puesto de relieve nuevos retos para el aprendizaje, ajustándose en cada momento a las demandas socioculturales de cada época. Los entornos comunicativos de aprendizaje se han desarrollado sobre la base de la teoría sociocultural del aprendizaje, cuya base se fundamenta en las aportaciones de Vygotsky (1995). Éste enfoque muestra cómo la ley de la doble formación de los procesos psicológicos (primero se forman a nivel interpsicológico y luego a nivel intrapsicológico) y el concepto de Zona de Desarrollo Próximo ponen de relieve que el pensamiento es ante todo social, y que se desarrolla en la red de relaciones que ofrece un entorno social y cultural concreto. El aprendizaje y el desarrollo cognitivo son procesos culturales que se producen gracias al diálogo y la interacción con los otros (Cole \& Wertsch, 1996; Rogoff, 1990; Wenger, 2001). En la actualidad, y partiendo de las aportaciones de Vygotsky, autores como Edwards (2011) o Lave y Wenger (1991) entienden el aprendizaje como algo situado en una (inter)acción entre los individuos y los elementos del entorno. Para Carrión et al. (2016) estas teorías son las que mejor explican actualmente el aprendizaje y que mejor responden al reto de conseguir el éxito educativo para todos.

Estos elementos sociales en el aprendizaje se ponen de relieve también desde la antropología evolutiva (Tomasello, 1999) que se centra en los orígenes culturales de los procesos cognitivos humanos, aportando evidencias de la naturaleza dialógica de la mente a través de representaciones cognitivas dialógicas (Tomasello, Carpenter, Call, Behne, \& Moll, 2005) que son necesarias para el apoyo de algunas formas de interacción colaborativas y para la 
creación y el uso de artefactos culturales que son socialmente construidos y bidireccionales. De otra parte, el sentido común basado en experiencias vividas se conforma en el proceso de interacción social (Forguson \& Gopnik, 1988) así como desde la antropología biológico-sociocultural (Ingold, 2014) evidencian que nuestras capacidades se desarrollan en campos relacionales. Esta concepción interactiva del aprendizaje deja atrás las concepciones constructivistas que obvian por completo los procesos de construcción conjunta de conocimiento (Carrión et al., 2016).

Todas estas ideas, conectan con el origen social del conocimiento y la creación de herramientas culturales que construyen las estructuras cognitivas del individuo en interacción. Entra en juego para la consolidación del aprendizaje lo que Moll, Amanti, Neff y Gonzalez (1992) denominan fondos de conocimiento. Se entienden por fondos de conocimiento aquellos cuerpos de saberes y habilidades, culturalmente desarrollados e históricamente acumulados, esenciales para el funcionamiento y bienestar individual y familiar (Moll, 1997).

Como mencionábamos más arriba, la inteligencia se encuentra de forma distribuida (Hutchins, 1995) alejándose de la perspectiva más individualista en la que la inteligencia se encuentra en una única persona. Desde esta perspectiva, Pea (1987) concibe la cognición humana como distribuida, más allá del ámbito del organismo propio, y abarcando a otras personas, apoyándose en medios simbólicos y aprovechándose del entorno y de los artefactos. La inteligencia se encuentra de forma distribuida entre nuestros entornos personales y los modelos mentales de las personas cercanas.

La influencia de la cultura provoca cambios en las estructuras de pensamiento de los sujetos, sin embargo, la estructura cambia la mente del sujeto y a su vez el sujeto provoca cambios en la estructura (Giddens \& Amaro, 1995). Según Engestrom (1987) hablamos por tanto de un aprendizaje ex- 
pansivo, donde la persona, dentro de un contexto social, transforma su cultura.

Los entornos comunicativos se erigen como espacios idóneos que presentan beneficios a nivel social, emocional y académico (Hernández-Sellés, González Sanmamed, \& Muñoz Carril, 2015). Estas conclusiones enlazan con las aportaciones de Howe, Tolmie, Duchak-Tanner y Rattray (2000) donde ponen de relieve los efectos positivos del trabajo en grupo en los escolares destacando la interacción entre familiares y alumnos son beneficiosas para el aprendizaje. Dichos espacios generadores de amistad promueven más interacciones, entre más personas y de mejor calidad.

Un resumen de todo lo expuesto puede verse en la Figura 1. 


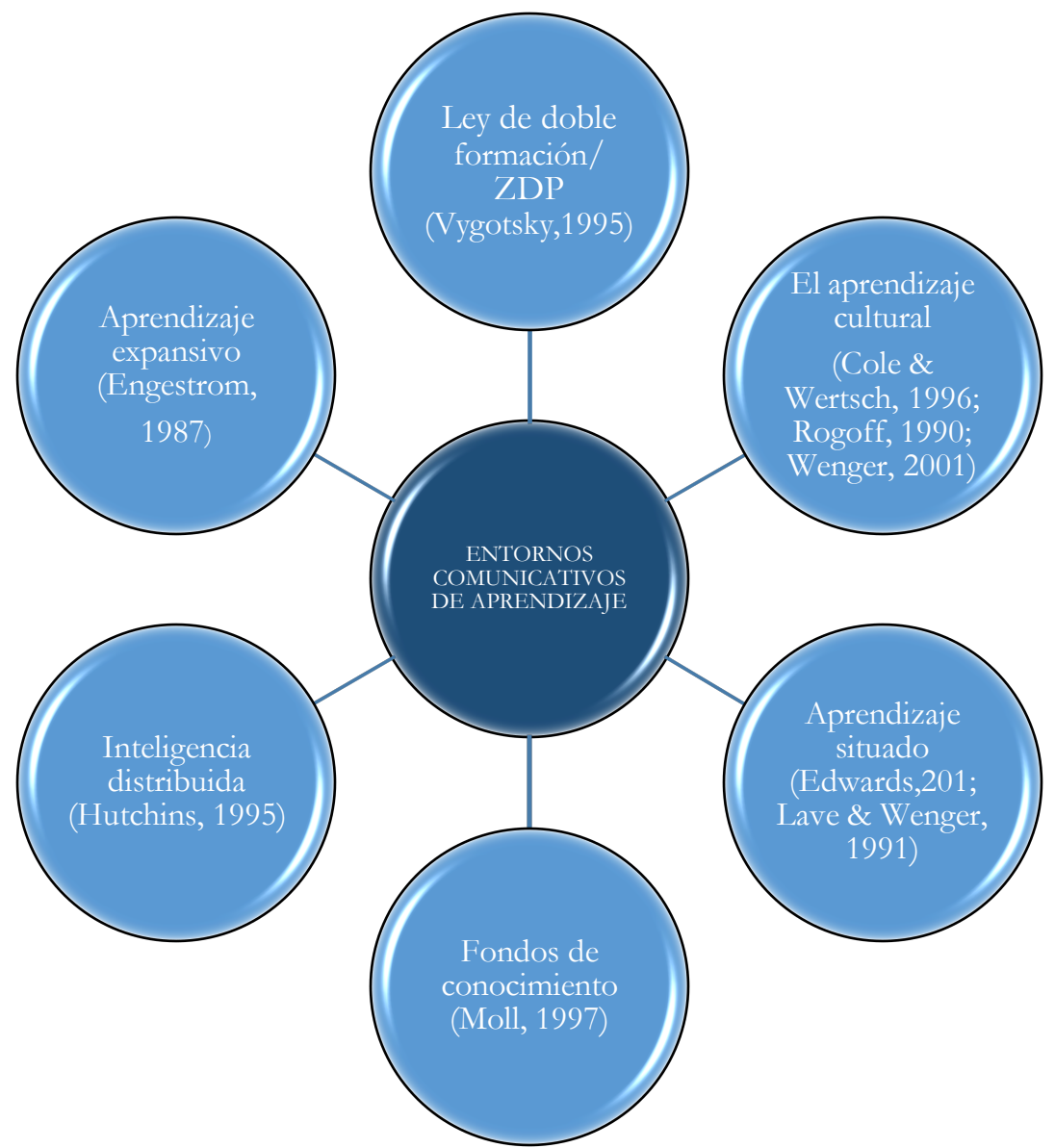

Figura 1. Aportaciones a los entornos comunicativos de aprendizaje

\subsection{Propuestas de entornos comunicativos de aprendizaje}

Tal como venimos mostrando, la influencia de Vygotsky en la investigación sociocultural ha consolidado la idea de que la creación de conocimientos está situada donde sus miembros comparten formas de conocimiento y de resolución de problemas e incluso una identidad común (Lave \& Wenger, 1991). De hecho, numerosas investigaciones han analizado el aprendizaje como participación en múltiples comunidades, dando lugar a diferentes prácticas 
como las sub-comunidades de aprendices mutuos, las comunidades de indagación dialógica, las comunidades de práctica o las comunidades de aprendizaje.

Las sub-comunidades de aprendices mutuos (Bruner, 1996) en las cuales se explica la necesidad existente de que el alumnado se ayude entre sí para resolver problemas de orden superior. Bruner, señala la importancia de transformar las aulas en subcomunidades de aprendices donde los docentes no tengan únicamente el conocimiento y se consolide la solidaridad entre el alumnado.

Las comunidades de indagación dialógica (Wells, 2001) la actividad emprendida conjuntamente crea un contexto en el que todos los participantes se pueden ayudar mutuamente en sus zonas de desarrollo próxima, enseñando cada uno a los demás y aprendiendo de ellos.

Las comunidades de práctica (Lave \& Wenger, 1991), definidas como un grupo de personas que comparten intereses, un conjunto de problemas o una pasión sobre un tema, profundizando en su conocimiento y compartiendo experiencias en el área a través de una interacción continua que fortalece sus relaciones. Estas comunidades tienen la meta de desarrollar conocimiento y compartir aprendizajes a través de la reflexión compartida sobre la práctica.

Las comunidades de aprendizaje (Gatt, Ojala, \& Soler, 2011) en las cuales se desarrollan varias actuaciones educativas de éxito cuyo denominador común reside en la construcción del conocimiento de forma dialógica entre toda la comunidad escolar y social (Valls \& Kyriakides, 2013). Una de las actuaciones educativas de éxito más extendida dentro de las comunidades de aprendizaje son los Grupos Interactivos definidos por Molina (2005) como:

«Una organización flexible del aula que pretende maximizar las interacciones entre sus miembros, fomentando la comunicación, el aprendizaje cooperativo y la motivación hacia el aprendizaje mediante una dinámica activa y estimulante. Se ponen en práctica principalmente para trabajar contenidos más ins- 
trumentales, que desde las comunidades de aprendizaje se consideran especialmente relevantes.»

Suponen una forma de organización de trabajo en el aula, que consiste en trabajar en grupos heterogéneos de tres a siete alumnos, dependiendo de los recursos humanos con lo que se cuente y con el número de alumnos y alumnas que haya. Donde un adulto, familiar, voluntario, independientemente de la formación que tenga, dinamiza el grupo de alumnos para que trabajen las actividades que les ha preparado el profesor. Cada grupo tiene una actividad diferente y a los veinte minutos se cambia de grupo. Esta práctica no se utiliza en todas las horas de clase, si no en aquellas que el profesorado crea conveniente.

El principio básico de este procedimiento es ampliar el intercambio de conocimientos mediante una trama de interacciones entre el alumnado y alumnado, entre el alumnado y las personas adultas que estén en el aula. Se ha comprobado (Valls \& Kyriakides, 2013) que esta práctica educativa beneficia a todos los alumnos, haciendo que las mezclas heterogéneas del alumnado enriquezcan más estos procesos de aprendizaje, por otra parte, este intercambio de conocimientos incrementa la transferencia de aprendizajes llevados a cabo en situaciones distintas a las de partida debido a la mayor conexión de los aprendizajes previos con las nuevas situaciones de aprendizaje llevadas a cabo de manera conjunta.

Tal y como venimos destacando, el aprendizaje es ante todo social, está situado en el contexto de aprendizaje en el que se produce del mismo modo que la transferencia del aprendizaje, ambos conceptos han sufrido una evolución similar ligada a las corrientes pedagógicas de cada época.

\subsection{Conceptualización de la transferencia en el aprendizaje escolar}

Dentro del contexto educativo, hablamos de transferencia del aprendizaje cuando aplicamos un conocimiento adquirido en un contexto particular a 
una situación distinta (Salmerón, 2013). La transferencia se puede considerar en un contínuum que abarca distintos niveles o grados según la perspectiva de referencia.

Plantear una única definición de transferencia del aprendizaje no es tarea fácil, ya que desde que apareciera la primera definición a principios del siglo $\mathrm{XX}$ el concepto se ha debatido desde distintas áreas como la psicología de la educación, la pedagogía o las ciencias de la salud.

Numerosos estudios relacionados con la transferencia señalan las enormes dificultades que suelen tener los estudiantes de todos los niveles académicos para transferir lo que han aprendido en el aula a nuevas situaciones (Bransford, Brown, \& Cocking, 2000), otros han tratado de explicar que actividades son las que facilitan el proceso de transferencia y cuales los dificultan (Salmerón, 2013) y otros cuales son las dimensiones y variables de las que se compone (Bransford \& Schwartz, 1999; Engle, Lam, Meyer, \& Nix, 2012; Gentner, Loewenstein, \& Thompson, 2004; Gick \& Holyoak, 1983; Sanjosé López, Valenzuela, Fortes del Valle,\& Solaz-Portolés, 2007).

A pesar que desde la psicología de la educación (tanto conductistas, cognitivistas y constructivistas) se lleven ocupando de este tema desde principios del siglo XX, ésta ha constituido un tema periférico en el ámbito de las ciencias cognitivas, tan sólo un $1 \%$ de los trabajos de las revistas más prestigiosas se han ocupado de la transferencia (Chen \& Klahr, 2008). Sin embargo, el estudio de la transferencia en el aprendizaje ha seguido un proceso paralelo al de las concepciones educativas en las ciencias sociales de la educación.

En los primeros años del siglo $\mathrm{XX}$, las ideas pioneras sobre la transferencia en el aprendizaje se recogían en la denominada doctrina de la disciplina formal, esta teoría expuso que ciertas materias llamadas disciplinas formales, tales como la geometría o las matemáticas podían usarse como herramientas para aprender a razonar y de esta forma generar destrezas cognitivas transfe- 
ribles a diferentes ámbitos o dominios. Thorndike cuestionó las bases de esta teoría y no encontró evidencias empíricas de la misma (Thorndike, 1924). Otros trabajos posteriores mostraron que puede aumentarse la transferencia en el aprendizaje mediante la instrucción en tareas específicas que incidan en aplicaciones, relaciones y metodología; lo que conlleva, además, a un aumento de la comprensión y del conocimiento utilizable (Klausmeier, 1984). El mismo Thorndike (1932) formuló la ley de los elementos idénticos en la que plantea que la transferencia es el resultado de aplicar el conocimiento adquirido mediante un aprendizaje previo, a una nueva tarea que requiere exactamente la misma conducta que la que se aprendió.

Estos primeros enfoques que ofrece la literatura respecto a la transferencia se vinculan a las corrientes de corte conductual. La transferencia se entiende como un proceso independiente del contexto y de las interacciones sociales, la aplicación del conocimiento está más relacionada con aspectos de corte académico, técnico e instrumental. Estudios posteriores relacionados con la relación entre analogías (Catrambone, 1996; Cummins, 1992; Harpaz-Itay, Kaniel, \& Ben-Amram, 2006) concluyeron con la idea de que "resolver es independiente de comprender" (Sanjosé López et al., 2007) y que la transferencia por tanto requería de elementos más complejos para su comprensión.

Otras corrientes constructivistas se suceden en el tiempo y a partir de los años 80 , la transferencia se plantea en el terreno científico, como un sistema de interacción entre las personas y su entorno (Nokes-Malach \& Mestre, 2013) que posibilitan procesos de aprendizaje relacionados con la autorregulación metacognitiva (Egbert \& Roe, 2014; Georghiades, 2000; Hovelynck, 2000; Leberman \& Martin, 2004). Se empieza a estudiar los beneficios de la transferencia producidos por el trabajo en grupo (Georghiades, 2000), la importancia de analizar o identificar perspectivas en las tareas cotidianas (Egbert \& Roe, 2014) o la importancia de los tiempos de reflexión (Leberman \& Martin, 2004). Destacan también las destrezas de pensamiento de 
Perkins y Salomon (2012) o el estudio de Hovelynck (2000) que presenta un modelo educativo que integra acción y reflexión. Las propuestas didácticas en las aulas (Adey \& Shayer, 1993; Kok- Auntoh \& Woolnough, 1994) emplean patrones de interacción cotidianos para relacionarlo con el proceso de aprendizaje, la contextualización de los contenidos y su aplicación (Engle, 2012). Otros estudios tratan de incluir en las tareas los procesos de mapping (Reed, 2012), de noticing y prácticas discursivas (Lobato, Rhodehamel, \& Hohensee, 2012). Desde esta noción, los estudios sobre transferencia han sido aplicados en las diferentes áreas de conocimiento, sobre todo en la etapa de secundaria. En el deporte (Barnett \& Ceci, 2002; Rosalie \& Müller, 2012), matemáticas (Engelbrecht, Harding, \& Du Preez, 2007), biología (Pugh, Koskey, \& Linnenbrink-Garcia, 2014) o idiomas (Chamot, 1993; Olivares, 2002; Seddon \& Waweru, 1987). A caballo entre los estudios sobre la transferencia de tipo constructivo y los de tipo sociocultural, se encuentran todos aquellos que ponen el énfasis en la motivación como aspecto central de dicho proceso (Belenky \& Nokes-Malach, 2012; Peters, Barbier, Faulx, \& Hansez, 2012).

Una vez perfilado el concepto de transferencia y revisados los estudios más relevantes dentro del ámbito de la transferencia, vamos a vincularlo con el otro eje central de la investigación que son los entornos comunicativos de aprendizaje.

\subsection{Transferencia en entornos comunicativos de aprendizaje}

El enfoque situado (Lave \& Wenger, 1991; Scribner, 1986) ubicado dentro de los paradigmas socioconstructivos presenta la transferencia como un sistema de interacción entre las personas y el entorno y se basa en la perspectiva dialógica (Nokes-Malach \& Mestre, 2013). Desde esta perspectiva la transferencia en los entornos comunicativos del aprendizaje tiene en cuenta patrones de interacción en diversas situaciones donde la transferencia se produce en la medida en la que los sistemas de interacción son similares entre una 
situación y otra. La transferencia se vincula a un espacio de aprendizaje basado en la interacción social y en el llegar a acuerdos mediante el diálogo, de forma que se produzca aprendizaje no sólo de tipo académico, sino de corte social y cultural. Lo que Mercer, Warwick, Kershner y Staarman, (2010), denominan, oportunidad de pensar con otros. Este diálogo, tal como veíamos antes, se produce en contextos educativos que organizan sus espacios en torno a comunidades de práctica que posibilitan una mayor cantidad y calidad de las interacciones sociales entre los miembros de la comunidad educativa. La investigación sociocultural contemporánea ha ampliado la visión del aprendizaje de Vygostky a través del concepto comunidades de práctica donde sus miembros comparten formas de conocimiento y de resolución de problemas e incluso una identidad común (Lave \& Wenger, 1991). Encontramos en esta línea, diferentes estudios que han analizado el aprendizaje como participación e interacción en múltiples comunidades, dando lugar a nociones distintas sobre la conceptualización de la trasferencia. Como ya mencionamos anteriormente son, las subcomunidades de aprendices mutuos (Bruner, 1996), las comunidades de indagación dialógica (Wells, 2001), las comunidades de aprendices (Brown \& Campione, 1996; Rogoff, Turkanis, \& Bartlett, 2002) y las comunidades de aprendizaje (Gatt et al., 2011). Es precisamente desde este enfoque donde ubicamos este estudio cuya finalidad radica en analizar el tipo de transferencia que se produce en aulas donde se organizan las prácticas escolares en torno a la interacción social y a la comunicación entre profesor-alumno y entre iguales.

Todas las definiciones recopiladas tienen en común la aplicación de un conocimiento ya adquirido en una situación o contexto a otro distinto, el enfoque clásico se ha centrado en el conocimiento previo, en las características de la tarea, pero ha ignorado el entorno social, la motivación y cómo estos elementos interactúan. Por ello, el enfoque situado se centra en las diversas personas que interaccionan, en los materiales de enseñanza- 
aprendizaje, los recursos disponibles, y en cómo el individuo interactúa con todos estos otros factores.

\subsection{Tipos de transferencia}

Las investigaciones sugieren distintos tipos de transferencia que ocurren a diferentes niveles e influyen en todos los aprendizajes, memoria, resolución de problemas, y procesos cognitivos (Mayer, 1987). Aunque la transferencia de habilidades básicas, conocimiento y habilidades de pensamiento es parte integral de nuestras aspiraciones y expectativas educativas, algunos estudiantes creen que poco de lo que aprendieron en la escuela lo aplicaron más tarde en la vida, constituyendo un puente entre lo que se aprende en la escuela y su aplicación práctica a la vida diaria. Por ello, la transferencia del aprendizaje persiste como uno de los problemas más acuciantes en el aula (Bevevino, Dengel, \& Adams, 1999; Borich \& Tombari, 1997; Rossett, 1997) debido a la complejidad en su definición e identificación.

La transferencia, difiere en tipo según el autor o autores que lo definan y de la perspectiva teórica desde que se sustenta, a pesar de los elementos comunes que todas ellas tienen, algunos autores hablan de niveles de transferencia, otros de categorías y otros de tipos para diferenciar la transferencia según el aprendizaje que se ponga en marcha, los mecanismos necesarios o el contexto de referencia del aprendizaje previo. Es por esto que resulta complejo encontrar una única definición.

Partiremos de la definición de Haskell (2001) como referente en nuestra investigación. Este autor define los niveles de transferencia como los grados de similitud entre los aprendizajes, cada grado añade un nivel mayor de especificidad en la conexión de aprendizaje pasado con situaciones nuevas, tiene relación con el contexto en el que se produce la transferencia. Describe seis niveles; (1) la transferencia no específica implica que todo aprendizaje es esencialmente transferencia de aprendizaje ya que todo aprendizaje es con- 
tingente a ser conectado al aprendizaje pasado, es inherente al propio aprendizaje; (2) la transferencia de aplicación hace referencia a la aplicación o puesta en práctica de lo aprendido en situaciones específicas, es decir aplicar ciertos conocimientos, estrategias o habilidades aprendidas en una situación específica a otra; (3) transferencia de contexto que se refiere a la aplicación de lo que hemos aprendido bajo situaciones ligeramente diferentes, cambiando el lugar de aprendizaje en el que se desarrolla; (4) transferencia cercana se produce cuando transferimos conocimientos previos a situaciones similares a las del aprendizaje original; (5) la transferencia lejana conlleva la aplicación de lo aprendido a situaciones totalmente disímiles al aprendizaje inicial y (6) transferencia creativa, se refiere al desplazamiento o transferencia de resultados creativos en la creación de un nuevo concepto debido a la interacción de la similitud recién percibida entre lo nuevo y lo viejo. Este tipo de transferencia es el más complejo, y difícilmente se consigue en los contextos académicos convencionales (Gómez, Sanjosé, \& Solaz-Portolés, 2012).

Las categorías planteadas por Haskell (2001) se centran en aspectos diversos del proceso de transferencia, conforman un esbozo un tanto confuso de categorías, ya que no queda claro el criterio de clasificación empleado. Sin embargo, aportan luz sobre el tema, ofreciendo información interesante sobre algunos factores influyentes en la transferencia. Uno de ellos es la importancia del control de los propios procesos cognitivos llevados a cabo en la resolución de una determinada tarea, lo que se recoge en la transferencia estratégica que consiste en la adquisición de conocimientos sobre estos procesos cognitivos, a través del control de las actividades cognitivas realizadas durante el aprendizaje, así como en la transferencia condicional que permite decidir qué aprendizajes aplicar en cada contexto y la transferencia inversa que consiste en la modificación o revisión de los esquemas cognitivos a partir de las similitudes establecidas con la nueva información. Además, se menciona la importancia de los conocimientos previos y el modo en que se rela- 
cionan con nuevas situaciones o tareas, en este apartado se encuentra la transferencia general o transferencia no específica que permite emplear los aprendizajes pasados en nuevas situaciones, aunque no existan similitudes con la situación de aprendizaje inicial, también la transferencia literal en la que la aplicación de los conocimientos se realizada de forma directa y la transferencia vertical en la que se requiere de una serie de habilidades previas. Otros tipos planteados son: la transferencia teórica que tiene lugar cuando se traspasan conocimientos estableciendo relaciones de causa y efecto de un área a otra, la transferencia lateral en la que se traspasan los aprendizajes pasados a un nivel o tarea idéntico, la transferencia relacional que permite percibir tareas o situaciones similares, a pesar de no mostrar ninguna relación causal subyacente y por último uno de los tipos más abstractos de transferencia denominado transferencia proporcional (Calais, 2006).

De nuevo se pone de relieve la importancia de las características pragmáticas del entorno de aprendizaje ya que, como indica Gagné (1970), el nivel de similitud del contexto que enmarca las situaciones de aprendizaje determina que la transferencia sea más o menos probable. A partir de esta semejanza plantea dos tipos de transferencia: una transferencia lateral en la que la nueva tarea o problema y el conocimiento adquirido previamente presentan la misma naturaleza y el mismo grado de dificultad y la transferencia vertical en la que tanto la naturaleza como el nivel de complejidad son distintos (Gómez et al., 2012). Posteriormente a Gagné, Klausmeir (1984) renombra estos tipos de transferencia diferenciando entre transferencia cercana y lejana.

Más reciente, Rebello et al. (2007) distinguen la transferencia según las asociaciones creadas por los estudiantes a partir de una situación problemática distinguiendo ente transfer horizontal, cuando un estudiante extrae explícitamente la información de enunciado y ésta activa algún esquema en la memoria del sujeto y transfer vertical, cuando se reconocen las características de 


\section{Definición de la transferencia en los entornos comunicativos de}

aprendizaje

la situación que intuitivamente activan elementos del conocimiento previo sin poseer a priori un esquema para asociar, construyendo un modelo mental in situ.

Por su parte Perkins y Salomon (1988) diferenciaron entre transferencia de escaso recorrido, caracterizada por un alto nivel de automaticidad y escaso pensamiento reflexivo, ya que no requiere de abstracciones, y transferencia de largo recorrido que por el contrario sí implica el desarrollo de habilidades más complejas para la comprensión de reglas abstractas.

Todas las categorías propuestas presentan como elemento común el establecimiento de analogías o semejanzas entre las tareas y los aprendizajes, surge de este modo el concepto de transferencia analógica empleada para definir la aplicación de estrategias o conocimientos de resolución de problemas en la realización de otros problemas en situaciones similares (Gómez et al., 2012). Diversos estudios explican cómo esta nueva modalidad de transferencia se lleva a cabo en la resolución de problemas. En primer lugar, se realiza un problema fuente $\mathrm{u}$ origen, en un determinado contexto, y posteriormente se aplica lo aprendido en nuevos problemas, denominados también, problemas diana. En este proceso es fundamental saber transferir las estrategias y conocimientos desde las tareas iniciales a otras nuevas que no suelen ser iguales. Se trata de un procedimiento que profundiza en las características de los problemas y de las tareas a resolver, va más allá de la asociación entre las características más superficiales entre problemas fuente y diana (Sanjosé, Valenzuela, Fortes, \& Solaz-Portolés, 2007). Como indica Oliva (2004), es necesario potenciar y practicar este tipo de transferencia analógica en las aulas, con el fin de propiciar un aprendizaje más profundo y, por tanto, más valioso para los estudiantes. Asimismo, se añade un nuevo elemento importante, la adaptación, ya que cuando los problemas fuente y diana no son completamente iguales en su estructura, la aplicación de los métodos y 
estrategias en el nuevo problema debe incluir un proceso de acomodación y ajuste a las nuevas características de la tarea (Sanjosé López et al., 2007).

\begin{tabular}{|c|c|c|c|}
\hline Haskell (2001) & Gagné (1971) & $\begin{array}{l}\text { Rebello et al. } \\
\text { (2007) }\end{array}$ & $\begin{array}{c}\text { Perkins \& } \\
\text { Salomon (1988) }\end{array}$ \\
\hline $\begin{array}{l}\text {-Aplicación } \\
\text {-Contexto } \\
\text {-Cercana } \\
\text {-Lejana } \\
\text {-Creativa } \\
\text {-Teórica } \\
\text {-Específica }\end{array}$ & $\begin{array}{l}\text { - Lateral } \\
\text { - Vertical } \\
\text { - Cercana } \\
\text { - Lejana }\end{array}$ & $\begin{array}{l}\text { •Horizontal } \\
\text {-Vertical }\end{array}$ & $\begin{array}{l}\cdot \text { Escaso } \\
\text { recorrido } \\
\text { - Largo } \\
\text { recorrido }\end{array}$ \\
\hline
\end{tabular}

Figura 2. Diversidad de tipologías de transferencia

Como hemos visto hasta ahora, toda transferencia implica el establecimiento de analogías o semejanza entre el aprendizaje previo y los subsecuentes. Dichos aprendizajes previos pueden dejar cierta impronta que conduzca a los aprendices a que cualquier situación que se produzca es análoga a la anterior, surge así el concepto de transferencia negativa que se asocia con la falta de percepción consciente de las analogías entre la situación de aprendizaje y la nueva situación (Chaplin, Krawiec, \& Hernández, 1983; Novick, 1988).

El mapa trazado (Figura 2) muestra una gran diversidad de tipologías de transferencia que pone nuevamente de manifiesto la complejidad de la transferencia, muestra pos su parte, diversas perspectivas desde donde analizar y entender dicho concepto. 


\section{Estado de la cuestión: Antecedentes y estudios previos que analizan la transferencia}

Una vez definida la transferencia y dibujado un mapa sobre los tipos principales de la misma, revisaremos los principales estudios que analizan la transferencia haciendo hincapié en los métodos empleados y los resultados más relevantes.

Dividimos los estudios en tres grandes grupos que integran los temas centrales de la transferencia. Estos grupos se clasifican en función de los distintos tipos de pensamiento que se generan con la transferencia y sus analogías en las tareas y la resolución de problemas, la metacognición y la metodología didáctica.

\subsection{Analogías en tareas y resolución de problemas}

Las analogías y su relación con la transferencia es uno de los temas en los que se centran numerosas investigaciones ya que se considera elementos indispensables para que se produzca el traspaso de los conocimientos. Uno de los estudios más relevantes es el llevado a cabo por Harpaz-Itay et al. (2006) en el que analiza la influencia de la construcción y de la solución de analogías en la transferencia analógica. Plantea un diseño metodológico con tareas de razonamiento inductivo en alumnos de 12 y 13 años, llevadas a cabo después de una formación previa en distintas estrategias metacognitivas tomando como referente el modelo de Sternberg (1982). Los principales resultados ponen de manifiesto que la construcción es preferible a la resolución puesto que permite: (a) emplear más tiempo en comprender el problema; (b) utilizar una estrategia global de planificación que conecte con los conocimientos previos y (c) revisar y evaluar tanto las tareas realizadas como 
el proceso seguido. Estos resultados contrastan con otros estudios (Catrambone, 1996; Cummins, 1992; VanderStoep \& Seifert, 1994) que también evidencian una mejora de la transferencia analógica después de una formación.

En Educación Secundaria Obligatoria y Formación Profesional, destaca la investigación sobre resolución de problemas matemáticos (Gómez et al., 2012), se constata que: (1) El análogo (o problema fuente) más adecuado para facilitar la transferencia es aquel que presenta una estructura similar al problema que se intenta resolver (o problema diana); (2) cuando el problema fuente y el problema diana tienen la misma estructura superficial se produce un apantallamiento de las diferencias estructurales, perturbándose con ello el proceso de transferencia y (3) el problema fuente ayuda menos en la transferencia si el contexto del enunciado del problema resulta poco familiar para los estudiantes.

Múltiples trabajos han llevado a desarrollar múltiples teorías especializadas en transferencia incluyendo transferencia por analogías (Gentner, 1983; Gick \& Holyoak, 1983), compilación de conocimientos (Anderson, 1983), violación de restricción (Ohlsson, 1996) y procesamiento de transferencia apropiada (Morris, Bransford, \& Franks, 1977).

\subsection{Metacognición}

Numerosos estudios establecen una relación entre la metacognición definida como el proceso de pensar en el propio pensamiento (Adey \& Shayer, 1993) y la transferencia, otorgando un papel clave a la reflexión y procesos de pensamiento para favorecer la transferencia.

Georghiades (2000) da un paso más en la metacognición e incluye aspectos como la durabilidad o el cambio conceptual de los aprendizajes. Impartió la misma lección a niños de cinco años, sin embargo, los grupos experimentales pusieron en práctica estrategias metacognitivas. Esto dio lugar a mejores 
resultados en dichos grupos debido a la participación activa de los alumnos de modo que fueron capaces de recordar más aprendizajes adquiridos en clases previas. Por otro lado, se corroboró que el trabajo en grupos pequeños promovía diálogo y debates más efectivos.

\subsection{Metodología didáctica}

Hasta el momento los estudios habían centrado la atención en variables intrapersonales, sin embargo, son números los estudios que muestran la figura del maestro como elemento clave para la transferencia ya que de acuerdo al diseño de cierto tipo de actividades puede favorecer un aumento de la transferencia del aprendizaje ya que el traspaso del conocimiento es un esfuerzo consciente no sólo por parte del alumnado, sino también de los maestros, por lo que es esencial favorecer la transferencia en las aulas (Adey \& Shayer, 1993; Kok-Auntoh \& Woolnough, 1994).

Siguiendo estos argumentos, autores como Broad y Newstrom (1992) inciden en que es necesario que los maestros tengan en cuenta lo aprendido y sucedido antes, durante y después de los diversos temas o cursos del programa didáctico para promover el traspaso de los conocimientos. Por otra parte, es relevante que el maestro emplee patrones de interacción en el aula, similares a los utilizados en las situaciones cotidianas (Au, 1980) poniendo de relieve nuevamente la importancia de las interacciones y el contexto donde suceden.

Greeno (1997) ahondó en la importancia de las interacciones producidas entre profesor y alumno, mostrando que los estudiantes eran capaces de aprender y transferir los conocimientos construidos para así dar respuesta a problemas del mundo real, esto enlaza con la idea de Engle (2012) de que los maestros han de contextualizar los contenidos y dar a conocer las aplicaciones prácticas para facilitar así el proceso de transferencia. 
Dentro de los entornos comunicativos de aprendizaje, destaca el modelo planteado por Botma, Van Rensburg, Coetzee y Heyns (2015), en el que se establece una comunidad de aprendizaje y proponen cuatro pasos para favorecer el aprendizaje y su transferencia: (1) la activación del conocimiento existente; (2) la conexión con nueva información, (3) la puesta en práctica y demostración de diversas competencias y (4) finalmente la aplicación de lo aprendido en la vida real.

Como pone de manifiesto los distintos estudios revisados es esencial tener presente para favorecer la transferencia del aprendizaje aspectos tales como el establecimiento de analogías, ser conscientes de lo que se aprende, conectar los aprendizajes con el contexto en el que se producen, así como aspectos metodológicos que ha de tener en cuenta el docente a la hora de plantear las distintas situaciones educativas.

Los estudios referidos a lo largo de este apartado ponen de relieve múltiples aspectos relacionados con la transferencia, muchos otros se relacionan con los entornos comunicativos de aprendizaje, pero ningún estudio previo relaciona la transferencia y los ECA, tal como manifestábamos con anterioridad.

En el siguiente apartado, ahondaremos en estos aspectos clave destacando las dimensiones y variables que definen la transferencia. Teniendo en cuenta estos aspectos clave a la hora de plantear situaciones de enseñanzaaprendizaje, será mucho más fácil que los alumnos sean capaces de transferir los conocimientos siendo por tanto alumnos más competentes.

\section{Dimensiones y variables que definen la transferencia educati-} va

Es frecuente confundir transferencia con aprendizaje, autores como Smedslund (1953) argumentan que la transferencia es un concepto redundante y que distinguir entre qué se transfiere y qué se aprende es indistingui- 
ble (Marton, 2006), sin embargo, para Perkins y Salomon (2012) la transferencia tiene un significado inclusivo, siempre parte del aprendizaje y es una cuestión de grado: cuánto más tarde, cómo de lejos y bajo qué condiciones diferentes se producen ambas. La transferencia como normalmente la usan los investigadores adquiere un significado contrastivo- un aprendizaje inicial exitoso influye positivamente en el desempeño en una ocasión posterior y con un aspecto diferente (transferencia) frente a la no influencia (transferencia fallida). La transferencia del aprendizaje se trata de un proceso cognitivo esencial en la educación (Voss, 1987) y por ello, resulta especialmente importante comprender las diferentes experiencias de aprendizaje que conducen al éxito en la transferencia. Al igual que el concepto de transferencia deja ver desde que perspectiva se plantea, los mecanismos, dimensiones y variables que influyen en el éxito de la transferencia también depende de la lupa con la que lo miremos.

La literatura explica la transferencia a partir de una serie de variables ( $\mathrm{Fi}$ gura 3) que tienen que ver con aspectos de tipo cognitivo y metacognitivo entre los que se incluyen la resolución y construcción de analogías (HarpazItay et al., 2006), la generalización y la codificación (Gentner, Loewenstein, \& Thompson, 2003; Georghiades, 2000), la comprensión conceptual (Bernardo, 2001; Egbert \& Roe, 2014; Georghiades, 2000; Sanjosé López et al., 2007) y la reflexión y metacognición (Ayers \& Ayers, 2014; Harpaz-Itay et al., 2006); aspectos emocionales y motivacionales que implican la motivación (Peters et al., 2012) y la participación activa del alumnado en las tareas (Chapman, 2003; Lin, Hong, \& Huang, 2012) mediante oportunidades de colaboración y de interacción (Egbert, 2009); por último, los aspectos contextuales en los que se incluyen las características temporales y espaciales del entorno de enseñanza-aprendizaje (Bernardo, 2001; Rosalie \& Müller, 2012), la necesidad de ofrecer contextos variados de aprendizaje (Boitel, Farkas, 
Fromm, \& Hokenstad, 2009) y la conexión con el entorno cotidiano (Egbert $\&$ Roe, 2014).

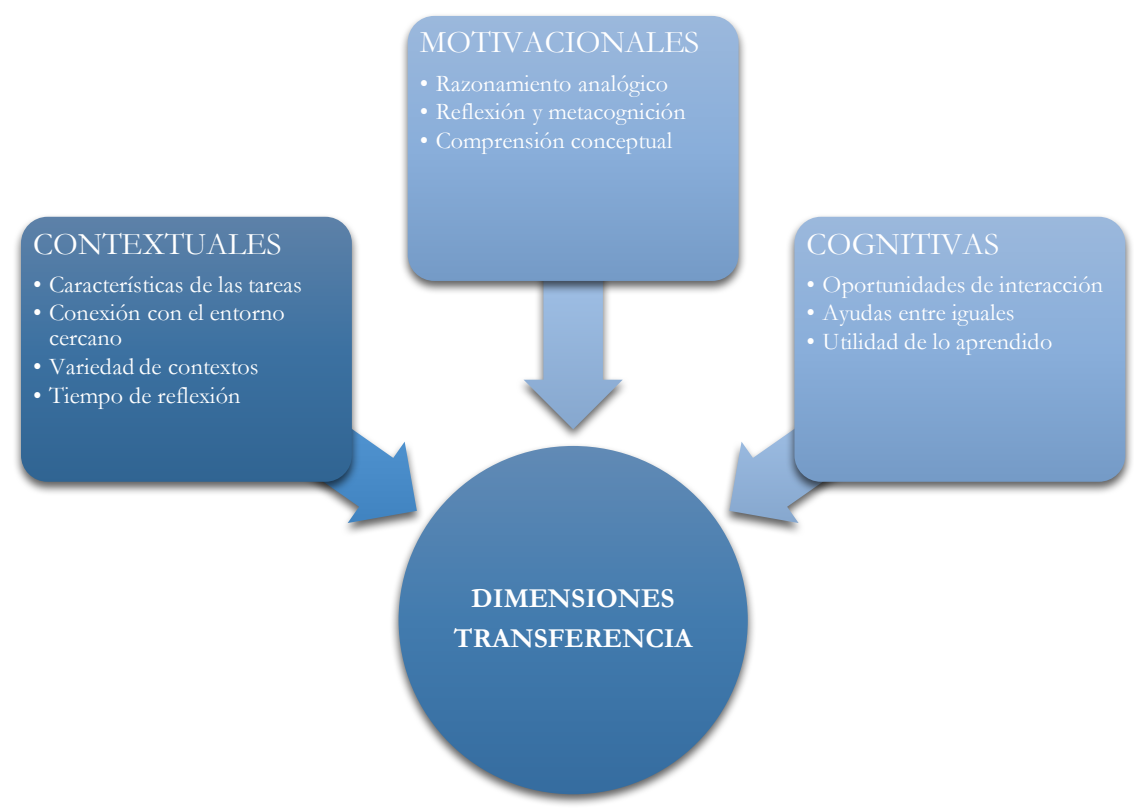

Figura 3. Dimensiones de la transferencia

\subsection{Aspectos de tipo cognitivo y metacognitivo}

La capacidad de transferir el conocimiento relacional a través de contextos es de importancia central en la cognición humana (Gentner, 2003). Sin embargo, las personas no adquieren abstracciones relacionales sin esfuerzo (Chase \& Simon, 1973; Chi, Feltovich, \& Glaser, 1981), ni tampoco siempre se aplican cuando son útiles (Gick \& Holyoak, 1980). Estos dos desafíos se pueden abordar a través del establecimiento de analogías durante el aprendizaje (Catrambone \& Holyoak, 1989; Gentner et al., 2003).

La mayoría de las investigaciones se centran en explicar la transferencia de alguna forma sobre el contenido esencial que los alumnos han de transfe- 
rir (Mestre, 2003; Reeves \& Weisberg, 1994; Schwartz \& Nasir, 2003). Por ejemplo, el estudio clásico de Gick y Holyoak (1983) proporciona evidencia de su hipótesis de que la inducción de un esquema general de analogías concretas facilitará la transferencia analógica. Su idea general era que los aprendices son más propensos a aplicar lo que han aprendido de un problema análogo a otro si forman una generalización basada en el contenido (también conocido como esquema) en el nivel adecuado de abstracción tal que puede ser aplicado a un nuevo problema. Investigaciones posteriores han aportado pruebas adicionales para la importancia de la formación de tales generalizaciones (Chi \& VanLehn, 2012; Gentner et al., 2003; Reeves \& Weisberg, 1994; Rittle-Johnson \& Star, 2007) con investigaciones recientes que muestran cómo las interacciones de instrucción pueden llevar a los estudiantes a centrarse en la creación de determinados tipos de generalizaciones más que otros (Lobato, Ellis, \& Munoz, 2003).

Desde entonces, la mayoría de las investigaciones sobre la explicación de la transferencia se ha centrado, en una u otra forma, en el contenido sustantivo que esperamos los participantes puedan transferir. Además de la importancia de las generalizaciones basadas en contenido, hay un consenso de que el requisito previo fundamental para la transferencia es que el contenido concreto a transferir se ha aprendido de una manera suficientemente profunda, fuerte y duradera (Bransford et al., 2000; Chi \& VanLehn, 2012).

En segundo lugar, la comparación de múltiples ejemplos y contraejemplos de una idea potencialmente transferible es particularmente importante para la inducción de tres mecanismos de transferencia: (a) construir generalizaciones apropiadas (Chang, 2006; Gentner et al., 2003; Gick \& Holyoak, 1983; Goldstone, Landy, \& Son, 2010; Ming, 2009; Richland, Stigler, \& Holyoak, 2012; Rittle-Johnson \& Star, 2007), (b) la formación de asignaciones útiles entre los ejemplos y generalizaciones (Goldstone \& Wilensky, 2008; Reed, 2012; Reeves \& Weisberg, 1994) y (c) la construcción de asignaciones entre 
ejemplos como parte del razonamiento analógico (Holyoak \& Morrison, 2005; Reed, 2012). Todos estos mecanismos de ayuda a la transferencia afectan exactamente a qué contenido particular se transfiere.

Aunque no hay un acuerdo entre investigadores sobre la naturaleza de la transferencia y cómo se produce (Lobato, 2006), parece existir un consenso generalizado entre ellos en señalar al establecimiento de analogías como el recurso más utilizado en el aprendizaje cuando se emplean los mecanismos de transferencia del conocimiento (Duit, 1991; Gentner \& Markman, 1997; Van Lehn, 1990). Una vez establecidos los vínculos analógicos entre dos situaciones, el conocimiento que se posee sobre una de las situaciones permite realizar inferencias sobre la otra. Si no fuera por el reconocimiento de una analogía entre situaciones previamente experimentadas y una nueva situación, este conocimiento almacenado en la memoria sería difícil de utilizar ya que la probabilidad de vivir dos veces exactamente la misma experiencia vital es muy baja (Gentner, Holyoak, \& Kokinov, 2001).

\section{Similitud entre la situación de aprendizaje y de aplicación (darse cuenta de las similitudes)}

Como hemos visto a lo largo del capítulo el proceso de transferencia no es un hecho casual, sino causal, es decir, intervienen distintos mecanismos que se encargan de que la transferencia se produzca con éxito o no. Para que haya transferencia según Thorndike (1932) debe haber una similitud de hechos, actitudes y habilidades específica que estarían influenciadas por: (a) la mayor o menor similitud entre dos situaciones (la de aprendizaje y la nueva o de aplicación); (b) la actitud del aprendiz para aplicar de un modo más o menos activo, y más o menos consciente lo aprendido a la nueva situación; y (c) la disponibilidad de aprendizajes no solo conceptuales, sino también estratégicos que puedan permitir reconocer los elementos idénticos entre dos situaciones, activar el conocimiento apropiado y aplicarlo a la situación nueva planteada. 
Para que haya transferencia de conocimiento, son necesarias ciertas habilidades para reconocer la similitud entre dos situaciones, activar el conocimiento necesario y aplicarlo correctamente (Gómez et al., 2012). En este mismo sentido Bransford et al. (1986) señala que el hecho de que la gente disponga de conocimiento relevante para una situación particular no garantiza que puedan acceder a él, Bereiter y Scardamalia (1985) nombraron a este problema como el problema de conocimiento inerte.

\section{Nivel de cognición o pericia}

Bransford et al. (2000) recopilaron todos los aspectos clave que influyen en la transferencia señalando como el principal factor el grado de pericia que se tiene sobre el dominio que se trate. Sin un adecuado nivel de conocimiento no puede esperarse transferencia alguna.

\section{Instrucción previa}

La transferencia en el aprendizaje puede aumentarse mediante la instrucción en tareas específicas que incidan en aplicaciones, relaciones y metodología; lo que conlleva además a un aumento de la comprensión y del conocimiento utilizable (Klausmeier \& Davis, 1969). La transferencia se mejora mediante una instrucción que ayude a los estudiantes a representar de manera abstracta las situaciones problemáticas. Se deben proporcionar muchas oportunidades de observar similitudes y diferencias en situaciones diversas (Bransford et al., 1986).

Una característica importante de esta tarea es que el conocimiento previo del patrón puede hacer que estos problemas sean más fáciles de resolver. En trabajos anteriores (Nokes \& Ohlsson, 2003; 2005) han demostrado que tanto el conocimiento declarativo del patrón y el conocimiento procedimental de las inferencias de extrapolación puede facilitar la solución de los nuevos problemas que tienen la misma estructura patrón. Nokes (2009) investigó las condiciones en las que se utilizan tres estructuras de conocimiento para resol- 
ver problemas nuevos, comparando específicamente conocimiento ejemplar del patrón al conocimiento táctico para la búsqueda y la extrapolación de los patrones a la restricción del conocimiento de cómo se forman los patrones.

\section{Escoger la estrategia y evaluar (Comparable a detect-elect-conect)}

La transferencia es un proceso dinámico que demanda del aprendiz escoger y evaluar estrategias, tomar en consideración recursos y recibir retroalimentación (Bransford et al., 2000).

Para alcanzar la transferencia los alumnos han de construir tres puentes mentales (Perkins \& Salomon, 2012): detectar, elegir y conectar. Estos tres puentes a veces ocurren en serie, no obstante, otras prácticamente de manera simultánea. Cuando se produce en serie primero se detecta, se elige y por último se conecta. Sin embargo, la transferencia ocurre comúnmente a través del reconocimiento repentino de la importancia o de la ausencia inesperada o un entendimiento anómalo en un instante que lleva de manera conjunta a detectar, elegir y conectar.

Lobato (2012), discutiendo la perspectiva de transferencia orientada al actor, enfatiza que el enfoque tradicional de la investigación sobre transferencia tiende a subestimar los casos de generalización del aprendizaje. De hecho, la transferencia es más fácil cuando los aprendizajes previos, las señales de superficie, las respuestas directas y la preselección de objetivos accesibles apoyan a los tres puentes mentales: detecto-elijo-conecto.

\subsection{Aspectos emocionales y motivacionales que implican la trans- ferencia}

\section{Actitud del alumno}

Desde un encuadre amplio de la transferencia en cuanto a las funciones, los alumnos se colocan como participantes activos en un contexto de aprendizaje donde sirven como autores de sus propias ideas y que responden a las ideas de otros. Dentro de este tipo de ambiente de aprendizaje, las ideas 
públicas de los estudiantes son reconocidos e integrados en las discusiones en clase y otras actividades (Mercer, 1995), siguiendo esta misma idea SolazPortolés y Sanjosé (2008) señalan que trabajar en grupo fomenta las funciones socio-cognitivas que orientan la transferencia.

El encuadre amplio explica cómo se puede promover la transferencia a través de: (a) los ajustes de conexión, que promueven expectativas para transferir en un futuro; (b) los ajustes de conexión, el contenido previo sigue siendo relevante en un contexto de transferencia potencial; (c) tanto la autoría como la conexión con los conocimientos previos durante el aprendizaje conducen a un apoyo de la transferencia posterior; (d) la autoría promueve tanto la rendición de cuentas al contenido particular como la generación y adaptación de los conocimientos a los contextos de transferencia.

Como vemos, es esencial el rol del alumno (autoría) a la hora de ser capaz de transferir el aprendizaje, cuanta más implicación y participación del alumno más sencillo será transferir conocimientos, afirmación que pone de manifiesto nuevamente una evidente vinculación de la transferencia del aprendizaje y los entornos comunicativos de aprendizaje donde el alumno presenta un rol activo dentro del proceso de enseñanza-aprendizaje.

Los métodos de enseñanza tradicionales (clases magistrales, resolución de problemas algorítmicos o trabajo individual en exclusiva) no son compatibles con la consecución del aprendizaje significativo de conceptos ni con el fomento de habilidades cognitivas de alto nivel (Zoller, Lubezky, Nakhleh, Tessier, \& Dori, 1995). La educación científica tiene que desplegar prácticas instruccionales de trabajo colaborativo para desarrollar capacidades básicas y de razonamiento científico (formular hipótesis, poner a prueba hipótesis, explicar, interpretar, diseñar experimentos o dispositivos, justificar decisiones, razonar críticamente). Esto es, el trabajo en grupo en el aula debería ser diseñado para maximizar su función sociocognitiva, de modo que pueda produ- 
cirse un conflicto beneficioso (Gómez et al., 2012), de nuevo conecta con la filosofía de los entornos comunicativos de aprendizaje y su papel potenciador de las interacciones para favorecer el aprendizaje.

\subsection{Aspectos contextuales}

El contexto ha sido poco valorado en las investigaciones sobre transferencia y cuando se ha tenido en cuenta se ha tratado como una realidad física. En esta conceptualización, el contexto incluye características que podrían ser capturados en una fotografía incluso cuando se lleva a cabo un aprendizaje o sesión de transferencia, cuando se produce, y quién y qué está presente (Catrambone \& Holyoak, 1989; Reeves \& Weisberg, 1994; Spencer \& Weisberg, 1986; Thorndike, 1903). Diversas investigaciones ponen de manifiesto que la probabilidad de transferencia aumenta cuanto más se superponen los rasgos físicos entre el contexto de aprendizaje y transferencia (Barnett \& Ceci, 2002; Catrambone \& Holyoak, 1989; Ross, 1987; Spencer \& Weisberg, 1986). Este hallazgo ha sido explicado por el recuento de acciones cognitivas clásicas siguiendo la idea de que las características contextuales se almacenan en la memoria junto con el contenido que se está aprendiendo lo que las características contextuales similares en un contexto de transferencia terminan de recuperarse con el contenido asociado (Anderson \& Bower, 2014; Godden \& Baddeley, 1980; Godden \& Baddeley, 1975; Reeves \& Weisberg, 1994; Ross, 1984; Smith, Glenberg, \& Bjork, 1978). En los recuentos de acciones basadas en el contexto físico, hay cuatro pasos para la transferencia exitosa: (1) asociar el contexto físico en el aprendizaje con el contenido a aprender; (2) aprender el contenido; (3) darse cuenta de las similitudes físicas entre el contexto de aprendizaje y transferencia; y (4) transferir con éxito el contenido debido a que el contenido está siendo complementado por las características físicas del contenido de la transferencia.

Como hemos puesto de manifiesto ya, los contextos de aprendizaje y de transferencia pueden ser socialmente enmarcadas de diferentes maneras $y$ 
que esto, influirá en la propensión de los estudiantes para transferir lo que aprenden (Engle, 2006; Engle, Nguyen, \& Mendelson, 2011). Entendemos por enmarcar como el acto metacomunicativo de caracterizar lo que está ocurriendo en un contexto determinado y cómo diferentes personas están participando en ella (Bateson, 1972; Goffman, 1974; Goodwin \& Duranti, 1992; Tannen, 1993).

Otros estudios se basan en el encuadre expansivo de la transferencia y ahondan en la idea de los principios de teorización situativa y sociocultural en la transferencia (Greeno, Smith, Moore, Detterman, \& Sternberg, 1993; Lave, 1988; Pea, 1987), es decir, no son sólo los aspectos físicos de un contexto es lo que importa para que suceda la transferencia (Barnett \& Ceci, 2002; Catrambone \& Holyoak, 1989; Reeves \& Weisberg, 1994; Spencer \& Weisberg, 1986) sino también las interacciones sociales son importantes como marco de aprendizaje y de transferencia de contextos como tipos de realidades sociales (Gee \& Green, 1998; Searle, 1995).

Desde el enfoque cognitivo, centrado en las representaciones mentales se describen los tres componentes clave para la construcción de una representación del contexto:

(a) Framing: el concepto framing se describe como el acto metacomunicativo con el que un individuo intenta dar sentido a una determinada situación (Bateson, 1972; Goffman, 1974; MacLachlan \& Reid, 1994; Tannen, 1993). El individuo intenta responder a la pregunta, ¿Qué está pasando aquí? (Hammer, Elby, Scherr, \& Redish, 2005; Hutchison \& Hammer, 2010; Scherr \& Hammer, 2009). Para enmarcar una situación, una persona la interpreta teniendo en cuenta acontecimientos o experiencias similares que ha tenido en un pasado y plantea diversos puntos de vista sobre lo que espera de dicha situación. 
(b) Knowledge: se plantea la hipótesis de que el conocimiento previo es se puede descomponer en KCs. Definimos KCs como unidades encapsuladas de información. Los KCs pueden cambiar en la complejidad de las representaciones de las unidades individuales o reglas.

(c) Environment: Los recursos disponibles del entorno activan los $\mathrm{KCs}$, así como los criterios para el satisficing. Entre los recursos del medio se incluyen: la naturaleza del aprendizaje y los materiales de prueba/ de la tarea (i.e., el tipo, el formato o la presentación), el tiempo disponible, las herramientas disponibles (i.e., la calculadora, el acceso a los materiales de aprendizaje en la prueba o tarea) y más. Por ejemplo, las limitaciones de tiempo durante la transferencia pueden conducir a estrategias de representación peores, lo contrario cuando hay más tiempo para desarrollar un análisis profundo de un problema.

Este entorno social se caracteriza por el estatus social y la legitimidad social del alumno (Lave \& Wenger, 1991) y las expectativas sociales puestas en ella. Estos factores influyen directamente en la transferencia en términos de (a) los factores de motivación extrínseca (Lepper \& Greene, 2015), (b) los factores de motivación intrínseca (Deci \& Ryan, 1985; Malone, 1981), y (c) la conducta para cada situación (Lave \& Wenger, 1991).

La transferencia se ve afectada por el contexto en que se produjo el aprendizaje inicial. La transferencia se dificulta si los sujetos han aprendido en un solo contexto y se favorece cuando se aprende en múltiples contextos (Bassok \& Holyoak, 1989), de ahí la relevancia de aportar múltiples contextos de aprendizaje desde la propia escuela, promoviendo en la enseñanza la conexión de los aprendizajes en el centro educativo con los conocimiento de la vida diaria de los estudiantes así como la importancia de facilitar la resolución de problemas, la reflexión, la toma de decisiones, el razonamiento crítico y otras habilidades relevantes (Jerlock, Falk, \& Severinsson, 2003). 
A lo largo de este apartado hemos puesto de relieve las dimensiones y variables que conforman la transferencia del aprendizaje. Cada una de las variables se centra en aspectos distintos del proceso de transferencia, como poníamos de manifiesto con anterioridad, es esencial que los docentes tengan en cuenta estas dimensiones y las potencien al máximo para facilitar a los alumnos el proceso de transferencia del aprendizaje.

Una vez revisadas distintas concepciones de transferencia, estudios previos y las variables procedemos a aportar la concepción de la transferencia que empleamos en nuestra investigación.

\section{Enfoque de la transferencia aportado}

De las diferentes concepciones ofrecidas hasta ahora, la conceptualización de Haskell (2001) es la más apropiada para nuestro estudio ya que considera la transferencia en un continuo que va desde la transferencia contextual a la transferencia lejana, se trata de un concepto amplio. Se refiere a la influencia del aprendizaje pasado en el aprendizaje actual y futuro y para la aplicación o adaptación de aprendizaje anterior o actual a situaciones similares o novedosas (Haskell, 2001) definición similar a otros autores (Holding, 1987; Newstrom, 1984; Singley \& Anderson, 1989; Wexley, Latham, Kettering, Rivaldo, \& Christensen, 1991) que la definen como el grado en que los alumnos aplican activamente los conocimientos adquiridos en la formación previa al aprendizaje de una nueva habilidad o una habilidad en un nuevo entorno. Sin embargo, el concepto de transferencia que proponemos para nuestra investigación se basa en las definiciones de Haskell (2001) y Salmerón (2013), entendemos la transferencia del aprendizaje como la aplicación o puesta en práctica de un conocimiento (ya ser declarativo, procedimental o de cualquier otro tipo) que ha sido adquirido en un contexto o situación educativa particular a otra situación distinta a la de aprendizaje. 
Entre los múltiples tipos de transferencia que nos ofrece la literatura hemos tratado de reunir en cuatro aspectos que abarcan los intereses centrales de nuestra investigación yendo de menor a mayor grado de complejidad en cuanto a mecanismos puestos en marcha:

No transferencia, cuando hay ausencia de transferencia o transferencia fallida.

Transferencia teórica, nos referimos a aquel tipo de transferencia que se basa en la conexión de la tarea con conocimientos declarativos previos y que no requiere aplicación práctica alguna.

Transferencia aplicativa, nos referimos cuando la transferencia se basa en la conexión de la tarea con conocimientos previos (sea cual sea la naturaleza) y que requiere de una aplicación práctica.

Transferencia creativa, cuando existe una conexión con el aprendizaje previo y se produce un nuevo concepto.

\section{Análisis del discurso en el aula}

En los últimos años se ha incrementado el interés por parte de los investigadores de conocer y entender qué ocurre dentro del aula entre el profesorado y el alumno, este interés ha llevado a analizar el discurso de los profesores y su papel en el proceso de aprendizaje de los alumnos, los patrones de conversación o el proceso que lleva a los alumnos a hacer suyos ciertos conceptos y procedimientos. A causa de esto surgen numerosos trabajos sobre el análisis de la interacción en el aula (Coll et al., 1992; Edwards \& Mercer, 1988; Lemke, 1997; Sánchez et al., 2010) que permiten conocer los tipos de patrones de interacción más comunes o unidades de análisis más utilizadas en este tipo de investigación.

Las prácticas educativas escolares se entienden como el conjunto de actividades que profesores y alumnos despliegan en las aulas, no son fenómenos 
que se puedan estudiar y comprender de forma plena al margen de los contextos socio-institucionales en los que tienen lugar (Coll \& Sánchez, 2008) sino que han de contemplarse otros factores, procesos y decisiones más allá del aula y que son decisivos para comprender lo que sucede en ella.

Por ello, cualquier aproximación al estudio de las prácticas educativas obliga a elegir los factores y procesos que considera relevantes para centrar su atención.

Desde los enfoques situados de la cognición (Edwards, 2001; Lave \& Wenger, 1991) defienden la idea de que nuestra actividad mental está anclada en la situación o contexto específico en la que transcurre (aprendizaje situado), por ello, es necesario analizar las prácticas educativas en el contexto en el que se producen de forma natural.

\subsection{Antecedentes}

Una vez que hemos realizado una introducción teórica a nuestro objeto de estudio (la transferencia del aprendizaje en los entornos comunicativos) vamos a introducir el sistema de clasificación de la interacción que hemos elegido para llevar a cabo el proceso de análisis e interpretación de los datos cualitativos.

Los sistemas más relevantes en los últimos años centran su atención en aspectos tales como el discurso del profesor y alumno, cómo se comunican ideas científicas en el aula, la conexión entre distintas actividades llevadas a cabo en el aula o la lectura en el aula.

\section{Interacción profesor y alumnos y comunicación en el aula (Edwards \& Mercer, 1988)}

La característica principal de este estudio es que las clases eran poco numerosas, los participantes tenían ente 8 y 10 años pertenecientes a escuelas de primaria, la muestra utilizada fueron la transcripción y análisis de cuatro lec- 
ciones de dichos cursos. Se grabaron las sesiones en videos y los profesores fueron entrevistados, posteriormente se llevó a cabo un análisis de los datos recopilados y se desveló de manera inductiva algunas de las irregularidades que se presentaban el discurso tanto de profesores como de alumnos. Los resultados de los análisis presentan recursos y reglas comunicativas implícitas en la interacción entre el profesor y alumnos en el aula.

\section{Comunicación y transmisión del conocimiento durante la interacción (Lemke, 1997)}

En el estudio se realizó un análisis de la interacción de profesorado en clases de ciencias con el objetivo de describir cómo se comunican las ideas científicas en el aula. El sistema de análisis comprendía tres momentos: 1) la clase se divide en episodios a partir del cambio de tema o estructura de la actividad, 2) se analiza cada episodio para identificar las estructuras de la actividad y las acciones y estrategias usadas por profesores y alumnos, y 3 ) los episodios se analizan semánticamente para descubrir los temas tratados y las estrategias lingüísticas utilizadas para su desarrollo.

\section{Actividad e interacción profesor-alumnos (Coll et al., 1992)}

Estos autores analizan el tipo de actividades que llevan a cabo profesores y alumnos en el aula con el fin de establecer conexiones entre ellas. Emplean datos obtenidos de situaciones variadas de enseñanza-aprendizaje en lo que refiere participantes, edades, contextos y contenidos.

El sistema de análisis empleado utiliza como unidad de análisis la secuencia didáctica o secuencia de actividad conjunta diferenciado tres niveles: (1) Secuencia didáctica o secuencia de actividad conjunta, equivalente a una unidad didáctica. (2) Sesiones, entendidas como unidades de análisis menor. (3) Segmentos de interactividad o segmentos de actividad conjunta, refiriéndose al conjunto de acciones esperadas o esperables determinadas por una 
unidad temática o de contenidos y un patrón de comportamientos dominante.

\section{Análisis de la interacción en aula (Sánchez et al., 2010)}

Sánchez et al. (2010) para realizar el análisis de las sesiones objeto de estudio, en este caso la lectura en el aula, los autores segmentan la interacción de los participantes mediante distintas unidades de análisis de mayor a menor globalidad comenzando por la unidad didáctica y acabando con el ciclo tal como vemos en la Tabla 1.

\section{Tabla 1}

Unidades de análisis (Sánchez et al., 2010)

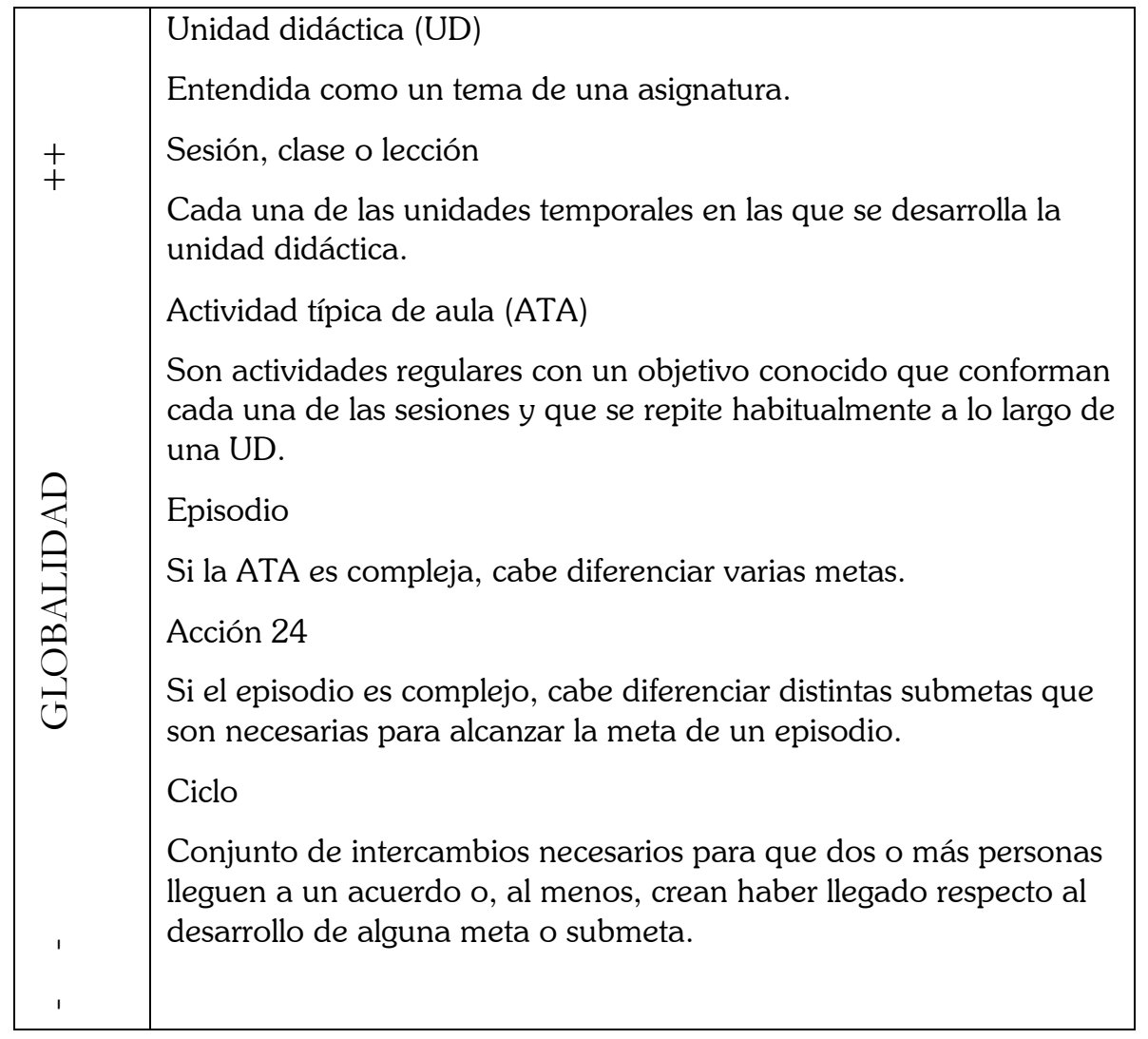


Según este sistema de análisis son cinco pasos a través de los cuales se procede a hacer el análisis de la transcripción de la situación educativa objeto de estudio. Los dos primeros pasos delimitan las unidades de análisis y los tres últimos nos permiten valorar lo que ocurre en los segmentos resultantes.

Descomposición de las interacciones en unidades globales: ATA y episodios. Este primer paso consiste en ubicar el material objeto de análisis dentro de la unidad más global que éste pueda permitir. Al estudiar una unidad didáctica completa, habría que segmentarla en lecciones o sesiones, cada sesión en diferentes ATA y cada ATA en sus episodios constitutivos.

División de cada episodio en ciclos. Una vez identificadas las unidades globales se identifican segmentos más elementales, es decir, se identifica, si se estima oportuno, cada uno de los ciclos. Un ciclo comienza con una orden o pregunta inicial y finaliza cuando ésta es satisfecha.

Una vez determinadas las unidades de análisis se procede al análisis propiamente dicho según las dimensiones cómo, qué y quién.

Análisis de la dimensión cómo. En este paso se desvela cómo se organiza comunicativamente el segmento de interacción, es decir, el patrón de interacción que tiene lugar en ese segmento. Se distinguen cuatro pautas: estructura monologal, cuando solo interviene el profesor, estructura IRE, estructura IRF y estructura dialógica o simétrica.

Análisis de la dimensión qué. En este cuarto paso se identifican aquellas ideas o proposiciones que recoge un acuerdo entre las partes. Puede haber contenido público, es decir, el conjunto de ideas del texto que son compartidas, o puede ser que solo se lea y se asume que no se hace público ningún contenido.

Análisis de la dimensión quién. En el último paso se identifican las ayudas del profesor en cada uno de los intercambios de cada ciclo. 


\subsection{Nuestro sistema de análisis}

Los distintos sistemas de análisis revisados presentan puntos fuertes y puntos débiles, ninguno de ellos se ajusta a la realidad que pretendemos estudiar tanto a nivel contextual como a nivel conceptual, por ello, de todos ellos hemos adaptado el sistema de análisis de la interacción social de Sánchez et al. (2010). Este sistema es el único que contempla las distintas estructuras de participación en el aula tal como podemos ver en lo que ellos denominan patrones de intercambio en los ciclos o estructuras de participación local distinguiendo las estructuras IRE, IRF y simétrica o dialógica, siendo ésta última la más importante para nosotros.

Por otro lado, la variable ayuda resulta también de suma importancia para nosotros (al igual que para los autores) ya que nos permite partir de situaciones de ayuda como punto de inicio de nuestra categorización, dotando a las interacciones entre los participantes de una relevante notoriedad. Ha resultado necesario precisar y definir con la mayor claridad posible las unidades de análisis utilizadas en cada caso, el nivel de sistematicidad que presentan, la naturaleza y el grosor de los datos a los que se aplican, los criterios operacionales de aplicación que garantizan su fiabilidad, su vinculación con los objetivos del análisis y con el marco teórico y conceptual de referencia (Coll \& Sánchez, 2008).

Para realizar el análisis de las actividades pertenecientes a nuestro proyecto integrado Los textos de nuestros días segmentamos la interacción de los participantes mediante distintas unidades de análisis de mayor a menor globalidad comenzando con el proyecto integrado y acabando con el ciclo tal como vemos en la Tabla 2. Tanto el procedimiento llevado a cabo como las variables que hemos incluido las explicamos en el capítulo 2 dedicado al método. 
Tabla 2

Unidades de análisis adaptadas

\begin{tabular}{|l|l|}
\hline & $\begin{array}{l}\text { Proyecto integrado (o Unidad Didáctica) } \\
\text { El Proyecto Integrado es una forma distinta de plantear la tarea de } \\
\text { enseñanza-aprendizaje, una forma de englobar las tareas, una forma } \\
\text { distinta de programar y enseñar. Se basa fundamentalmente en el } \\
\text { trabajo en equipo educativo y en las relaciones de interdisciplinari- } \\
\text { dad de las distintas Áreas (Lengua Castellana y Literatura y Educa- } \\
\text { ción Física) y la supeditación de las mismas a la adquisición de las } \\
\text { Competencias Básicas. } \\
\text { Actividad } \\
\text { Cada una de las unidades temporales en las que se desarrolla el } \\
\text { proyecto integrado. } \\
\text { Episodio } \\
\text { Son diferentes partes típicas de las actividades de aula. } \\
+\end{array} \quad \begin{array}{l}\text { Ciclo } \\
\text { Conjunto de intercambios necesarios para que dos o más personas } \\
\text { lleguen a un acuerdo o, al menos, crean haber llegado respecto al } \\
\text { desarrollo de alguna meta o submeta }\end{array}$ \\
\hline
\end{tabular}

\subsection{Relación del análisis de la práctica educativa y la transferencia}

Tal como hemos analizado a lo largo de este capítulo tanto el análisis de las prácticas educativas como la transferencia del aprendizaje son temas de suma relevancia dentro del campo de la educación. Ambos temas no se han estudiado de manera conjunta a pesar de existir un vínculo claro entre ambos. Por ello, nuestro estudio no se centra exclusivamente en el análisis de la práctica educativa tal como lo han tratado otros autores, sino más bien que tomamos la práctica educativa como vehículo para lograr entender la interacción entre las distintas variables que intervienen en la práctica educativa (estructura de participación, ayuda y formato de la tarea) ligadas al proceso de transferencia del aprendizaje. 
Entendemos que a través del análisis de la práctica educativa comprenderemos mejor cómo se lleva a cabo el proceso de transferencia del aprendizaje y cómo éste se vincula a las distintas estructuras de participación.

Como hemos visto, el análisis de la práctica educativa se ha centrado principalmente en los procesos psicológicos subyacentes a la práctica educativa, por otra parte, ha centrado su atención en el discurso del profesor, en cómo de distintas materias, pero hasta ahora ningún estudio ha centrado la atención en aunar estos puntos, es decir, en cómo la estructura de participación en aula influye en la transferencia del aprendizaje inter/intra-área. 
ESTUDIO EMPÍRICO

CAPÍTULO 2 


\section{Objetivos e hipótesis}

\section{Objetivos e hipótesis}

Esta investigación, de carácter descriptivo-exploratoria, tiene como objetivo principal realizar un análisis teórico sobre el concepto de transferencia educativa: explicar el concepto, extraer las variables y dimensiones de las que se compone la transferencia según la literatura.

Los objetivos específicos son:

- Extraer un modelo que explique el concepto de transferencia a través de análisis multivariado.

- Explicar este modelo relacionándolo con la teoría y con inferencias cualitativas.

- Relacionar las variables predictoras con la transferencia/no transferencia.

Hipótesis de investigación:

H1- Los entornos comunicativos de aprendizaje facilitan y potencian la transferencia de los conocimientos entre diferentes áreas curriculares.

H2- El tipo de estructura de participación influye en la transferencia del conocimiento.

H3- La estructura dialógica produce más transferencia que el resto de estructuras de participación.

H4- El tipo de ayuda repercute positivamente en la transferencia

H5-El tipo de formato de la tarea influye positivamente en la transferencia

H6- La estructura, la ayuda y el formato de la tarea afectan de conjuntamente de modo positivo a la transferencia. 


\section{Variables y definición}

Para tener una visión más global de la investigación es necesario conocer tanto la teoría que subyace a la misma como la definición operativa de las variables que vamos a emplear. Estas variables están extraídas de la literatura como aspectos claves a tener en cuenta a la hora de valorar y mejorar los procesos de transferencia. Hemos seleccionado por tanto, como variables a estudiar: (1) estructura de participación, (2) ayudas, (3) formato de la tarea y (4) transferencia. A continuación, explicaremos con detalle a qué nos referimos en cada una de ellas.

En un principio se valoraron las variables área (Educación Física y Lengua) y tipo de tarea (igual o distinta), incluidas en los análisis iniciales, sin embargo, al no aportar información relevante se han excluido de las categorías finales.

\subsection{Estructura de participación}

El rol que juegan los profesores y su discurso es vital ya que además de modelar el uso de estrategias, actúan como mediadores en la interacción social. En la actualidad existe consenso sobre la importancia de modelar el uso de estrategias de comprensión, incorporando además el rol clave de los conocimientos previos como vehículo para facilitar la comprensión de los contenidos, así como el tipo de diálogo que se establece en las aulas (Iturra Herrera, 2013).

Sin embargo, hay diferencias sustanciales entre los tipos de diálogos, se producen desde aquellas indagaciones orientadas exclusivamente a la confirmación de respuestas, pasando por patrones de tipo IRF hasta diálogos que incluyen retroalimentación a las respuestas de los alumnos, como patrones simétricos o dialógicos que implican una mayor participación de los alumnos en la discusión, siendo muchas veces estos, los encargados de la iniciación y retroalimentación de las indagaciones. 


\section{Variables y definición}

La estructura de participación social se refiere al sistema de normas y patrones culturales explícitos o tácitos que rigen los intercambios y las relaciones sociales en el grupo de aula. Entre las estructuras de participación más frecuentes en el aula encontramos cuatro dependiendo del mayor o menor control sobre las interacciones por parte del docente. A saber, monologal, IndagaciónRespuesta-Evaluación (IRE en adelante), Indagación-Respuesta-Feedback (IRF en adelante) y simétrica o dialógica. En un principio en nuestra investigación consideramos las cuatro categorías, descartamos la estructura monologal tanto por su valor nulo en los análisis cuantitativos, como por el poco sentido que tiene incluirla en una dinámica de grupos interactivos, en la que no se muestran momentos de discurso de una única persona. A continuación, explicaremos con más detalle en qué consiste cada una de ellas.

\section{Indagación-Respuesta-Evaluación}

Sinclair y Coulthard (1975) describieron un patrón sistemático de intercambios que se repiten una y otra vez en el aula y que tiene tres posiciones: primero el profesor pregunta algo al alumno o sugiere la necesidad de llevar a cabo una acción (I-Indagación); segundo, el alumno, elegido por el propio profesor, contesta o lleva a cabo esa acción (R-respuesta) y, finalmente, el profesor, contesta o evalúa lo sucedido (E-Evaluación). Es la denominada estructura tripartita Indagación-Respuesta-Indagación.

En nuestra investigación, hemos considerado un ciclo IRE cuando:

- No se demanda ningún proceso de selección, integración o razonamiento, tan solo es necesario recuperar información para responder a una demanda.

- El adulto es quien pregunta algo al alumno o sugiere la necesidad de llevar a cabo una acción (indagación)

- El alumno contesta o lleva a cabo esa acción (Respuesta) 
- El adulto es la única persona que evalúa lo sucedido (Evaluación)

\section{Indagación-Respuesta-Feedback}

Existen otras estructuras de participación en aula más abiertas que la IRE, donde el profesor no es el único protagonista del discurso del aula. Wells (2001) describe el patrón IRF (Indagación-Respuesta-Feedback) donde se espera que sea el alumno el que elabore una respuesta y no se limite simplemente a recordarla, si bien es cierto que el control sigue estando bajo el profesor ya que es quien formula la pregunta y determina el valor de las respuestas.

El predominio de estas secuencias triádicas ha sido cuestionado porque podría desfavorecer a niños de culturas en las que este intercambio es poco común y, además, proveer pocas oportunidades para que los estudiantes expresen sus ideas o comenten las de otros (Wells \& Arauz, 2006). Sin embargo, se ha sugerido también que la secuencia triádica permite satisfacer las metas de escolarización y provee de un cierre a la interacción pedagógica (Newman, Griffin, \& Cole, 1989): alguien que sabe (el conocedor primario) pide una respuesta, el conocedor secundario da la respuesta y el conocedor primario acepta la respuesta, dando el cierre necesario a la interacción (Berry \& Coulthard, 1981).

En nuestra investigación hemos considerado que un ciclo es IRF cuando cumple las siguientes condiciones:

- Requiere de negociación entre los interlocutores para elaborar la respuesta a una determinada tarea.

- El adulto pregunta algo al alumno o sugiere la necesidad de llevar a cabo una acción (Indagación).

- Se produce la negociación de la respuesta, esta negociación puede llevarse a cabo entre los alumnos o con los mediadores adultos (Respuesta). 


\section{Variables y definición}

- Se lleva a cabo un proceso de evaluación que hace continuar el diálogo entre el mediador adulto y los alumnos, se hace una evaluación conjunta (Feedback).

\section{Dialógico o simétrico}

Más abiertas que las anteriores estructuras son las dialógicas o simétricas, en las que el estudiante puede iniciar el intercambio o contribuir activamente en el proceso de confirmación o en ambos (Sánchez et al., 2010).

Hemos considerado que un ciclo es dialógico cuando:

- Requiere de negociación entre los interlocutores para elaborar la respuesta a una determinada tarea.

- Las preguntas no las formula únicamente el mediador, sino que los alumnos elaboran y responden a sus preguntas.

- El alumno realiza preguntas que sugieren nuevas perspectivas que modifican las decisiones tomadas o cuando evalúan a sus compañeros.

- La respuesta que se da no es cerrada, hay múltiples respuestas que surgen del diálogo.

\subsection{Ayudas}

La segunda variable a tener en cuenta en los análisis son las ayudas. Nos referimos a la ayuda como un préstamo de conciencia que hacen los interlocutores (alumnos o adultos) para facilitar la realización de alguno de los múltiples procesos que intervienen en la realización de las tareas. Las ayudas de las que vamos a hablar son ayudas muy concretas, que van dirigidas a movilizar un ciclo comunicativo, formando parte de la interacción entre participantes, haciendo más viable el éxito del grupo en relación con la tarea planteada. 


\section{Capitulo 2: ESTUDIO EMPÍRICO}

Podemos distinguir las ayudas en dos grandes bloques según Sánchez et al. (2010): ayudas frías y cálidas. Ambos tipos se desgranan en subcategorías más concretas, que se hacen imprescindibles para tener una visión general de esta variable.

Las ayudas frías son aquellas que permiten movilizar cualquiera de los procesos cognitivos ligados a la comprensión de la tarea. Dentro de las ayudas frías podemos distinguir las ayudas regulatorias, internas, invasivas y de feedback.

\section{Regulatorias}

Se trata de apoyos que guían la organización y desarrollo de las tareas, no están relacionados directamente con los contenidos que en ella se tratan, sino con su planificación y los pasos a seguir para realizarla.

Voluntaria_1 Entonces tenemos que ordenar estos trozos según esa forma, y tenemos, claro desordenados y tenemos que poner primero, segundo, tercero y el cuarto, ¿vale?

(miércoles 9 de abril 2014, 9:35 am)

Voluntaria_1 - Vale, ahora entonces quien me cuenta la historia un poco. ¿Os habéis enterado?

(miércoles 9 de abril 2014, 9:47 am)

Dentro de todas las posibilidades de ayudas regulatorias podemos encontrar los siguientes tipos:

Cuando va orientada a describir una determinada estrategia a través de las explicaciones de una serie de pasos a realizar la actividad

Voluntaria_1: No, el cuento es aquí y después por aquí tenemos el código $Q R$ que es para comprobar si está bien ordenado o no

(viernes 20 de mayo 2014, 9:15 am)

Cuando se propone una estrategia que se pueda seguir 


\section{Variables y definición}

Voluntaria_1: Vale. ¿Hacemos el primero? Esta parte ¿Os parece? Y después hacemos todo esto.

(viernes 20 de mayo 2014, 9:20 am)

Voluntaria_1: Pero espera, piensa antes de escribir, di toda la idea completa antes

(viernes 27 de mayo ,2014, 9:40 am)

Evoca aprendizajes anteriores tratados en clase

Maestra: - Cuando fuimos al castillo el año pasado a...

(miércoles 5 marzo 2014, 9:43 a.m.)

Alumno_3: Mira, lo hicimos en el gimnasio con la Maestra y la Voluntaria_1:

Había cuatro narra...narradores

(viernes 27 de mayo 2014, 9:07 am)

Resume lo que se ha dicho en el grupo durante el desarrollo de la tarea

Voluntaria_1: Dice que una vez que se enteró que había ofendido a los dioses pues claro, tuvo miedo y se quiso suicidar, entonces la perdonó la diosa y la convirtió en araña.

(miércoles 9 de abril 2014, 9:38 am)

Voluntaria -1: A ver ¿dónde os habéis quedado? En...el dragón que salía de la mazmorra

(miércoles 5 marzo 2014, 9:29 a.m.)

Establece la meta de la tarea grupal

Voluntaria_1:Vale ¿hasta ahí tenéis claro lo que tenéis que hacer?

(miércoles 5 marzo 2014, 9:12 a.m.)

Describe o señala un problema

Voluntaria_1: Es solo un ejemplo, vosotros sois los que tenéis que hacer las instrucciones porque aquí no las han incluido ¿̇vale?

(miércoles 4 junio, 2014, 9:17am)

Maestra: Vale, yo vi un problema, que tampoco es un problema vaya, que hacéis este circuito todos individual, esto vaya (señala una parte). Vale, entonces Alumno_6 ha cogido lo ha hecho el primero, ha hecho la voltereta, ha hecho el salto y luego le ha tocado esperar a los compañeros para hacer el relevo ¿cómo lo podíamos hacer para solucionar eso? 
Capitulo 2: ESTUDIO EMPÍRICO

(miércoles 26 marzo 2014, 9:34am)

Identifica el tema o contenido del que se está hablando

Propone un índice que incluya los puntos más importantes que se han tratado en la realización conjunta de la tarea

\section{Internas}

Se trata de ayudas que ofrecen parte de los elementos necesarios para dar respuesta a la tarea.

Voluntaria_1: ¿Qué siguió? ¿̇e retaron y qué más?

Existen múltiples casos de ayudas internas en las que se buscan distintas metas como sonsacar, ofrecer un contra-modelo entre otras. A continuación, mostraremos algunos tipos de ayudas más relevantes.

Se pide que se complete una determinada respuesta o se busque una diferente (sonsacar)

Voluntaria_1: Una definición ¿qué es una definición? Decir cómo es algo ¿no? En este caso el cuento motor ¿qué es el cuento motor?

(martes 27 mayo 2014, 9:10 am)

Se dan pistas llamando la atención hacia un determinado aspecto que facilitará la resolución de la actividad

Voluntario_4: A ver ¿cuántas pruebas queréis hacer?

(miércoles 26 marzo 2014, 9:35 a.m.)

Se ofrece un contra modelo, consiste en ofrecer una respuesta incorrecta para que se trate de encontrar la correcta.

Maestra: ¿Curandros? Risas

(miércoles 5 marzo 2014, 9:39 a.m.)

Se invita a reconsiderar la respuesta dada

Voluntario_3: ¿Pero tres?, tenemos que trabajar todo lo que pone carrera, marcha, saltos y relevos

(miércoles 26 marzo 2014; 9:35 a.m.)

Voluntario_3: ¿Creéis que con eso es suficiente?

(miércoles 9 abril 2014, 9:40 a.m.) 


\section{Variables y definición}

Se dan apoyos físicos con recursos instrumentales y materiales que faciliten la tarea

Maestra les enseña en el iPad imágenes de un candelabro y de unas mazmorras

(miércoles 5 marzo 2014, 9:42 a.m.)

Alumno_2: en Neo Reader, Alumno_3.

(martes 20 de mayo 2014, 9:21 am)

Se inicia un razonamiento aportando alguna premisa que dé lugar a nuevas ideas o aportaciones

Voluntario_3: En el tiempo ¿no? ¿Vosotros que creéis que es lo que hacen primero?

(miércoles 9 abril 2014, 9:43 a.m.)

Se pide rellenar huecos ofreciendo parte de la respuesta para que el alumnado la continúe

Voluntario_3: Pero, ¿por donde empiezan? ¿Por hacer el tapiz? Empiezan por...

(miércoles 9 abril 2014, 9:41 a.m.)

Se propone diferentes opciones de respuesta y de resolución de la actividad.

Maestra: puede ser el príncipe y el hermano del príncipe, el príncipe y el rey...

(miércoles 5 marzo 2014, 9:27 a.m.)

\section{Feedback}

Son apoyos que permiten fijar las respuestas correctas aportadas durante la tarea, consolidando ideas o completándolas. Hemos considerado que las ayudas de feedback no figuran únicamente a final de ciclo, como explican Sánchez et al. (2010), debido a la propia dinámica de grupos interactivos en la que se crea un diálogo complejo entre todos los participantes. Por ello, dichas ayudas se identificarán en cualquier momento del ciclo.

Establecimos por acuerdo del equipo también, el no tener en cuenta aportaciones del tipo vale o aham, sino solamente aquellas respuestas de confirmación 


\section{Capitulo 2: ESTUDIO EMPÍRICO}

en las que se aporte una información más completa que configure una verdadera ayuda. Las ayudas de feedback están orientadas a tres ideas principales:

La ayuda va orientada a fijar la respuesta correcta

Voluntario_3: Están haciendo hilo, hemos dicho ino?

(miércoles 9 abril 2014, 9:08 am)

Se consolidan ideas

Voluntaria_1: Vale, esas tres partes las tenemos que tener en cuenta para ordenarlo, ¿vale? iPues venga!

(martes 20 mayo 2014, 9:06 am)

Se completan ideas

Voluntaria_1- Claro como la otra era diosa (...) se enfadó y rajó la tela. Entonces ya lo que ha dicho Alumno_9, que Aracne se dio cuenta de que había hecho mal y se arrepintió y la castigaron y la convirtieron en araña.

(lunes 9 abril 2014, 9:47 am)

\section{Cálidas}

Las ayudas cálidas son aquellas que permiten movilizar procesos cognitivos emocionales-motivacionales influyentes en la realización conjunta de la tarea, hacen más o menos probable el éxito del grupo, pero sin aportar nada a los contenidos generados en la interacción.

Además de las categorías de ayudas cálidas aportadas por Sánchez et al. (2010) que ejemplificaremos a continuación, hemos completado con una nueva categoría emic emergente del propio análisis relacionada con apoyos dirigidos a buscar consenso en el grupo.

Se explica la dificultad de la tarea y se desafía a los miembros del grupo a enfrentarse a ella y superarla (desafío ajustado)

Maestra: ¿Vale? ¿qué alternativa proponéis para que Alumno_5 la pueda hacer, en vez de hacer una voltereta?

(miércoles 26 marzo 2014; 9:38 a.m.) 


\section{Variables y definición}

Se trata de remarcar elementos como la curiosidad o relevancia (justificación)Voluntaria_1: Alumno_3 no vale decir que no y punto, tendrás que decir que no y dar otra idea.

(martes 27 mayo 2014, 9:23 am)

Se elogia al interlocutor

Voluntaria_1: claro, si ya habías dicho tú que esta era la primera.

(martes 20 mayo 2014, 9:27 am)

Se evocan logros pasados

Voluntaria_1: Claro, eso lo sabéis hacer, además, que ya lo habéis hecho.

(martes 20 mayo 2014, 9:12 am)

Se emplean expresiones motivadoras y que refuerzan el pasamiento de que se puede alcanzar los objetivos propuestos y con ello resolver la tarea (expectativas de auto eficacia)

Voluntaria_1: mira, Alumno_1 te acaba de decir que a lo mejor es este después, este que pone aquí.

(martes 20 mayo 2014, 9:18am)

Voluntaria_1- ¿y qué más Alumno_3? Bueno Alumno_3 o Alumno_4 que las dos lo saben

(martes 27 mayo 2014, 9:16 am)

Se presenta la meta propuesta en la tarea grupal de un modo más atractivo (control motivacional)

Maestra: ...escucha ¿ंvale? Y ahora habláis vosotros, entonces lo que quiero es que montéis un circuito con el material que usamos normalmente ¿vale?

(miércoles 26 marzo 2014, 9:32 am)

Se fomenta la toma de decisiones para que el alumnado se compromete con la acción y defienda con ánimo una determinada idea u opinión (parsimonia en el procesamiento de la información)

Voluntaria_1: ¿Te acuerdas? Pues venga díselo a ellos a ver.

(martes 27 mayo 2014, 9:08 am)

Se ayuda a expresar y comprender las emociones o sentimientos propios (reflejar)

Se normalizan las emociones experimentadas a través de declaraciones que calmen y regulen el ambiente grupal 
Voluntario_3: Pero ¿cómo no te van a ayudar?

(miércoles 9 abril 2014, 9:27 a.m.)

Se empatiza con el interlocutor

Se valoran los resultados sin hacer generalizaciones

Voluntaria_1: iAnda, este lo tenéis chupado!

(martes 20 mayo 2014, 9:27 am)

Se evita hacer concesiones

Voluntaria_1: ¿Escucháis? iQue no estáis escuchando!

(martes 20 mayo 2014, 9:18 am)

Se orienta a la búsqueda de consenso (categoría émic)

Voluntaria_2: entre todos poneros de acuerdo

(miércoles 5 marzo 2014, 9:18 a.m.)

Alumno_2: A ver, esperaros un momento. A ver, escucharme un momento.

(martes 20 mayo 2014, 9:33 a.m.)

\subsection{Transferencia del aprendizaje}

La tercera variable se refiere a la transferencia del aprendizaje. De todas las categorías, subcategorías y taxonomías de transferencia hemos seleccionado las más relevantes de las que propone Haskell (2001) ya que plantea una amplia variedad de niveles y tipos de transferencia dependiendo del nivel de complejidad y de las implicaciones psicológicas que se llevan a cabo durante el proceso. Además, no existe una propuesta de categorías que sea unívoca y que sea fácil de identificar y no confundir con ninguna otra. En la propuesta de niveles de Haskell (2001) hemos seleccionado la de aplicación (nivel 2) y creativa (nivel 6) ya que son claramente diferentes y un tipo de transferencia, teórico que es excluyente del resto. Por otra parte, hemos tomado otro valor de variable cuando hay ausencia de transferencia. Así de menor a mayor nivel de complejidad hemos empleado los siguientes valores de la variable transferencia: 


\section{Variables y definición}

\section{No transferencia}

Hemos categorizado una observación con no transferencia cuando hay ausencia de la misma.

\section{Transferencia teórica}

Cuando la transferencia se basa en la conexión de la tarea con conocimientos pasados, pero no requiere una aplicación práctica en la actividad, solamente expresar verbalmente la relación entre contenidos pasados y la tarea.

Hemos considerado que hay transferencia teórica cuando:

Hay evidencia del establecimiento entre contenidos pasados y la tarea Hay evidencia de que el alumno verbaliza conocimientos

Sírvanos como ejemplo el ciclo 11.6.3 de la sesión Cuento Motor 1 donde se evidencia que el Alumno_2 verbaliza una parte imprescindible del cuento motor aprendido con anterioridad cuando la Voluntaria_1 pregunta por el significado de las palabras destacadas en el texto del cuento motor.

\section{Sesión 11, Cuento Motor 1 Ciclo 11.6.3, (20 mayo de 2014)}

Voluntaria_1: ¿Qué es esto que está aquí en negro? ¿Qué diferencia esto de aquí? (se refiere a las palabras destacadas del cuento motor que indican que hay que realizar alguna acción)

Alumno_2: Pues que tenemos que coger todos una varita y haremos magia.

Voluntaria_1: vale, son como indicaciones, ¿no?

Alumno_2: Que hay que coger cosas del material.

Voluntaria_1: iVenga!

Alumno_3: Ya lo sé, pero no hay varitas. 


\section{Transferencia aplicativa}

La transferencia aplicativa o de aplicación es más compleja que la teórica, al requerir la puesta en práctica de lo aprendido en situaciones específicas. Esas situaciones pueden ser situaciones similares a las del aprendizaje inicial o totalmente diferentes.

A la hora de categorizar la variable transferencia consideramos que se produce transferencia aplicativa cuando:

Se evidencia la puesta en práctica de algo aprendido en una actividad anterior en una situación similar a la de aprendizaje

Se evidencia la puesta en práctica de algo aprendido en una actividad anterior en una situación distinta a la de aprendizaje

Veamos el caso del ciclo 11.6.2 donde se evidencia transferencia de aplicación porque comienzan a decidir cómo ordenar los fragmentos del cuento motor dado siguiendo la estructura del cuento aprendida en sesiones anteriores.

\section{Sesión 11, Cuento Motor 1 Ciclo 11.6.2, (20 mayo de 2014)}

Voluntaria_1: ¿Cuál será primero, chicas?

Alumno_2: Este. Ellos andaban y andaban apartando los matojos.

Voluntaria_1: Alumno_3 y Alumno_1, a ver (están mirando el iPad).

Alumno_2: Después llegaron ...

Voluntaria_1: ¿Cómo lo vais a ordenar?

Alumno_1: La...

Alumno_2: No, es este el primero.

Alumno_1: El título.

Alumno_2: Pero no lo mováis más, ique me hago un lío!

Voluntaria_1: No, pero también echad un ojo a estas que también son.

Alumno_2: Espérate.

Alumno_3: Érase una vez. Este empieza.

Alumno_2: Esta sí, no ves que pone érase una vez. 


\begin{abstract}
Alumno_3: A ver. Ellos ... ja, pero tenemos que leer este haber que dice
Alumno_2: Érase una vez, hace mucho tiempo, existía un mundo de magia, donde podríamos encontrar hechiceros poderosos y hadas pícaras y juguetonas. Y todos ellos, vivían en las profundidades de los bosques. Los hechiceros vivían en un pueblo llamado Misterio y las hadas vivían en un pueblo vecino, llamado Amanecer. Los hechiceros eran unos tipos muy altos y corpulentos, los cuales siempre llevaban consigo su varita mágica. Consigo, sería con ellos, ¿no?

Voluntaria_1: (Risas)

Alumno_2: Cojamos todos, la varita mágica, con la cual haremos magia. ¿Habéis escuchado lo que hay que hacer?

Alumno_3: Sí.
\end{abstract}

\title{
Creativa
}

Es la más compleja, es aquella transferencia de los aprendizajes para la creación de nuevos conceptos y conocimientos. Consideramos que hay transferencia creativa cuando un alumno crea un concepto nuevo relacionándolo con uno existente.

La transferencia creativa es el ideal al que todo profesor quiere que lleguen sus alumnos, en nuestras observaciones no hemos encontrado transferencia creativa, sin embargo, uno de los jueces considera que en la observación 7.v se produce transferencia creativa.

\section{Sesión 7, Aventuras en la selva 1 Ciclo 7.6.2, (10 junio de 2014)}

Maestra- Vale, a mí me ha gustado del cuento del primero, del grupo 1 que habéis utilizado material que normalmente no hemos utilizado y de manera distinta, las indiakas nunca las hemos puesto en el suelo y las habéis utilizado hoy de árboles ¿no?

Alumno_3- No, de camino

Maestra- De piedras. Y la pelota de barco, que a mí no se me hubiera ocurrido que la pelota fuera un barco, ¿̇vale? De vosotros me ha gustado que ha- 
béis retomado la idea del día del circuito de escalada con Voluntario_3 y Voluntario_4 y la habéis adaptado a la historia de hoy. Me ha gustado mucho como habéis cogido las ideas que ya habíamos trabajado y las habéis adaptado.

Alumno_3-Era igual, con el gusano así.

\subsection{Formato de la tarea}

Uno de los elementos clave que aporta la literatura acerca del proceso de la transferencia son la inclusión de apoyos que faciliten la comprensión de la tarea y la activación de los contenidos que puedan ser transferidos a una nueva tarea. Nos referimos a formato de la tarea a aquellos elementos distintivos que se incluyen en las instrucciones escritas (en el propio enunciado) para la realización de la tarea que organizan y facilitan la ejecución de una tarea como son incluir una explicación, un ejemplo y contenidos relacionados con el contexto cercano del alumno.

Para que se lleve a cabo el proceso de transferencia es necesario establecer analogías entre la situación inicial y la de transferencia, sin embargo, se ha probado que la dificultad de transferir aprendizajes con éxito se asocia a la cantidad de modelos mentales que deben ser construidos y procesados simultáneamente (Solaz-Portolés \& Sanjosé López, 2007). Pero muchas de las explicaciones asociadas a la dificultad de transferir proceden del análisis de la estructura semántica de los enunciados habituales usados para enseñar (Orrantia, González, \& Vicente, 2005) y del modo en que dicha estructura semántica dificulta o facilita encontrar el esquema adecuado (Carpenter, Hiebert, \& Moser, 1981; Carpenter \& Moser, 1984; Nesher \& Hershkovitz, 1994; Valentin \& Chap-Sam, 2005; Wilson, 1967).

Algunos estudios centran la atención en la provisión de múltiples ejemplos sin instrucción explícita en reglas generalizadas para transferir conocimientos con éxito (Catrambone \& Holyoak, 1989). Otros resultados (Mendelson, 2010) también sugieren que la ayuda de experto (expert support) se ofrece mejor a 


\section{Variables y definición}

través del modelado que mediante la intervención del grupo didáctico recibido, es decir, la instrucción directa acerca de estrategias útiles con ejemplos.

Basándonos en estos resultados se crean estas categorías teniendo en cuenta:

La teoría científica, fijándonos solo en aquellos aspectos que mejoran la transferencia que no se solapan con ayudas o tipos de interacción

La estructura general de nuestras tareas, que nos hizo descartar la posibilidad de incluir todas las combinaciones posibles entre explicación, ejemplos y contexto, ya que muchas resultarían nulas, por lo que sería un problema en los análisis cuantitativos.

\section{Explicación}

Se considera que una actividad contiene explicación cuando en el enunciado de la tarea propuesta se incluye una explicación de ciertos contenidos. Como vemos en la actividad El Mito de Aracne y Atenea 1 se incluye únicamente una explicación de la actividad, sin tener en cuenta ningún otro elemento que sirva de apoyo en la realización de la tarea.

\section{EL MITO DE ARACNE Y ATENEA 1 \\ $1^{\circ}$ LEEMOS Y ORDENAMOS \\ A continuación, tenéis el Mito griego de Aracne y Atenea, pero iATEN- CIÓN! Los fragmentos están desordenados, por lo que debéis organizarlos teniendo en cuenta la estructura de los textos narra}

\section{Explicación y ejemplos}

Se considera que una actividad contiene explicación y ejemplos cuando además de lo anterior se incluyen ciertos ejemplos que ayudan a entender mejor la tarea. 
Como vemos en la sesión El cuento Motor 1 la primera parte del enunciado de la tarea incluye una explicación de lo que consiste el cuento motor y en la segunda se presenta el cuento motor Una pizca de magia a modo de ejemplo, pero fragmentado para que lo ordenen.

\section{EL CUENTO MOTOR. PARTE 1}

\section{$1^{\circ}$ ANTES DE EMPEZAR IINFÓRMATE!}

El cuento motor, es una variante del cuento hablado, podríamos denominarlo como el cuento representado, un cuento jugado, en el cual hay un narrador y un grupo de alumnos/as que representa lo que dice, dicho narrador. Se trata de una variante del cuento, motivadora, educativa y estimulante, que resulta muy eficaz para el desarrollo tanto psíquico, físico como mental del alumno, donde el factor fundamental es el juego.

\section{$2^{\circ}$ LEEMOS Y ORDENAMOS}

A continuación, tenéis el cuento motor Una pizca de magia, pero iAtención! Los fragmentos están desordenados, por lo que debéis organizarlos teniendo en cuenta la estructura de los textos narrativos.

¿Por qué hay frases en negrita?

$3^{\circ}$ ACTUAMOS

iBUEN TRABAJO! Ahora nos queda llevarlo a la práctica.

Poneos de acuerdo en:

Quién va a ser el narrador o narradores de la historia

Qué materiales necesitamos (en caso de necesitar algo)

Cómo distribuimos el espacio donde se va a desarrollar el juego

\section{Explicación y contexto cercano}

Se considera que una actividad contiene explicación y contexto, cuando además de incluir una explicación la actividad está relacionada con temas o contenidos que se refieren o se llevan a cabo en su contexto cercano. Como a continuación vemos en el ejemplo el enunciado de la tarea incluye la explicación de la meta de la actividad, en concreto la creación de un circuito y las partes que 
debe contener. Además, se conecta con el contexto cercano del alumno ya que la tarea convierte a los alumnos en profesores de EF, conectando así con actividades similares llevadas a cabo con anterioridad en dicha área.

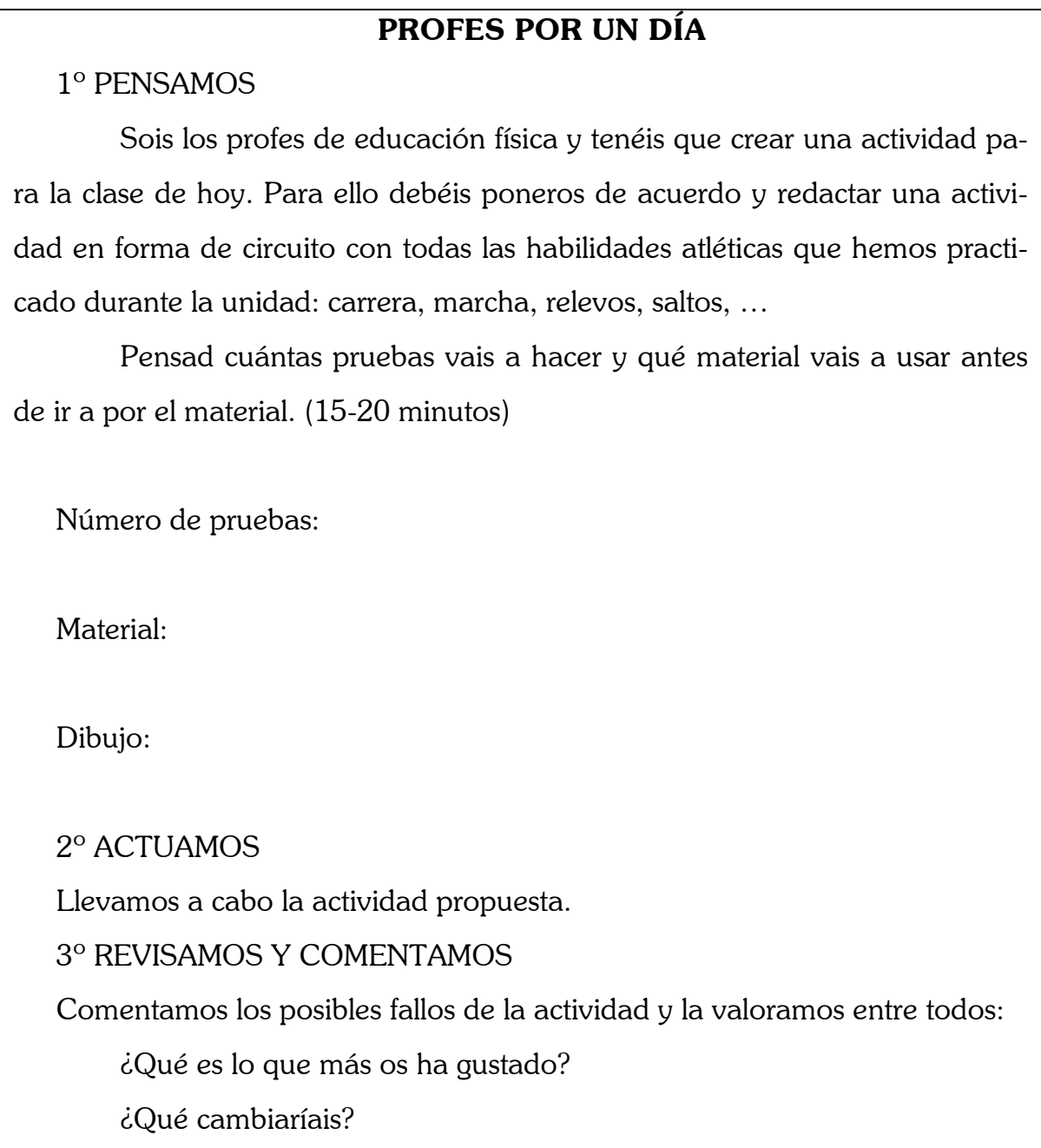

\section{Explicación, ejemplos y contexto cercano}

Se considera este valor de la variable como la combinación del primer valor con el anterior. 
En la actividad Nos vamos de festival contiene el formato de tarea más completo. Por un lado, contiene la explicación de lo que son los textos expositivos, a continuación, se presenta un ejemplo de texto expositivo y por último conecta con el contexto cercano al referirse a una actividad que se realiza en el propio colegio como es un festival de primavera además conecta con actividades que se realizan en el aula como el uso y manejo de libros de texto y diccionario.

\footnotetext{
NOS VAMOS DE FESTIVAL

$1^{\circ}$ ANTES DE EMPEZAR iINFÓRMATE!

En más de una ocasión habréis leído textos sobre un hecho o un tema determinado que no incluyen opiniones personales. Por ejemplo: las explicaciones del libro de texto o las definiciones de los diccionarios $₫$ Son textos expositivos.

\section{$2^{\circ}$ MANOS A LA OBRA}

En el colegio se llevará a cabo un festival de primavera y iTENEIS QUE HACER CORRER LA NOTICIA! Porque el periódico del colegio aún no ha dado ninguna información y necesitáis difundir la noticia para que asistan padres, amigos etc. Vuestra misión es crear un texto que expliqué de forma objetiva qué obras de teatro se realizarán, las canciones que se interpretarán etc.

$1^{\circ}$ Dar ideas sobre el tema propuesto. Podéis ir anotándolas para que no se os olviden.

$2^{\circ}$ Ordenar la información y emplear vocabulario preciso y relacionado con el tema. Podéis ayudaros del diccionario.
}

A modo de facilitar una panorámica general de las variables y su relación con la literatura se presenta la Figura 4. 
7. Variables y definición

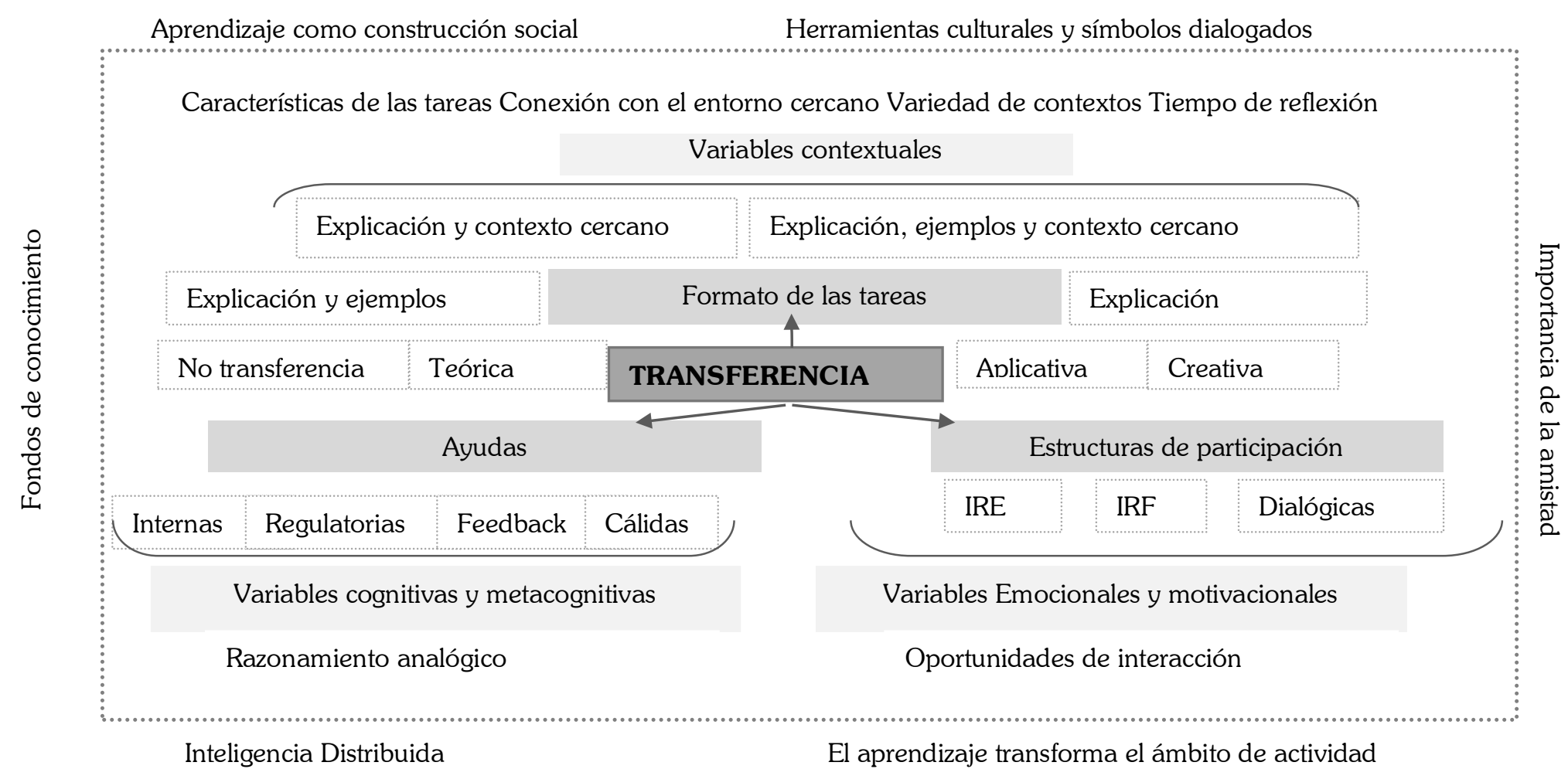

Figura 4. Modelo completo de las variables de estudio. 


\subsection{Codificación de las variables}

Una vez realizada la categorización definitiva de los datos se procede al análisis estadístico utilizando para el mismo el programa R (R Core Team, 2015) versión 3.2.03 para Mac. Las variables que se han empleado son las siguientes variables cualitativas nominales que pueden verse en la Tabla 3.

Tabla 3

Codificación de las variables

\begin{tabular}{|c|c|c|c|c|}
\hline & $\begin{array}{l}\text { Estructura de } \\
\text { participación } \\
(\mathrm{EST})\end{array}$ & $\begin{array}{l}\text { Transferencia } \\
\text { (TRA) }\end{array}$ & $\begin{array}{l}\text { Ayuda } \\
\text { (AYU) }\end{array}$ & $\begin{array}{l}\text { Formato de la } \\
\text { tarea } \\
\text { (FOR) }\end{array}$ \\
\hline 1 & IRE & $\begin{array}{l}\text { NO } \\
\text { (No transfreren- } \\
\text { cia) }\end{array}$ & INT (Interna) & EX (Explicación) \\
\hline 2 & IRF & TEO (Teórica) & $\begin{array}{l}\text { REG (Regula- } \\
\text { toria) }\end{array}$ & $\begin{array}{l}\text { EX_EJ (Explica- } \\
\text { ción y ejemplo) }\end{array}$ \\
\hline 3 & $\begin{array}{l}\text { DIAL (Dialógi- } \\
\text { ca) }\end{array}$ & $\begin{array}{l}\text { APLI (Aplica- } \\
\text { ción) }\end{array}$ & $\begin{array}{l}\text { FEE } \\
\text { (Feedback) }\end{array}$ & $\begin{array}{l}\text { EX_CC (Explica- } \\
\text { ción y contexto } \\
\text { cercano) }\end{array}$ \\
\hline 4 & & & $\begin{array}{l}\text { CAL } \\
\text { (Cálida) }\end{array}$ & $\begin{array}{l}\text { EX_EJ_CC (Expli- } \\
\text { cación, ejemplo y } \\
\text { contexto cercano) }\end{array}$ \\
\hline
\end{tabular}

\section{Método}

Una vez que hemos hecho un análisis profundo que nos permite establecer las bases teóricas de la investigación, así como la explicación de las variables que intervienen en el proceso investigador, este apartado lo dedicaremos a la explicación del proceso llevado a cabo. Dicho método incluye desde los participantes en la investigación, al propio procedimiento en sí mismo, así como el análisis de datos y los principales resultados obtenidos. 


\section{Método}

\subsection{Participantes/Muestra}

El contexto de esta investigación es el colegio Miguel Íscar de la ciudad de Valladolid, en el que se lleva a cabo el proyecto de Comunidades de Aprendizaje, siendo la selección de los participantes de manera intencional siguiendo el criterio de acceso al campo. La totalidad del alumnado del centro pertenece a familias de etnia gitana con graves problemas socioeconómicos, cuya implicación en el colegio ha conseguido mejorar la convivencia y el aprendizaje del alumnado, logrando traspasar estas mejoras al entorno familiar y a nuevos contextos de su día a día.

En este centro los entornos comunicativos de aprendizaje se plasman a través de las Comunidades de Aprendizaje, y una de las medidas de trabajo dentro del aula son los grupos interactivos, en concreto los llevados a cabo en el tercer ciclo de primaria en las áreas curriculares de Lengua Castellana y Literatura y Educación Física. Como ya se ha explicado anteriormente, se trata de una dinámica basada en el aprendizaje dialógico en la que se realizan una serie de tareas grupales y en la que participan tanto alumnado como mediadores adultos. Todos y cada uno de los miembros del grupo deben dialogar e interactuar con sus compañeros, aportando ideas y cooperando entre sí, con el fin de dar respuesta a la tarea que se les presenta.

Los participantes son ocho alumnos de $5^{\circ}$ de primaria y nueve alumnos de $6^{\circ}$, la distribución de los alumnos en el centro se puede ver en la Tabla 4. El grupo de $5^{\circ}$ lo componen cinco ANCES y tres repetidores, la clase de $6^{\circ}$ la integran cinco ANCES y cuatro repetidores. Todos ellos presentan bajo nivel curricular ( 6 alumnos de $5^{\circ}$ presentan un nivel de competencia curricular de $3^{\circ}$ de primaria, 7 alumnos de $6^{\circ}$ presentan un nivel de competencia curricular de $4^{\circ}$ de primaria) y cierta dificultad a la hora de adquirir y poner en práctica los contenidos trabajados durante las sesiones. Sin embargo, muestran una gran variedad de capacidades y habilidades que, al combinarse en los grupos, se convierten en una fuente importante de aprendizaje conjunto. A partir de esta

$$
-70-
$$




\section{Capitulo 2: ESTUDIO EMPÍRICO}

multitud de características se logra un aprendizaje más rico y diverso, lo que ayuda en todo momento al proceso de construcción conjunta de conocimiento y a la transferencia de estos aprendizajes a nuevas situaciones. Entre los demás participantes se encuentran los mediadores adultos: cuatro voluntarios de la universidad de Valladolid procedentes de estudios de Grado en Educación Primaria y Grado en Educación Social, así como un familiar gitano y la propia tutora del grupo.

Tabla 4

Distribución de los alumnos

\begin{tabular}{llll}
\hline Curso & Niños & Niñas & TOTAL \\
\hline 3 años & 8 & 2 & 10 \\
$4-5$ años & 3 & 6 & 9 \\
1er Ciclo & 5 & 4 & 9 \\
$3^{\circ}$ & 4 & 3 & 7 \\
$4^{\circ}$ & 4 & 4 & 8 \\
$5^{\circ}$ & 2 & 6 & 8 \\
$6^{\circ}$ & 3 & 6 & 9 \\
\hline TOTAL & 29 & 31 & 60
\end{tabular}

Como señalamos anteriormente, el criterio de selección seguido para acceder al campo fue principalmente intencional y de acceso ya que durante el proceso de recogida de datos fui la tutora y maestra de Educación Física de los alumnos de $5^{\circ}$ y $6^{\circ}$ permitiendo poder investigar la trasferencia entre dichas áreas durante las sesiones que trabajamos en grupos interactivos. Por otra parte, tuvimos en cuenta la disponibilidad de horario de los voluntarios para asistir a la dinámica de grupos interactivos. Se cuenta con el consentimiento informado de todos los participantes.

Debido a la asistencia irregular de los alumnos, cada día se dispone de un número de participantes distinto, no pudiendo fijar la atención en un grupo de referencia concreto. Otra de las dificultades encontradas fue que no siempre en las sesiones de Lengua Castellana y Literatura se podía contar con ambos gru- 


\section{Método}

pos debido a la programación de las tutoras y del centro, por lo que no todas las sesiones muestran a las dos clases unidas en la dinámica de grupos interactivos.

Para el análisis se cuenta con 1506 secuencias de interacción con ayuda identificadas en el proceso de codificación de las transcripciones. Cada una de las secuencias presenta asociada una ayuda que se prestan los participantes con el fin de resolver la tarea propuesta.

Cabe mencionar a otros participantes, que, aunque no han intervenido de forma directa en los grupos interactivos, han sido una importante fuente de ideas y sugerencias. Se trata del Grupo de Análisis de la Interacción Social y el grupo ACOGE, formados por profesorado y alumnos de la Facultad de Educación y Trabajo Social. De este modo se ha podido integrar el saber científico con la experiencia práctica y la visión de los propios participantes en la escuela, ya que es importante tener presentes tanto los conocimientos científicos como las voces de los sujetos (González \& Holford, 2010).

\subsection{Procedimiento}

Para llevar a cabo nuestra investigación hemos empleado métodos preferentemente cuantitativos con algún elemento de investigación cualitativa como podemos ver en la Figura 5. De este modo se ha realizado una aproximación a los métodos mixtos permitiendo una mejor comprensión del problema que empleando un único método de investigación.

En la etapa inicial de recogida de datos se han empleado técnicas cualitativas como las grabaciones, el grupo de discusión y el diario de campo.

La etapa de análisis de datos consta de tres fases: una primera fase cualitativa en la que se ha llevado a cabo el análisis de contenido de las transcripciones seleccionadas y el grupo de discusión, a continuación, una fase cuantitativa en la que se ha realizado un análisis de datos categóricos con distintos paquetes estadísticos. Finalmente, en la tercera fase se ha realizado una interpretación de 


\section{Capitulo 2: ESTUDIO EMPÍRICO}

la información obtenida y se ha completado mediante fragmentos ilustrativos de las sesiones. Este proceso de investigación ha permitido enriquecer los resultados y las conclusiones generadas con la información aportada por ambas perspectivas metodológicas.

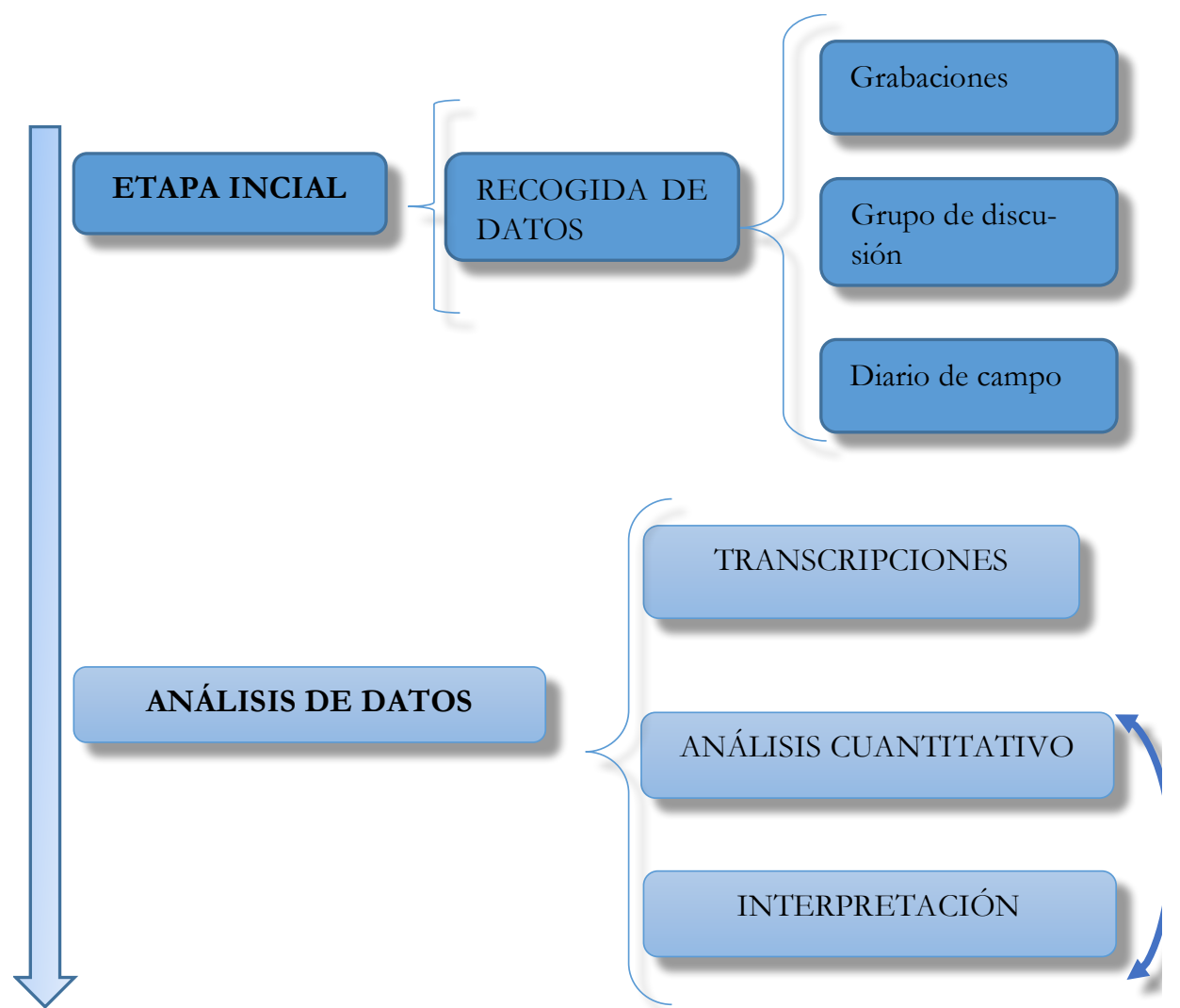

Figura 5. Síntesis del procedimiento llevado a cabo

Siguiendo las motivaciones que señalaban Greene y Caracelli (2003) para aplicar métodos mixtos, justificamos la elección del empleo de este método en nuestra investigación:

Triangulación, buscando la convergencia de los resultados obtenidos por los distintos métodos, con el fin de aumentar la validez de los resultados obtenidos. El uso de diferentes métodos permite eliminar resultados parciales que no queden confirmados por otros, y evitar así el peligro de dar por buenos resultados 
debidos a sesgos del método, del investigador, del diseño de la investigación, entre otros.

Complementariedad, buscando la elaboración, la mejora y clarificación de los resultados de un método con los resultados de los otros.

Iniciación, pretendiendo encontrar contradicciones entre los resultados obtenidos mediante los diferentes métodos, y estimular de esta forma la búsqueda de nuevas preguntas de investigación.

Extensión, aumentando la extensión y la profundidad de la investigación por medio de uso de diferentes métodos para cada aspecto/momento de la investigación.

\section{Creación de una estructura de aprendizaje común}

Esta investigación se enmarca dentro del Proyecto de Innovación Docente bajo el título Acoge: Comunidades de aprendizaje y formación del profesorado, dentro de dicho Proyecto de Innovación se han llevado distintas actuaciones para la creación de una estructura de aprendizaje común en el que todas las personas implicadas en dicho Proyecto tuvieran una misma visión y aportar así un enfoque global del tema de investigación desde distintos puntos de vista. Esta estructura se creó en varias fases.

La primera fase se inicia con la grabación de cuatro sesiones de GI tanto en el área de Lengua como en $\mathrm{EF}$, posteriormente esas sesiones se visionan de manera conjunta y se trata de establecer qué aspectos son susceptibles de ser transferidos y a partir de ahí crear unas categorías que sirvan para analizar las subsecuentes sesiones. Se debate acerca del concepto de transferencia y se presentan unas categorías iniciales (ver Apéndice A) que sirvan de base para el análisis de los vídeos de las sesiones. El debate surgido y la reflexión conjunta dan lugar a establecer nuevas categorías de análisis, así como una nueva orientación a la investigación. La complejidad a la hora de identificar los distintos tipos de transferencia en las sesiones hace necesario definir nuevos objetivos en 


\section{Capitulo 2: ESTUDIO EMPÍRICO}

las actividades, por lo que deben concretarse una serie de contenidos que puedan conectar las áreas elegidas.

La segunda fase es crucial para el posterior desarrollo de esta tesis ya que teniendo en cuenta lo leído hasta el momento sobre transferencia y las reflexiones conjuntas del GAIS (Grupo de Análisis de la Interacción Social) da lugar a nueva orientación de las tareas que se van a llevar a cabo durante la fase de recogida de datos.

La creación del proyecto Los textos de nuestros días de actividades con un eje vertebrador común a ambas áreas permite identificar aquellos elementos transferibles (según nuestra propia visión) de manera que decidimos trabajar los tipos de textos literarios a través de las áreas de Lengua y $\mathrm{EF}$ ya que resulta fácil conectar dichas áreas a través del diálogo conjunto y el aprendizaje activo en GI. De una parte, permite utilizar un elemento común a todas las áreas, la lectura y de otra permite establecer puentes visibles entre ambas áreas. Las tareas deben permitir la reflexión y la creatividad, ofreciendo al alumnado la oportunidad de negociar y llegar a acuerdos para crear un proyecto conjunto. Por este motivo, las tareas se vinculan a situaciones relacionadas con su entorno próximo, mostrando al alumnado la importante utilidad de las actividades en su día a día. Además, las tareas se conectan con otros aprendizajes desarrollados durante el curso, de modo que se activa la capacidad del alumnado de recuperar conocimientos previos y de establecer relación entre ellos, dos características clave de la transferencia. Los elementos susceptibles de transferencia pueden verse en la Tabla 5. 
Tabla 5

Elementos de transferencia entre áreas

\begin{tabular}{|c|c|c|}
\hline $\begin{array}{l}\text { ELEMENTOS DE } \\
\text { TRANSFERENCIA }\end{array}$ & TAREAS DE LENGUA CASTELLANA Y LITERATURA & TAREAS DE EDUCACIÓN FÍSICA \\
\hline $\begin{array}{l}\text { Estructura y características de } \\
\text { los textos instructivos }\end{array}$ & $\begin{array}{l}\text { iInventamos una receta!: Crear y redactar un texto instructivo en forma de receta } \\
\text { ¿Cómo usar bien los patines?: Crear y redactar un texto instructivo en forma de } \\
\text { cartel que explique las normas de uso de los patines. }\end{array}$ & $\begin{array}{l}\text { Profes por un día: crear, redactar y poner en práctica un texto instructivo en forma de } \\
\text { circuito }\end{array}$ \\
\hline $\begin{array}{l}\text { Estructura y características de } \\
\text { los textos argumentativos y } \\
\text { expositivos }\end{array}$ & $\begin{array}{l}\text { Periodistas en acción: crear y redactar un texto argumentativo a modo de artículo } \\
\text { de opinión sobre un grupo musical } \\
\text { Nos vamos de festival: crear y redactar un teto expositivo a modo de noticia sobre } \\
\text { un festival que se celebrará en el colegio }\end{array}$ & $\begin{array}{l}\text { Aventuras en la selva: crear, redactar y poner en práctica un texto expositivo a modo } \\
\text { de juego y argumentar una serie de cuestiones sobre la tarea }\end{array}$ \\
\hline $\begin{array}{l}\text { Estructura y características de } \\
\text { los textos narrativos y descripti- } \\
\text { vos }\end{array}$ & $\begin{array}{l}\text { Luces, cámaras y acción } 1 \text { y 2: crear y redactar un texto narrativo en forma de } \\
\text { argumento de una película. } \\
\text { El mito de Aracne y Atenea 1: Ordenar fragmentos de un texto narrativo } \\
\text { El mito de Aracne y Atenea 2: Crear y redactar un texto descriptivo. } \\
\text { El cuento motor 2: Crear y redactar un texto narrativo a modo de cuento motor e } \\
\text { identificar los elementos característicos. } \\
\text { El cuento motor 3: identificar los elementos característicos de un texto narrativo y de } \\
\text { los cuentos motores. Crear y redactar las instrucciones de uno de los cuentos crea- } \\
\text { dos en sesiones anteriores }\end{array}$ & $\begin{array}{l}\text { El cuento motor 1: Una pizca de magia!: Ordenar fragmentos de un texto narrativo, } \\
\text { identificar los elementos característicos de los cuentos motores y representar el relato. }\end{array}$ \\
\hline
\end{tabular}




\section{Capitulo 2: ESTUDIO EMPÍRICO}

Todas las tareas propuestas en el proyecto integrado siguen una misma estructura, las tareas se dividen en distintos momentos o episodios según el tipo de actividad:

Primer momento, en el que se leen las instrucciones de la actividad, se ponen en marcha aprendizajes previos o se explican contenidos nuevos. Las instrucciones son: (a) Pensamos, (b) Antes de empezar infórmate!, (c) Antes de emperezar iRecuerda! y (d) Leemos y ...

Segundo momento, en el que se negocian los aspectos propios de la tarea y se llega a un acuerdo consensuado de cómo resolverla.

Tercer momento de ejecución de la tarea, este momento en ocasiones se compagina con el segundo. Las instrucciones son: (a) Actuamos (b) iManos a la obra!, (c) Exponemos y (d) Creamos.

Cuarto momento, en el que o bien se intercambian las tareas con otro grupo o se realiza una evaluación de la puesta en marcha de la tarea. Las instrucciones son: (a) Revisamos y comentamos, (b) iAntes de acabar! y (c) Cambiamos.

En el área de EF solo son susceptibles de ser tenidas en cuenta aquellas tareas que no implican una resolución motriz, sino el propio proceso de diálogo, reflexión y negociación que se lleva a cabo para resolver la tarea propuesta.

\section{Implementación en las clases de Lengua y Educación Física}

Una vez planificado y desarrollado tanto la estructura de las tareas como el contenido de las mismas, el siguiente paso es el de su puesta en práctica desde enero a junio de 2014 durante una sesión de educación física por cada dos de Lengua para respetar la ratio de horas que se imparten semanalmente dichas áreas según la LOE (Ley orgánica 2/2006, de 3 de mayo, de educación).

Se llevan a cabo un total de 13 sesiones de las cuales fueron nueve Lengua y cuatro de Educación Física, durante las mismas se procedía de la siguiente manera: 


\section{Método}

Una primera fase de planificación de las actividades que se iban a desarrollar, siempre una de EF ligada a dos de Lengua bajo la misma tipología de texto literario (Tabla 5). Una vez planificada, se elaboran las actividades para las sesiones de GI, dichas actividades cuentan con la supervisión del equipo docente de las áreas.

La puesta en práctica siempre se lleva a cabo en el aula de $5^{\circ}$ de primaria en el caso de Lengua y en el salón de usos múltiples en el caso de EF.

El reparto de los grupos no es estanco debido al alto nivel de absentismo que presentan los alumnos de este centro. Los voluntarios tampoco son fijos ya que depende de la disponibilidad de los mismos.

La selección de las áreas de Lengua y Educación física como parte de la investigación responde al criterio de acceso ya que las áreas son impartidas por el mismo docente y en ambas se llevan a cabo grupos interactivos periódicamente. Por otro lado, como mencionábamos antes, el estudio de la transferencia en este contexto nos permite establecer puentes visibles entre ambas áreas a través de la propuesta de un proyecto integrado, dando respuesta a contenidos curriculares comunes en ambas áreas tales como la lecto-escritura.

Investigaciones llevadas a cabo en neurociencia avalan desde los años 70, la importancia que un correcto desarrollo motor y trabajo corporal tienen sobre el funcionamiento de distintas funciones cerebrales (Ramachandran, 2008; Rizzolatti \& Sinigaglia, 2006). Por ello son varios aspectos los que pueden ejercer de influyentes entre las tareas de aprendizaje de dichas áreas y la transferencia producida. Por otra parte, se ha comprobado que cambios en el repertorio de conductas motrices, producen también cambios en los niveles cognitivos o mentales (Payne, 1992). Así, las cualidades de cualquiera de nuestros movimientos son manifestaciones de cómo la mente se expresa a través del cuerpo en ese momento. 


\section{Capitulo 2: ESTUDIO EMPÍRICO}

Vinculando el área de Lengua y Educación Física también se pretende dar un mayor contenido al área de Educación Física, no basándose únicamente en contenidos eminentemente motores. Lo mismo ocurre con el área de Lengua, que su vinculación con el área de Educación Física demuestra la importancia de la lectoescritura, la negociación y el diálogo en cualquier circunstancia.

\section{Grabación de las sesiones en videos}

Para la recogida de los datos primarios empleamos la grabación en soporte audiovisual de las sesiones en dos de los grupos de la clase ya que, por un lado, los investigadores forman parte de las sesiones y por otro garantizan la correcta transcripción de las sesiones para su posterior análisis. Disponemos de varios medios técnicos; para las grabaciones de video se emplea un MacBook Pro y un iPad 2 dispuestos cerca del grupo sin distraer su atención, se mantienen fijos durante toda la sesión, salvo en aquellas actividades de EF que implican movimiento por parte de los alumnos (ir a por material o colocarlo); y para el registro de audio disponemos de dos grabadoras Olympus (modelos VN-731PC y VN7200) propiedad de la Uva y un Smartphone, dichos dispositivos se colocan en el centro de las mesas que conforman el grupo para garantizar así que se todo lo dicho quede registrado.

Las sesiones son registradas tanto en audio como en video en dos de los grupos de la clase en cada una de las sesiones lo que posteriormente permite transcribir dichas sesiones y así analizar la transferencia del conocimiento entre las sesiones objeto de estudio.

Con el proceso de transcripción se inicia el análisis con la reducción cualitativa de datos, priorizando el criterio de la relevancia interpretativa y eliminando lo superfluo o redundante, tratando en lo posible de no perder la esencia o lo sustancial de lo expresado por los participantes (Tójar, 2006).

Otros instrumentos de recogida de datos son el diario de campo, documento donde se recogen tanto los pasos seguidos en el proceso de investigación, como las reflexiones y observaciones que se llevan a cabo de las sesiones objeto de 
estudio. El diario de campo es un documento importante en el que se refleja tanto el proceso seguido, así como las dificultades encontradas y las diferentes reformulaciones que ha sufrido esta investigación. También el diario de campo ha sido el medio por el cual hemos reflejado los acuerdos y cambios pactados en el grupo de investigación.

El grupo de discusión durante la investigación es otro instrumento clave que permite analizar los videos y las propuestas de categorías, a través del mismo ha permitido perfilar y definir con operatividad tanto las variables como las categorías finales empleadas.

Al formar parte de la investigación como maestra tutora del aula y maestra especialista de educación física se emplea también la observación participante. Se denomina observación participante a aquella observación que involucra la interacción social entre el investigador y los participantes, recogiéndose los datos de modo sistemático y no intrusivo captando la realidad mediante la inclusión del investigador en el grupo (Bogdan \& Taylor, 1990; Maestre, 1990).

\section{Sistema de categorización de análisis (criterios)}

El planteamiento de las tareas resultante precisa de un sistema de categorización adecuado a sus características y a las del contexto dialógico donde se llevaban a cabo. Aproximarse al estudio de las prácticas educativas en el aula exige optar por uno u otro esquema básico de análisis (Coll, 1999), a sabiendas de que dicha opción dejará inevitablemente fuera del foco de atención y análisis algunos de los aspectos de dichas prácticas.

Tras revisar varios sistemas de categorización (Bullen, 1997; Gunawardena, Lowe, \& Anderson, 1997; Henri, 1992), Sistema de Análisis de la Interactividad y construcción de sistemas de significados compartidos propuesto por Coll et al. (1992), Sistema de Análisis de la Interacción propuesto por Sánchez et al. (2010) y ver si se ajustan o no tanto al contexto de investigación como a los objetivos planteados se opta por seguir la tipología de ayudas y de patrones de 
interacción propuesta por Sánchez et al. (2010) ya que es el único que contempla la vertiente dialógica en las estructuras de participación. Se trata de categorías similares al primer sistema planteado, pero con el añadido de presentar mayor validez y fiabilidad al haber sido aplicadas en diversos entornos de enseñanza-aprendizaje caracterizados por la lectura y el diálogo en el aula. Cabe mencionar que los casos de los apoyos son ofrecidos por la figura del profesor al alumnado, por lo que es necesario adaptarlos al rol de mediador adulto $e$ intentar observar y analizar si también se muestran entre iguales.

Los rasgos principales de la dinámica de grupos interactivos hicieron posible adaptar estas categorías al contexto de la presente investigación, ya que permiten analizar los diferentes aspectos influyentes en la construcción conjunta de conocimiento. En cuanto a los tipos de transferencia, se sigue la clasificación realizada por Haskell (2011), con pequeñas modificaciones que se ajustan más al entorno dialógico investigado.

\section{Explicación del proceso de análisis de las interacciones en nuestra investi- gación}

Hay cinco pasos a través de los cuales se procede a hacer el análisis de la transcripción de cada una de las sesiones objeto de estudio (1. División en episodios, 2. División en ciclos, 3. Identificación de secuencias de interacción de ayuda, 4. Categorización variables comunes al ciclo, 5. Categorización variables comunes a la sesión). Los dos primeros vienen determinados por las unidades de análisis en las que se segmenta la interacción y el resto nos permite analizar qué ocurre en cada segmento.

\section{División en episodios}

En el primer paso se ubica el material objeto de análisis dentro de la unidad más global que éste pueda permitir. La primera labor es reconstruir los diferentes episodios tratando de diferenciar cuándo se cambia ostensiblemente de objetivo y recomponer el mapa completo de la actividad. Los episodios según una rutina normal de aula se dividen en episodio de planificación, episodio de 
activación de conocimientos previos, episodio de lectura, de evaluación (Sánchez et al., 2010). Nuestro foco de atención se centra en la medida de éxito educativo Grupos Interactivos, por lo tanto, no se rigen por los mismos criterios que pueden suceder en un aula ordinaria, sino que se rigen por el enfoque dialógico, ya que intervienen más adultos en grupos reducidos y todos los alumnos han de negociar y llegar a un consenso para desarrollar la tarea entre todos, surge así la necesidad de reformular los tipos de episodios que se pueden dar en los Grupos Interactivos. Esta nueva división requiere de unos criterios fijos que permitan decidir de manera unívoca la apertura y cierre de cada una de las unidades de análisis. Para ello, se sigue el Manual de Análisis del Discurso en el Aula creado por profesorado de la Universidad de Salamanca y los criterios propios de los investigadores. Un episodio viene marcado por las diferentes actividades realizadas por el alumnado. La estructura de las tareas planteadas para grupos interactivos permite diferenciar varios tipos de episodios:

\section{Episodio de preparación/predisposición}

Es aquel en el que tanto los alumnos como los adultos se preparan para iniciar una nueva tarea. Son aquellas rutinas que se llevan a cabo en cada ficha, poner nombre y fecha, preparar el material, hablar de cosas cotidianas antes de empezar a leer la ficha.

Alumno_4: propone nombre para el grupo-Grupo los mejores

Alumno_8: Ahh puess grupo dos

Alumno_4: ¿Grupo los mejores o grupo 2?

Maestra: Como queráis

Maestra: Alumno_7, Alumno_6, venid, nos acercamos nosotros o...

Alumno_7: Nos acercamos nosotros

(Los miembros del grupo se colocan) 


\section{Episodios de lectura}

Momentos en los cuales los alumnos leen algunas de las explicaciones incluidas al comienzo de cada ficha o el enunciado de cada actividad, éste puede llevarse a cabo en uno varios episodios.

Alumno_2: A ver (se dirige a Alumno_3) ¿Qué queréis coger?

Voluntario_4 - No, lee en alto que se enteren todos [Voluntaria Alumno_3 léelo en alto]

Alumno_2 - ¿otra vez leo esto? Uno inventar un circuito con todas las habilidades atléticas que hayamos practicado durante la unidad, carrera, marcha, saltos... pensad cuántas pruebas vais a hacer y qué material vais a usar, antes de ir a por el material, quince y veinte minutos. Número de pruebas, material a utilizar y dibujo del circuito

\section{Episodio de negociación (interpretación)}

Es aquel episodio en el que los alumnos negocian qué es lo que tienen que hacer mostrando cada uno de ellos su opinión. Suele ir precedido por el de lectura.

Alumno_6: Podíamos coger una colchoneta.

Alumno_2: ¿Y vas a ir tú con la colchoneta?

Alumno_6: Sí.

Voluntario_4: A ver ¿cuántas pruebas queréis hacer?

Alumno_6: Por lo menos cinco [Alumno_3, Alumno_2 y Alumno_4 - tres, tres].

Voluntario_3: Pero tres, tenemos que trabajar todo lo que pone carrera, marcha, saltos y relevos.

Alumno_3: Tres.

Alumno_6: Por eso, cuatro, la colchoneta para saltar.

Voluntario_3: Vale.

Alumno_2: Pero ... ¿̇y qué hacemos, volteretas?

Alumno_6: Lo que queráis.

Alumno_4: Para saltar. 
Alumno_2: revisa lo que han escrito en la ficha - carrera, marcha, relevos, saltos y...y ya está, cuatro [Voluntario_1 - cuatro].

Maestra: ¿Vale? Pues venga.

Alumno_3: dice a Alumno_2 - venga, vamos a por el material

\section{Episodio de desarrollo de la tarea}

Es aquel en el que los alumnos llevan a cabo la tarea específica después de haber negociado. Se pueden intercalar episodios de tarea y negociación.

Maestra: ¿Cómo lo redactamos?

Alumno_8: - Miramos la talla de los patines.

Alumno_7: Una talla más ¿no?

Alumno_6: Miramos la talla.

Alumno_7: le corrige- Mirar.

Alumna_4: continua con la redacción- la talla del patín.

Alumno_6: Recita en alto lo que va escribiendo-de los pa-ti-nes y que te baile un poco.

Voluntario_3: Que te bailen un poco- entre risas- ¿Pero eso lo pones en las instrucciones? Que te bailen un poco y se pone delante otro y se pone así (imitando que baila).

Alumno_6: Se ríe- que queden un poco desahogados.

Alumno_7: Que se muevan un poco.

Voluntario_4: Vale.

Alumno_4: Ponerse las protecciones.

Voluntario_3: Vale, pero vamos a escribir todos lo mismo. Eso está bien, ¿vale? Alumno_4: insiste-Ponerse las protecciones.

Alumno_8: continúa redactando el paso anterior- que se te muevan.

Alumno_7: ¿Y qué más?

Alumno_6: Y que se te desahoguen.

Alumno_4: todo lo está diciendo él.

Alumno_6: Fua! Es que no decís nada. 
Alumno_4: Vuelve a insistir-Ponerse las protecciones.

Voluntario_4: Vale, Alumno_4 hay que acabar el punto 1 que es..

Voluntario_3: Vamos a acabar esta frase y luego ya ponemos la tuya- dirigiéndose a Alumno_4

Voluntario_4: Luego ponemos la que tú has dicho que está muy bien.

Alumno_7: Sigue redactando el punto uno y preguntando a sus compañeros para completar la frase.

\section{Episodio de evaluación de la tarea}

Es aquel en el que los alumnos junto con los adultos (voluntarios o maestra) llevan a cabo una evaluación de lo que han trabajado en la tarea propuesta.

Maestra: Vale, nos sentamos un segundito, a ver, nos sentamos un segundito, vamos a ver.

Se sientan en el palco que hay en el gimnasio

Maestra: Alumno_6 si te acercas un poquito mejor (ya que se había sentado muy separado del resto de compañeras)

Maestra: ¿Habéis organizado bien el espacio?

Alumnos: Siii.

Maestra: ¿Habéis acabado todos el circuito a la vez, o había ahí un problema de atasco?

Voluntario_4 se sienta con ellos

Alumno_6: hay un problema de atasco

Alumno_2: ha salido disparados y yo me he quedado...

Maestra: vale, yo vi un problema, que tampoco es un problema vaya. Que hacéis este circuito todos individual, esto vaya (señala una parte). Vale, entonces Alumno 6 ha cogido lo ha hecho el primero, ha hecho la voltereta, ha hecho el salto y luego le ha tocado esperar a los compañeros para hacer el relevo ¿cómo lo podíamos hacer para solucionar eso?

Alumno_3: Pues...hacemos todos todo esto [Alumno_2 la interrumpe-pues ...] [Alumno_6 -

¿cuántas hay seis no?] [Alumno_2- cuando el compañero llegue al último verde, al que está en el ladrillo, sale el otro...]

Maestra: Aham.

Alumno 2: Así mientras Alumno 6 hace la voltereta, nosotros ya hemos llega$-85-$ 


\section{Método}

do ahí. Cuando

Alumno_6: Salte los bancos, cuando se llegue ya que vaya a terminar el último que salga el otro, así.

Maestra: Y si lo hacéis de dos en dos ¿se solucionaría el problema? (como se quedan callados, Maestra repite la pregunta) ¿si lo hacéis de dos en dos, se solucionaría el problema? Estoy preguntando.

Alumno_6: tres ahí y otros tres ahí...

Maestra: pensamos ¿y si lo hiciésemos de dos en dos, se solucionaría el problema?

Todos dicen: Siii

Maestra: ¿Sí?

Alumno_3: sí, porque salimos dos, yo y Alumno_5e [Alumno_6 - habrá que haber dos colchonetas] o yo y Alumno_2, salimos las dos y luego ya cuando lleguemos al... al palo verde, ya salen otros dos]

\section{División en ciclos}

Una vez identificadas las unidades globales, los episodios, se identifican los segmentos más elementales que lo conforman, si es el caso, se analizan los ciclos.

Un ciclo comienza por una pregunta o una orden y finaliza cuando esta se resuelve, en él se incluyen las negociaciones y los diálogos intermedios que permiten dar respuesta al interrogante planteado. La propuesta de los autores es distinguir ciclos procedimentales en el que la pregunta demanda hacer algo y los de contenidos que es en el que se elaboran ideas y conceptos (Sánchez et al., 2010). En nuestro caso no hacemos esta distinción por no considerarlo relevante en nuestra investigación.

Los criterios para abrir y cerrar un ciclo son los siguientes:

Un ciclo comienza por una pregunta o una orden.

Sírvanos como ejemplo el ciclo 2.1.1 que comienza con la pregunta de la Voluntaria_1 después de haber leído el enunciado.

Voluntaria_1: entonces ¿qué tenéis que hacer? 


\section{Capitulo 2: ESTUDIO EMPÍRICO}

Se cierra un ciclo cuando se realiza una pregunta y ésta recibe respuesta; cuando no se obtiene respuesta satisfactoria a una determinada pregunta, pero se realiza otra diferente; cuando se realizan varias preguntas y se da respuesta a una de ellas; cuando se responde a una pregunta muy genérica (en la que no se dan opciones de respuesta) y surge otra orden o pregunta con nueva información; o cuando se emplean marcadores lingüísticos como, además, por otro lado y ahora.

Siguiendo el ejemplo anterior, el ciclo 2.1 .1 se cierra cuando todos los alumnos se dan cuenta de que tienen que hacer una receta y van proponiendo distintas recetas.

Un ciclo se mantiene abierto cuando se realiza una pregunta instrumental, es decir, aquella que sirve para llegar a un acuerdo sobre otra pregunta formulada; cuando la pregunta se emplea para aclarar una orden; cuando un interlocutor responde a la pregunta planteada por otro no da por concluida la interacción añadiendo más información; o cuando se realizan preguntas $\mathrm{u}$ órdenes relacionadas con una pregunta principal.

Voluntrario_1: ¿Qué ha leído Alumno_2? a ver. (Espera a que respondan) ¿Qué es el cuento motor?

Alumno_2: Es una variante de un cuento.

Alumno_5: Vale, que es una cosa así, de la mente.

Voluntraio_1: Vale, y lo vais a tener que hacer después, ¿no?

Todas: Sí, como representar...

Voluntario_1: Es como representar algo, como hacer una especie de teatro o algo así.

Alumno_3: Sí

Como podemos ver en el ejemplo, el ciclo se inicia con una pregunta de comprensión de la actividad y se cierra tras un pequeño diálogo entre el mediador y los alumnos, con una respuesta a modo de confirmación. 


\section{Método}

Todas las divisiones realizadas son unidades de significado con sentido completo, de modo que están representadas por un tema u objetivo, bien sea resolver una pregunta, realizar una corrección o llegar a un acuerdo en el orden de participación. Este criterio es fundamental en los ciclos más amplios, en los que se formulan preguntas guía en relación directa con las ideas que van aportando los alumnos, de modo que se considera necesario no separar en ciclos más pequeños, pues el proceso de negociación pierde sentido e importancia.

El tercer paso consiste en identificar cómo se organiza comunicativamente el episodio; es decir qué patrón o estructura de participación se da en dicho episodio. En nuestro caso distinguimos tres tipos de estructuras de participación dentro de los GI: Indagación, Respuesta y Evaluación (IRE); Indagación, Respuesta y Feedback (IRF) y Dialógica.

\section{Identificación de secuencias de interacción de ayuda}

Una vez dividida cada sesión en ciclos se procede a identificar cada una de las variables objeto de análisis cuya definición y criterios de identificación se establecen en el apartado Variables y definición, comenzando por la variable ayuda. A lo largo del texto se señalarán las secuencias de interacción de ayuda, es decir, cuando se produzca una ayuda por parte de cualquiera de los interlocutores presentes en la sesión. Una vez identificada se añade un cuadro en el que consta el número de observación (i.e., 1.1) donde el primer número hace referencia a la sesión dentro de la unidad Los textos de nuestros días y el segundo al ciclo. Cuando hay más de una observación en el mismo ciclo se le añaden las letras del abecedario en orden (1.1a, 1,1b, 1,1c y así sucesivamente). A continuación, se completa el tipo de ayuda (1=Regulatoria, $2=$ Interna, $3=$ Feedback, $4=$ =álida)

Alumno_6: Podíamos coger una colchoneta.

Alumno_2: Y ¿vas a ir tú con la colchoneta?

Alumno_6: Sí. 


\section{$\mathrm{N}^{\circ}$ Observación Estructura de Ayuda Transferencia Formato de} participación la tarea

\begin{tabular}{|l|l|l|l|l|}
\hline 1.1 & 3 & 2 & 1 & 2 \\
\hline
\end{tabular}

Alumno_6: Por lo menos cinco [Alumno_3, Alumno_2 y Alumno_4 - tres, tres]

\section{Categorización variables comunes al ciclo}

Una vez señalado el número de observación y tipo de ayuda se categorizan las variables que son comunes al ciclo, es decir, las variables Estructura de participación ( $1=\mathrm{IRE}, 2 \mathrm{IRF}, 3=$ Dialógico) y transferencia $(1=$ No transferencia, $2=$ Transferencia teórica, $3=$ Transferencia aplicativa, $4=$ Transferencia creativa)

\section{Categorización variables comunes a la sesión}

Por último, se categoriza la variable Formato de tarea que será común en toda la sesión (1= Explicación, $2=$ Explicación y ejemplos, $3=$ explicación y contexto cercano, $4=$ Explicación, ejemplos y contexto)

\section{Control de la calidad de los datos obtenidos}

Entre los diversos aspectos que influyen en los diseños observacionales, el control de calidad del dato es un aspecto destacado debido a la multitud de errores y sesgos posibles. En la fase de recogida de datos se han tenido en cuenta dichos sesgos, se debe establecer un control de calidad basado en el grado de acuerdo entre los observadores. Dicho control supone una garantía de que los datos recogidos son susceptibles de ser analizado en la siguiente fase.

Para aumentar el grado de acuerdo entre los observadores hay que tener en cuenta el complejo sistema de codificación, por ello la codificación se realizó de manera conjunta por parte de los observadores. Previamente se pactaron y definieron con claridad cada uno de los aspectos a tener en cuenta para categorizar correctamente cada unidad de análisis, en el caso de existir discrepancias entre los jueces se revisan y debaten ambas propuestas teniendo en cuenta los criterios pactados para la categorización. 


\section{Método}

Como en la mayoría de las situaciones de investigación aplicada en ciencias sociales es necesario cuantificar el grado de acuerdo existente entre las medidas reportadas por dos o más observadores (Ato, Benavente, \& López, 2006). Según Johnson y Bolstad (1972) el término concordancia se utiliza cuando se comparan dos jueces y se persigue describir el grado de acuerdo entre ambos.

El grado de acuerdo interobservador o intraobservador es una medida muy extendida en los estudios que emplea la observación sistemática, y se puede decir que se toma prácticamente como sinónimo de fiabilidad. Se define la fiabilidad como el grado de concordancia entre los registros (datos) obtenidos en dos observaciones independientes de la conducta de un mismo participante por observadores fiables (Losada \& López-Feal, 2003).

Siguiendo con la metodología de representación gráfica de los datos que empleamos en esta investigación, emplearemos los diagramas de acuerdo de Bangdiwala (Bangdiwala \& Bryan, 1987) que aporta información fácilmente interpretable.

Una vez registradas y codificadas las situaciones de aprendizaje, se procedió al estudio de la fiabilidad entre los registros de tres jueces. El primer paso ha sido analizar el acuerdo entre jueces. La tarea de cada juez ha sido categorizar 20 observaciones $(1,32 \%)$ extraídas aleatoriamente del conjunto de las 1506 observaciones. La categorización de los jueces puede verse en la Tabla 6. 
Capitulo 2: ESTUDIO EMPÍRICO

Tabla 6

Categorización observaciones aleatorias jueces

\begin{tabular}{|c|c|c|c|c|c|c|c|c|c|c|c|c|}
\hline \multirow{2}{*}{$\begin{array}{l}N^{\circ} \text { Obser- } \\
\text { vación }\end{array}$} & \multicolumn{3}{|c|}{ Estructura } & \multicolumn{3}{|c|}{ Ayuda } & \multicolumn{3}{|c|}{ Transferencia } & \multicolumn{3}{|c|}{$\begin{array}{l}\text { Formato de } \\
\text { la tarea }\end{array}$} \\
\hline & $\mathrm{J} 1$ & $\mathrm{~J} 2$ & J3 & $\mathrm{J} 1$ & $\mathrm{~J} 2$ & J3 & J1 & $\mathrm{J} 2$ & J3 & J1 & J2 & J3 \\
\hline 113 & 3 & 3 & 2 & 2 & 3 & 4 & 1 & 1 & 3 & 3 & 2 & 3 \\
\hline 181 & 3 & 1 & 2 & 1 & 1 & 2 & 3 & 1 & 2 & 4 & 1 & 1 \\
\hline 210 & 3 & 3 & 3 & 2 & 3 & - & 3 & 2 & 2 & 4 & 1 & 1 \\
\hline 231 & 2 & 1 & 2 & 4 & 1 & 1 & 3 & 1 & 2 & 4 & 1 & 1 \\
\hline 303 & 1 & 3 & 2 & 1 & 3 & 1 & 1 & 1 & 1 & 4 & 1 & 1 \\
\hline 341 & 2 & 1 & 1 & 2 & 3 & 1 & 3 & 2 & 2 & 4 & 2 & 1 \\
\hline 380 & 1 & 2 & 1 & 2 & 2 & 2 & 3 & 1 & 2 & 4 & 1 & 1 \\
\hline 431 & 1 & 1 & 1 & 2 & 1 & 2 & 1 & 1 & 1 & 3 & 1 & 3 \\
\hline 482 & 3 & 2 & 2 & 2 & 3 & 2 & 3 & 1 & 1 & 3 & 2 & 3 \\
\hline 740 & 2 & 1 & 3 & 3 & 2 & 4 & 3 & 2 & 3 & 3 & 1 & 1 \\
\hline 764 & 3 & 3 & 3 & 3 & 4 & 4 & 3 & 4 & 3 & 3 & 2 & 1 \\
\hline 834 & 1 & 3 & 1 & 2 & 2 & 1 & 1 & 1 & 2 & 1 & 1 & 1 \\
\hline 1023 & 2 & 3 & 3 & 2 & 2 & 3 & 3 & 1 & 1 & 4 & 1 & 2 \\
\hline 1028 & 2 & 1 & 3 & 2 & 2 & 4 & 3 & 1 & 2 & 4 & 2 & 2 \\
\hline 1109 & 1 & 1 & 1 & 2 & 3 & 2 & 1 & 1 & 1 & 4 & 1 & 2 \\
\hline 1263 & 2 & 3 & 1 & 4 & 2 & 1 & 1 & 1 & 1 & 2 & 1 & 2 \\
\hline 1381 & 2 & 2 & 3 & 4 & 2 & 1 & 3 & 1 & 3 & 1 & 1 & 1 \\
\hline 1417 & 1 & 2 & 1 & 2 & 3 & - & 1 & 1 & 2 & 1 & 1 & 1 \\
\hline 1427 & 1 & 2 & 1 & 1 & 4 & 1 & 1 & 1 & 1 & 1 & 1 & 1 \\
\hline 1476 & 3 & 3 & 3 & 4 & 3 & 4 & 3 & 3 & 3 & 1 & 2 & 1 \\
\hline 113 & 3 & 3 & 2 & 2 & 3 & 4 & 1 & 1 & 3 & 3 & 2 & 3 \\
\hline
\end{tabular}

Para analizar el acuerdo entre los jueces, podemos emplear los coeficicentes de concordancia de Bangdiwala, tanto sobre acuerdos puros (BN) como ponderados (BWN) (Bangdiwala \& Bryan, 1987). Los coeficientes sobre acuerdos 


\section{Método}

puros tienen en cuenta solamente los acuerdos estrictos (i.e., los jueces asignas la misma puntación al ítem) y utilizan la información contenida en los totales marginales, por lo tanto, cuenta con el acuerdo por azar (véase ecuación 1).

$$
B_{N}=\frac{\sum_{i=1}^{k} X_{i i}^{2}}{\sum_{i=1}^{k} x i \cdot x \cdot i}
$$

Sin embargo, la versión ponderada permite conocer los acuerdos parciales (i.e., los jueces proporcionan puntuaciones en mayor o menor medida alejadas de la diagonal) (Verdugo, Gómez, Arias, \& Navas, 2010). En la tabla de concordancia, el acuerdo parcial puede ser visualizado como áreas sombreadas sucesivamente más claras cuanto más lejos se encuentre las diagonales de acuerdo perfecto. Este concepto es especialmente apropiado para las categorías ordinales, donde los pesos apropiados se pueden unir a las áreas sombreadas (ecuación 2).

$$
B_{N}^{W}=\frac{1-\sum_{i=1}^{K}\left[x_{i} \cdot x_{\cdot i}-x_{i i}^{2}-\sum_{s=1}^{q} W_{s} A_{s i}\right]}{\sum_{i=1}^{k} x_{i} \cdot x \cdot 1}
$$

Teniendo en cuenta lo dicho en referencia a los coeficientes de concordancia, hemos empleado el ponderado BWN ya que los datos analizados en este caso se refieren a categorías ordinales donde cada una de las variables se puede ordenar de manera que influya más o menos en el proceso de transferencia. 
Capitulo 2: ESTUDIO EMPÍRICO
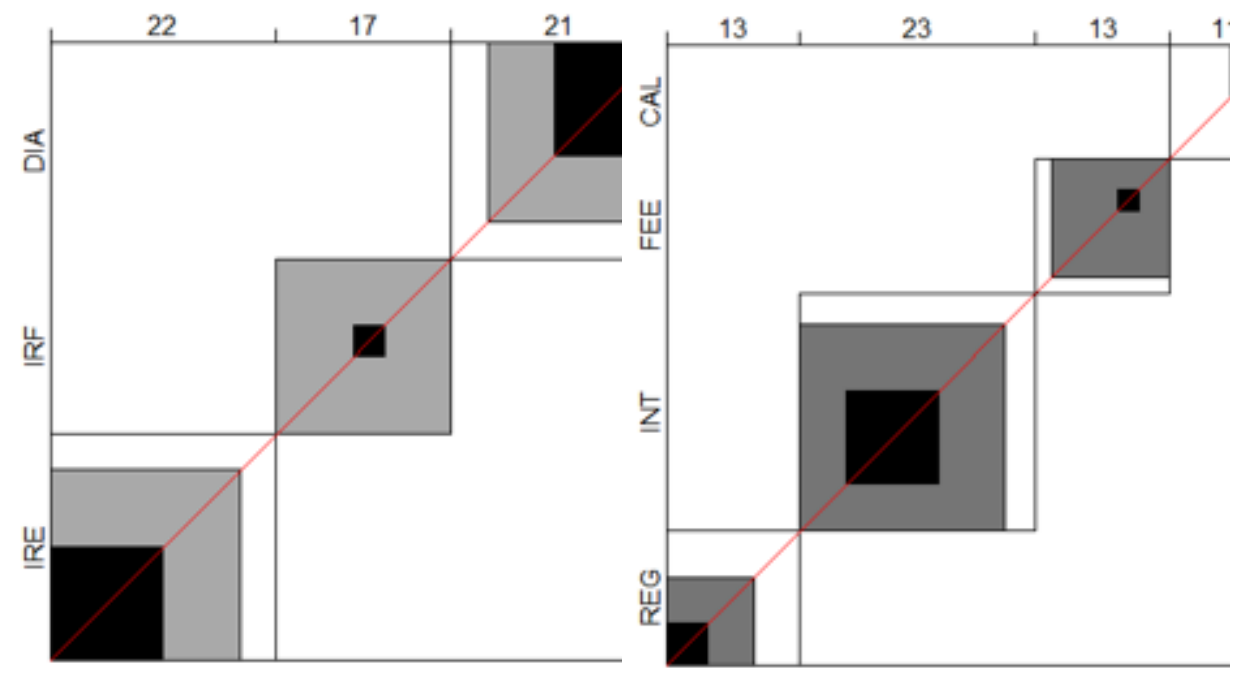

ESTRUCTURA BWN $=.631$

AYUDA BWN $=.578$

Nota: IRE = Interacción-Respuesta- Nota: REG = Regulatoria; INT = Interna;

Explicación; IRF = Interacción-Respuesta- $\quad \mathrm{FEE}=$ Feedback; CAL $=$ Cálida.

Feedback; DIA = Dialógica.
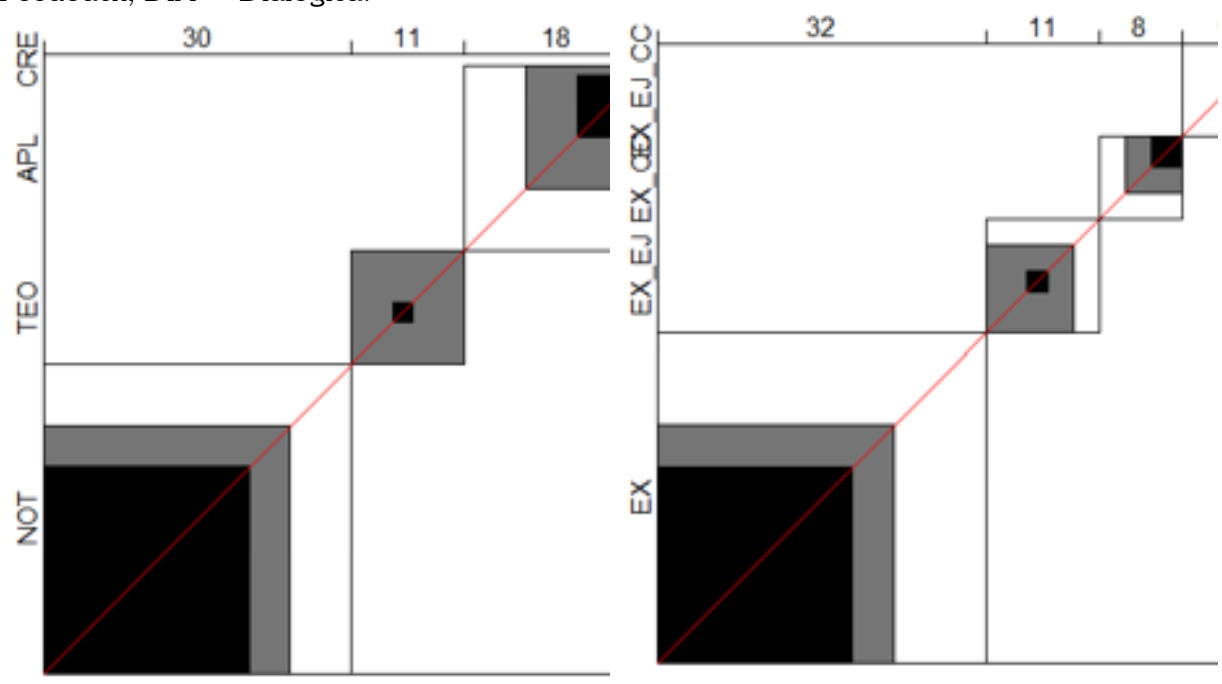

TRANSFERENCIA BWN $=.592$

FORMATO BWN $=.467$

Nota: NOT $=$ No transferencia; TEO $=$ Nota: EX $=$ Explicación; EX EJ $=$ Teórica; $\mathrm{APL}=$ Aplicativa; $\mathrm{CRE}=$ Explicación $\mathrm{y}$ ejemplos; $\mathrm{EX}$ C $\bar{C}=$ Creativa. Explicación y contexto cercano; EX_EJ_CC = Explicación, ejemplos $\mathrm{y}$ contexto cercano.

Figura 6. Resultados de la concordancia entre jueces. 
El diagrama de concordancia de Bangdiwala, que se muestra en la Figura 6, sirve para ilustrar gráficamente los resultados, señalando el respectivo valor del acuerdo. Se construye como un cuadrado de $\mathrm{n} x \mathrm{n}$ donde $\mathrm{n}$ es el tamaño total de la muestra, los cuadrados negros muestran el acuerdo entre observadores y el cuadrado gris indica el máximo acuerdo posible.

Para interpretar los coeficientes, tomamos como referencia los valores de la Tabla 7. En la mayor parte de las investigaciones suelen considerarse adecuados coeficientes superiores a .400 . Según nuestros resultados, los coeficientes de concordancia denotaron un grado de acuerdo satisfactorio situados entre buenos y moderados. El acuerdo más elevado se alcanzó en Estructura (BWN = .631) y el más bajo en Formato (BWN = .467). Se alcanzaron coeficientes muy parejos en Ayuda $(B W N=.578)$ y en Transferencia $(B W N=.592)$.

Tabla 7

Interpretación de los valores de los coeficientes de concordancia $B^{W}$

\begin{tabular}{llllll}
\hline $\begin{array}{l}\text { Fuerza de la } \\
\text { concordancia }\end{array}$ & Pobre & Débil & Moderada & Buena & $\begin{array}{l}\text { Muy } \\
\text { buena }\end{array}$ \\
\hline $\begin{array}{l}\text { Valor del coe- } \\
\text { ficiente }\end{array}$ & $.000-.200$ & $.201-$ & $.401-.600$ & $.601-$ & $.801-1$ \\
& & .400 & & .800 & \\
\hline
\end{tabular}

Una vez comprobada la concordancia entre los jueces, podemos emplear la matriz de datos resultante del análisis categórico como base para el posterior análisis cuantitativo empleando el programa R (R Core Team, 2015).

\subsection{Análisis de datos}

Como indicamos con anterioridad, el objetivo principal de esta tesis es realizar un análisis teórico sobre el concepto de transferencia educativa que nos permita explicar el concepto de transferencia, extraer las variables y dimensiones de las que se compone la transferencia según la literatura. Como objetivos específicos pretendemos extraer un modelo que explique el concepto de transferencia, así como relacionar las variables predictoras con la transferencia/no transferencia. 


\section{Capitulo 2: ESTUDIO EMPÍRICO}

Para dar respuesta al problema de investigación llevamos a cabo un acercamiento multimetódico en el que se han combinado distintos tipos de técnicas.

Los datos categóricos recogidos para la investigación pueden ser analizados y comprendidos con estadísticos simples, pero para convertir esos datos en conocimiento requiere de técnicas estadísticas multivariadas más complejas (Hair, Black, Babin, \& Anderson, 2014), así mediante los métodos estadísticos disponibles es posible generar una explicación más rica y cercana a la realidad (Closas et al., 2013). Por ello nos permite comprender mejor nuestro problema de investigación y ofrecer una respuesta más completa que empleando un único método.

Según lo precedente, y examinadas las posibilidades de análisis se emplearon tanto técnicas exploratorias (i.e., análisis de correspondencias múltiples), como confirmatorias (i.e., regresión logística), así como para la puesta a prueba de modelos teóricos (i.e., análisis log-lineal).

Una vez recogida toda la información pertinente se llevó a cabo el análisis de datos (1506 secuencias de aprendizaje) mediante tres procedimientos distintos que permiten responder a nuestro problema de investigación: (1) una exploración inicial de los datos a través de técnicas multivariadas que nos aportó información relevante en cuanto a las variables, (2) un análisis log-lineal cuyo objetivo fue el establecimiento del mejor modelo que se ajustase a los datos obtenidos y (3) un estudio mediante una regresión logística directa que nos permitió establecer una relación entre la variable criterio (transferencia) y las variables predictoras (formato, ayuda y estructura de participación). Estas técnicas son perfectamente compatibles entre sí ya que todas ellas requieren variables categóricas (Hair et al., 2014; Tabachnick \& Fidell, 2012).

En primer lugar, se ha implementado un análisis multivariado para llevar a cabo una descripción de los datos ya que este tipo de análisis tiene un efecto simplificador y reductor de los datos. Por otra parte, las técnicas multivariable nos permiten un tratamiento global de todas las variables y de todas las unida- 


\section{Método}

des independientemente o de forma combinada entre variable, o de forma parcial, tomando subconjuntos de variables. Además, nos permite un tratamiento simultaneo de todas las variables o un tratamiento escalonado. Este análisis se ha llevó a cabo con el programa R (R Core Team, 2015) ya que este software es de licencia libre y completamente programable lo que brinda mayor flexibilidad en el análisis. Además, al programa lo suplementan un gran número de paquetes lo que le convierte en un sistema integrado de herramientas para el análisis de datos.

En segundo lugar, se ha implementado un análisis log-lineal con las librerías MASS y vcd. Para un análisis más detallado y gráfico de las relaciones que establecen entre las variables se realizó un análisis de correspondencias (Joraisti \& Lizosain, 2000), donde se obtiene una interpretación en términos de modelos log-lineales. Para ello, se analiza la relación entre dos variables categóricas, descomponiendo el $\chi^{2}$ de una tabla de contingencia. Esta descomposición permite llegar a un modelo de independencia en el que la fila y columna se puedan representar por puntos en un espacio. Además, empleamos el paquete ca (correnspondence analysis) para calcular las correspondencias de tablas bidimensionales y obtener los ejes principales, al calcular las posiciones relativas de las tablas respecto a los dos primeros ejes principales dan una idea más exacta de las posiciones relativas de las variables. El análisis log-lineal se ha iniciado con el planteamiento del modelo saturado en términos de regresión log-lineal desarrollando los distintos procesos que intervienen en el ajuste del modelo ( $\mathrm{McCu}$ llagh \& Nelder, 1989), y se determina cuál es el mejor modelo que se ajusta a los datos observados. Se procedió a la estimación de los parámetros para su posterior interpretación y a una modelación gráfica, con la técnica mosaic (Friendly, 1992, 1994, 1999). Los criterios de selección del modelo empleados han sido el Criterio de Información Akaike (AIC), el criterio de Información Bayesiana (BIC) y la Desvianza explicada. El AIC es definido como (veáse ecuación 3): 


$$
A I C=-\log L+2 k
$$

donde $\mathrm{k}$ es el número de parámetros por estimar y evalúa tanto el ajuste del modelo a los datos como la complejidad del modelo. Cuanto menor sea el valor de AIC mejor será el ajuste. El criterio de Información Bayesiana es muy similar al AIC pero incorpora el tamaño de muestra, penaliza la adición de parámetros en mayor medida que el AIC. Se recomienda su uso cuando el tamaño de muestra es grande y el número de parámetros pequeño. Está definido como (veáse ecuación 4):

$$
B I C=-2 \ln L+\ln (n) *(p)
$$

La desvianza explicada, llamado también como pseudo R2 (Dobson \& Barnett, 2008), que nos da una idea de la variabilidad de los datos y se calcula como:

\section{Desviación explicada}

$$
=100 x \frac{\text { desviación nula }- \text { desviación residual }}{\text { desviación nula }} \%
$$

donde la desvianza nula se calcula igual que la desvianza residual, pero en vez del modelo ajustado utiliza el modelo nulo.

En tercer lugar, se ha implementado una regresión logística directa (modelo logit binario), utilizando como técnica de optimización para maximizar la función de verosimilitud la puntuación de Fisher. Los modelos de regresión logística permiten establecer una relación entre una variable binaria (criterio) y un grupo de variables predictoras continuas, ordinales o categóricas. Modelan la probabilidad transformada logit como relación lineal entre las variables predictoras. En este estudio, la variable criterio (binaria) ha sido transferencia (codificada como 1) frente a no transferencia (codificada como 0) del aprendizaje. Si consideramos $\mathrm{p}$ como la probabilidad de transferencia (1), entonces $\mathrm{p}=$ $\operatorname{prob}(y=1)$. Las variables predictoras fueron $\mathrm{x} 1$ (ayuda), $\mathrm{x} 2$ (formato) y $\mathrm{x} 3$ (estructura de participación). Así, la regresión logística estima los valores de los 


\section{Método}

parámetros para $\beta 0, \beta 1, \beta 2, \beta 3$ mediante máxima verosimilitud a partir de la ecuación (5):

$\operatorname{logit}(p)=\log (p /(1-p))=\beta 0+\beta 1 * \times 1+\beta 2 * \times 2+\beta 3 * \times 3$

En términos de probabilidades, la anterior se transforma en la ecuación (6):

$p=\exp \left(\beta 0+\beta 1^{*} x 1+\beta 2 * x 2+\beta 3^{*} \times 3\right) /(1+\exp (\beta 0+\beta 1 * x 1+\beta 2 * x 2$

$\left.\left.+\beta 3^{*} \times 3\right)\right)$

En el estudio se ha modelado logit $(p)=\beta 1$ (i.e., constatación de la existencia de transferencia en las observaciones). No hubo casos perdidos, por lo que no fue preciso utilizar ningún método de imputación. Los análisis se han llevado a cabo mediante el paquete estadístico SAS, versión 9.4 (SAS Institute, 2015). Para la confección de los gráficos se ha usado R, versión 3.2.2 (R Core Team, 2015). Para realizar algunos análisis específicos, se ha usado Stata, versión 14 (StataCorp, 2015). Por último, para calcular los intervalos de confianza de los coeficientes pseudo-R2, se ha usado R2, versión 1.1 (Steiger \& Fouladi, 1997).

\section{Verificación del cumplimiento de los supuestos de la regresión logística}

Se ha comprobado el cumplimiento de los principales supuestos de la regresión logística (Allison, 2012; Field, Miles, \& Field, 2012; Hair et al., 2014; Tabachnick \& Fidell, 2012) en términos de razón, frecuencias esperadas, linealidad, multicolinealidad, errores de especificación, outliers y sobredispersión.

(a) En cuanto a la razón entre casos y variables, se ha comprobado que no existe ni separación completa (i.e., combinación de variables predictoras que predice perfectamente la variable criterio) ni cuasi-completa (i.e., alguno de los valores de una variable predictora corresponde a valores 1 o 0 en todos los casos, lo que provoca que el coeficiente estimado, el error estándar y el valor $\mathrm{p}$ sean muy grandes), toda vez que la variable de salida (transferencia frente a no transferencia del aprendizaje) no ha separado a las variables predictoras ni individualmente ni en combinación. 


\section{Capitulo 2: ESTUDIO EMPÍRICO}

(b) Las frecuencias esperadas entre todos los pares de variables utilizadas en el modelo (predictoras y criterio) en ningún caso han resultado excesivamente pequeñas.

(c) La linealidad del logit ha quedado refrendada por la ausencia de significación estadística de las interacciones entre cada variable predictora y su logaritmo natural.

(d) La posible multicolinealidad de los predictores se ha evaluado mediante el cálculo de la tolerancia y el factor de inflación de la varianza usando el procedimiento propuesto por Allison (2012). A partir de un primer análisis de regresión logística, se creó un nuevo conjunto de datos con todas las variables del modelo (ayuda, formato, estructura, transferencia) más una nueva variable que contenía las probabilidades estimadas de la variable criterio. Estos valores estimados se usaron para construir una variable ponderada. Finalmente, se llevó a cabo un análisis de regresión por mínimos cuadrados ponderados utilizando $\mathrm{W}$ como variable de ponderación. Los resultados indicaron ausencia de multicolinealidad (Ayuda, $\mathrm{TOL}=0.988, \mathrm{VIF}=1.013$; Formato, $\mathrm{TOL}=0.980, \mathrm{VIF}=$ 1.020; Estructura, $\mathrm{TOL}=0.970, \mathrm{VIF}=1.031$.

(e) En lo que atañe a los errores de especificación, asumimos que en un modelo de regresión logística el logit es una combinación lineal de las variables independientes (predictoras). Una implicación de tal asunción es que en el modelo se han incluido variables relevantes, a la par que se ha evitado la inclusión de variables irrelevantes. Se ha usado el comando linktest en Stata para comprobar la existencia de errores de especificación. Si el modelo está adecuadamente especificado, no podríamos encontrar predictores adicionales que resulten estadísticamente significativos salvo por azar. Tras realizar el análisis, se utiliza el valor lineal estimado y su valor al cuadrado como predictores para reconstruir el modelo. El valor lineal debería ser significativo puesto que es el valor predicho por el modelo, en tanto que el valor al cuadrado no debería serlo. En caso contrario, tendríamos un problema de especificación del modelo. 
Constatamos que en nuestros datos, de acuerdo con lo dicho, no existen errores de especificación.

(f) Prácticamente no se han observado outliers ni valores extremos en la solución.

(g) Finalmente, no se ha constatado la presencia de sobredispersión, lo que nos lleva a concluir que se ha cumplido el supuesto de independencia de los errores.

\subsection{RESULTADOS}

Una vez analizados los datos obtenidos durante la fase de recogida de datos y constado que son válidos para el análisis, presentamos a continuación los principales resultados obtenidos a partir de los mismos. Al igual que en el apartado anterior, éste hará referencia a los resultados de cada uno de los análisis realizados comenzando por los resultados en el análisis multivariado.

\subsubsection{Resultados de los análisis descriptivos}

Categorizadas las variables en la matriz de datos realizamos un análisis multivariado para tratar de extraer un modelo que explique los datos obtenidos.

El análisis multivariado se refiere a todas las técnicas estadísticas que analizan simultáneamente múltiples medidas con distintos individuos u objetos bajo investigación. Por lo tanto, cualquier análisis simultáneo de más de dos variables puede ser considerado análisis multivariado (Hair et al., 2014).

Muchas técnicas multivariables son extensiones de análisis univariado (análisis de la distribución de una sola variable) y el análisis bivariante (clasificación cruzada, la correlación, el análisis de la varianza, y la regresión simple utilizado para analizar dos variables). Otras técnicas multivariables, sin embargo, tienen un diseño único para hacer frente a los problemas multivariados, tales como el análisis factorial, que identifica la estructura subyacente de un conjunto de va- 
riables, o el análisis discriminante, que diferencia entre los grupos en función de un conjunto de variables.

La confusión surge a veces de lo que el análisis multivariable se debe a que el término no se utiliza constantemente en la literatura. Algunos investigadores utilizan multivariable simplemente en el sentido de examinar las relaciones entre dos o varios más de dos variables. Otros utilizan el término sólo para problemas en los que se asumen todas las múltiples variables a tener una distribución normal multivariable. Para ser considerado realmente multivariado todas las variables deben ser al azar y relacionados entre sí en tales formas que sus diferentes efectos no pueden ser interpretados de manera significativa por separado. Algunos autores afirman que el propósito del análisis multivariable es medir, explicar y predecir el grado de relación entre las variables aleatorias (combinaciones ponderadas de las variables). Por lo tanto, el carácter multivariable radica en las múltiples variables aleatorias (múltiples combinaciones de variables), y no sólo en el número de variables u observaciones.

Emplearemos métodos descriptivos como el análisis de frecuencias, tablas de contingencias y análisis de correspondencias, así como métodos explicativos a través de los modelos log-lineales como análisis complementarios.

\section{Análisis de frecuencia}

Una vez depurados los datos, analizando las frecuencias de cada una de las variables en busca de casos perdidos o valores fuera de rango, procedemos al análisis de las frecuencias de cada una de las variables objeto de estudio que nos aportarán información relevante para el análisis inicial.

\section{Estructura de participación}

La tabla de frecuencias de los valores de la variable estructura de participación (Tabla 8) muestra un claro predominio de los ciclos de tipo IRF (43.8\%), seguido de los ciclos de tipo dialógico (36.5\%). Se evidencia así que, a pesar de tratarse de una dinámica caracterizada por las interacciones de tipo dialógico, 
estas no se producen durante el desarrollo de todas las tareas. En este punto es necesario reflexionar sobre la diferencia exacta entre los ciclos IRF y dialógico. En ambos se produce intercambio de ideas y diálogo entre los miembros del grupo, sin embargo, en el segundo tiene lugar dos aspectos fundamentales: la propuesta de cambios en la tarea y el planteamiento de preguntas por parte del propio alumnado. Se trata de ciclos con mayor autonomía y capacidad reflexiva.

Esta sutil diferencia hace que se pueda considerar un análisis conjunto, en el que se evidencia de nuevo el claro predominio de ciclos caracterizado por el diálogo, IRF y dialógico (80.3\%), frente a una menor frecuencia de los ciclos de tipo IRE (19.7\%), en los que el diálogo libre no está presente y el mediador alumno es el que pregunta y evalúa las propuestas y respuestas dadas por el alumnado.

Tabla 8

Frecuencia Estructura de Participación

\begin{tabular}{lll}
\hline & Frecuencia & Porcentaje \\
\hline IRE & 297 & 19.7 \\
IRF & 659 & 43.8 \\
Dialógica & 550 & 36.5 \\
Total & 1506 & 100 \\
\hline
\end{tabular}

\section{Ayuda}

El análisis de los valores de la variable ayuda (Tabla 9) muestra un claro predominio de las ayudas de tipo interno (53.7\%) seguido de las ayudas regulatorias $(20.7 \%)$, y una frecuencia reducida de las ayudas de feedback (6.1\%). Se evidencia de esta manera que las ayudas ofrecidas primordialmente son aque- 
llas que dirigen su atención principalmente a la resolución propia de la tarea, así como a las directrices a nivel organizativo para realizarlas con éxito. Dentro de las secuencias de aprendizaje observadas, apenas se dan las ayudas de tipo feedback orientadas a la fijación de la respuesta correcta debido a la dinámica propia de los grupos interactivos.

Tabla 9

Frecuencia Ayudas

\begin{tabular}{lll}
\hline & Frecuencia & Porcentaje \\
\hline Regulatoria & 312 & 20.7 \\
Interna & 808 & 53.5 \\
Feedback & 92 & 6.1 \\
Cálida & 294 & 19.5 \\
\hline
\end{tabular}

\section{Formato de la tarea}

El análisis de los valores de la variable formato de la tarea (Tabla 10), muestra una mayor frecuencia en las actividades que en su enunciado combinan explicación, ejemplos y vínculo con un contexto cercano al alumnado (42.5\%). Sin embargo, los enunciados que incluyen explicación y ejemplos, pero sin contexto cercano, presentan la frecuencia más reducida de la tabla.

Estos datos ponen de manifiesto que relacionar la tarea con los contextos de aprendizaje son de vital importancia tal como reflejan diversos autores (Barnett \& Ceci, 2002; Catrambone \& Holyoak, 1989; Engle et al., 2012; Reeves \& Weisberg, 1994; Ross, 1984; Spencer \& Weisberg, 1986).

Profundizando más en el análisis, se evidencia la importancia de una pequeña parte en las tareas a modo de explicación o recordatorio de algunos de los contenidos tratados. 
Tabla 10

Frecuencia Formato de la tarea

\begin{tabular}{lll}
\hline & Frecuencia & Porcentaje \\
\hline Explicación & 361 & 24 \\
Explicación y ejemplo & 125 & 8.3 \\
Explicación y contexto & 380 & 25.2 \\
Explicación, ejemplo y contexto & 640 & 42.5 \\
\hline
\end{tabular}

\section{Transferencia}

En cuanto a los valores de la variable de transferencia, se evidencia un predominio de la transferencia de aplicación, que consiste en poner en práctica diversos contenidos en nuevas tareas. No sucede los mismo con la transferencia de tipo teórica, caracterizada por la simple verbalización de relación entre contenido la cual presenta le frecuencia más reducida de la Tabla 11 (7.6\%).

No obstante, se puede considerar un análisis conjunto, en el que se evidencia el predominio de casos de transferencia $(63.6 \%)$, frente a una menor frecuencia de los casos de no transferencia (36.3\%).

En el planteamiento inicial de los valores de la variable transferencia se contempló la transferencia creativa ya que sí que aparecía en la literatura, sin embargo, al presentar una frecuencia de 0 no aparece en los análisis esto contrasta y verifica lo que señala la literatura sobre la dificultad de su consecución en contextos académicos convencionales (Gómez et al., 2012). Algunas de las posibles justificaciones de esta desaparición pueden ser la ausencia de capacidad por parte de los docentes/investigadores de observar la creatividad en el 


\section{Capitulo 2: ESTUDIO EMPÍRICO}

alumnado, el papel que ejerce la escuela sobre la creatividad y sus restricciones o la promoción de patrones estandarizados escolares que anulan otra serie de capacidades creativas.

\section{Tabla 11}

Frecuencia Transferencia

\begin{tabular}{lll}
\hline & Frecuencia & Porcentaje \\
\hline No transferencia & 547 & 36.3 \\
Teórica & 115 & 7.6 \\
Aplicativa & 844 & 56 \\
\hline
\end{tabular}

\section{Tablas de contingencia}

Para realizar un análisis más profundo de los datos con los que contamos, creamos una serie de tablas de contingencia con las variables dos a dos para comprobar su idoneidad para ulteriores análisis. Los datos numéricos se resumen a menudo en este tipo de tablas (Tabla 12). Si bien estas tablas permiten la presentación de todos los datos relevantes, que no se prestan a un rápido descubrimiento de patrones importantes. La principal dificultad es que el impacto visual de los valores numéricos no es proporcional a la magnitud de los números representados (Jain \& Warnes, 2006).

Con el comando balloonplot de $\mathrm{R}$ podemos ver lo que aumentan los valores numéricos en tablas con los círculos coloreados con área proporcional al tamaño de la entrada de la tabla correspondiente (Figura 7). Esto resalta visualmente las características destacadas de datos, preservando al mismo tiempo los datos transmitidos por los propios valores numéricos. Por tanto, para facilitar el análisis las tablas de contingencia se trasladaron a gráficos de balón. 


\section{Método}

\section{Estructura de participación y ayuda}

Desde una perspectiva general, la combinación con un mayor recuento es la de estructura de participación de tipo IRF con las ayudas de tipo interno. Seguida de la combinación de la estructura de tipo dialógico con las ayudas de tipo interno. La combinación de menor frecuencia es la de estructura de tipo IRE con las ayudas feedback.

Estos resultados muestran que las ayudas internas, al estar conectadas de forma directa con los contenidos de las tareas, están muy presentes en todos los tipos de ciclos, promoviendo la relación entre los contenidos y las actividades a realizar.

Tabla 12

Tabla contingencia estructura y ayuda

\begin{tabular}{lllll}
\hline & Regulatoria & Interna & Feedback & Cálida \\
\hline IRE & 94 & 149 & 21 & 33 \\
IRF & 133 & 363 & 25 & 138 \\
Dialógica & 85 & 296 & 46 & 123 \\
\hline
\end{tabular}




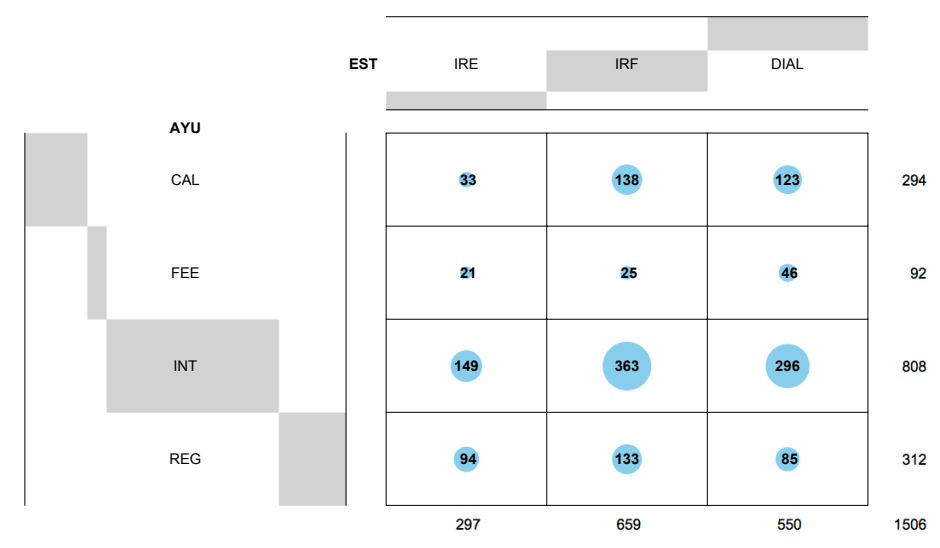

Figura 7. Gráfico de balón estructura de participación y ayuda.

Si planteamos un análisis parcelado, se comprueba cómo las estructuras de participación de tipo IRF y dialógico muestran un mayor recuento cuando se combinan con ayudas internas, seguida de la combinación con ayudas cálidas y a continuación con las ayudas regulatorias. Este resultado evidencia lo ya comentado en relación a las ayudas internas, pero además hace reflexionar sobre la importancia de las ayudas cálidas en los ciclos con una estructura más comunicativa, marcada por el diálogo, la negociación la formulación de preguntas y la valoración de la tarea.

Estos resultados varían al detenernos en la estructura de participación de tipo IRE, ya que, aunque también muestra un recuento mayor cuando se combina con ayudas internas, a esta le siguen las ayudas regulatorias y en tercer lugar las cálidas. En este caso, las ayudas cálidas pasan a una tercera posición, ya que en ciclos IRE, caracterizados por menos diálogo y negociación, los apoyos relacionados con aspectos emocionales y motivacionales tienen menos presencia.

En los tres tipos de estructura de participación al combinarse con ayudas de feedback su recuento es el más bajo de la tabla. Esto puede deberse a que las 
ayudas de este tipo únicamente permiten fijar las respuestas correctas aportadas durante la tarea, y este es un proceso que no es demasiado frecuente en la propia esencia de los grupos interactivos, en los que hay pocos momentos durante su desarrollo que requieran una única respuesta correcta, ya que se trata de integrar diversas aportaciones.

\section{Estructura y formato de la tarea}

Desde una perspectiva general, el recuento más numeroso como podemos ver en la Figura 8 corresponde a la combinación de estructura de tipo IRF con las tareas que incluyen explicación, ejemplos y contexto cercano, seguido de la estructura dialógica con tareas que incluyen explicación y contexto cercano. Estos resultados pueden deberse a que las tareas que presentan explicación, ejemplos y se relacionan con un contexto cercano favorecen un mayor diálogo entre los miembros del grupo, una negociación con más variedad de ideas, ejemplos y opiniones que aportar al estar vinculada la tarea con un entorno conocido por los miembros del grupo.

Por el contrario, la combinación con un menor recuento corresponde a la combinación de estructura de tipo dialógico y tareas que incluyen explicación y ejemplos. Esto hace reflexionar sobre el hecho que no sea suficiente con ejemplos y explicación para potenciar el intercambio comunicativo, sino que es necesario el contexto cercano para que se promueva el diálogo, la negociación y la formulación de propuestas y sugerencias durante la tarea. 


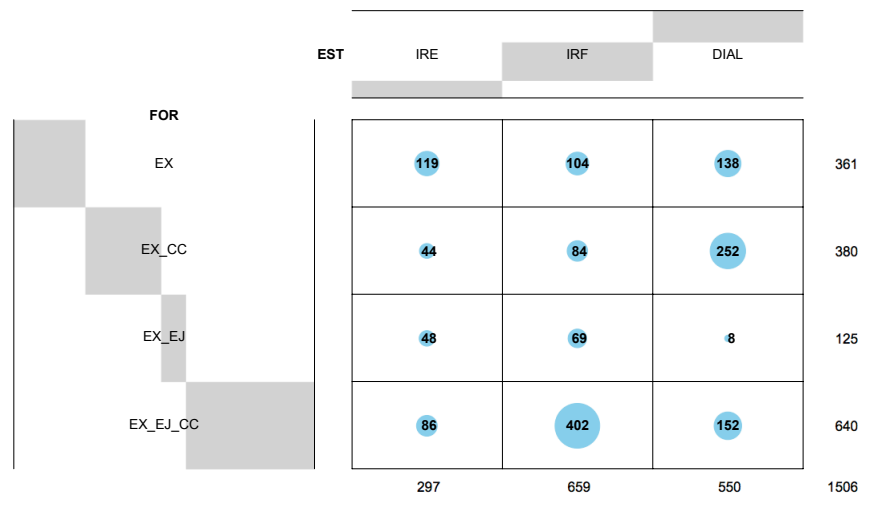

Figura 8. Gráfico de balón Estructura de participación y formato de la tarea.

Para comprender mejor los resultados anteriores, realizamos ahora un análisis más detallado de las diferentes partes que nos muestra lo siguiente:

En el caso de los ciclos de tipo IRE, el recuento más numeroso se produce cuando se combinan con tareas que contienen únicamente explicación. Este resultado evidencia cómo el hecho de que una tarea contenga únicamente apoyos en forma de explicación, reduce el diálogo y da lugar a un ciclo de tipo IRE.

En el caso de los ciclos de tipo IRF, el recuento más numeroso surge cuando se combina con tareas que incluyen explicación, ejemplos y contexto cercano. De nuevo se evidencia que cuando las tareas se relacionan con el contexto cercano del alumnado, ofrecen ejemplos y explicaciones promueven el diálogo y la negociación. Sin embargo, el segundo resultado más numeroso no se produce con las tareas que contienen explicación y contexto, sino con los que contienen solo explicación.

El análisis de los ciclos dialógicos nos hace descubrir una relación muy interesante: en este caso el recuento más numeroso no surge cuando se combina 
con tareas que incluyen explicación, ejemplos y contexto cercano, sino cuando incluyen solamente explicación y contexto cercano.

En definitiva, estos resultados muestran la gran importancia que tiene el contexto y la explicación para que se produzca más diálogo, más negociación, más valoración de la tarea y más preguntas entre el alumnado.

\section{Estructura de participación y transferencia}

Desde una panorámica general la combinación con recuento mayor es la de estructura de tipo IRF con la transferencia de aplicación, seguida de la estructura dialógica con la misma transferencia de aplicación. Se muestra en la Figura 9 como los ciclos caracterizados por el intercambio de ideas y la negociación, aunque no $100 \%$ dialógicos, se relacionan en gran medida con la producción de transferencia de aplicación, es decir, a través de las conversaciones entre el alumnado, de la propuesta de ideas, opiniones y de la búsqueda de acuerdo se favorece que los aprendizajes se puedan poner en práctica en las tareas. En estos dos casos el resultado obtenido es mayor que la frecuencia esperada.

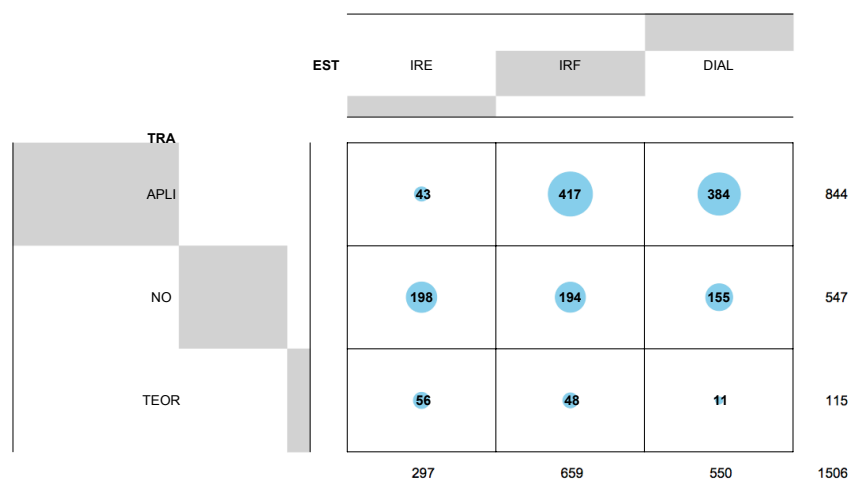

Figura 9. Gráfico de balón Estructura de participación y transferencia. 


\section{Capitulo 2: ESTUDIO EMPÍRICO}

Si centramos el foco en los resultados más bajos de la tabla se muestra que, aunque la menor frecuencia esperada corresponde a la estructura de tipo IRE y la transferencia teórica, el menor recuento obtenido corresponde a la estructura dialógica y a la transferencia teórica. Esto puede deberse a que este tipo de estructura se caracteriza no solo por el diálogo, sino también por la negociación, la formulación de preguntas y valoraciones, que promueve un tipo de transferencia más compleja como la de aplicación.

Desde un análisis de las diferentes partes se comprueba lo que la transferencia de aplicación presenta una mayor frecuencia tanto combinada con estructuras de tipo dialógico como de tipo IRF. Pero no es así cuando se combina con estructura IRE, con la que el mayor recuento corresponde a IRE en combinación con la no transferencia.

Como se ha explicado anteriormente, los rasgos que definen los ciclos IRF y dialógicos (negociación, diálogo entre los miembros del grupo y planteamiento de preguntas) promueven en mayor medida una transferencia más compleja, en la que no sólo se han de verbalizar la relación entre contenido y tarea, sino que esta relación se lleva a la práctica, lo que permite realizar correctamente la actividad.

\section{Ayuda y formato de la tarea}

Realizando un análisis detallado se aprecia que, en el caso de las ayudas internas, de las ayudas regulatorias y de las ayudas cálidas el mayor recuento se produce cuando se combinan con tareas que incluyen explicación, ejemplos y contexto cercano (Figura 10). Se muestra que las tareas que tengan estos tres tipos de apoyos promueven estos tipos de ayudas.

En el caso de las ayudas regulatorias y de feedback, el segundo mayor recuento corresponde cuando se combinan con tareas que incluyen solamente explicación. Mientras que en el caso de ayudas internas y ayudas cálidas el segundo mayor recuento corresponde cuando se combinan con tareas que incluyen explicación y contexto. 


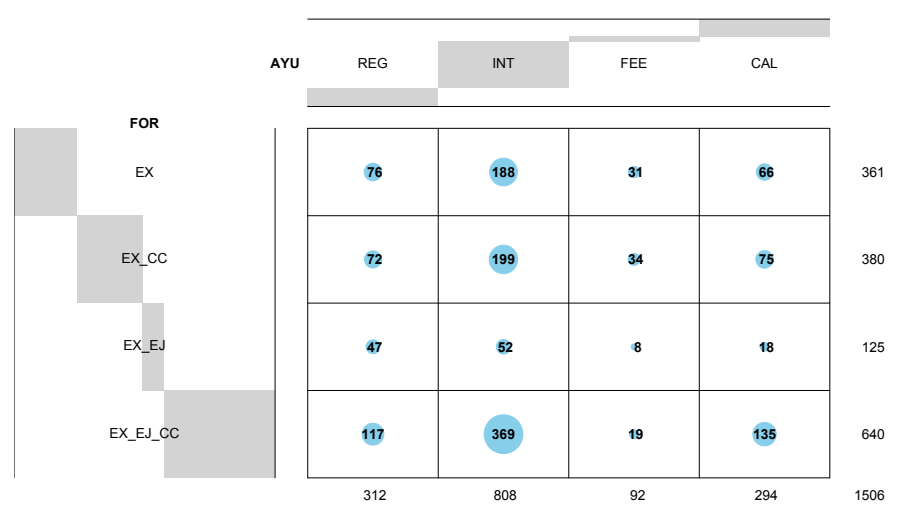

Figura 10. Gráfico de balón Formato de la tarea y ayuda.

\section{Ayuda y transferencia}

Un análisis general de la Figura 11 indica que la combinación con un recuento mayor corresponde a la transferencia de aplicación con ayudas de tipo interno, seguido de la transferencia de aplicación con no transferencia y en tercer lugar la transferencia de aplicación con ayudas cálidas. Estos resultados, resaltan la importancia de las ayudas internas, relacionadas con los contenidos de la propia tarea para facilitar su resolución y con ello la puesta en práctica de los aprendizajes adecuados que permiten realizar con éxito dicha tarea. Asimismo, resalta la relación de las ayudas cálidas con este tipo de transferencia, se muestra así que los refuerzos positivos, la motivación y otros aspectos emocionales son un elemento esencial para que la aplicación de los aprendizajes se lleve a cabo de forma eficaz.

Por el contrario, el recuento menor corresponde a la combinación de transferencia teórica y ayudas cálidas, seguida de la combinación con ayudas de feedback. La escasa presencia de las ayudas cálidas en los casos de transferencia teórica, puede deberse a que la simple explicación en alto de la relación entre contenido y tarea no requiere de apoyos emocionales y motivacionales, aunque sí lo requiere su puesta en práctica, como se ha comentado anteriormente. En el caso de las ayudas de feedback, al tratarse de apoyos que únicamente permiten fijar las respuestas correctas aportadas durante la tarea, no 
favorece procesos como la negociación o la relación entre contenidos para que se produzca transferencia teórica.

Realizando un análisis más detallado, se muestra cómo la transferencia de aplicación y la transferencia teórica muestran un recuento más numeroso cuando se combinan con ayudas internas. De nuevo estos datos pueden tener relación con la facilidad que ofrecen los apoyos de tipo interno, tanto para verbalizar la relación entre contenido y tarea, como para poner en práctica esa relación, dando lugar a transferencia teórica y de aplicación.

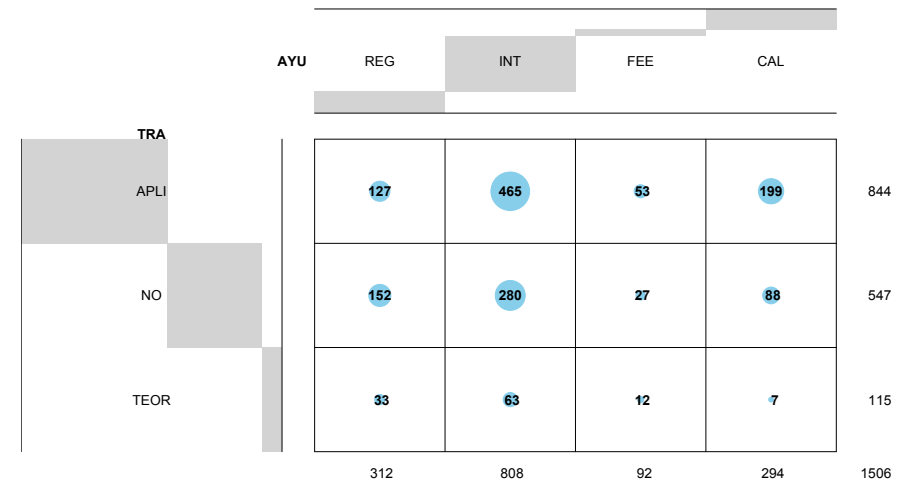

Figura 11. Gráfico de balón transferencia y ayuda.

\section{Formato de la tarea y transferencia}

La no transferencia se produce cuando se presentan actividades con explicación-ejemplo y explicación-contexto tal como muestra la Figura 12. Por otra parte, presenta menos frecuencia de la esperada cuando las actividades son presentadas con explicación y explicación, ejemplos y contexto. Lo lógico sería pensar que cuanto menos apoyo tenga la tarea más casos de no transferencia deberían aparecer y viceversa. Con todo, los datos no ofrecen esos mismos resultados.

En cuanto a la transferencia teórica, los datos nos muestran que se produce más de lo esperado en explicación y explicación-ejemplo. 


\section{Método}

Y por último, la transferencia aplicativa sólo presenta recuento muy por encima de lo esperado en las tareas en cuya presentación se utiliza explicación, ejemplos y contexto cercano. Al tratarse del tipo de transferencia que más se produce y al ser el tipo de actividad más completa, parece que estos resultados son los esperados para nuestro estudio.

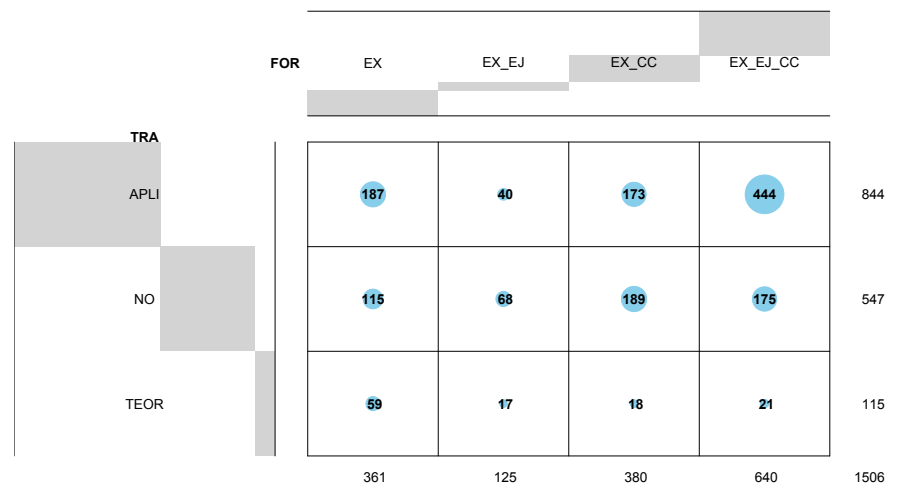

Figura 12. Gráfico de balón formato de la tarea y transferencia.

\section{Odds ratio}

Al objeto de entender mejor los resultados, cabe decir que se entiende por probabilidad el número de veces que un evento ocurre dividido por el número de veces que el evento podría ocurrir (sus valores posibles se sitúan entre 0 y 1). Por su parte, se entiende la odds como la probabilidad de que un evento ocurra dividida por la probabilidad de que el evento no ocurra, esto es, probabilidad (éxito) / probabilidad (fracaso). De esta forma, la odds ratio sería la razón de la odds de éxito para un grupo dividida por la odds de éxito para el otro grupo: (probabilidad(éxito)A / probabilidad(fracaso)A) / (probabilidad(éxito)B / probabilidad(fracaso)B). Finalmente, la log odds es el logaritmo natural de la odds.

Una vez realizados los cálculos de las odds ratio presente en la Tabla 13, realizamos un análisis global de los resultados. 


\section{Capitulo 2: ESTUDIO EMPÍRICO}

Si nos fijamos de manera general en las filas de la Tabla 13 caben destacar aquellos valores de variable que presentan valores superiores a 1,40 en todos sus cruces.

En primer lugar, nos encontramos con la ayuda regulatoria frente a feedback, destacando que es más probable que se produzca cualquier tipo de estructura, transferencia o apoyo en la tarea cuando la ayuda es regulatoria que cuando la ayuda es feedback. Esto presenta una gran relevancia ya que nos indica que, en cualquier caso, la ayuda regulatoria favorece el resto de variables independientemente de su valor.

En segundo lugar, cuando nos encontramos con ayuda interna frente a feedback y cálida, es más probable (entre valores de 2.32 a 19.42) que se produzca cualquier valor del resto de variables cuando la ayuda es interna. Destacan valores tan elevados como 19.42 de que se las tareas posean un formato que incluye explicación, ejemplo y contexto cuando la ayuda es de tipo interno.

En tercer lugar, los cruces de no transferencia y transferencia aplicativa frente a transferencia teórica también presentan valores superiores a 1.40 en todas sus filas. Estos resultados, nos indican una dicotomía en torno a la transferencia, ya que o no sucede (no transferencia) o si sucede es del tipo aplicativa. 
Tabla 13

Odds ratio

Reg Int Fee Cal No Ter Apli Ex Ex_Ej Ex_Cc Ex_Ej_Cc

\begin{tabular}{|c|c|c|c|c|c|c|c|c|c|c|c|}
\hline IRF/IRE & 1.41 & 2.44 & 1.19 & 4.18 & 0.98 & 0.86 & 9.70 & 0.87 & 1.44 & 1.91 & 4.67 \\
\hline Dial/IRE & 0.90 & 1.99 & 2.19 & 3.73 & 0.78 & 0.20 & 8.93 & 1.16 & 0.17 & 5.73 & 1.77 \\
\hline Dial/IRF & 0.64 & 0.82 & 1.84 & 0.89 & 0.80 & 0.23 & 0.92 & 1.33 & 0.12 & 3.00 & 0.38 \\
\hline Reg/Int & - & - & - & - & 0.54 & 0.52 & 0.27 & 0.40 & 0.90 & 0.36 & 0.32 \\
\hline Reg/Fee & - & - & - & - & 5.63 & 2.75 & 2.40 & 2.45 & 5.88 & 2.12 & 6.16 \\
\hline Reg/Cal & - & - & - & - & 1.73 & 4.71 & 0.64 & 1.15 & 2.61 & 0.96 & 0.87 \\
\hline Int/Fee & - & - & - & - & 10.37 & 5.25 & 8.77 & 6.06 & 6.50 & 5.85 & 19.42 \\
\hline Int/Cal & - & - & - & - & 3.18 & 9.00 & 2.34 & 2.85 & 2.89 & 2.65 & 2.73 \\
\hline Fee/Cal & - & - & - & - & 0.31 & 1.71 & 0.27 & 0.47 & 0.44 & 0.45 & 0.14 \\
\hline No/Teo & - & - & - & - & - & - & - & 1.95 & 4.00 & 10.50 & 8.33 \\
\hline No/Apli & - & - & - & - & - & - & - & 0.61 & 1.70 & 1.09 & 0.39 \\
\hline Teor/Apl & - & - & - & - & - & - & - & 0.32 & 0.43 & 0.10 & 0.05 \\
\hline Teor/No & - & - & - & - & - & - & - & 0.51 & 0.25 & 0.10 & 0.12 \\
\hline Apli//No & - & - & - & - & - & - & - & 1.63 & 0.59 & 0.92 & 2.54 \\
\hline Apli/Teo & - & - & - & - & - & - & - & 3.17 & 2.35 & 9.61 & 21.14 \\
\hline
\end{tabular}

Nota. Amarillo valores comprendidos entre 0.8 y 1.39 y verde valores superiores a 1.4

Siguiendo con ese análisis general por filas, destacamos la ayuda regulatoria frente a la interna, ya que presenta odds inferiores a 1 en todas sus celdas, lo 


\section{Capitulo 2: ESTUDIO EMPÍRICO}

mismo ocurre con el feedback, estos datos contrastan con los anteriores prevaleciendo la ayuda interna frente a la regulatoria. En cuanto a los valores de la variable transferencia, la teórica frente a las otras dos presenta valores muy próximos a cero, lo que no hace más que confirmar los análisis previos.

\section{Mosaic plot}

Existen varios esquemas para representar gráficamente las tablas de contingencia, dichos esquemas se basan en el hecho de que cuando las variables de fila y columna son independientes, la frecuencia esperada es el producto de las filas y las columnas totales (dividido por el total general). Uno de estos esquemas de representación gráfica es el gráfico de mosaico que representa los recuentos en una tabla de contingencia de rectángulos cuyo tamaño es proporcional al recuento (Friendly, 1992).

Cada celda puede ser representado por un rectángulo cuya área muestra la frecuencia de celdas o la desviación de la independencia. El gráfico de mosaico, que presentan Hartigan y Kleiner (1984), representa cada célula directamente por un rectángulo cuya área es proporcional a la frecuencia de la célula. Hartigan y Kleiner mantienen que el patrón de azulejos mostrada por la pantalla de mosaico es útil para sugerir hipótesis, haciendo comparaciones visuales a través de porciones de una tabla de frecuencia, y pone de relieve los recuentos inusualmente grandes y pequeños.

Estas técnicas de visualización gráfica son complementos comunes en los métodos estadísticos para el análisis de datos categóricos tales como los modelos log-lineales y de regresión logística, aunque no se utilizan frecuentemente como métodos para la visualización de datos de la tabla de contingencia.

El gráfico de mosaico (Figura 13) pone de manifiesto de manera visual los análisis que hemos realizado hasta el momento. Los colores de los recuadros nos indican el nivel de residuos estandarizados, el color azul y sus distintas intensidades indican residuos superiores a 2.4. 


\section{Método}

Caben destacar los residuos estandarizados con mayor valor tales como los que presenta la estructura de tipo IRF con ayuda interna, transferencia aplicativa y ex_ej_cc destacando una frecuencia esperada superior a la observada. Pone de relieve la importancia de los valores de las variables en relación con las secuencias didácticas planteadas.

Por otro lado, destacan también con frecuencias altas, la estructura de tipo IRF con ayuda cálida, transferencia aplicativa y ex_ej_cc. Así como, dentro de la estructura dialógica con ayuda interna, no transferencia y Formato de tipo ex_cc.

Estos resultados, contrastan con los obtenidos hasta ahora, con un papel importante por parte de las estructuras de tipo dialógicas, ayudas internas y tareas que contiene referencias al contexto.

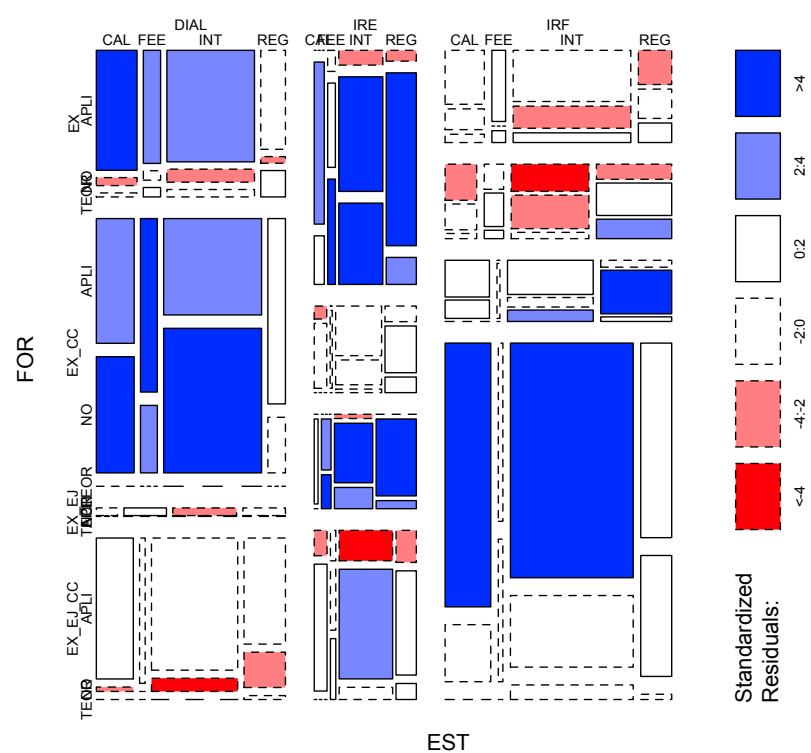

Figura 13. Mosaic plot. 


\section{Capitulo 2: ESTUDIO EMPÍRICO}

\section{Association plot}

El gráfico conocido como association plot (Friendly, 1992) muestra en primer plano las desviaciones de independencia: el área de cada caja es proporcional a la frecuencia observada/esperada. En association plot, cada celda está representada por un rectángulo cuya altura $\sim \mathrm{d}_{\mathrm{ij}}$ y anchura $\sqrt{e i j}$. El área de cada rectángulo es, por tanto, proporcional a $\mathrm{f}_{\mathrm{ij}}-e_{\mathrm{ij}}$. Los rectángulos para cada fila de la tabla se posicionan en relación a una línea de base que representa la independencia $\left(\mathrm{d}_{\mathrm{ij}}=0\right)$ se muestra por una línea de puntos. Las células con mayor frecuencia observada que esperada suben por encima de la línea y son de color azul; las células que contienen menos de la frecuencia esperada caen por debajo de ella y están sombreadas de color rojo.

Los gráficos de asociación nos permiten establecer patrones, por otro lado, nos permite aceptar o rechazar la hipótesis de nulidad o establecer si las variables son independientes.

A gran escala, el associaction plot expuesto en la Figura 14 nos muestra los mismos resultados que hasta ahora, con la certeza de saber que las variables tienen cierta relación entre sí (residuos elevados). Cabe destacar los casos con frecuencias observadas elevadas como el formato de la tarea con explicación y contexto con estructura dialógica, ayuda cálida y no transferencia. También destacan por tener frecuencias observadas mayores a las esperadas el formato de la tarea con explicación, ejemplo y contexto, estructura IRF, ayuda interna y transferencia aplicativa.

En el caso opuesto, que se presentan frecuencias por debajo de lo esperado el formato de la tarea explicación, ejemplo y contexto, estructura dialógica, ayuda interna y no transferencia. Así como el formato de la tarea con explicación y contexto, ayuda interna, estructura IRF y transferencia aplicativa. 


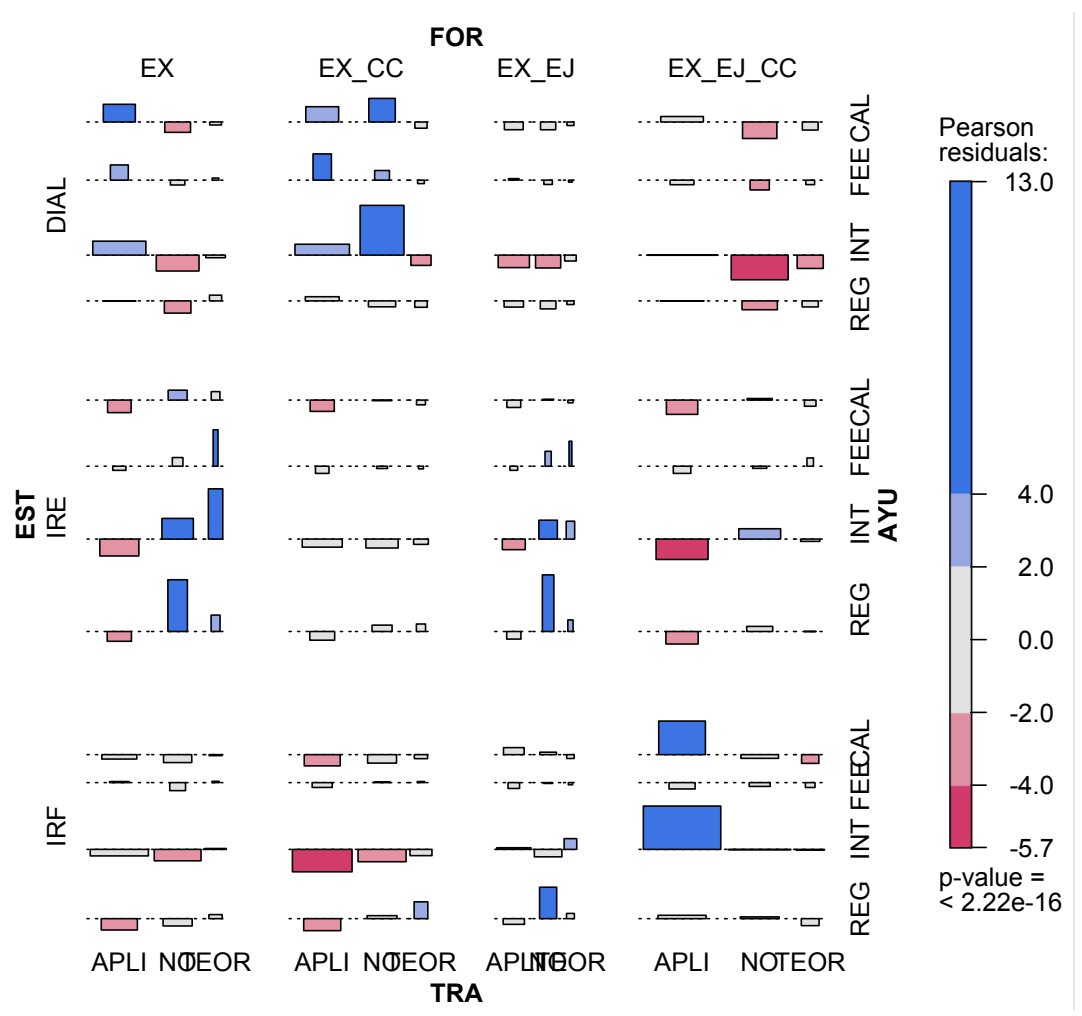

Figura 14. Association plot.

\section{Análisis de correspondencias de tablas bidimensionales}

El análisis de correspondencias es una técnica de interdependencia recientemente desarrollada que facilita el mapeo perceptual de objetos en un conjunto de atributos no métricos (Hair et al., 2014) cuya finalidad es poner de manifiesto gráficamente las relaciones de dependencia existentes entre las diversas modalidades de dos o más variables categóricas a partir de la información proporcionada por sus tablas de frecuencias cruzadas, es un análisis exploratorio que nos permite determinar si es posible observar patrones. Los investigadores se enfrentan constantemente con la necesidad de cuantificar los datos cualitativos que se encuentran en las variables nominales. El análisis de correspondencia difiere del resto técnicas de interdependencia ya que posee capacidad para alojar tanto los datos no métricos y relaciones no lineales. 


\section{Capitulo 2: ESTUDIO EMPÍRICO}

En su forma más básica, el análisis de correspondencias emplea una tabla de contingencia, que es la tabulación cruzada de dos variables categóricas. A continuación, transforma los datos no métricos a un nivel métrico y lleva a cabo la reducción de dimensiones (similar al análisis de los factores) y el mapeo perceptual. El análisis de correspondencia proporciona una representación multivariante de la interdependencia de los datos no métrica que no es posible con otros métodos.

Las distancias entre las diferentes categorías indican la mayor o menor relación entre ellas. Para ello se asocia a cada modalidad un punto en el espacio bidimensional de forma que, cuanto más alejado del origen de coordenadas está el punto asociada a una modalidad de una variable, más diferente es su perfil condicional del perfil marginal correspondiente a las otras variables; además, los puntos correspondientes a dos modalidades diferentes de una misma variable estarán más cercanas cuanto más se parezcan a sus perfiles condicionales y, finalmente, dichos puntos tenderán a estar más cerca de aquellas modalidades con las que tienen una mayor afinidad, es decir, aquéllas en los que las frecuencias observadas de la celda correspondiente tiende a ser mayor que la esperada bajo la hipótesis de independencia de las variables correspondientes.

Al calcular las correspondencias de tablas bidimensionales y obtener los ejes principales, se pueden calcular las posiciones relativas de las tablas respecto a los dos primeros ejes principales, que dan una idea más exacta de las posiciones relativas de las variables.

Para un análisis más detallado y gráfico de las relaciones que establecen entre las variables se realizó un análisis de correspondencias (Joraisti \& Lizosain, 2000), donde se obtiene una interpretación en términos de modelos loglineales. Para ello, se analiza la relación entre dos variables categóricas, descomponiendo el $\chi^{2}$ de una tabla de contingencia. Esta descomposición permite llegar a un modelo de independencia en el que la fila y columna se puedan representar por puntos en un espacio (ecuación 7). 


\section{Método}

$$
\log (Y i j)=E S T+F O R+E S T * F O R
$$

Para los dos efectos la diferencia entre el modelo saturado y el modelo de independencia es el parámetro de la interacción de primer orden [est*for]. En este caso (Figura 15) la inercia principal nos indica que la primera variable contribuye a un $28 \%$ y que las dos variables contribuyen un $72 \%$ por lo que se concluye que las dependencias observadas en la tabla están adecuadamente representadas por los dos primeros efectos, estructura de participación y formato de la tarea.

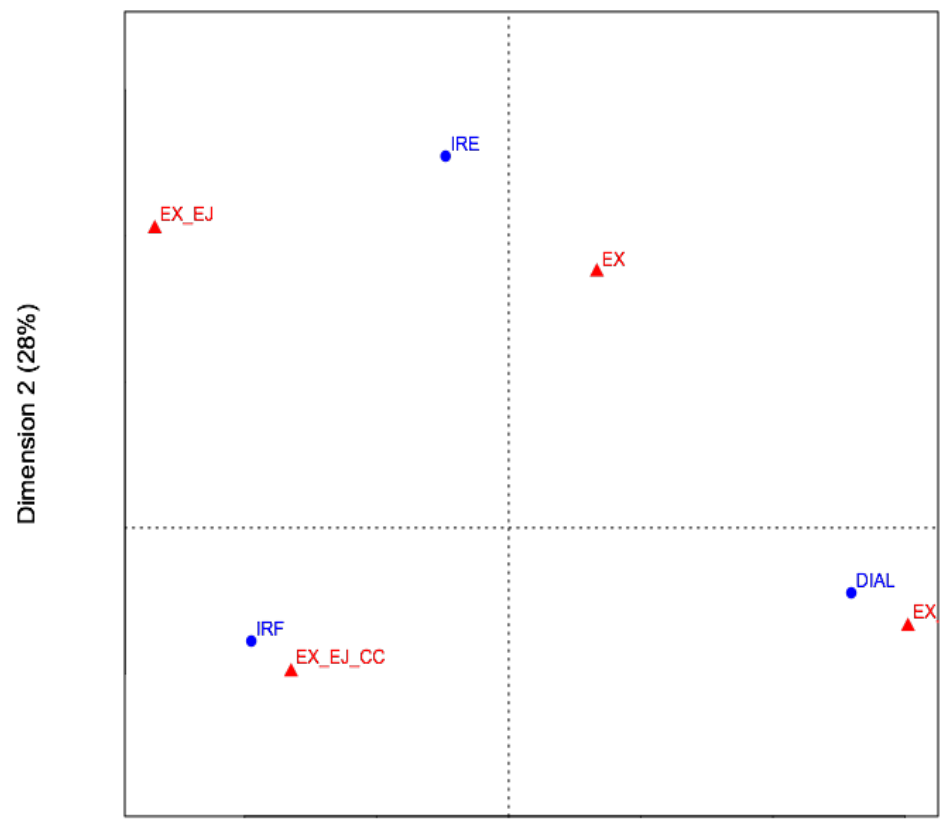

Dimension 1 (72\%)

Figura 15. Análisis de correspondencias entre Estructura de participación y Formato de la tarea.

En la Figura 16 se presenta una gráfica con los resultados del análisis de correspondencia, donde el conjunto de puntos correspondientes a los perfiles 


\section{Capitulo 2: ESTUDIO EMPÍRICO}

condicionales fila y columna, pone de manifiesto las relaciones de dependencia existentes ente las dos variables. Las distancias ente ellas, nos indican su grado de asociación. De esta forma, se observa una asociación positiva entre la estructura de participación de tipo IRE y el formato de la tarea explicación, ejemplo y contexto. También podemos de hablar de una asociación entre la estructura de tipo dialógica y el formato de la tarea solo con ejemplo.

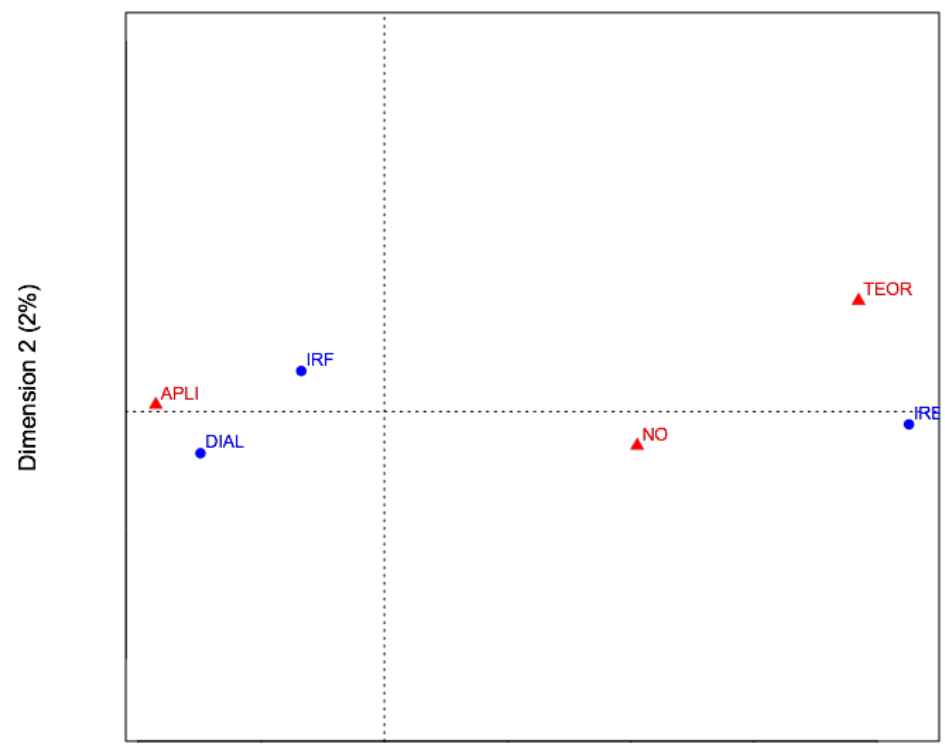

Dimension 1 (98\%)

Figura 16. Análisis de correspondencias ente Estructura de participación y Transferencia.

La interacción de primer orden [estu*tra] (Figura 16) nos indica que la primera variable contribuye únicamente a un $2 \%$ y que las dos variables contribuyen un $98 \%$ por lo que se concluye que las dependencias observadas en la tabla están adecuadamente representadas por los dos primeros efectos, estructura de participación y transferencia. De esta forma se observa una asociación 


\section{Método}

positiva entre la estructura de participación dialógica y la transferencia aplicativa.

En relación con la interacción de primer orden [for*tra] mostrado en la Figura 17 observamos como la primera variable contribuye en $34 \%$ y que las dos variables contribuyen en un $66 \%$. Así podemos observar como la transferencia aplicativa correlaciona con el formato de la tarea combinado (ex_ej_cc), del mismo modo que lo hace la no transferencia con ex_cc. Sin embargo, cabe destacar que la transferencia teórica dista mucho del resto de variables.

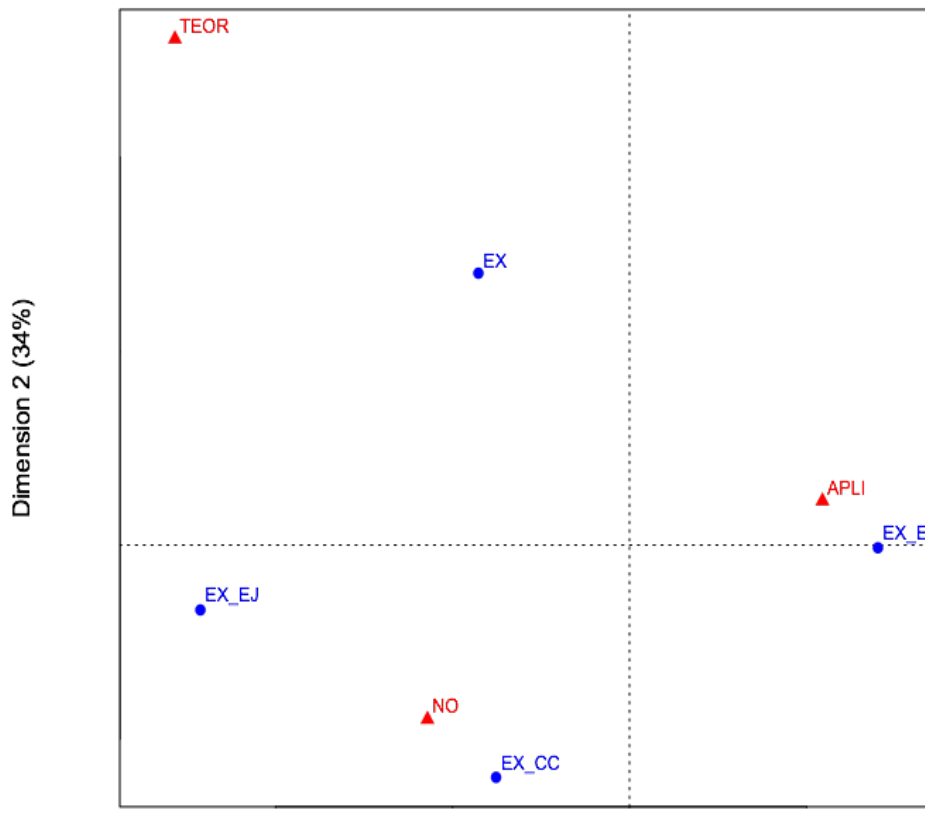

Dimension $1(66 \%)$

Figura 17. Análisis de correspondencias entre Formato de la tarea y transferencia.

La Figura 18 nos muestra la interacción de primer orden [ayu*for] nos indica que la primera variable contribuye a un $34.1 \%$ y que las dos variables con- 


\section{Capitulo 2: ESTUDIO EMPÍRICO}

tribuyen un $65.7 \%$ por lo que se concluye que las dependencias observadas en la tabla están adecuadamente representadas por los dos primeros efectos, ayuda y formato de la tarea. De esta forma se observa una asociación positiva entre la ayuda interna y cálida y las tareas que incluyen explicación, ejemplo y están relacionadas con el contexto. Por otra parte, la ayuda tipo feedback no presenta cercanía a ninguna de las dimensiones.

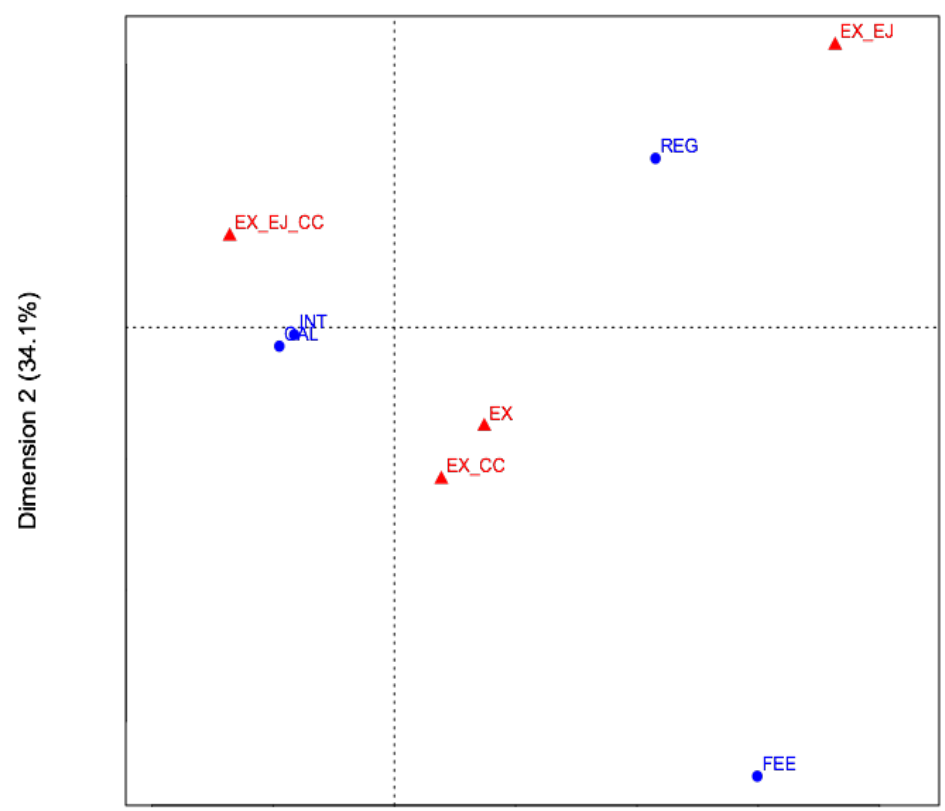

Dimension 1 (65.7\%)

Figura 18. Análisis de correspondencias entre Ayuda y formato de la tarea.

En cuanto a la correspondencia entre las dimensiones estructura y ayuda observamos en la Figura 19 que existe cierta relación entre la ayuda regulatoria 


\section{Método}

y la estructura IRE así como entre la ayuda interna e IRF. Por otro lado, la ayuda de tipo feedback no presenta ninguna asociación.

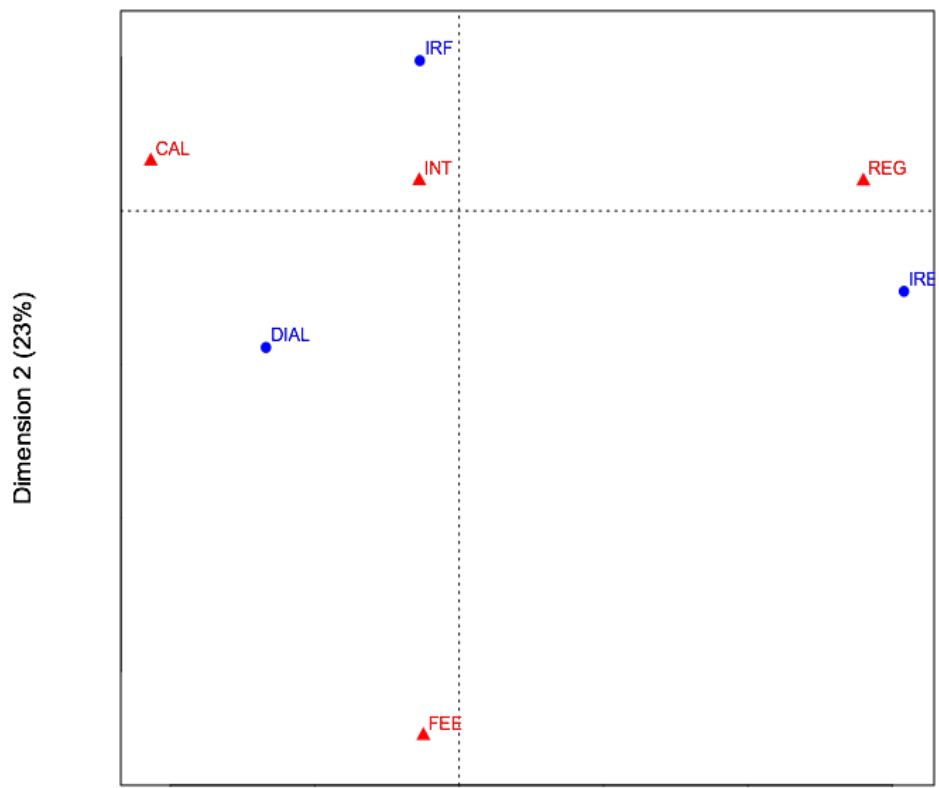

Dimension 1 (77\%)

Figura 19. Análisis de correspondencias entre Estructura de participación y ayuda.

En cuanto a la ayuda y la transferencia (Figura 20) no parecen existir asociaciones claras, si bien cabe destacar que las ayudas cálidas e internas presentan cierta correlación con la transferencia aplicativa y la regulatoria con la no transferencia. 
Capitulo 2: ESTUDIO EMPÍRICO

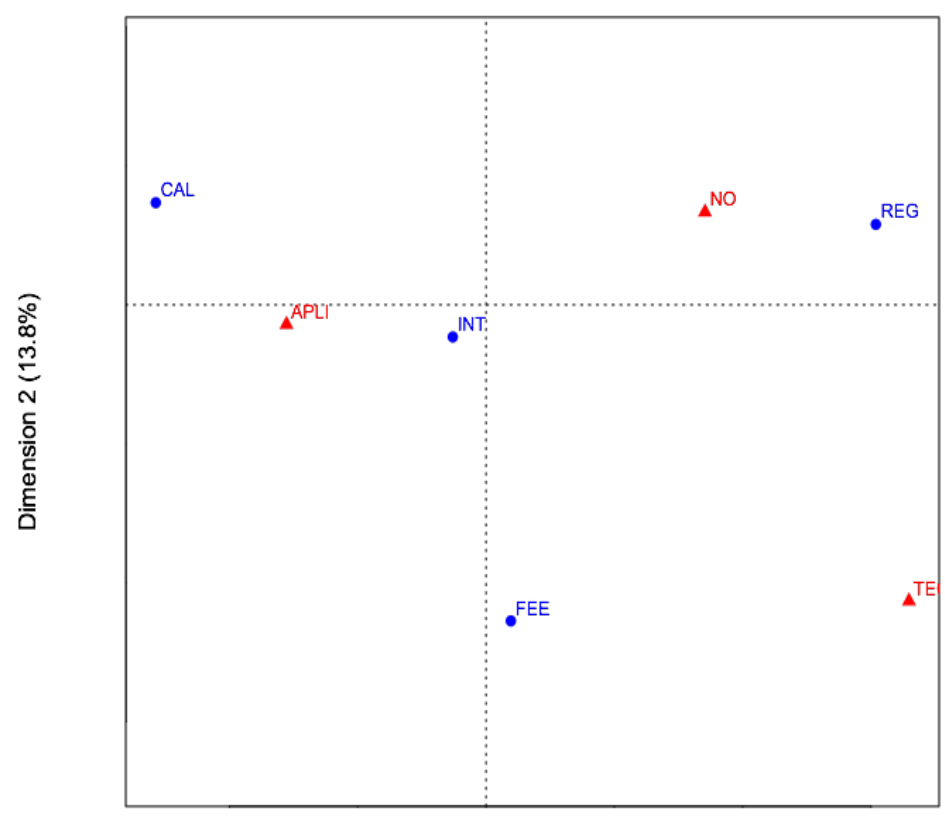

Dimension 1 (86.2\%)

Figura 20. Análisis de correspondencias ente Transferencia y Ayuda.

\subsubsection{Análisis log-lineal}

El origen del análisis logarítmico lineal suele atribuírsele a Birch (1963), a raíz de sus aportaciones relacionadas con el tema de la asociación entre tres variables. A partir de entonces, diversos estadísticos (Agresti \& Kateri, 2011; Goodman, 1968; Goodman \& Kruskal, 1979; Haberman, 1979; Knoke \& Burke, 1980) han contribuido de manera notable, tanto al desarrollo de esta metodología, como a su difusión. Los modelos de regresión log-lineal pertenecen a la familia de técnicas estadísticas multivariadas de interdependencia, cuyo rasgo principal es que no diferencian entre variables dependientes e independientes. Su denominación log-lineal obedece a que las frecuencias observadas en cada casilla de la tabla se transforman en logaritmos naturales, dado que esto permite 


\section{Método}

la obtención de un modelo aditivo y favorece la minimización de la asimetría positiva que supone analizar frecuencias (d'Ancona, 2002).

Así, a diferencia de los procedimientos estadísticos más comunes (i.e. regresión lineal o logística), en los modelos log-lineales la unidad de análisis no son las puntuaciones individuales de cada sujeto de la muestra, sino conjuntos de sujetos que comparten ciertas características especificadas por las categorías de las variables. Es decir, el concepto de variable dependiente se reconceptualiza por el de probabilidad de casilla: la probabilidad de que un individuo seleccionado al azar pertenezca a determinadas categorías de interés, en lugar de a otras, es decir, la probabilidad de que tenga una determinada combinación de características (Correa, 2002). De esta forma, el objetivo del análisis consiste en obtener un modelo que describa adecuadamente las relaciones e interacciones que se dan entre las variables o factores que integran una tabla de contingencia multidimensional, y que determinan las frecuencias de casilla.

Existe una gran cantidad de modelos para realizar el cálculo de las frecuencias esperadas en cada casilla. Aumentan en tamaño y complejidad conforme se van incorporando dimensiones al análisis. Es caso más sencillo sería el de una tabla bidimensional.

Aquí, las frecuencias esperadas, o sus logaritmos, se expresan en función de una serie de parámetros. Como sucede con los modelos de regresión lineal o logística, pueden existir parámetros de efectos principales y de interacción. Su presencia o ausencia determina la estructura de los modelos. Entre los modelos posibles, tenemos los que figuran a continuación.

En el modelado log-lineal, puede emplearse tanto el procedimiento de eliminación hacia atrás, como hacia adelante. En este último caso, se van añadiendo parámetros a partir de un modelo simple, como por ejemplo el de independencia. La primera estrategia, eligiendo el modelo que presente los valores más bajos asociados al indicador BIC, propuesto por Raftery (1986), y conside- 
rado como el más consistente de los indicadores de ajuste hasta ahora desarrollados para el caso de los modelos log-lineales (Ato \& López, 1996).

Hemos incluido en el modelo saturado las variables estructura de participación, ayuda, transferencia y formato de la tarea ya que han sido las que nos han aportado mayor información en los análisis de las tablas de contingencia y odds ratio.

Las variables área y estructura de la tarea no han aportado mayor información lo que hemos considerado que no van a influir en el modelo.

Se ha utilizado el modelo [EFAT], que es el modelo general para cuatro criterios, y se define como modelo saturado o completo por incluir todos los criterios (efectos) individuales y todas las posibles interacciones (efectos de $2^{\circ}, 3^{\text {er }}$ y $4^{\circ}$ orden) entre los criterios seleccionados. Al tratarse del modelo saturado presenta un ajuste perfecto con una razón de verosimilitud de 0 y un tamaño de significación a posteriori de 1 .

\section{Selección del modelo}

Puesto que el modelo log-lineal tiene por objetivo identificar las relaciones más significativas que se producen entre las variables seleccionadas, es obvio que el modelo saturado, de entre todos los posibles, no es el más indicado ya que recoge la totalidad de los parámetros. Por tanto, debemos quedarnos con el modelo que solo considere lo más significativo de la relación entre las variables y por ende que cumpla el principio de parsimonia.

Para encontrar el modelo que mejor se ajusta a nuestros datos hemos eliminado del modelo saturado las interacciones de orden mayor para encontrar el modelo más parsimonioso sin que afecte al modelo aplicando el método backward. En cada paso se analizan los efectos de orden superior que permanecen en el modelo, se suprimen aquellos que al pasar del modelo original al obtenido al suprimir dicho efecto produzca un cambio mínimo en la razón de verosimilitud Ji-cuadrado. En nuestro caso, al eliminar del modelo las interac- 
ciones de $4^{\circ}$ orden el modelo presenta una razón de verosimilitud de 36.707 con 36 grados de libertad y un tamaño de significación de 0.436 tal como muestra la Tabla 14, lo que nos indica que si eliminamos estas interacciones el modelo no sufre ninguna merma.

Al calcular las diferencias entre el modelo saturado y el modelo sin las interacciones de $4^{\circ}$ orden podemos observar que la interacción de $4^{\circ}$ orden no tiene efecto sobre cuán bien ajusta el modelo ya que observamos que no hay diferencias significativas en el modelo sin las interacciones y el saturado.

Tabla 14

Comparación de modelos

\begin{tabular}{lll}
\hline & Delta (df) & Delta (Dev) \\
\hline Modelo 2 & 36 & 0.436 \\
Saturado & 0 & 1.0000 \\
\hline
\end{tabular}

El estadístico razón de máxima verosimilitud muestra la bondad de ajuste del modelo, y se calcula comparando el modelo saturado con el modelo especificado. En este caso, la diferencia es 0 , dado que se trata del mismo modelo, por lo tanto, el modelo se ajusta perfectamente (modelo saturado).

El análisis de máxima verosimilitud (Tabla 15) muestra que los modelos de segundo orden que contemplan todas las interacciones de los cuatro criterios es significativo con un $\chi^{2}$ elevado $(\mathrm{p}=0)$ lo que indica que las interacciones de segundo orden deben estar presentes en el modelo, por tanto, rechazamos la hipótesis de equiprobabilidad en todos los casos. 
Tabla 15

Razón de verosimilitud

\begin{tabular}{lll}
\hline & Ji-cuadrado Pearson & $\mathrm{p}$ \\
\hline EST*AYU & 50.031 & 0 \\
EST*FOR & 348.090 & 0 \\
EST*TRA & 282.2009 & 0 \\
AYU*FOR & 46.978 & 0 \\
AYU*TRAN & 56.649 & 0 \\
FOR*TRAN & 149.8546 & 0 \\
\hline
\end{tabular}

Si hacemos la prueba a nivel general nos encontramos con un Ji-cuadrado de 1500.6 con 133 grados de libertad y un valor p asociado de 0.0 (4.869e230).

Podemos concluir por tanto que este modelo no es adecuado para explicar las frecuencias asumiendo que los factores interactúan o están asociados de alguna manera, es decir que no son independientes.

Una vez llevado a cabo el proceso de modelaje, volvemos a poner a prueba el modelo que habíamos obtenido a través de la función step, es decir el modelo eliminando las interacciones de $4^{\circ}$ orden y una de $3^{\text {er }}$ (EST:AYU:TRA) con una razón de verosimilitud de 57.719 con 48 grados de libertad y un p a posteriori de 0.159 concluyendo que la relación entre estructura y transferencia está condicionada por formato de la tarea. 
Tabla 16

Analysis of Deviance Table I

\begin{tabular}{|c|c|c|c|c|c|}
\hline & $\mathrm{df}$ & $\begin{array}{l}\text { Deviance } \\
\text { Resid. }\end{array}$ & df & $\begin{array}{l}\text { Resid. } \\
\text { Dev. }\end{array}$ & $\operatorname{Pr}(>\mathrm{Chi})$ \\
\hline Null & & & 143 & 3045.45 & \\
\hline EST & 2 & 147.34 & 141 & 2898.12 & $<2.2 e-16 * * *$ \\
\hline FOR & 3 & 382.15 & 138 & 2515.97 & $<2.2 e-16 * * *$ \\
\hline AYU & 3 & 711.86 & 135 & 1804.11 & $<2.2 e-16 * * *$ \\
\hline TRA & 2 & 624.05 & 133 & 1180.06 & $<2.2 e-16 * * *$ \\
\hline EST:FOR & 6 & 351.92 & 127 & 828.14 & $<2.2 e-16 * * *$ \\
\hline EST:AYU & 6 & 46.83 & 121 & 781.31 & $2.019 e-08 * * *$ \\
\hline FOR:AYU & 9 & 30.12 & 112 & 751.19 & $0.0004191 * * *$ \\
\hline EST:TRA & 4 & 310.36 & 108 & 440.83 & $<2.2 e-16 * * *$ \\
\hline FOR:TRA & 6 & 153.93 & 102 & 286.90 & $<2.2 e-16 * * *$ \\
\hline AYU:TRA & 6 & 30.33 & 96 & 256.57 & $3.403 e-05 * * *$ \\
\hline EST:FOR:AYU & 18 & 51.34 & 78 & 205.23 & $4.723 e-05 * * *$ \\
\hline EST:FOR:TRA & 12 & 92.42 & 66 & 112.81 & $1.679 e-14 * * *$ \\
\hline EST:AYU:TRA & 12 & 34.11 & 54 & 78.70 & $0.0006472 * * *$ \\
\hline FOR:AYU:TRA & 18 & 30.21 & 36 & 48.49 & $0.0354333 *$ \\
\hline EST:FOR:AYU:TRA & 36 & 48.49 & 0 & 0.00 & 0.0798770 \\
\hline \multicolumn{6}{|c|}{ 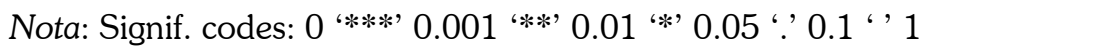 } \\
\hline
\end{tabular}




\section{Capitulo 2: ESTUDIO EMPÍRICO}

Siguiendo con la búsqueda del mejor modelo, realizamos un análisis Anova (Tabla 16), que nos sugiere que eliminemos del modelo las interacciones de $4^{\circ}$ orden y la de $3^{\text {er }}$ orden FOR:AYU:TRA, estos resultados no contrastan con los obtenidos mediante la función step ya que nos sugiere la eliminación de una interacción de tercer orden distinta.

Volvemos a realizar de nuevo el análisis Anova eliminado las interacciones de $4^{\circ}$ orden y la interacción de $3^{\text {er }}$ orden EST:AYU:TRA, en consecuencia, todos los valores obtenidos con el nuevo análisis son altamente significativos lo que indica que ya no podemos eliminar ninguna interacción más del modelo sin que este se vea afectado tal como muestran los resultados de la Tabla 17. 
Tabla 17

Analysis of Deviance Table II

\begin{tabular}{|c|c|c|c|c|c|}
\hline & df & $\begin{array}{l}\text { Deviance } \\
\text { Resid. }\end{array}$ & $\mathrm{df}$ & Resid. Dev. & $\operatorname{Pr}(>C h i)$ \\
\hline Null & & & 143 & 3045.45 & \\
\hline EST & 2 & 147.34 & 141 & 2898.12 & $<2.2 e-16 * * *$ \\
\hline FOR & 3 & 380.13 & 138 & 2517.98 & $<2.2 e-16 * * *$ \\
\hline AYU & 3 & 712.08 & 135 & 1805.91 & $<2.2 e-16 * * *$ \\
\hline TRA & 2 & 631.98 & 133 & 1173.93 & $<2.2 e-16 * * *$ \\
\hline EST:FOR & 6 & 349.00 & 127 & 824.93 & $<2.2 e-16 * * *$ \\
\hline EST:AYU & 6 & 50.65 & 121 & 774.28 & $3.484 e-09 * * *$ \\
\hline FOR:AYU & 9 & 29.59 & 112 & 744.70 & $\begin{array}{l}0.0005154 \\
* * *\end{array}$ \\
\hline EST:TRA & 4 & 301.20 & 108 & 443.49 & $<2.2 e-16 * * *$ \\
\hline FOR:TRA & 6 & 151.82 & 102 & 291.67 & $<2.2 e-16^{* * *}$ \\
\hline AYU:TRA & 6 & 31.50 & 96 & 260.17 & $2.031 e-05 * * *$ \\
\hline EST:FOR:AYU & 18 & 50.97 & 78 & 209.20 & $5.380 e-05^{* * *}$ \\
\hline EST:FOR:TRA & 12 & 105.55 & 66 & 103.65 & $<2.2 e-16 * * *$ \\
\hline FOR:AYU:TRA & 18 & 46.12 & 48 & 57.52 & $0.0002848 * * *$ \\
\hline Not & & 0.001 & 0 م & 0.00 & ‘' 1 \\
\hline
\end{tabular}

Los modelos obtenidos a través del comando step y Anova no son modelos totalmente adecuados para las frecuencias observadas puesto que el nivel de $\mathrm{p}$ es de 0 por lo que habría que considerar si uno o más de los términos que he- 
mos eliminado deberían recuperarse (la de $3^{\text {er }}$ orden), para ello hemos sometido a prueba 6 modelos.

\section{Modelos sometidos a prueba}

Los modelos evaluados fueron definidos para determinar si existen relaciones significativas entre las variables. En la Tabla 18 se describe cada uno de los modelos de forma esquemática y sus valores de ajuste. Para seleccionar el mejor modelo se han utilizado dos estrategias comunes en este tipo de investigaciones (Burnham \& Anderson, 2002; Mood, Graybill, \& Boes, 1974; Sorensen \& Gianola, 2002: (a) prueba de razón de verosimilitud y (b) el criterio de información de Akaike.

Prueba de razón de verosimilitud.

Se basa en las diferencias entre dos modelos en los valores de los logaritmos de las funciones de verosimilitud, las cuales se distribuyen como ji cuadrado, con grados de libertad igual a la diferencia en el número de parámetros. Esta prueba indica si la diferencia entre los valores de las funciones de verosimilitudes para un modelo $A$ con $p$ parámetros y otro modelo $B$ con $p+q$, es significativamente diferente como para afirmar que los q parámetros extras incluidos en $\mathrm{B}$ explican variación adicional en la variable respuesta, a la que explican los p parámetros incluidos en A; pero esto depende también de si los datos contienen o no suficiente información para soportar el número de parámetros del modelo (Mood et al., 1974; Sorensen \& Gianola, 2002).

Criterio de información de Akaike (AIC).

Mide la información que se pierde cuando se utiliza un modelo alterno para aproximarse al modelo real o desconocido. El objetivo es buscar el modelo aproximado, partiendo del modelo completo, que proporcione la menor pérdida de información posible. La expresión de AIC es $-2 \log \mathrm{L}+2 \mathrm{p}$, donde L es la función de verosimilitud y $\mathrm{p}$ es el número de parámetros independientes estimados en el modelo. La función de verosimilitud es una medida de la capa- 
cidad de ajuste del modelo, mientras que $2 \mathrm{p}$ representa una penalización debida al número de parámetro (Burnham \& Anderson, 2002; Sorensen \& Gianola, 2002).

Tabla 18

Modelos sometidos a prueba

\begin{tabular}{lllll}
\hline Modelo & Chi-cuadrado & gl & $\mathrm{p}$ & AIC \\
M1 [E][A][F][T] & 744.6955 & 112 & $2.22 e-16$ & 288 \\
M2 [EAF][T] & 636.4075 & 94 & $2.22 e-16$ & \\
M3 & 180.5086 & 78 & $2.22 e-16$ & \\
[EAF][ET][AT][FT] & & & & \\
M4 [EAT][ET][AFT] & 460.9746 & 72 & $2.22 e-16$ & \\
M5 [EAF][EAT][EFT] & 59.69653 & 54 & 0.22888 & 250.83 \\
M6 [EAF][EFT][AFT] & 51.94052 & 48 & 0.30694 & 252.71 \\
\hline
\end{tabular}

Tal como observamos en la Figura 21 el Modelo 1 de independencia, no ajusta a los datos de nuestra investigación puesto que presenta un elevado valor de Ji-cuadrado (744.6955) y el mayor valor de AIC, con lo que rechazamos dicho modelo.

El Modelo 2 (Joint Independence) [EAF][T] sometimos a prueba la hipótesis de que las variables Estructura, Formato de la tarea u Ayuda influían en la transferencia, tampoco ajusta a nuestros datos, al presentar un elevado valor de Ji-cuadrado (636.4075). Este modelo lo analizamos más adelante mediante la regresión logística.

Los modelos 5 [EAF][EAT][EFT] y 6 [EAF][EFT][AFT] ajustan a los datos de nuestra investigación presentando unos residuos estandarizados muy bajos. 
El Modelo 5 tiene el valor más bajo de AIC y p, sin embargo, el Modelo 6 es el más parsimonioso al tener menos grados de libertad. Estos datos contrastan con los modelos aportado por el comando Step en R (Modelo 6) y ANOVA (Modelo $5)$.

Una vez analizados los modelos anteriores, encontramos que el modelo más parsimonioso y que mejor se ajusta a los datos que tenemos es el modelo 6 compuesto por tres interacciones triples [EST*AYU*FOR][EST*FOR*TRA][AYU*FOR*TRA], con un Ji-cuadrado de 51.94052 con 48 grados de libertad y un p de 0.30694 .

Como podemos observar se trata de un modelo complejo ya que consta de tres interacciones triples. El modelo muestra como el formato de la tarea es una variable importante ya que interviene en los tres términos del modelo. Por otro lado, las otras tres variables resultan también importantes al intervenir en dos términos. Habrá que averiguar mediante análisis posteriores cómo influye cada una de las variables sobre el resto.

Otra forma de interpretar los modelos log-lineales es, a través de una representación gráfica mosaic (Friendly, 1994) de los residuales del modelo. Estos gráficos de mosaico nos permiten interpretar de una manera visual los resultados anteriores. Podemos observar, que los residuos estandarizados de los modelos M1 a M6 van disminuyendo.

Se observa que los modelos 5 y 6 presentan un $\mathrm{p}$ similar, sin embargo, el M6 podemos observar como todas las celdas presentan un color gris uniforme indicando un ajuste con los datos empíricos del estudio.

Estos datos representados de manera gráfica, no hacen más que poner de manifiesto nuevamente que el modelo que mejor ajusta a nuestros datos es el Modelo 6. 


\section{Método}
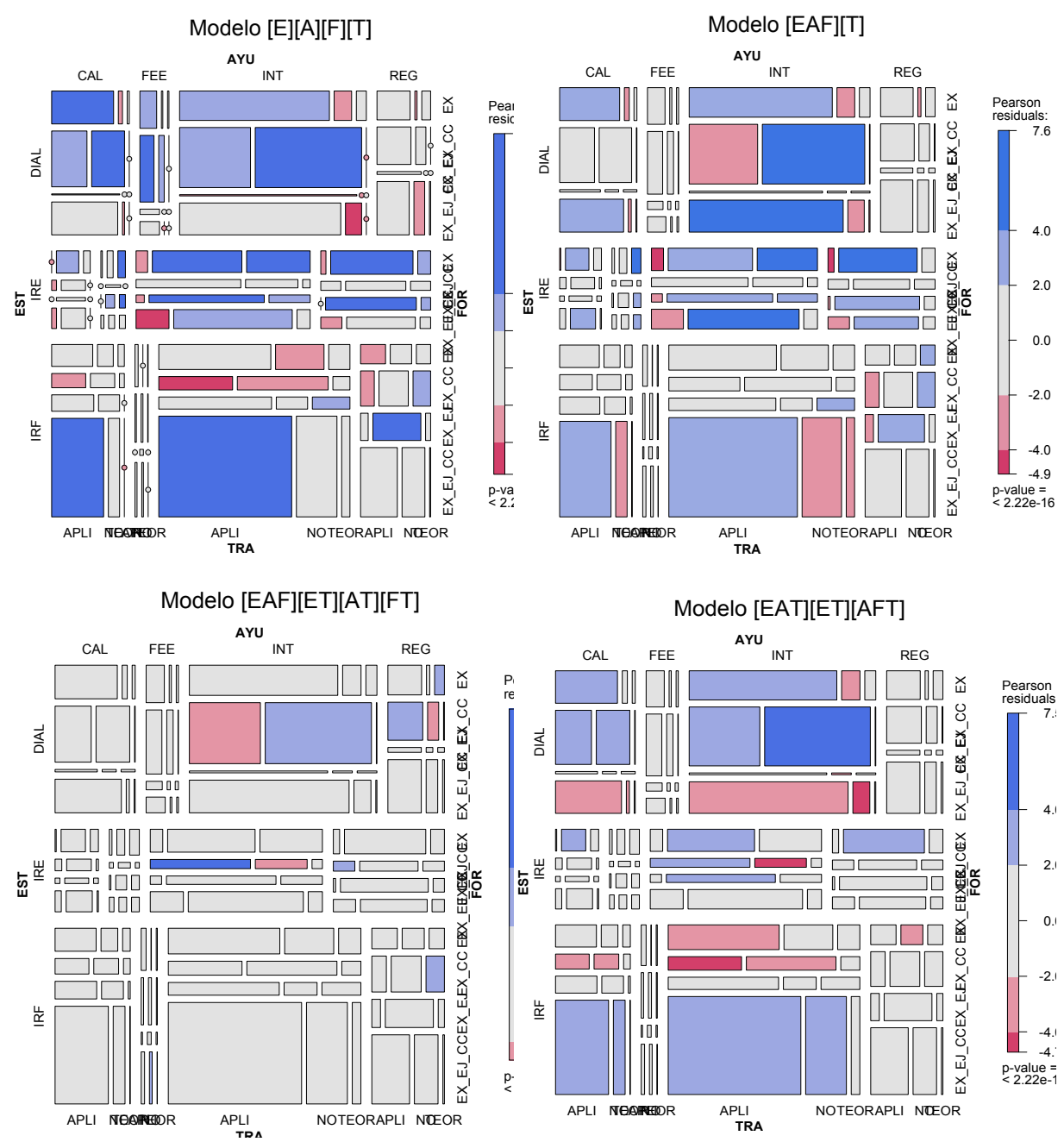

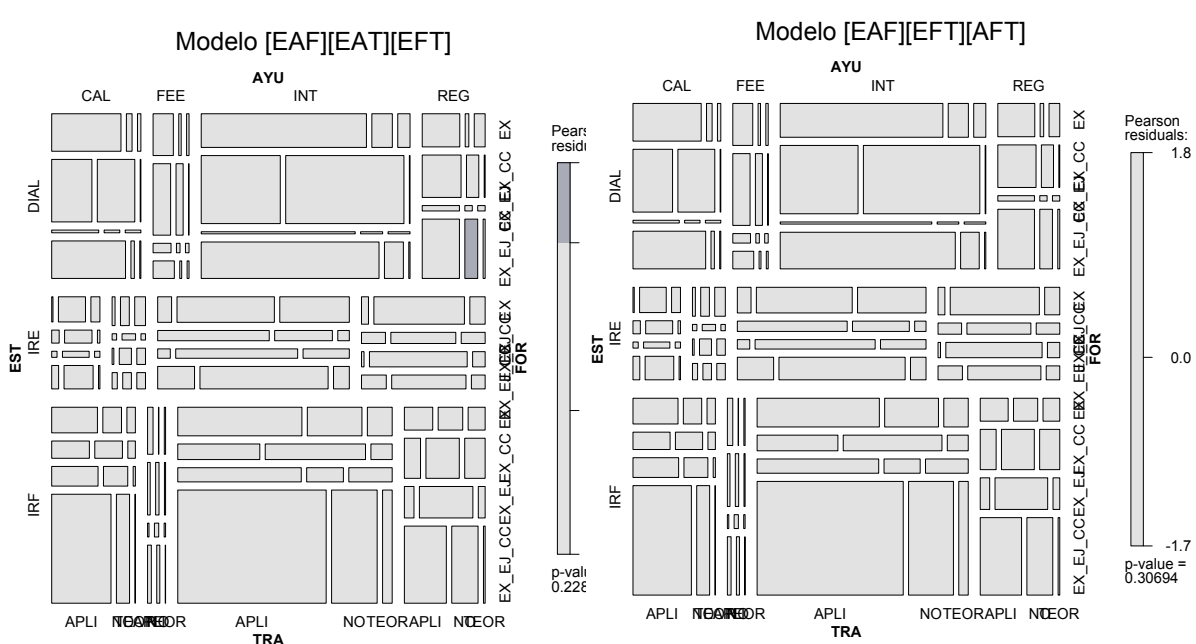

Figura 21. Representación gráfica de los modelos sometidos a prueba.

\subsubsection{Regresión logística}

Complementamos los análisis referenciados hasta este momento en con un análisis de regresión logística sobre las mismas 1506 secuencias de aprendizaje. En los próximos párrafos señalaremos el proceso de análisis y los resultados obtenidos.

En cada una de las secuencias de aprendizajes se ha recopilado información sobre el tipo de ayuda otorgado (1: cálida; 2: feedback; 3: interna; 4: regulatoria), el formato de la tarea (1: explicación, ejemplos y contexto cercano; 2: explicación y contexto cercano; 3: explicación y ejemplos; 4: explicación) y la clase de estructura de participación (1: dialógica; 2: IRF; 3: IRE). En la Tabla 18 se muestran los estadísticos descriptivos (frecuencias y proporciones) de las tres variables predictoras. Las categorías que han mostrado frecuencias más altas han sido explicación-ejemplos-contexto cercano en Formato de la tarea (42.5\%), el feedback en Ayuda (53.65\%) y la indagación-respuesta-feedback en Estructura de participación (43.76\%). En lo que atañe a la transferencia de aprendizajes, se han observado 547 (36.32\%) casos de no transferencia y 959 $(63.68 \%)$ casos de transferencia. 
Tabla 19

Descriptivos por categoría de predictores

\begin{tabular}{lllll}
\hline Variable & Categ Etiqueta & $\mathrm{N}$ & $\%$ \\
\hline FORMATO & 1 & ex_ej_cc & 640 & 42.50 \\
& 2 & ex_cc & 380 & 25.23 \\
& 3 & ex_ej & 125 & 8.30 \\
& 4 & ex & 361 & 23.97 \\
\hline AYUDA & 1 & cálida & 312 & 20.72 \\
& 2 & feedback & 808 & 53.65 \\
& 3 & interna & 92 & 6.11 \\
& 4 & regulatoria & 294 & 19.52 \\
\hline ESTRUCTURA & 1 & dialógica & 550 & 36.52 \\
& 2 & IRF & 659 & 43.76 \\
& 3 & IRE & 297 & 19.72 \\
\hline
\end{tabular}

Se ha sometido a prueba un modelo logístico de tres predictores categóricos (con las codificaciones señaladas en la Tabla 19) para probar la hipótesis de que la variable binaria de salida (transferencia o no transferencia) está relacionada con los tres predictores incluidos en el modelo.

Para evaluar el modelo de regresión logística y, consecuentemente, determinar su eficacia predictiva, se han utilizado cuatro estrategias comunes en este tipo de investigaciones (Hair et al., 2014; Hosmer, Lemeshow, \& Sturdivant, 2013): (a) evaluación del modelo global; (b) pruebas estadísticas de los predictores individuales; (c) estadísticos de bondad del ajuste; y (d) validaciones de las probabilidades estimadas, además de diferentes análisis para realizar el diagnóstico del modelo utilizado. 


\section{Evaluación global del modelo}

Un modelo logístico presenta ajuste a los datos si demuestra ser mejor que el modelo nulo, 'ingenuo' o de línea de base (i.e., un modelo que consta solo de la intercepción, sin predictores). Por una parte, tanto los valores AIC (Criterio de Información de Akaike) como SC (Criterio de Schwartz o BIC, Bayesian Information Criterion) y -2 Log $\mathrm{L}$ han sido menores en el modelo con predictores que en el modelo nulo, lo que sugiere la superioridad predictiva de aquel sobre este (tanto AIC como SC y -2 Log L no son en sí mismos significativos, considerándose mejor aquel modelo en el que dichos valores sean más bajos). Por otra parte, la mejora del modelo propuesto sobre el modelo vacío se examinó usando tres pruebas estadísticas inferenciales: la razón de verosimilitud, el Score Test y la prueba de Wald. Las tres pruebas han puesto de manifiesto la superioridad del modelo propuesto sobre el modelo de intercepción: $L R, \chi^{2}(8)=252.107$. $p$ $=.000 ;$ Score Test, $\chi^{2}(8)=245.314, p=.000 ;$ Wald, $\chi^{2}(8)=206.107, p=$ .000. De acuerdo con estos valores, se rechaza la hipótesis nula y concluimos que al menos uno de los coeficientes de regresión de los predictores no es igual a cero.

Las tres variables predictoras, consideradas globalmente, resultaron estadísticamente significativas: Ayuda, $\chi^{2}(3)=14.129, \mathrm{p}=.0027$; Formato de la tarea, $\chi^{2}(3)=88.622, p=.000$; Estructura de participación, $\chi^{2}(2)=138.772, p$ $=.000$. En consecuencia, todas ellas contribuyeron significativamente a la mejora del modelo predictivo y a su ajuste a las observaciones empíricas.

\section{Pruebas estadísticas de los predictores individuales}

Se comprobó la significación estadística de los coeficientes $\beta$ de regresión individuales mediante el estadístico $\chi^{2}$ de Wald. En la Tabla 20 se muestran los resultados del análisis de las estimaciones de máxima verosimilitud. Es de destacar que (a) el término de intercepción ha resultado no significativo: $\chi 2(1)=$ $1.052, \mathrm{p}=.305$, de lo que se deduce que un modelo alternativo al que presentamos podría no incluir la intercepción para ajustarse a los datos empíricos; (b) 


\section{Método}

solo una de las modalidades de ayuda (cálida) ha resultado estadísticamente significativa: $\chi^{2}(1)=7.318, \mathrm{p}=.007$, como opuesta a la categoría omitida regulatoria; (c) dos de las modalidades de formato de la tarea (explicacióncontexto cercano, con $\chi^{2}(1)=60.412$. $p=.000$, y explicación-ejemplos, con $\left.\chi^{2}(1)=12.022, p=.000\right)$ han resultado significativas como opuestas a la categoría explicación, y (c) las dos modalidades de estructura de participación (dialógica, con $\chi^{2}(1)=125.780 . p=.000$, y IRF, con $\chi^{2}(1)=95.409, p=$ .000) han sido asimismo significativas, como opuestas a la categoría IRE. Para interpretar el significado de estos coeficientes, es preciso tomar en consideración tanto la significación estadística como el signo. Así, por ejemplo, el hecho de que la ayuda sea de tipo cálido, frente a una ayuda regulatoria, reduce la log odds de que se produzca transferencia en 0.504. O, el contar con una estructura de participación de tipo dialógico, incrementa la log odds de que se produzca transferencia en 2.022 frente al hecho de que la estructura sea IRE. Por su parte, si la estructura es de tipo IRF, la log odds de que se produzca transferencia, en comparación con la estructura de tipo IRE, es de 1.591.

El análisis de las interacciones entre predictores ha resultado en que únicamente la interacción entre formato de la tarea y estructura de participación ha sido estadísticamente significativa: $\chi^{2}(6)=49.832, p=.000$. En consecuencia, se optó por simplificar en lo posible los análisis evitando la inclusión de interacciones. 
Capitulo 2: ESTUDIO EMPÍRICO

Tabla 20

Análisis de los estimadores de máxima verosimilitud

\begin{tabular}{|c|c|c|c|c|c|c|c|}
\hline Parámetro & & & GL & $\beta$ & $\mathrm{EE}$ & $\chi^{2}$ Wald & $p$ \\
\hline Intercept & & & 1 & -0.2076 & 0.2025 & 1.0518 & 0.3051 \\
\hline$\overline{A Y U}$ & 1 & cálida & 1 & -0.5043 & 0.1864 & 7.3184 & 0.0068 \\
\hline AYU & 2 & feedback & 1 & -0.1045 & 0.1579 & 0.4385 & 0.5079 \\
\hline AYU & 3 & interna & 1 & 0.3891 & 0.2829 & 1.8920 & 0.1690 \\
\hline AYU & 4 & regulatoria & & & & & \\
\hline FOR & 1 & ex_ej_cc & 1 & -0.0869 & 0.1641 & 0.2806 & 0.5963 \\
\hline FOR & 2 & ex_cc & 1 & -1.4007 & 0.1802 & 60.4115 & $<.0001$ \\
\hline FOR & 3 & ex_ej & 1 & -0.8187 & 0.2361 & 12.0223 & 0.0005 \\
\hline FOR & 4 & ex & & & & & \\
\hline$\overline{E S T}$ & 1 & dialógica & 1 & 2.0226 & 0.1803 & 125.7802 & $<.0001$ \\
\hline EST & 2 & IRF & 1 & 1.5911 & 0.1629 & 95.4089 & $<.0001$ \\
\hline EST & 3 & IRE & & & & & \\
\hline
\end{tabular}

\section{Estadísticos de bondad del ajuste}

Los estadísticos de bondad del ajuste evalúan en qué medida el modelo logístico se ajusta a los datos empíricos. Se ha utilizado una prueba inferencial y tres medidas descriptivas. La prueba inferencial es el test de Hosmer-Lemeshow (HL) que ha resultado en un valor $\chi^{2}(8)=28.82, p=.0003$, lo que sugiere un relativo desajuste del modelo a los datos. Con todo, este resultado debe tomarse con precaución, a la vista de las limitaciones de la prueba (Allison, 2013; 2013; Kuss, 2001). Debido a tales limitaciones, se calculó, mediante la macro goflogit para SAS (Kuss, 2001) la prueba estándar de Pearson (Standard Pearson Test), obteniéndose un valor de 1525.436, $\mathrm{p}=.331$, lo que denota un ajuste satisfactorio del modelo a los datos empíricos.

Se ha desarrollado una cantidad considerable de medidas descriptivas de la bondad del ajuste. Entre las muchas disponibles (Menard, 2000; Mittlböck \& 


\section{Método}

Schemper, 1996) se han elegido las que presentamos a continuación, por ser las de más amplio uso en este tipo de estudios. Se trata de los coeficientes pseudo R2 definidos como el coeficiente de determinación generalizado de Cox y Snell (1989), el coeficiente de determinación ajustado de Nagelkerke (1991) y el coeficiente R2 de McFadden (1973) respectivamente. Estos índices son variaciones del coeficiente R2 usado en la regresión OLS. A diferencia de R2, estos valores no representan la proporción de varianza de la variable dependiente explicada por el conjunto de variables predictoras, ni tampoco se refieren estrictamente a la eficacia predictiva (Long, 1997; Menard, 2000). Por estas razones, han de considerarse mutuamente complementarios, útiles como elementos evaluativos (como, por ejemplo, la evaluación global del modelo a que más arriba hemos aludido), o como estadísticos de bondad del ajuste (Peng, Lee, \& Ingersoll, 2002). En nuestros datos se han obtenido R2Cox \& Snell $=.154$ (IC $95 \%=.121-.187) ;$ R2Nagelkerke $=.211$ (IC 95\% = .174 - .247); R2McFadden $=.128($ IC 95\% $=.097-.160)$. A la vista de la controversia en torno a cuál de los valores R2 es el más adecuado para su uso en regresión logística (Allison, 2012; Mittlböck \& Schemper, 1996), se ha calculado también el recomendado por el propio Allison, el R2 de Tjur (Tjur, 2009), que viene dado por la diferencia entre las medias de los coeficientes estimados para ambos grupos (observaciones con y $=1$ y observaciones con $y=0$ ) en la variable criterio. El resultado ha sido R2Tjur $=.164$ (IC 95\% = .130 - .198). Puesto que valores de pseudo-R2 cercanos a cero indican que el modelo especificado no ha mejorado el modelo nulo (restringido al término independiente), en términos generales, los valores R2 obtenidos denotan una asociación débil, tomando como puntos de corte $\mathrm{R} 2<.3$ (débil) $.3<\mathrm{R} 2<.6$ (moderada) y R2 > 6 (fuerte) según la propuesta de Garson (2014).

\section{Validaciones de las probabilidades estimadas}

Como más arriba quedó dicho, la regresión logística predice el logit de un evento a partir de un conjunto de predictores. Debido a que el logit es el logaritmo natural de la odds (o probabilidad / [1-probabilidad]), puede transformarse de 
nuevo a la escala de probabilidad. Las probabilidades predichas resultantes pueden revalidarse entonces con el resultado real para determinar si, efectivamente, las probabilidades altas están asociadas con la ocurrencia del evento y las bajas con la no ocurrencia del evento. El grado en que las probabilidades predichas concuerda con las observaciones empíricas se expresa en diversas medidas de asociación y mediante una tabla de clasificación. El propósito de ambas estrategias se centra en evaluar la capacidad predictiva del modelo. Las medidas de asociación utilizadas en el presente estudio han sido Tau-a de Kendall, Gamma de Goodman-Kruskal, D de Somers y el índice de concordancia c. El número de pares fue 524573 (i.e., el producto de 959 observaciones calificadas con 'transferencia' por las 547 observaciones calificadas como 'no transferencia'). La pregunta a responder es: Un caso calificado con 1 (transferencia) ¿tiene un valor predicho más alto que un caso calificado con 0 (no transferencia)? La proporción de pares concordantes, esto es, pares de observaciones con respuestas observadas distintas en los que la observación con el valor de respuesta más bajo (transferencia $=0$ ) tienen una puntuación media estimada inferior a la del valor de respuesta más alto (transferencia $=1$ ) fue del $73.1 \%$. Lo contrario sucede con los pares discordantes. i.e., pares de observaciones con respuestas observadas distintas en los que la observación con el valor de respuesta más bajo (transferencia $=0$ ) tienen una puntuación media estimada superior a la del valor de respuesta más alto (transferencia $=1$ ). La proporción de pares discordantes ha sido del $22.5 \%$. Finalmente, se ha observado un $4.4 \%$ de empates (i.e., pares ni concordantes ni discordantes). En todas las medidas de asociación utilizadas, $\mathrm{N}$ es la suma de frecuencias observadas en los datos, $\mathrm{t}$ es el total de pares con respuestas diferentes, nc el número de pares concordantes, nd el número de pares discordantes y (t-nc-nd) el número de empates.

El estadístico Tau-a es el coeficiente de correlación por rangos de Kendall sin ajustes para empates. Se define como la ratio de la diferencia entre el número de pares concordantes y el número de pares discordantes respecto al número de pares posible: $\tau_{-} \mathrm{a}(\mathrm{nc}-\mathrm{nd}) /(0.5 \mathrm{~N}(\mathrm{~N}-1))$. En nuestro caso se ha obtenido 
$\tau_{-} \mathrm{a}=.234$. Se trata de una modificación del coeficiente $\mathrm{D}$ de Somers que toma en consideración la diferencia entre el número de observaciones apareadas posibles y el número de observaciones apareadas con una respuesta diferente. Normalmente Tau-a es más pequeño que D de Somers, dado que son posibles muchas observaciones apareadas con la misma respuesta.

El estadístico Gamma se basa en $\tau_{-}$a de Kendall, pero con ajustes para los empates. Se define como $\gamma=(\mathrm{nc}-\mathrm{nd})(\mathrm{nc}+\mathrm{nd})$ y su rango teórico va de -1.0 (ausencia de asociación) a 1.0 (asociación perfecta). Se ha obtenido un valor $\gamma=.530$. Este resultado se interpreta como el 53\% menos de errores cometidos en la predicción de cuál de dos observaciones cualesquiera resultará en notransferencia usando las probabilidades estimadas por el modelo que si se utilizara el mero azar (DeMaris, 1992).

El estadístico D de Somers se usa para determinar la fuerza y la dirección de una relación entre pares de variables. Su rango teórico va de -1.0 (todos los pares en desacuerdo) a 1.0 (todos los pares de acuerdo). Se define como $\mathrm{D}=((\mathrm{nc}-\mathrm{nd})) / \mathrm{t}$. En nuestro estudio, $\mathrm{D}$ equivale a la diferencia entre el porcentaje de pares concordantes y el porcentaje de pares discordantes dividido por 100: $(73.1-22.5) / 100=.507$. Disponemos de dos formas asimétricas de D: Dxy y Dyx. Solamente Dyx representa correctamente el grado de asociación entre el resultado $(\mathrm{y})$ o variable dependiente y la probabilidad estimada $(\mathrm{x})$, designada como variable independiente (DeMaris, 1992). Puesto que el software disponible solo ofrece Dxy, se ha corregido a Dyx utilizando un algoritmo ad hoc en SAS. En nuestros datos se han obtenido Dxy $=.507$ y Dyx $=.249$.

Finalmente, el índice de concordancia c representa la proporción de pares de casos con diferentes resultados (i.e., transferencia o no transferencia) para los cuales el modelo predice correctamente una probabilidad más alta para las observaciones en las que se ha constatado transferencia que para las observaciones en las que se ha constatado no transferencia. Se define como $\mathrm{c}=((\mathrm{nc}+0.5)(\mathrm{t}-\mathrm{nc}-\mathrm{nd}))) / \mathrm{t}$. 


\section{Capitulo 2: ESTUDIO EMPÍRICO}

En el modelo analizado, se ha obtenido un valor $\mathrm{c}=.753$, lo que significa que para el $75.3 \%$ de todos los pares posibles de observaciones (i.e., un par en que se ha constatado transferencia y otro en que se ha constatado no transferencia) el modelo asigna correctamente una probabilidad más alta a aquellos casos en los que se ha observado transferencia. Como se puede apreciar en la Figura 22, c coincide con AUC (el área bajo la curva en una curva $\mathrm{ROC}$ ). El rango teórico de c va de 0.5 a 1 . Un valor de 0.5 indica que el modelo no es mejor que la asignación aleatoria (i.e., asignar al azar las observaciones a las categorías de resultado -transferencia y no transferencia), en tanto que un valor de 1 significa que el modelo realiza una discriminación perfecta de la respuesta.

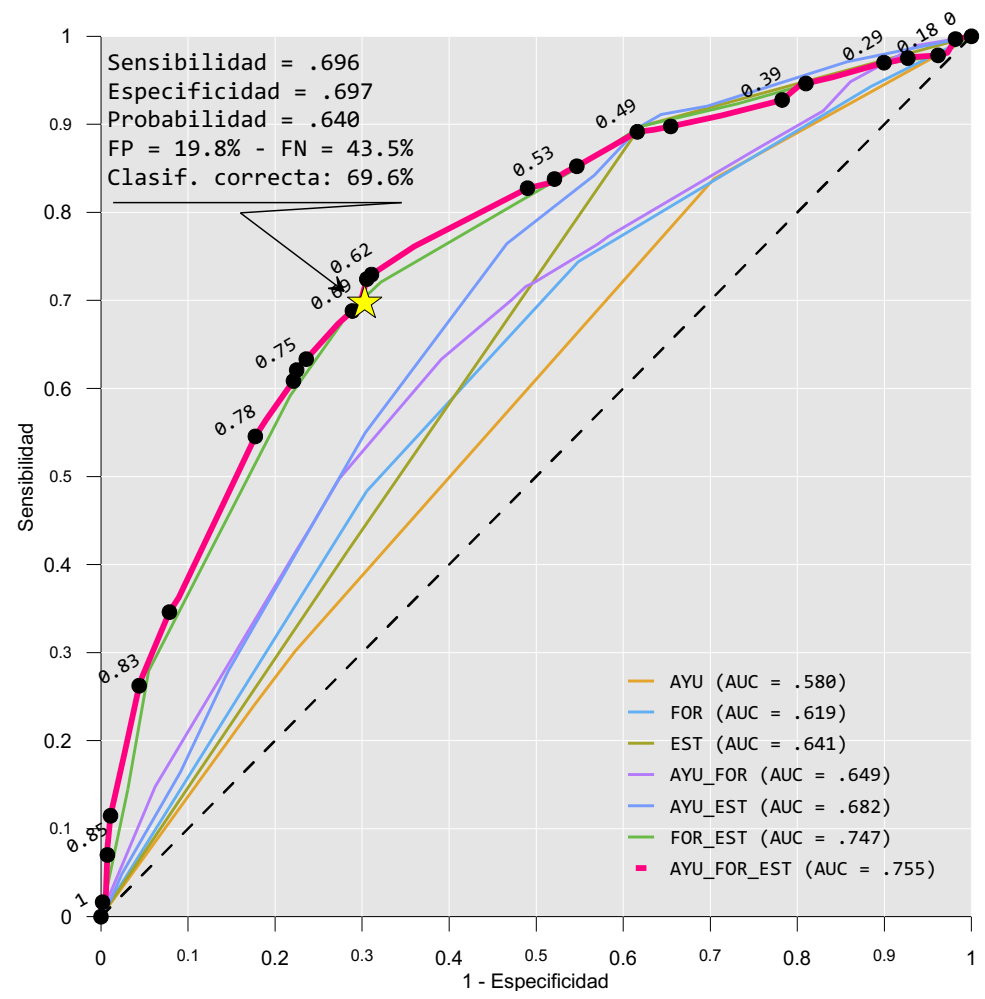

Figura 22. Comparación de curvas ROC con distintas combinaciones de predictores. 


\section{Método}

Los números en la curva ROC 'AYU_FOR_EST' de la Figura 22 indican thresholds o puntos de corte (probabilidad estimada) a lo largo de las diferentes combinaciones entre sensibilidad y especificidad. El contraste de las siete curvas ROC obtenidas ha conducido a las siguientes conclusiones: (a) los valores de AUC y D de Somers indicaron que la variable predictora Estructura de Participación es la que presenta mejor poder clasificatorio, toda vez que si se omite dicha variable se obtiene $\mathrm{AUC}=.648, \mathrm{D}=.297$ ) seguida de Formato de la tarea $(\mathrm{AUC}=.656 ; \mathrm{D}=311$ ) y Ayuda (AUC $=.742 ; \mathrm{D}=.483$ ); (b) la conclusión anterior queda refrendada por el contraste entre el modelo completo y el modelo omitiendo Estructura de Participación $\left(\chi^{2}=65.304, \mathrm{p}=.000\right)$, el contraste entre el modelo completo y el modelo omitiendo Formato $\left(\chi^{2}=58.158\right.$, $\mathrm{p}=.000)$ y el contraste entre el modelo completo y el modelo omitiendo Ayuda $\left(\chi^{2}=7.231, p=.007\right)$ y (c) han resultado significativos los contrastes entre omitir Ayuda y omitir Formato $\left(\chi^{2}=33.322, \mathrm{p}=.007\right)$ y entre omitir Ayuda y omitir Estructura de Participación $\left(\chi^{2}=37.932, p=.000\right)$, pero no entre omitir Formato y omitir Estructura de Participación $\left(\chi^{2}=0.138, \mathrm{p}=.710\right)$.

\section{Odds ratios}

En la Figura 23 se presentan las odds ratios, tanto de cada predictor frente al predictor de referencia (i.e., el último de cada listado de categorías), como entre todos los pares de predictores. Como se ha comentado en el apartado 8.4.1 Análisis multivariado, la odds de un evento es la razón de la probabilidad de que el evento ocurra y la probabilidad de que no ocurra, y equivale al exponente de las estimaciones $\beta$. Por ejemplo, la odds ratio 1.48 (AYU_inte vs AYU_regu) nos dice que la odds estimada de que se produzca transferencia cuando la ayuda es interna es 1.48 veces la odds de cuando la ayuda es regulatoria. En otras palabras, la odds de que se constate transferencia del aprendizaje si la ayuda es interna es un $48 \%$ mayor que si la ayuda es regulatoria. Pese a que esta odds no es estadísticamente significativa (ya que el intervalo de con- 


\section{Capitulo 2: ESTUDIO EMPÍRICO}

fianza incluye el valor 1 como puede apreciarse en la Figura 23), es nuestra mejor estimación del efecto de esta variable.

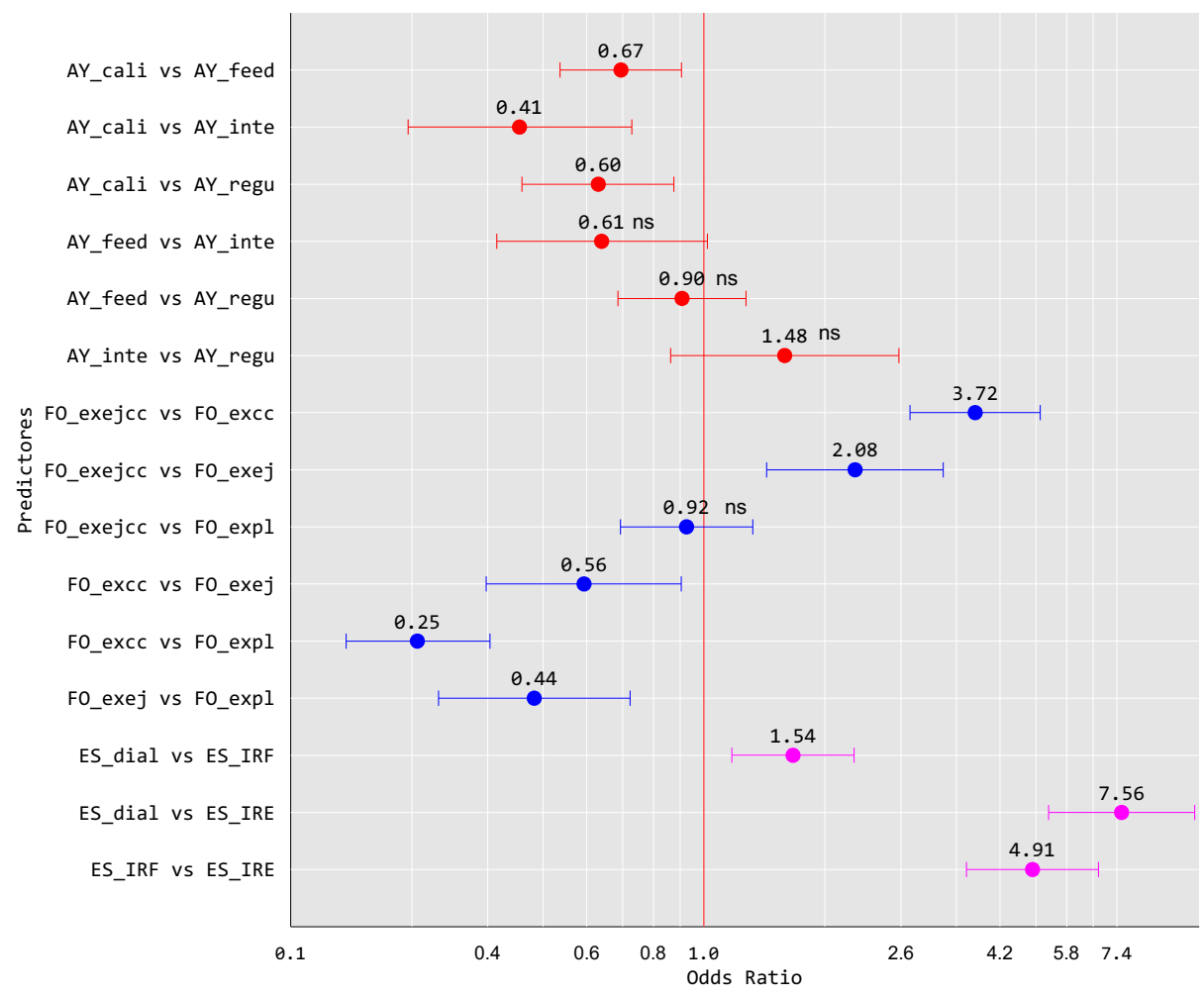

Figura 23. Odds ratios con límites de confianza (95\%) de Wald.

Del mismo modo, cuando la estructura de participación es dialógica, la odds de que se produzca transferencia es 7.56 veces mayor que si la estructura es IRE. Cuando la estructura es IRF, la odds de que se observe transferencia es 4.91 veces mayor que si la estructura es IRE. Del mismo modo se interpretaría el resto de las odds ratios, con excepción de AYU 2 vs 3 (i.e., feedback frente a interna), AYU 2 vs 4 (i.e., feedback frente a regulatoria), AYU 3 vs 4 (i.e., interna frente a regulatoria) y FOR 1 vs 4 (i.e., explicación-ejemplos-contexto cercano frente a explicación): en los cuatro casos el valor 1 está incluido en el intervalo de confianza al 95\%, por lo que no podemos rechazar la hipótesis nula de que los correspondientes coeficientes de regresión $\beta$ sean iguales a cero (y, 
en consecuencia, las odds ratios iguales a 1 , dados los restantes predictores presentes en el modelo). Además de las odds ratios, en la Figura 23 se presentan los límites de confianza de Wald (95\%) de cada odds ratio individual, manteniendo constantes los demás predictores presentes en el modelo.

La interpretación es simple: para una variable predictora determinada, con un nivel de confianza del 95\%, podemos afirmar que en pruebas repetidas el 95\% de los intervalos de confianza incluirán el valor verdadero de la odds ratio en la población.

Además de las medidas a las que se ha aludido en los párrafos precedentes, en la Tabla 21 puede observarse el resultado de la clasificación de los casos utilizando como punto de corte .50 . Pese a que existe cierta controversia al respecto (Allison, 2012), hemos considerado el mejor punto de corte como aquel en que los valores de sensibilidad y especificidad son más similares, a la par que es mayor el porcentaje global de casos correctamente clasificados. En nuestro caso, el punto de corte de probabilidad en que tales valores son similares es .640. Observamos que, en dicho punto de corte, de los 547 casos en los que se constató no-transferencia, el modelo ha clasificado correctamente a 382 , e incorrectamente a 165, con lo que se obtiene una especificidad del 69.8\%. De forma contraria, de los 959 casos en los que se observó transferencia, el modelo ha clasificado incorrectamente 291 , y correctamente 668 , con lo que se ha obtenido una sensibilidad del $69.7 \%$ (el resumen de la representación gráfica de estos resultados se constata en la curva ROC de la Figura 24). La tasa de clasificación correcta global es del $69.7 \%$. La tasa de falsos positivos ha sido $19.8 \%$, y la de falsos negativos $43.2 \%$. En consecuencia, el modelo se muestra considerablemente más eficaz para clasificar correctamente los casos de transferencia que los de no transferencia. 
Capitulo 2: ESTUDIO EMPÍRICO

Tabla 21

Tabla de clasificación

\begin{tabular}{|c|c|c|c|c|c|c|c|c|c|}
\hline & \multicolumn{2}{|c|}{ Correctos } & \multicolumn{2}{|c|}{ Incorrectos } & \multirow[b]{2}{*}{ 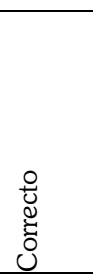 } & & \multicolumn{2}{|c|}{ Porcentaje } & \multirow[b]{2}{*}{ 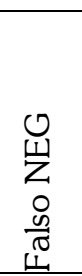 } \\
\hline & & 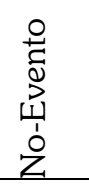 & 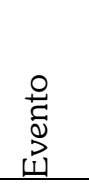 & 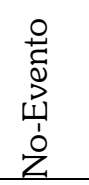 & & & 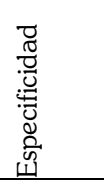 & 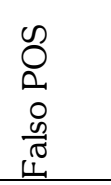 & \\
\hline 0.100 & 959 & 0 & 547 & 0 & 63.7 & 100.0 & 0.0 & 36.3 & \\
\hline 0.200 & 935 & 40 & 507 & 24 & 64.7 & 97.5 & 7.3 & 35.2 & 37.5 \\
\hline 0.300 & 929 & 57 & 490 & 30 & 65.5 & 96.9 & 10.4 & 34.5 & 34.5 \\
\hline 0.400 & 884 & 120 & 427 & 75 & 66.7 & 92.2 & 21.9 & 32.6 & 38.5 \\
\hline 0.500 & 809 & 229 & 318 & 150 & 68.9 & 84.4 & 41.9 & 28.2 & 39.6 \\
\hline 0.600 & 704 & 346 & 201 & 255 & 69.7 & 73.4 & 63.3 & 22.2 & 42.4 \\
\hline 0.640 & 668 & 382 & 165 & 291 & 69.7 & 69.7 & 69.8 & 19.8 & 43.2 \\
\hline 0.700 & 612 & 410 & 137 & 347 & 67.9 & 63.8 & 75.0 & 18.3 & 45.8 \\
\hline 0.800 & 227 & 520 & 27 & 732 & 49.6 & 23.7 & 95.1 & 10.6 & 58.5 \\
\hline 0.900 & 0 & 546 & 1 & 959 & 36.3 & 0.0 & 99.8 & 100.0 & 63.7 \\
\hline 0.920 & 0 & 547 & 0 & 959 & 36.3 & 0.0 & 100.0 & . & 63.7 \\
\hline
\end{tabular}

Una representación gráfica de la clasificación de las observaciones en función de las probabilidades estimadas se ofrece en la Figura 24, en la que se señalan los diferentes valores obtenidos tomando como puntos de corte las probabilidades estimadas de .5 y .64 . 


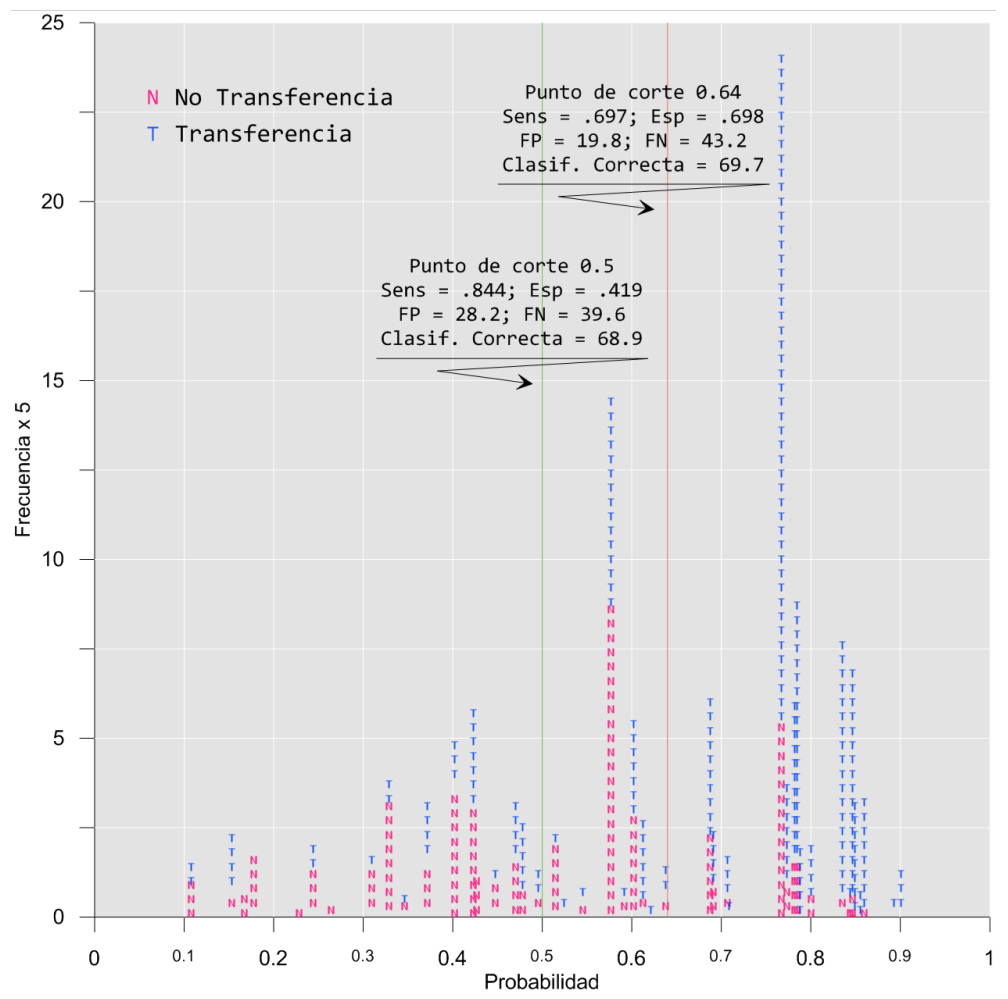

Figura 24. Clasificación de los casos.

Nota: Sens $=$ Sensibilidad; Esp $=$ Especificidad; FP $=$ Falsos Positivos; FN $=$ Falsos Negativos. Cada símbolo representa 5 casos.

\section{Análisis de los residuos}

Se realizó por último un análisis de residuos (Figura 25) para comprobar si existían casos ('influential observations') que pudieran tener un impacto significativo sobre modelo logístico. El análisis de los residuos es fundamental por dos razones: (a) para detectar y, en su caso, aislar los puntos en los que el modelo muestra un ajuste pobre y (b) para comprobar si existen puntos que ejercen una influencia indebida sobre el modelo. Para analizar los primeros calculamos para cada observación los residuos estandarizados de Pearson (i.e., diferencia estandarizada entre la frecuencia observada y la estimada), los residuos de desvia- 


\section{Capitulo 2: ESTUDIO EMPÍRICO}

ción -deviance residuals- (i.e., raíz cuadrada de -2 x el log de la probabilidad estimada para el grupo observado, añadiendo signo negativo si la transferencia no ha tenido lugar en ese caso) y los residuos estudentizados (i.e., cambio en la desviación del modelo si el caso es excluido). Para examinar los segundos, se utilizaron los estadísticos de influencia DFBeta, $\Delta \Delta \mathrm{l}, \Delta \chi 2 \mathrm{l}$, distancia de Cook y leverage.
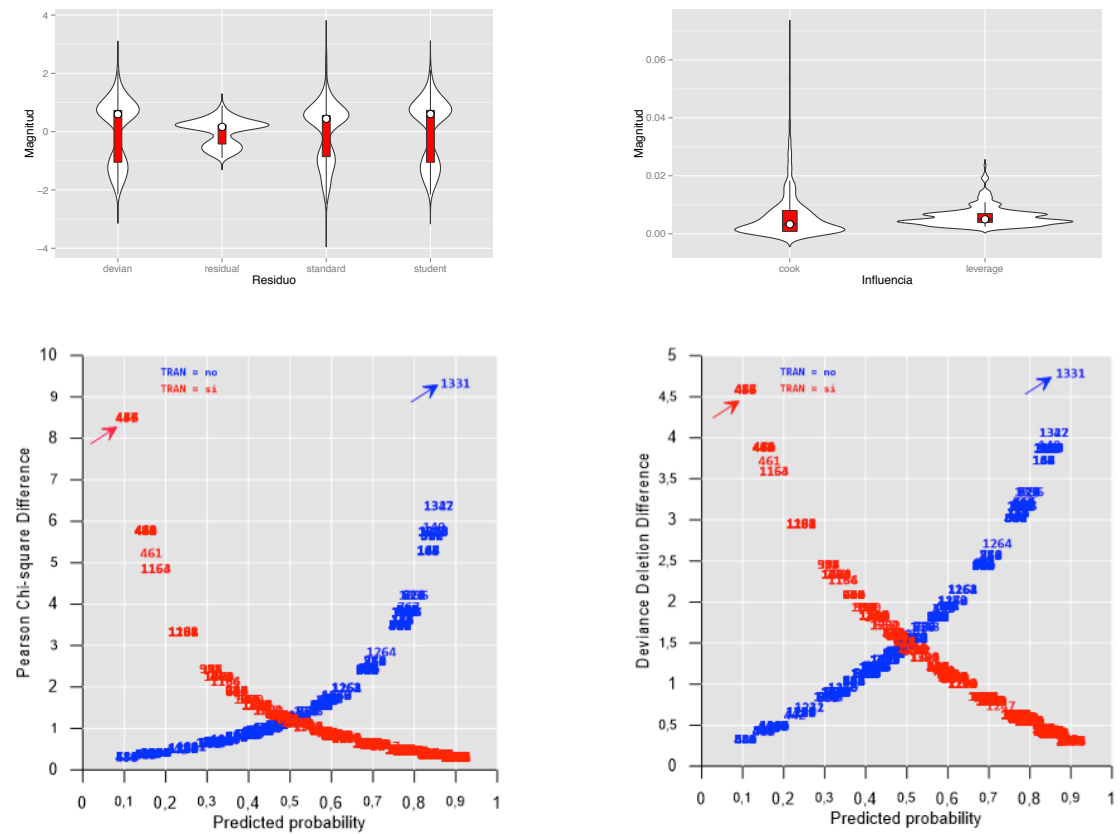

Figura 25. Diagnóstico de los residuos y estadísticos de influencia.

Nota: Panel superior izquierdo: Distribución de valores deviance, residuos, residuos estandarizados y residuos estudentizados. devian $=$ deviance; residual $=$ residuo (diferencia pronosticado / observado); standard $=$ standardized residuals; student $=$ studentized residuals. Panel superior derecho: Distribución de estadísticos de influencia (distancias de Cook y valores Pregibon leverage).

Panel inferior izquierdo: Pearson Chi-square Deletion Differences by Predicted Probabilities para TRAN. Panel inferior derecho: Deviance Deletion Differences by Predicted Probabilities para TRAN. En ambos gráficos los números corresponden al número de caso. 


\section{Método}

En la Figura 25 (panel superior) se muestran las densidades de las distribuciones de los residuos estandarizados y estudentizados, junto con sus medias y cuartiles. Como se puede apreciar en las distribuciones representadas, los residuos se agrupan en torno al valor cero, siendo irrelevante el número de valores 'outliers' o extremos. En el panel inferior se muestran dos dispersigramas de las probabilidades estimadas frente a los valores $\Delta \Delta \mathrm{l}$ (deviance influence statistics o contribución de cada observación al chi-cuadrado de la desviación) y $\Delta \chi 21$ (diferencias en chi-cuadrado si se elimina el caso o contribución de cada observación al chi-cuadrado de Pearson). En ambos gráficos, la curva roja denota las observaciones en las que se ha constatado transferencia, y la azul aquellas en las que se ha constatado no transferencia. De acuerdo con Hosmer et al. (2013) estos gráficos son sumamente útiles para el diagnóstico del modelo. En concreto, siete de los casos $(0.46 \%)$ presentan valores que denotan un impacto significativo sobre el modelo y deberían, en consecuencia, revisarse o eliminarse.

Finalmente, en la Tabla 22 se ofrece un resumen tanto de los residuos como de los estadísticos de influencia. 
Tabla 22

Residuos y estadísticos de influencia

\begin{tabular}{|c|c|c|c|c|}
\hline & Media & Máx & Mín & Interpretación \\
\hline \multicolumn{5}{|l|}{ Residuos } \\
\hline $\begin{array}{l}\text { Residuos es- } \\
\text { tandarizados }\end{array}$ & 0.017 & 2.876 & $\overline{-}$ & $\begin{array}{l}\text { De los residuos estandarizados, } 51 \\
(3.39 \%) \text { son superiores a |1.96|. De } \\
\text { ellos, } 7(0.46 \%) \text { son superiores a } \\
|2.58| .\end{array}$ \\
\hline $\begin{array}{l}\text { Estadísticos de } \\
\text { deviance }\end{array}$ & 0.084 & 2.110 & $\begin{array}{l}- \\
2.149\end{array}$ & $\begin{array}{l}\text { Entre los valores de deviance, } 9 \\
(0.60 \%) \text { son superiores a }|1.96| \text {. } \\
\text { Ninguno es superior a }|2.58| .\end{array}$ \\
\hline $\begin{array}{l}\text { Residuos es- } \\
\text { tudentizados }\end{array}$ & 0.084 & 2.115 & $\begin{array}{l}- \\
2.157\end{array}$ & $\begin{array}{l}\text { De los residuos estudentizados, } 9 \\
(0.60 \%) \text { son superiores a }|1.96| \text {. } \\
\text { Ninguno es superior a }|2.58| \text {. }\end{array}$ \\
\hline
\end{tabular}

Estadísticos de Influencia

DfBeta (cons- $0.000 \quad 0.026$ - $\quad$ Los valores DfBeta tanto para la constante) 0.022 tante como para los predictores son DfBeta (pre- $0.000 \quad 0.039$ - en todos los casos inferiores a 1. dictores) $\quad 0.056$

\begin{tabular}{|c|c|c|c|}
\hline DIFDEV & $\begin{array}{ll}1.149 \quad 4.686\end{array}$ & 0.210 & \\
\hline DIFCHISQ & 1.0079 .130 & $\overline{0.111}$ & $\begin{array}{l}435,436,445,457,466 \text { y } 472 \text { (trans- } \\
\text { ferencia) muestran una influencia } \\
\text { significativa (i.e, } \Delta \chi^{2}, \text { o } \Delta \Delta_{\imath}>3.84 \text { ). }\end{array}$ \\
\hline
\end{tabular}

Distancia de $\quad 0.006 \quad 0.069 \quad 0.001 \quad$ En todos los casos las distancias de Cook (D) Cook son inferiores a 1.

Leverage (h) $\quad \begin{array}{lllll}0.006 & 0.024 & 0.002 & \text { Ningún caso presenta un leverage }\end{array}$ observado superior a 0.2 .

De acuerdo con los resultados del análisis de los residuos sintetizados en la Tabla 22, se concluye que (a) la mayoría (99.5\%) de los residuos estudentizados fue inferior a $|2|$; (b) por su parte, aunque en una proporción algo menor, también la mayoría de los residuos estandarizados (96.9\%) fueron inferiores a $|2|$, y ninguno superó $|3|$, por lo que descartamos la presencia de outliers o valores atípicos o extremos; (c) finalmente, en lo referente a los estadísticos de 
desviación (deviance), únicamente $9(0.60 \%)$ fueron superiores a $|1.96|$, y ninguno fue superior a $|2.58|$, por lo que no se ha considerado oportuno la eliminación de ninguna de las 1506 observaciones analizadas.

En lo referente a los estadísticos de influencia, los resultados han sido los siguientes: (a) todos los casos los valores DfBeta (que evalúan cuánto cambia cada uno de los coeficientes de regresión cuando se elimina una observación y, por tanto, indican en qué casos concretos el modelo presenta desajuste), tanto para la constante como para los predictores fueron inferiores a 1 (i.e., valor crítico para considerar la existencia de desajuste); (b) los valores 'deviance influence' $\Delta \Delta$ i (i.e., qué cambio se produce en la desviación cuando se elimina una observación) han revelado que siete de los casos ejercen impacto sobre el modelo logístico (seis casos, $\Delta \Delta \mathrm{l}=4.491$; caso $1331, \Delta \Delta \mathrm{l}=4.686$ ); (c) los valores de diferencias en chi-cuadrado $\Delta \chi 2 \imath$ (i.e., qué cambio se produce en el valor chi-cuadrado de Pearson cuando se elimina una observación) han identificado esos siete mismos casos como muy alejados del resto (seis casos, $\Delta \chi 21=$ 8.307; caso 1331, $\Delta \chi 21=9.130$ ); (d) los valores leverage (h) evalúan cuán extrema es cada una de las observaciones en el espacio de las variables predictoras (Cook, 1998). El nivel de leverage se sitúa entre 0 (la observación no ejerce influencia sobre el modelo) y 1 (la observación ejerce una influencia o determinación completa sobre el modelo). Habitualmente, se considera alto el leverage cuando es superior a $2 \mathrm{k} / \mathrm{n}$, donde $\mathrm{k}$ es el número de predictores no referencia (8 en nuestros datos) y n el tamaño de la muestra. Este punto de corte equivale a dos veces el leverage promedio, i.e., $\mathrm{k} / \mathrm{n}$. Los casos con $\mathrm{h}<.2$ no suelen considerarse problemáticos. En los casos con $\mathrm{h}>.5$ debería examinarse la posibilidad de un error de medida excesivo y, en consecuencia, la conveniencia de su eliminación. En nuestros datos, el leverage promedio ha sido h $=.006, \mathrm{DE}=.003$. En ninguna de las observaciones se ha superado el valor $\mathrm{de} \mathrm{h}=.2$, por lo que concluimos que no existen observaciones individuales que ejerzan influencia reseñable sobre el modelo; y (e) tampoco se han apreciado valores altos en las distancias $\mathrm{D}$ de Cook (función del leverage del caso y de su 
residuo estandarizado, que evalúa en qué medida la eliminación de un caso afecta a los residuos del resto de casos). Ninguno de los valores superó 1 (Cook, 1998), abarcando un rango de .001 a .069 , lo que implica que no existen casos de influencia que tengan efecto sobre el modelo.

\section{Marginales}

Para entender mejor los resultados del modelo, se han utilizado las probabilidades estimadas mediante el cálculo de los marginales. Así, tomando en consideración la clase de ayuda prestada, la probabilidad estimada de que se produzca transferencia utilizando ayuda interna ha sido .761; con ayuda regulatoria, .684; con ayuda feedback, .660; y con ayuda cálida, .566 (manteniendo constantes los predictores formato de la tarea y estructura de participación). Si consideramos el formato de la tarea, la probabilidad de transferencia con tareas que incluyen explicación ha sido .748; con explicación, ejemplos y contexto cercano, .732; con explicación y ejemplos, .568; con explicación y contexto cercano, .423 (manteniendo constantes ayuda y estructura). En lo que atañe a la estructura de participación, la probabilidad de transferencia con estructura dialógica ha sido .772; con estructura IRF, .687; y con estructura IRE, .309 (manteniendo constantes ayuda y formato de la tarea). En todos los casos el valor de p ha sido .000 .

\subsubsection{Grado de cumplimiento o verificación de las hipótesis}

De acuerdo con los resultados expuestos en los apartados anteriores, revisamos a continuación el grado de cumplimiento de las hipótesis planteadas:

1. Hipótesis 1: Los entornos comunicativos de aprendizaje facilitan y potencian la transferencia de los conocimientos entre diferentes áreas curriculares.

La hipótesis que planteamos como central en nuestra investigación ha quedado en gran medida verificada según los resultados obtenidos en los distintos análisis. De una parte, los resultados de la regresión logística, odds ratio, mostraban un $75,6 \%$ más de probabilidades de que se produjera transferencia 
cuando la estructura de participación llevada a cabo en el aula era de tipo dialógico frente a IRE. De otra parte, el análisis multivariado puso de relieve un predominio de estructuras eminentemente dialógicas (IRF y dialógicas) cuando se llevaban a cabo procesos de transferencia del aprendizaje.

Estos mismos resultados nos permiten asimismo afirmar que se han corroborado las hipótesis 2 (El tipo de estructura de participación influye en la transferencia del conocimiento) y 3 (La estructura dialógica produce más transferencia que el resto de estructuras de participación).

2. Hipótesis 4: El tipo de ayuda repercute positivamente en la transferencia.

En lo referente a la repercusión de la ayuda sobre la transferencia observamos que esta variable se erige como la tercera variable predictora de la misma. $\mathrm{Si}$ bien es preciso reconocer que con nuestros datos tanto la estructura de participación como el formato de la tarea presentaron un poder predictivo mayor sobre las diferentes formas de transferencia del aprendizaje, también la ayuda se ha mostrado como un predictor relevante.

3. Hipótesis 5: El tipo de formato de la tarea influye positivamente en la transferencia.

En cuanto a la influencia del formato de la tarea, veíamos como esta es la segunda variable que más influye sobre la transferencia. En consecuencia, los resultados parecen avalar esta hipótesis.

4. Hipótesis 6: La estructura, la ayuda y el formato de la tarea afectan conjuntamente de modo positivo a la transferencia.

Tal como nos mostraron los resultados de los modelos de predicción, al tomar la transferencia como variable dependiente o criterio se constata una influencia marcada de ese conjunto de variables sobre la transferencia del aprendizaje. 
Como mencionábamos con anterioridad, cada una de ellas influye con distinto grado de intensidad siendo la estructura de participación la variable que más influye sobre la transferencia.

Una vez que hemos presentado los resultados de los diversos análisis de los datos de nuestra investigación tenemos suficiente información para proceder a realizar una discusión de los mismos para poder concluir con los aspectos más relevantes que se desprenden de este estudio. Para ello, el siguiente apartado lo dedicaremos a la discusión de los datos, a las aportaciones finales, así como al planteamiento de futuras vías de investigación.

\section{Discusión, limitaciones e implicaciones para investigaciones fu- turas}

Este apartado constituye una recopilación de las principales aportaciones del trabajo de investigación propuesto a lo largo de los apartados previos. Para tal fin, el apartado se divide en tres subapartados. El primer apartado pretende cerrar el ciclo de investigación llevado a cabo en el estudio empírico con la discusión de los datos obtenidos.

En el segundo apartado nos ocuparemos de mostrar las aportaciones finales del estudio en el que plantearemos los principales hallazgos, la interacción entre los aspectos cualitativos y cuantitativos de la investigación, así como algunas de las limitaciones para poner de relieve las principales restricciones que se han interpuesto durante el proceso investigador.

Para concluir, cerraremos el ciclo con la declaración de intenciones respecto a futuras vías de investigación a partir de ahora.

\subsection{Discusión}

Los entornos comunicativos de aprendizaje son un espacio de construcción conjunta del conocimiento en el que confluyen distintas personas, capacidades e ideas para llegar una visión común a través de la interacción entre los miembros que participan. La transferencia es una parte esencial de ese proceso de 
9. Discusión, limitaciones e implicaciones para investigaciones futuras

aprendizaje que permite poner en práctica aquellos aprendizajes que se construyeron de manera conjunta y emplearlos también de manera conjunta. Es sabido ya del complejo proceso de transferencia y su propia identificación dentro del proceso de enseñanza-aprendizaje. Cada una de las variables que forman parte de este estudio conforma una parcela de vital importancia para que la transferencia se produzca de manera efectiva. En este apartado, expondremos y discutiremos los principales hallazgos acerca de cada una de estas variables y cómo éstas influyen en el proceso de aprendizaje en general y de la transferencia en particular.

Cada vez son más los estudios dentro de las ciencias de la educación que demuestran la importancia del diálogo como herramienta desde la que construir el conocimiento en las aulas escolares (Lave \& Wenger, 1991; Rogoff et al., 2002). Consideramos que una buena forma de aportar evidencias acerca del diálogo y la capacidad de mejorar los procesos de aprendizaje en los escolares, es mediante la relación del diálogo con la transferencia de aquello que aprenden. Es decir, el aprendizaje a través del diálogo puede ser capaz de generar un pensamiento en el estudiante capaz de aplicar aquello que se ha adquirido a otras materias disciplinares incluso a otros escenarios.

A continuación, organizaremos este apartado teniendo en cuenta los resultados obtenidos por los diversos análisis llevados comenzando por el análisis preliminar de los datos, los modelos obtenidos, así como la predicción sobre la variable dicotómica transferencia/no transferencia.

\subsubsection{Análisis preliminar}

Los análisis previos realizados sobre los datos (análisis multivariado) son reveladores para los ulteriores análisis (log-lineal y regresión logística). Sin embargo, esta parte más descriptiva del estudio nos aporta información relevante sobre el proceso educativo llevado a cabo lo que permite extraer conclusiones más generales orientadas principalmente a la propia práctica educativa. 


\section{Capitulo 2: ESTUDIO EMPÍRICO}

Los datos obtenidos en las frecuencias de las variables ponen de manifiesto que la estructura de participación más concurrente fue la estructura IRE revelando la posibilidad de fallos en la puesta en práctica de los grupos interactivos, ya que es esperable que se produzca una mayor frecuencia de estructura dialógica. Las causas subyacentes a esta situación pueden deberse por un lado debido a razones de tipo docente y por otro lado debido a la participación de los alumnos. En cuanto a la práctica docente, puede que no se haya manejado con suficiente soltura los recursos metodológicos bien por desconocimiento de los mismos o por falta de dominio. Por otro lado, puede deberse a causa de los alumnos debido por ejemplo a la falta de participación en las actividades por causas tales como falta de motivación hacia la tarea, causas emocionales como vergüenza a participar, miedo a no aportar información relevante o impasividad ante las actividades. Al no poseer estudios relacionados con estos aspectos, sería conveniente valorar si en aquellas aulas en las que se emplea más eficientemente esta dinámica de trabajo la estructura de participación dominante es la dialógica o por el contrario si existe un tándem, como en este caso, de estructuras de participación más abiertas en el aula (IRF y dialógicas).

Siguiendo este análisis, encontramos que la estructura IRE correlaciona con mayor fuerza con la transferencia de tipo teórica y la ayuda regulatoria. Por su parte, la estructura IRF correlaciona con la transferencia aplicativa, la ayuda interna y la explicación, ejemplo contexto cercano como formato de la tarea a la tarea.

Así, en el caso de que la estructura dialógica correlaciona con la transferencia aplicativa y el formato de la tarea que presenta explicación y el contexto cercano como formato de la tarea. La estructura de participación de tipo dialógica favorece un mayor clima de participación y diálogo libre entre los interlocutores. Esto conlleva a una mayor fluidez de participación.

En cuanto a la dimensión transferencia nos encontramos con que la no transferencia correlaciona con aquellas actividades que presentan un formato 
con una explicación y que se vinculan al contexto cercano, estos resultados resultan contradictorios con la idea inicial, debido a que cuanto mayor apoyo en la tarea (más elementos que la definan) más transferencia (o de mejor calidad). Sin embargo, si tenemos en cuenta que en cada una de las sesiones de partida de cada tipología textual no se produce transferencia debemos poner atención al resto de actividades que sí eran susceptibles de presentar transferencia y no se ha producido.

Por otro lado, la transferencia teórica correlaciona con la estructura IRE y la transferencia aplicativa con las estructuras IRF y dialógica. Dichas asociaciones ponen de relieve nuevamente que cuanto más abierta y dialógica sea la estructura de participación que se lleva a cabo en el aula más transferencia de contenidos se produce y de mejor calidad. Así las estructura IRE favorece la transferencia teórica debido a su estructura semi-cerrada, donde es el adulto el que finalmente da por buena la respuesta sin que se produzca ningún tipo de feedback o negociación acerca de la respuesta o tarea a llevar a cabo. De hecho, la transferencia teórica, como poníamos de manifiesto, se produce cuando se verbaliza, sin embargo, la transferencia de aplicación pone de relieve lo transferido mediante su puesta en práctica. Si la estructura de aula es cerrada, no da lugar a la puesta en práctica de aprendizajes transferidos, sino únicamente a la verbalización del mismo.

Poniendo el énfasis en las ayudas, observamos como la ayuda regulatoria correlaciona con la estructura de participación IRE estos datos nos revelan que cuanto más guía en cuanto a la organización de las tareas y su desarrollo se produzcan más cerrada será la estructura de participación del aula, dejando a un lado la interacción entre los participantes para dar paso a estructuras donde la figura del adulto es la dominante y guía único en el proceso de enseñanzaaprendizaje.

En cuanto a las ayudas interna se correlacione con la estructura IRF ya que, al estar conectada de forma directa con los contenidos trabajados en las tareas, 
están muy presentes en este tipo de ciclos promoviendo una relación entre los contenidos y las actividades a realizar. Por otro lado, tanto las ayudas internas como las cálidas se correlaciona con aquellas actividades que presentan explicación, ejemplos y están conectadas con el contexto, cabe destacar el papel del formato de la tarea en cuanto a las ayudas, ya que cuanto más completas sean las tareas y más cercanas al contexto mayores y de mejor calidad serán las ayudas que se presten entre los interlocutores. Es obvio, que cuanto más cercanas sean al contexto de los alumnos, más conocimiento tendrán del contenido de la tarea y será más fácil establecer ayudas sean del tipo que sean. En concreto, las ayudas internas irán encaminadas a ofrecer los elementos necesarios para resolver la tarea y las cálidas movilizan procesos cognitivos emocionalesmotivaciones que influyen en la realización de la tarea, pero no aportan ningún contenido.

Por último, si atendemos a la dimensión formato de la tarea vemos como aquellas tareas que se componen de una explicación y son cercanas al contexto correlacionan en mayor medida con las estructuras dialógicas y a su vez con la ausencia de transferencia.

Finalizando este apartado, hacemos referencia a la correlación que se establece entre aquellas tareas que contienen explicación, ejemplo y son cercanas al contexto con la estructura IRF. Como destacábamos antes, aquellas tareas que están vinculadas al entorno cercano promueven ciclos comunicativos abiertos, donde se recibe un feedback por parte del adulto. A su vez, este tipo de tarea se correlaciona con la transferencia de tipo aplicativa.

\subsubsection{Modelos obtenidos}

Tras una exploración inicial de las variables objeto de estudio a través del análisis multivariado se llevó a cabo un análisis log-lineal con el fin de obtener el mejor modelo teórico que se ajustara a los datos empíricos obtenidos. Previa a dicha obtención del mejor modelo, se exploraron distintos modelos intermedios según diversos procedimientos tales como la función step de $\mathrm{R}$, la eliminación 
9. Discusión, limitaciones e implicaciones para investigaciones futuras

hacia atrás (método backward), el análisis de varianza o la propuesta de modelos teóricos según los datos previos. Todos los modelos obtenidos incluyen tres interacciones de $3^{\text {er }}$ orden, asumiendo por tanto que los factores objeto de estudio interactúan o están asociados entre sí de alguna manera tal como preveíamos. El modelo obtenido a través de la función step, a través del ANOVA así como a través de los modelos sometidos a prueba confirmaron un modelo complejo con tres interacciones triples (M6) [EAF][EFT][AFT].

Al realizar un análisis más profundo de los modelos obtenidos destaca que los modelos resultantes del análisis log-lineal no sugieren una relación de independencia entre las variables, pero sí resultan altamente significativas las interacciones de tercer orden en los dos mejores modelos obtenidos (M5 y M6) subrayando así la importancia de las relaciones complejas que se establecen entre unas variables y otras.

El trabajo se centra en determinar cuáles son las situaciones más favorables para que se produzca transferencia. Para estudiarla se han registrado 1506 situaciones de interacción con ayuda en distintas situaciones de aprendizaje. Esta información nos permite conocer qué tipo de ayudas prestadas durante la tarea, que estructura de participación y que formato de la tarea son más eficientes para que se produzca cualquier tipo de transferencia a través del modelo 6. Concretamente, la ayuda interna en combinación con la estructura IRF y actividades que incluyen en su formato una explicación, un ejemplo y están vinculadas con el contexto cercano del alumno es más facilitadora de la transferencia aplicativa.

Otro factor a tener en cuenta como facilitadora de la transferencia de aplicación son aquellas situaciones educativas en las que al igual que en el caso anterior se producen ayudas internas combinadas con una estructura dialógica y actividades que incluyen en su formato una explicación, un ejemplo y están vinculadas con el contexto cercano del alumno es más facilitadora de la transferencia aplicativa. Cabe destacar, por tanto, que dicha combinación de variables 


\section{Capitulo 2: ESTUDIO EMPÍRICO}

(ayuda interna, formato de la tarea con explicación ejemplos y contexto cercano) son facilitadoras de la transferencia aplicativa cuando la estructura de participación del aula es más abierta (siendo IRF o dialógica). Estos datos son de suma importancia a la hora de plantear situaciones educativas de provecho, en las que pretendamos que los alumnos no simplemente recuerden y ejecuten sus aprendizajes sino más bien que sean capaces de transferir conocimientos adquiridos de una situación a otra y aplicarlos con determinación.

Se ha observado por otra parte, que la ayuda interna en combinación con actividades cuyo formato presenta explicación y vinculación al contexto en una estructura de participación dialógica fomenta en mayor media respecto al resto de combinaciones de variables la no transferencia. Estos datos contrastan con los anteriores, sugiriendo que el papel más importante a la hora de favorecer la transferencia es la incursión de un ejemplo en el formato de la tarea ya que esa discrepancia decanta la balanza de la transferencia hacia un lado u otro.

Respecto a la transferencia teórica, el modelo no muestra una clara tendencia de combinación de variables que tiendan a favorecerla. Cabe reseñar por otra parte que una ayuda de tipo regulatoria en combinación con una estructura IRF y actividades que presentan una explicación de la tarea y un ejemplo son más favorecedoras de la transferencia teórica.

Para determinar en mayor medida como influyen unas variables sobre otras y sobre todo cómo influyen sobre el proceso de transferencia o no transferencia nos apoyaremos en los resultados obtenidos a través de la regresión logística que discutiremos en el siguiente apartado.

\subsubsection{Predicción}

El tercer procedimiento de análisis se trata de una regresión logística con el fin de analizar la relación entre la variable transferencia, considerándola en este caso como una variable dicotómica (transferencia/no transferencia) y el resto de variables. 


\section{Discusión, limitaciones e implicaciones para investigaciones futuras}

El procedimiento de regresión logística parece ser un instrumento idóneo para hacer una predicción de la transferencia/no transferencia, en lo que respecta a la capacidad predictiva del modelo en general, se sitúa entre débil y moderada ya que predice bien los casos de transferencia $(69.7 \%)$ pero por el contrario no predice muy bien los casos de no transferencia. Para mejorar dicha capacidad predictiva del modelo según los resultados de los análisis efectuados sería conveniente añadir más variables predictoras al modelo como por ejemplo la dificultad de la tarea o la motivación de los alumnos hacia la propia tarea (Montero, de Dios, \& Huertas, 2001; Schunk \& Zimmerman, 2012). Asimismo, los casos de transferencia son los más frecuentes, un resultado alentador para el estudio, pues refuerza la concepción del traspaso de conocimientos como un proceso vital y a tener en cuenta en las tareas de enseñanza aprendizaje.

En los resultados obtenidos las tres variables predictoras demostraron ser estadísticamente significativas, manifestando, por tanto, que sí existe tal relación entre el diálogo y la transferencia. Este dato aporta cierta dosis de optimismo ya que lo relacionamos con variables sobre las que es posible actuar. Se confirma que el mejor predictor de la transferencia en el aprendizaje es la estructura de participación dialógica. Además de la estructura de participación dialógica, se evidencia la importancia de las variables formato de la tarea y ayuda (Salmerón, 2013) en la predicción de la transferencia del aprendizaje. Para el formato de la tarea serían buenos predictores las tareas que incluyen explicación, ejemplo y son cercanas al contexto. Mientras que para la ayuda aparece como factor clave las ayudas de tipo internas

Nos parecen suficientemente sugestivas estas conclusiones, para seguir indagando nuevos predictores y perfilando nuevos estudios, a partir de la regresión logística, dado el alto porcentaje de clasificaciones correctas obtenidos en este estudio. A continuación, discutimos con más detalle los resultados obtenidos fijándonos en cada una de las variables. 


\section{Transferencia}

Si atendemos a los tipos de transferencia, dentro de nuestro estudio el valor que más ocurre es la transferencia aplicativa seguido de la teórica. Parece lógico pensar que las actividades que se plantearon no iban dirigidas a que se reprodujese lo aprendido en un contexto en otro distinto, sino más bien, los ejercicios se orientan a que los alumnos sean capaces de aplicar lo aprendido en una situación a otra. La pedagogía actual se inclina por el aprendizaje haciendo y demostrar que se es capaz de aplicar y no reproducir lo que se aprende. En este sentido, los resultados no hacen más que poner de manifiesto por un lado el carácter aplicativo de las actividades planteadas en el proyecto integrado objeto de estudio y por otro lado la congruencia pedagógica con los ideales que se transmiten a través de los entornos comunicativos de aprendizaje.

Sobre la transferencia creativa, tal como suponíamos al iniciar la investigación, no hemos encontrado ninguna muestra con lo que no hace más que confirmar la dificultad de que se produzca ese tipo de transferencia en la etapa educativa en la que se enmarca nuestro estudio. En este sentido, también poníamos de manifiesto con anterioridad, la capacidad por parte del sistema educativo de matar la creatividad de los alumnos y la dificultad de identificar este tipo de transferencia.

Una de las primeras reflexiones acerca del proceso de transferencia es tal y como se pone en evidencia en distintas investigaciones la dificultad que supone identificar los casos de trasferencia de manera correcta. Tal como nos mostraban los resultados de los análisis de las curvas $\mathrm{ROC}$ y la regresión logística es difícil clasificar bien los casos de no transferencia. Sin embargo, en la práctica resulta más complejo el proceso de categorización de aquellos casos que efectivamente son transferencia ya que se corre el riesgo de anotar un caso de transferencia cuando en realidad lo que se produce es simplemente proceso de aprendizaje. En capítulos anteriores hablamos sobre la controversia que existe 
en este sentido, y hacíamos especial hincapié en que en realidad se trataban de dos procesos bien diferenciados.

La dificultad de clasificar bien los casos de transferencia también se debe a la implicación subjetiva que pueda influenciar en el mismo proceso de categorización. A pesar de haberse llevado a cabo procesos de fiabilidad que dan por aceptables el sistema de categorización empleado es probable que el mismo proceso llevado a cabo haya sido sesgado o alterado a la hora de clasificar la transferencia o no transferencia principalmente por los jueces externos que no conocen la globalidad del trabajo educativo llevado a cabo durante el proyecto integrado Los textos de nuestros días.

\section{Estructura de participación}

La variable estructura de participación resultó ser la más influyente en los casos de transferencia $(\chi 2=138.772, p=.000)$ según el análisis de regresión logística. Se pone sobre la mesa, por tanto, la importancia de la interacción social como mediadora en el aprendizaje, así como la necesidad de elaborar estrategias de calidad que favorezcan tales aprendizajes de calidad (Bruner, 2012; Lave \& Wenger, 1991). Dentro de ésta, la estructura dialógica resultó ser la más influyente en la explicación de la transferencia, en segundo lugar IRF y en tercer lugar IRE. Estos datos ponen de manifiesto que cuanto mayor es la participación del adulto y menor autonomía se genere en el alumnado, menor transferencia de aprendizajes se produce tal como señalaban Solaz-Portolés y Sanjosé (2008). Por otro lado, el pensamiento analógico, exploratorio, generalizador, empático y razonado como procesos de aprendizaje subyacentes al diálogo (Chi \& VanLehn, 2012; Gentner et al., 2003; Rittle-Johnson \& Star, 2007) tienen una marcada importancia para entender la transferencia.

Al categorizar los datos para los análisis de curva $\mathrm{ROC}$ ordenamos las variables de aquellas que influirían menos en la transferencia según los datos obtenidos y la literatura a aquellas que serían más importantes para que se produjese 
una transferencia más exitosa condiciendo con los resultados en que la más influyente sería la estructura de participación.

Si bien antes veíamos como la estructura dialógica era capaz de predecir en mayor medida la transferencia, en cuanto a la frecuencia de las mismas no ocurre lo mismo. La estructura de participación con mayor frecuencia de aparición es la IRF, que se traduce en un claro predominio de un modelo de interacción marcado por la colaboración en grupo, pero sin llegar a generar estructuras profundas de aprendizaje basadas en el diálogo. Esta contradicción entre la mayor predicción de la transferencia a través del diálogo y que sin embargo, las prácticas escolares frecuenten prácticas de grupo pero no dialógicas, pone de manifiesto una clara necesidad de mejorar las intervenciones escolares otorgando mayor protagonismo a los procesos internos de aprendizaje en el alumnado mediante trabajos educativos como (programas de habilidades sociales, aprendizaje del uso adaptativo del leguaje a las situaciones sociales, mejora en los procesos de mediación para organizar las secuencias didácticas, técnicas cooperativas iniciales con las que generar un terreno fértil para el diálogo (Gillies, 2015; Mercer, Dawes, Wegerif, \& Sams, 2004; Mercer, 2008)).

Atendiendo a las probabilidades estimadas, la mayor probabilidad de que se produzca transferencia utilizando estructura de participación se corresponde con la categoría de estructura dialógica, seguida de la estructura IRF y por último de la estructura IRE. De modo similar, las odds ratio obtenidas indican que cuando la estructura de participación es dialógica, la odds de que se produzca transferencia es mayor que si la estructura es IRE. Lo mismo sucede cuando la estructura es IRF, cuya odds es mayor que si la estructura es IRE.

Estos resultados refuerzan la importancia del diálogo como impulsor del traspaso de los conocimientos, como un elemento que debe potenciarse durante la resolución de las tareas. Desde esta perspectiva, la guía del mediador resulta clave a la hora de promover un tipo de interacción u otra, pues la guía mediante ayudas invasivas disminuye la posibilidad de debate entre los miembros 
del grupo. Por el contrario, los apoyos menos dirigidos aumentan la negociación y la reflexión entre los participantes: De este modo se promueve la reflexión, la búsqueda y la investigación por parte del alumnado, y se ayuda a mantener un carácter igualitario de interacciones, a la vez que los estudiantes construyen discursos y respuestas más complejas (Reznitskaya et al., 2012). Las ayudas cálidas son otro tipo de apoyo imprescindible para lograr un diálogo respetuoso y activo en los grupos. Estas ayudas contribuyen a que el alumnado tenga en cuenta las diferentes formas de ser y las diferentes formas con las que puede ofrecer andamiaje a sus compañeros. En esta línea destaca la propuesta de Gillies (2015) basada en un modelo de tutoría entre iguales que plantea la secuencia pregunta-piensa-explica por qué. Esta idea integra tanto la importancia de los aspectos de razonamiento y argumentación en el trabajo conjunto como el empleo de un comportamiento social adecuado.

De igual modo, es necesario reflexionar sobre la importancia de plantear actividades que conecten de forma directa con intereses del alumnado y con situaciones reales, con el fin de promover la implicación activa del alumnado y el debate, y por tanto la interacción IRF y dialógica.

\section{Formato de la tarea}

El formato en la tarea resultó la segunda variable más influyente en la transferencia $(\chi 2=88.622, p=.000)$. Observamos en este aspecto una limitación del estudio, ya que existen otros factores influyentes que han condicionado las relaciones entre dichas variables (como pueden ser la dificultad en la tarea o la motivación del escolar a la hora de ejecutar la tarea). Lo que si puede evidenciarse con los datos obtenidos es que la transferencia se ve afectada por el contexto en que se produjo el aprendizaje inicial favoreciendo a dicho proceso, aquellos aprendizajes que se realizan en múltiples contextos (Bassok \& Holyoak, 1989). 


\section{Capitulo 2: ESTUDIO EMPÍRICO}

El formato en la tarea EX_EJ_CC presenta una frecuencia de aparición muy superior a las demás en los casos de transferencia, sin embargo, los estadísticos Wald nos indican que el tipo de formato que mejor predice la transferencia es EX_CC seguido de EX_EJ

En relación con el tipo de formato, la probabilidad de que se produzca transferencia con formato de explicación es la más destacada, seguido del formato con explicación, ejemplos y contexto cercano, del formato con explicación y ejemplos y por último el formato con explicación y contexto cercano. Estos datos destacan la importancia de incluir en las fichas fragmentos que expliquen parte del contenido desarrollado en sesiones anteriores y que será necesario rescatar para resolver la nueva actividad. Aunque esta explicación ofrece una ayuda importante, no es el formato más completo para promover la transferencia. Por ello, el resultado puede deberse a la influencia de otros factores como: el componente activo de la tarea (especialmente aquellas realizadas en educación física), la motivación del alumnado hacia la actividad o el nivel de complejidad que presente.

\section{Ayuda}

La ayuda (tercera variable predictora para la transferencia con un $\chi^{2}=14.129$, $p=.0027$ ), resultó significativa entendiéndola como facilitadora de las tareas que posibilitan el éxito en la realización de la tarea. Las ayudas frías (regulatorias, internas y de feedback) están orientadas a la resolución eficaz de la tarea, en el caso de la regulatoria sobre el proceso, en el caso de la interna sobre el contenido y en el caso de feedback como fijadora de la respuesta correcta. No existe diferencia entre ellas en la probabilidad de transferir. Dentro de los tipos de ayuda, la regulatoria, es decir, aquella que dirige y organiza la tarea, ofreció mayor capacidad predictiva hacia la transferencia que las ayudas cálidas o emocionales, en cuanto a la resolución de las tareas académicas, pudiendo manifestar que en el contexto escolar tienen más relevancia los aspectos académicos que los emocionales a la hora de transferir aprendizajes. 


\section{Discusión, limitaciones e implicaciones para investigaciones futuras}

En cuanto a la ayuda, en los casos de transferencia presenta una frecuencia mayor al resto la ayuda interna, sin embargo, los estadísticos Wald nos indican que la ayuda Regulatoria es la que mejor predice la transferencia tal como pensábamos nosotros.

Esta necesidad se hace todavía más notable cuando vemos que las ayudas más frecuentes en el aula se corresponden con las (Lakoff \& Johnson, 1999) ayudas de feedback y los tipos de formato más numerosos son las actividades que proporcionan ejemplos, un contexto cercano y explicaciones del contenido. De este modo se produce una ayuda en la resolución de la actividad al fijar y completar las ideas generadas en el grupo y apoya la idea de generar diseños de tareas didácticas conforme a esta secuencia.

En cuanto las probabilidades estimadas mediante el cálculo de los marginales, muestran que la mayor probabilidad de que se produzca transferencia utilizando ayudas corresponde a la categoría de ayuda interna, seguida de la categoría de ayuda regulatoria, de feedback y por último de ayuda cálida. Este resultado se debe a la relación directa que presentan las ayudas internas, las ayudas regulatorias y las ayudas de feedback con el contenido de aprendizaje, bien sea a través de pistas y razonamientos, mediante la consolidación de ideas o mediante estrategias con las que guiar y organizar la tarea. Son tres apoyos fundamentales para que se logre la transferencia.

No obstante, los datos evidencian una mayor relevancia de las ayudas internas, ya que la odds de que se produzca transferencia si la ayuda es interna es un $48 \%$ mayor que si la ayuda es regulatoria. Surge así un nuevo punto de reflexión que contrapone un tipo de ayuda más relacionada con los contenidos, con un tipo de ayuda organizativo, imprescindible en la resolución de la actividad. Desde el plano didáctico, es necesario complementar ambas modalidades, ya que los contenidos, abordados más directamente desde los apoyos internos, requieren de orden, de estructuración y de estrategias que permitan darles forma para resolver la actividad. Se trata de promover el qué y el cómo. 


\section{Capitulo 2: ESTUDIO EMPÍRICO}

Además, la puesta en práctica en los grupos de las ayudas internas, regulatorias y feedback precisa de modalidades más flexibles que permitan un intercambio de ideas creativo, dirigido por los propios alumnos, sin que el mediador guíe en exceso la resolución de la actividad. Por ello, en relación con las ayudas internas, es interesante promover lo que Sánchez et al. (2010) denominan como apoyos internos no invasivos, ayudas que no proporcionan de modo directo los elementos que dan forma a la respuesta. Otras propuestas son ayudas a través de ejemplos, de imágenes explicativas, de consejos o de textos aclaratorios (Gómez et al., 2012).

En cuanto a la escasa frecuencia de la transferencia en combinación con ayudas cálidas, sería recomendable aumentar el número de estos apoyos al reforzar aquellos relacionados con la motivación y con la consecución de acuerdos entre los miembros del grupo. Además, esta necesidad de llegar a un acuerdo genera un intercambio de ideas y un debate conjunto que favorece la búsqueda de aquellas opiniones y conocimientos más adecuados para resolver la tarea. De este modo, se comparan las diferentes propuestas, estableciendo analogías o diferencias entre actividades ya realizadas, a la vez que se crean relaciones entre contenidos, todos ellos procedimientos importantes para la transferencia (Gómez et al., 2012).

Después de todos estos resultados, podríamos concluir que el modelo educativo ideal para favorecer la transferencia debería incluir una estructura de participación en el aula de tipo dialógico en el que se difumine la figura del maestro y se plantee como mediador del aprendizaje, favoreciendo la interacción entre los alumnos y abriendo el aula a nuevos retos y planteamientos. En cuanto al tipo de actividades que se planteen han de contener una pequeña explicación lo suficientemente sencilla para que todos los alumnos sean capaces de entender y realizar de manera conjunta sin necesidad de ninguna explicación por parte del profesor, que contenga algún ejemplo y esté relacionado con el contexto cercano del alumno. Por último, se han de trabajar y fomentar el tipo 
de ayudas regulatorias, orientadas principalmente a la organización y desarrollo de la tarea.

\subsection{Aportaciones finales}

En este apartado presentaremos de manera más concreta los principales hallazgos de esta investigación y sus implicaciones en la práctica docente. Por otra parte, haremos referencia a los aspectos que han interactuado desde las perspectivas cuantitativas y cualitativas de la investigación, así como la explicación de las limitaciones del estudio.

\subsubsection{Principales hallazgos}

Desde el punto de vista teórico, nos ha costado encontrar estudios referidos a la transferencia en la etapa de educación primaria. Como mencionábamos el enfoque de Haskell nos aportó una visión amplia sobre el concepto de transferencia y sus distintos grados que nos permitió encontrar el punto de innovación y poder relacionar la transferencia con los entornos comunicativos de aprendizaje.

Partiendo de todo esto, nuestra investigación arroja un poco de luz acerca del proceso de transferencia de aprendizajes en la etapa de educación primaria y particularmente en organizaciones de aula basadas en la interacción y el diálogo. Los hallazgos realizados durante el proceso de investigación revelan una conexión evidente entre las variables objeto de estudio, abriéndose así un nuevo campo de investigación en torno a la transferencia en los entornos comunicativos de aprendizaje y sobre qué variables se deberían de manejar para favorecer el proceso de transferencia del aprendizaje. Por otra parte, nos desvela también datos acerca de cómo manejar cada una de las variables para favorecer o no la transferencia.

El estudio, no tiene como único fin teorizar acerca de la transferencia en los $\mathrm{ECA}$, sino también aportar datos que sean de interés desde el punto de vista aplicado a la docencia en general y en particular en la educación primaria. 
Como venimos destacando, una preocupación general de todo docente es conocer por qué los alumnos tienen dificultades en el proceso de transferencia de aprendizaje de un área a otra, o de situaciones de aprendizaje similares o distintas. Conocer cuáles son las debilidades de los alumnos y de los planteamientos docentes a la hora de proponer actividades que favorezcan ese proceso de transferencia supone un gran avance a la hora de diseñar procesos educativos más eficaces. A la vez, nos resulta interesante pensar en cómo proporcionar a los alumnos herramientas y situaciones en las que favorezcan la aplicación de unos conocimientos adquiridos a situaciones similares o diferentes. Resulta interesante, por tanto, conocer y establecer las relaciones entre los principales elementos que inciden en el proceso de aprendizaje en los entornos comunicativos de aprendizaje favorecedores de la transferencia, que como se ha puesto de relieve son: la estructura de participación, el formato que presenta la tarea y aquellos apoyos que se prestan a la hora de resolver la tarea entre los distintos interlocutores.

Dentro de los entornos comunicativos de aprendizaje o en cualquier situación de enseñanza-aprendizaje resulta imprescindible analizar qué estructura de participación se lleva a cabo en el aula y si esas dinámicas influyen o no en el proceso de aprendizaje y en qué sentido. Tal como muestran los resultados de nuestra investigación se hace necesaria una estructura de participación en el aula de tipo dialógica, en el que el alumnado sea parte activa de su propio proceso de aprendizaje y alejarnos de aquellas estructuras de aula donde la única misión del alumno sea absorber conocimientos sin formar parte de ellos. La formación inicial y permanente del profesorado ha de ir encaminada a la consecución de este fin, a sabiendas de que la tendencia actual en la educación es una propuesta docente en la que los alumnos trabajan en grupos, generalmente basado en proyectos a partir de sus propios intereses y creyéndose la parte más importante en el proceso de aprendizaje. Este auge de las metodologías activas irrumpe con fuerza en el panorama escolar, sin embargo, una de las mayores dificultades que existe en cuanto a la puesta en práctica de un modelo docente 
9. Discusión, limitaciones e implicaciones para investigaciones futuras

en el que se incluyan prácticas dialógicas en el aula proviene de acuerdo a las palabras de Fernández Pérez (1989) de que los profesores no aplican los métodos que nos han predicado, sino los métodos que nos han aplicado. Es sabida por parte del mundo docente que existe una asincronía entre los conceptos aprendidos en la formación inicial y/o permanente del docente y la posterior puesta en práctica en el aula. En la mayoría de los casos sigue siendo una práctica reproductiva, es decir, se reproducen los modelos docentes recibidos, sin reflexionar o tener en cuenta las nuevas corrientes pedagógicas. Otra parte del profesorado, sin embargo, muestra interés por mejorar su práctica docente adecuándose a las exigencias de la educación actual a través de la formación continua.

Resulta imprescindible que exista coherencia entre el modelo de formación del profesorado y el del modelo didáctico que se practica. Si no se da este principio de isomorfismo entre ambos modelos, los aprendices de docentes generarán mecanismos de resistencia que ahondarán en la convicción de que la teoría y la practica son dos ámbitos separados, cuando no contradictorios. Como indican García y Jiménez (1995) el profesor que se encarga de la formación de los futuros profesionales de la educación tiene que enseñar a enseñar enseñando.

En segundo lugar, en los entornos comunicativos de aprendizaje partimos de situaciones de aprendizaje conjunto donde las ayudas influyen en el proceso de transferencia de los aprendizajes, por tanto, debemos formar a alumnos y docentes para que sean capaces de gestionar y manejar correctamente las ayudas que se ofrecen/aportan para conseguir que estén orientadas a la mejora del proceso de transferencia del aprendizaje. Como veíamos en los resultados, las ayudas que más favorecen la transferencia son las ayudas regulatorias e internas, en ambos casos las ayudas están encaminadas a la propia resolución de la tarea. Si enseñamos a los alumnos y docentes a prestar ayudas en la resolución de cualquier tarea de estos tipos, conseguiremos que las tareas se resuelvan de 


\section{Capitulo 2: ESTUDIO EMPÍRICO}

manera exitosa en menor tiempo, con mayor calidad y con mayor profundidad. Gran parte del profesorado que comienza a trabajar con estructuras de tipo dialógica se queja de las dificultades que ello conlleva. Por una parte, requiere una formación teórico-práctica que permita al profesorado entender las bases psicopedagógicas de estas prácticas y, por otro lado, la falta de costumbre de la participación de los alumnos como parte esencial del proceso da una sensación de falta de control o dominio de la clase.

No debemos dejar a un lado las ayudas de tipo cálido, que ayudan a los alumnos a manejar mejor sus emociones y a interactuar con el resto de interlocutores haciéndoles poseedores de mejores habilidades sociales. Esto supondría un entrenamiento en cuanto a inteligencia emocional orientado a la resolución de tareas grupales.

En tercer lugar, en lo que formato de la tarea se refiere, sería muy recomendable que los docentes planteasen sus proyectos integrados, unidades didácticas o actividades teniendo en cuenta los resultados obtenidos en nuestra investigación, es decir el planteamiento de las mismas en las que el enunciado o instrucciones contenga una clara explicación en la que se manifieste el objetivo de la misma, un pequeño ejemplo que ayude a establecer puentes entre la actividad y contenidos (siguiendo el modelo detect-elect-conect de Perkins y Salomon (2012)) que se han trabajado en otras situaciones y por último, las actividades han de estar en conexión con los intereses de los alumnos, se han de plantear tareas que se vinculen directamente con el contexto de los alumnos, para ello es necesario un conocimiento profundo de los intereses de los alumnos y tener en cuenta sus aportaciones y opiniones.

La mayoría de las actividades que se llevan a cabo en el aula son prescritas por alguna editorial que el centro educativo selecciona, sin embargo, en muchos casos, esas actividades que se plantean no están vinculadas a los intereses de los alumnos y en ocasiones son difíciles de entender o por el contrario los alumnos adivinan qué se les pide sin leer lo que realmente se les pide. La inclu- 
9. Discusión, limitaciones e implicaciones para investigaciones futuras

sión de ejemplos sirve también para un entendimiento más ágil del proceso, así como para tender puentes hacia otros contenidos que se han trabajado en distintas circunstancias. Si los docentes, tienden puentes hacia otros contenidos, los alumnos se acostumbrarán a establecer vínculos más tangibles entre actividades y/o situaciones que en principio puede parecer que no los tengan. Los docentes, deben perder el miedo a crear sus propias actividades $e$ indagar en las cosas que más interesan a sus alumnos, asegurándose de esa manera que los contenidos que crea para ellos conecten directamente con su contexto y sus intereses.

\subsubsection{Interacción entre aspectos cuantitativos y cualitativos}

Como ya se puso de relieve, la investigación no solo nos parece novedosa por su temática, sino también por la aproximación a los métodos mixtos que plantea. Una estructura de métodos a servicio de la propia investigación, donde cada una de las partes que la componen predomina o interactúan uno o varios modelos metodológicos, es decir siguiendo un método adaptado a la propia investigación y no una investigación adaptada a un método concreto. Esta idiosincrasia permite seleccionar lo mejor de cada método, así, por ejemplo, en la parte inicial de la investigación se emplean sobre todo técnicas cualitativas como el grupo de discusión o las grabaciones de las sesiones y su posterior transcripción. Esta primera parte se lleva a cabo en un ambiente natural, un aula que no modifica para nada la dinámica de la clase llevada a cabo, no se controla ninguna variable, sino que pretende recoger la realidad tal como es en el contexto donde se produce.

Posteriormente, se llevaba a cabo un análisis de contenido, tratando de identificar las variables objeto de estudio para más tarde cuantificar esas variables cualitativas. Una vez hecho esto, se manejan las variables para responder al problema de investigación a través de diversos análisis estadísticos para analizar la causa-efecto y objetivizar la realidad estudiada. 


\section{Capitulo 2: ESTUDIO EMPÍRICO}

Pese a poseer un gran peso cuantitativo no se pretende ni generalizar los resultados ni la réplica de los mismos, sino que nos permite conocer con mayor profundidad el problema planteado visto y entendido desde distintos prismas y así describir lo que sucede, proponiendo pautas metodológicas adecuadas a nuestro caso, extensibles a otros contextos, pero nunca pautas universales.

\subsubsection{Limitaciones}

Todo trabajo de investigación presenta puntos fuertes y puntos débiles, a continuación, expondremos algunas de las limitaciones más importantes que presenta nuestro estudio.

En cuanto a la muestra son varios los aspectos destacables como limitaciones, comenzando por el tamaño restrictivo de la misma. La muestra tomada se trata de una muestra muy pequeña que además cuenta con un sesgo cultural importante al enmarcarse dentro de un contexto con unas características fuertemente marcadas como son la totalidad del alumnado de etnia gitana que presentan un nivel socio-cultural bajo-muy bajo.

Por otra parte, la ausencia de grupo de control para contrastar los datos también se constata como una limitación que impide la replicabilidad del estudio, aunque no era el fin de este estudio.

En cuanto al sistema de categorización de los datos, al haber utilizado un sistema existente, aunque se han realizado adaptaciones para ajustarse al contexto y tipo de variables a estudiar, no cuenta con la fiabilidad de un sistema validado. Este hecho conlleva la realización de la categorización de las variables por jueces externos para minimizar el impacto que esto pudiera ocasionar. Así se alcanzó un grado de concordancia BWN de .631 en estructura de participación, en transferencia de .592 , en ayuda de .578 , y el más bajo en formato de la tarea 467.

La elección de las variables y sus valores también puede haber condicionado los resultados, se han tenido en cuenta variables referentes a la organización 
9. Discusión, limitaciones e implicaciones para investigaciones futuras

del aula (estructura de participación), a las ayudas entre los participantes y al tipo de tarea como elementos clave en la transferencia, no siendo estos los únicos, como comentamos con anterioridad se podrían haber incluido variables motivacionales o relacionadas con la dificultad de la tarea.

La variable transferencia, es difícil de medir, ya que podemos medir aquella transferencia que deja rastro, es decir, solo podemos medir la transferencia de un contenido que se hace público.

\subsection{Vías futuras de investigación}

El análisis de datos su interpretación y discusión de esta tesis abre la puerta a futuras vías de investigación tanto desde el punto vista teórico como desde el punto de vista aplicado.

Desde el punto de vista teórico esta investigación nos ha proporcionado datos relevantes acerca de la transferencia y su relación con las tres variables predictoras, esto nos permite seguir investigando y ahondando en la literatura subyacente y en aquellos aspectos que se consideran como clave para que se produzca la transferencia, por ello seguiremos profundizando en los aportes que desde lo sociocultural se ofrece a la transferencia del aprendizaje.

Una de las propuestas de trabajo futuro es el planteamiento de un estudio longitudinal en que se pueda realizar un seguimiento más exhaustivo con una muestra poblacional representativa.

En la tesis, se incluyen únicamente las áreas de Lengua y Educación Física siguiendo el criterio de acceso al campo, sin embargo, creemos necesario poder establecer una relación más amplia de áreas en las que investigar y así conocer las posibilidades y debilidades que existen entre los planteamientos de una y otra en torno al proceso de transferencia. 


\section{Capitulo 2: ESTUDIO EMPÍRICO}

En cuanto a las variables predictoras, se podrían incluir aquellas que la literatura considera relevante y no hemos tenido en cuenta tales como la motivación o la dificultad de la tarea planteada.

Desde el punto de vista aplicado esta tesis abre un gran ventanal a posibilidades educativas encaminadas a la mejora del proceso de enseñanzaaprendizaje. Resulta interesante indagar en aquellos aspectos clave que hemos considerado como relevantes para el fomento de la transferencia. Planificar, llevar a cabo una propuesta educativa y valorar los resultados en cuanto a transferencia sería un buen modo de constatar los resultados obtenidos y refutar así las conclusiones extraídas.

Por otra parte, para ampliar los resultados obtenidos sería interesante plantear un estudio comparativo con las variables incluidas, una muestra representativa e incluyendo un estudio comparativo llevado a cabo en centros en los que se erigen como entornos comunicativos de aprendizaje y un centro ordinario. 

Referencias bibliográficas

\section{Referencias bibliográficas}

Adey, P., \& Shayer, M. (1993). An exploration of long-term far-transfer effects following an extended intervention program in the high school science curriculum. Cognition and Instruction, 11(1), 1-29.

Agresti, A., \& Kateri, M. (2011). Categorical data analysis. Springer.

Allison, P. (2013). Why I don't trust the hosmer-lemeshow test for logistic regression. Recuperado de Statistical Horizons at http://www.statisticalhorizons.com/hosmer-lemeshow.

Allison, P. (2012). Logistic regression using SAS: Theory and application SAS Institute.

Anderson, J. R. (1983). A spreading activation theory of memory. Journal of Verbal Learning and Verbal Behavior, 22(3), 261-295.

Anderson, J. R., \& Bower, G. H. (2014). Human associative memory. Psychology press.

Ato, M., Benavente, A., \& López, J. J. (2006). Análisis comparativo de tres enfoques para evaluar el acuerdo entre observadores. Psicothema, 18(3), 638-645.

Ato, M., \& López, J. J. (1996). Análisis estadístico para datos categóricos. Madrid: Síntesis.

Au, K. H. (1980). Participation structures in a reading lesson with hawaiian children: Analysis of a culturally appropriate instructional event. Anthropology \& Education Quarterly, 11(2), 91-115.

Ayers, R., \& Ayers, W. (2014). Teaching the taboo: Courage and imagination in the classroom. Teachers College Press. 
Bangdiwala, K., \& Bryan, H. (1987). Using SAS software graphical procedures for the observer agreement chart. Proceedings of the SAS Users Group International Conference, 12 1083-1088.

Barnett, S. M., \& Ceci, S. J. (2002). When and where do we apply what we learn? A taxonomy for far transfer. Psychological Bulletin, 128(4), 612.

Bassok, M., \& Holyoak, K. J. (1989). Interdomain transfer between isomorphic topics in algebra and physics. Journal of Experimental Psychology: Learning, Memory, and Cognition, 15(1), 153.

Bateson, G. (1972). Steps toward an ecology of mind. New York: Ballantine.

Belenky, D. M., \& Nokes-Malach, T. J. (2012). Motivation and transfer: The role of mastery-approach goals in preparation for future learning. Journal of the Learning Sciences, 21(3), 399-432.

Bereiter, C., \& Scardamalia, M. (1985). Cognitive coping strategies and the problem of inert knowledge. Thinking and Learning Skills, 2, 65-80.

Bernardo, A. B. (2001). Analogical problem construction and transfer in mathematical problem solving. Educational Psychology, 21(2), 137-150.

Berry, M., \& Coulthard, M. (1981). Studies in discourse analysis. Routledge.

Bevevino, M. M., Dengel, J., \& Adams, K. (1999). Constructivist theory in the classroom. internalizing: Concepts through inquiry learning. The Clearing House, 72(5), 275-278.

Birch, M. (1963). Maximum likelihood in three-way contingency tables. Journal of the Royal Statistical Society.Series B (Methodological), 220-233.

Bogdan, T. Y., \& Taylor, J. (1990). Introducción a los métodos de investigación cualitativa. Buenos Aires: Paidós. 
Boitel, C., Farkas, K., Fromm, L., \& Hokenstad, M. (2009). Learning transfer principles in a comprehensive integration model. Journal of Teaching in Social Work, 29(4), 400-417.

Borich, G. D., \& Tombari, M. L. (1997). Educational psychology: A contemporary approach. Longman Publishing/Addison Wesley L.

Bransford, J. D., Brown, A., \& Cocking, R. (2000). How people learn: Mind, brain, experience and school, expanded edition. DC: National Academy Press, Washington.

Bransford, J. D., \& Schwartz, D. L. (1999). Rethinking transfer: A simple proposal with multiple implications. Review of Research in Education, 61-100.

Bransford, J., Sherwood, R., Vye, N., \& Rieser, J. (1986). Teaching thinking and problem solving: Research foundations. American Psychologist, 41(10), 1078.

Broad, M. L., \& Newstrom, J. W. (1992). Transfer of training: Action-packed strategies to ensure high payoff from training investments. ERIC.

Brown, A. L., \& Campione, J. C. (1996). Psychological theory and the design of innovative learning environments: On procedures, principles, and systems. Lawrence Erlbaum Associates, Inc.

Bruner, J. (2012). What psychology should study. International Journal of Educational Psychology: IJEP, 1(1), 5-13.

Bruner, J. S. (1996). The culture of education. Harvard University Press.

Bullen, M. (1997). A Case Study of Participation and Critical Thinking in a University-Level Course Delivered by Computer Conferencing. (Doctoral Dissertation, University of British Columbia) 
Burnham, K. P., \& Anderson, D. R. (2002). Model selection and multimodel inference: A practical information-theoretic approach. Springer Science \& Business Media.

Calais, G. J. (2006). Haskell's taxonomies of transfer of learning: Implications for classroom instruction. National Forum of Applied Educational Research Journal, 20(3) 1-8.

Carpenter, T. P., Hiebert, J., \& Moser, J. M. (1981). Problem structure and firstgrade children's initial solution processes for simple addition and subtraction problems. Journal for Research in Mathematics Education, 27-39.

Carpenter, T. P., \& Moser, J. M. (1984). The acquisition of addition and subtraction concepts in grades one through three. Journal for Research in Mathematics Education, 179-202.

Carrión, R. G., Roldán, S. M., López, L. A. G., \& Valdez, N. B. (2016). Análisis de las interacciones entre alumnado y diversas personas adultas en actuaciones educativas de éxito: Hacia la inclusión de todos y todas. Revista Latinoamericana De Educación Inclusiva, 10(1), 115-132.

Catrambone, R. (1996). Generalizing solution procedures learned from examples. Journal of Experimental Psychology: Learning, Memory, and Cognition, 22(4), 1020.

Catrambone, R., \& Holyoak, K. J. (1989). Overcoming contextual limitations on problem-solving transfer. Journal of Experimental Psychology: Learning, Memory, and Cognition, 15(6), 1147.

Chamot, A. U. (1993). Student responses to learning strategy instruction in the foreign language classroom. Foreign Language Annals, 26(3), 308.

Chang, N. M. (2006). Learning to Discriminate and Generalize through Problem Comparisons (Doctoral Dissertion, Carnegie Mellon Universuty) . 
Chaplin, J. P., Krawiec, T. S., \& Hernández, J. C. P. (1983). Psicologia: Sistemas y teorías. Nueva Editorial Interamericana.

Chapman, E. (2003). Alternative approaches to assessing student engagement rates. Practical Assessment, Research and Evaluation, 13(8)

Chase, W. G., \& Simon, H. A. (1973). The mind's eye in chess. Cognitive Psychology, 4, 55-81

Chen, Z., \& Klahr, D. (2008). Remote transfer of scientific-reasoning and problem-solving strategies in children. Advances in Child Development and Behavior, 36, 420.

Chi, M. T., Feltovich, P. J., \& Glaser, R. (1981). Categorization and representation of physics problems by experts and novices. Cognitive Science, 5(2), 121-152.

Chi, M. T., \& VanLehn, K. A. (2012). Seeing deep structure from the interactions of surface features. Educational Psychologist, 47(3), 177-188.

Closas, A. H., Arriola, E. A., Zening, K., Isabel, C., Amarilla, M. R., \& Jovanovich, E. C. (2013). Análisis multivariante, conceptos y aplicaciones en psicología educativa y psicometría. Enfoques, 25(1), 65-92.

Cole, M., \& Wertsch, J. V. (1996). Beyond the individual-social antinomy in discussions of Piaget and Vygotsky. Human Development, 39(5), 250-256.

Coll, C. (1999). La concepción constructivista como instrumento para el análisis de las prácticas educativas escolares. Psicología de la instrucción: la enseñanza y el aprendizaje en la educación secundaria, 16-44.

Coll, C., Colomina, R., Onrubia, J., \& Rochera, M. J. (1992). Actividad conjunta y habla: Una aproximación al estudio de los mecanismos de influencia educativa. Infancia y Aprendizaje, 15(59-60), 189-232. 
Coll, C., \& Sánchez, E. (2008). Presentación. el análisis de la interacción alumno-profesor: Líneas de investigación. Revista De Educación, 346, 1532.

Correa, A. (2002). Análisis logarítmico lineal. Madrid: Editorial La Muralla, SA.

Cox, D. R., \& Snell, E. J. (1989). Analysis of binary data. CRC Press.

Cummins, D. D. (1992). Role of analogical reasoning in the induction of problem categories. Journal of Experimental Psychology: Learning, Memory, and Cognition, 18(5), 1103.

d'Ancona, M. A. C. (2002). Análisis multivariable: Teoría y práctica en la investigación social. Síntesis.

Deci, E., \& Ryan, R. M. (1985). Intrinsic motivation and self-determination in human behavior. Springer Science \& Business Media.

DeMaris, A. (1992). Logit modeling: Practical applications.SAGE.

Dobson, A. J., \& Barnett, A. (2008). An introduction to generalized linear models. CRC press.

Duit, R. (1991). On the role of analogies and metaphors in learning science. Science Education, 75(6), 649-672.

Edwards, A. (2011). Building common knowledge at the boundaries between professional practices: Relational agency and relational expertise in systems of distributed expertise. International Journal of Educational Research, 50(1), 33-39.

Edwards, D., \& Mercer, N. (1988). El conocimiento compartido: El desarrollo de la comprensión en el aula. Trad De Ramón Alonso. Temas de educación. Ed Paidós. 
Egbert, J. (2009). Supporting learning with technology: Essentials of classroom practice Pearson/Merrill/Prentice Hall.

Egbert, J., \& Roe, M. F. (2014). The power of why: Connecting curriculum to students' lives. Childhood Education, 90(4), 251-258.

Elboj, C., \& Oliver, E. (2003). Las comunidades de aprendizaje: Un modelo de educación dialógica en la sociedad del conocimiento. Revista Interuniversitaria de formación del profesorado, (48), 91-103.

Engelbrecht, J., Harding, A., \& Du Preez, J. (2007). Long-term retention of basic mathematical knowledge and skills with engineering students. European Journal of Engineering Education, 32(6), 735-744.

Engestrom, Y. (1987). Learning by expanding. Helsinki: Orienta-Konsultit Oy.

Engle, R. A. (2006). Framing interactions to foster generative learning: A situative explanation of transfer in a community of learners classroom. The Journal of the Learning Sciences, 15(4), 451-498.

Engle, R. A. (2012). The resurgence of research into transfer: An introduction to the final articles of the transfer strand. Journal of the Learning Sciences, 21(3), 347-352.

Engle, R. A., Lam, D. P., Meyer, X. S., \& Nix, S. E. (2012). How does expansive framing promote transfer? several proposed explanations and a research agenda for investigating them. Educational Psychologist, 47(3), 215-231.

Engle, R. A., Nguyen, P. D., \& Mendelson, A. (2011). The influence of framing on transfer: Initial evidence from a tutoring experiment. Instructional Science, 39(5), 603-628.

Fernández Pérez, M. (1989). Así enseña nuestra universidad. Salamanca: Hispagraphis.

Field, A., Miles, \& Field, J. (2012). Discovering statistics using R. SAGE 
Forguson, L., \& Gopnik, A. (1988). The ontogeny of common sense. Developing Theories of Mind, 226-243.

Friendly, M. (1992). Graphical methods for categorical data. SAS User Group International Conference Proceedings, 17 190-200.

Friendly, M. (1994). Mosaic displays for multi-way contingency tables. Journal of the American Statistical Association, 89(425), 190-200.

Friendly, M. (1999). Extending mosaic displays: Marginal, conditional, and partial views of categorical data. Journal of Computational and Graphical Statistics, 8(3), 373-395.

Gagné, R. (1970). Las teorías del aprendizaje. Madrid: Editorial Aguilar.

García, M. L. B., \& Jiménez, V. M. (1995). Los diarios de prácticas en la formación de maestros. Revista interuniversitaria de formación del profesorado, (23), 121-136.

Garson, G. D. (2014). Logistic regression: Binary and multinomial. Asheboro, NC: Statistical Publishing Associates.

Gatt, S., Ojala, M., \& Soler, M. (2011). Promoting social inclusion counting with everyone: Learning communities and INCLUD- ED. International Studies in Sociology of Education, 21(1), 33-47.

Gee, J. P., \& Green, J. L. (1998). Discourse analysis, learning, and social practice: A methodological study. Review of Research in Education, 23, 119-169.

Gentner, D. (1983). Structure- Mapping: A theoretical framework for analogy. Cognitive Science, 7(2), 155-170.

Gentner, D. (2003). Language in mind: Advances in the study of language and thought. MIT Press. 
Gentner, D., Holyoak, K. J., \& Kokinov, B. N. (2001). The analogical mind: Perspectives from cognitive science. MIT press.

Gentner, D., Loewenstein, J., \& Thompson, L. (2003). Learning and transfer: A general role for analogical encoding. Journal of Educational Psychology, 95(2), 393.

Gentner, D., Loewenstein, J., \& Thompson, L. (2004). Analogical encoding: Facilitating knowledge transfer and integration. Proceedings of the TwentySixth Annual Meeting of the Cognitive Science Society, b18.

Gentner, D., \& Markman, A. B. (1997). Structure mapping in analogy and similarity. American Psychologist, 52(1), 45.

Georghiades, P. (2000). Beyond conceptual change learning in science education: Focusing on transfer, durability and metacognition. Educational Research, 42(2), 119-139.

Gick, M. L., \& Holyoak, K. J. (1980). Analogical problem solving. Cognitive Psychology, 12(3), 306-355.

Gick, M. L., \& Holyoak, K. J. (1983). Schema induction and analogical transfer. Cognitive Psychology, 15(1), 1-38.

Giddens, A., \& Amaro, B. H. (1995). La transformación de la intimidad. Cátedra.

Gillies, R. M. (2015). Dialogic interactions in the cooperative classroom. International Journal of Educational Research.

Godden, D. R., \& Baddeley, A. D. (1975). Context- dependent memory in two natural environments: On land and underwater. British Journal of Psychology, 66(3), 325-331.

Godden, D., \& Baddeley, A. (1980). When does context influence recognition memory? British Journal of Psychology, 71(1), 99-104. 


\section{Referencias bibliográficas}

Goffman, E. (1974). Frame analysis: An essay on the organization of experience. Harvard University Press.

Goldstone, R. L., Landy, D. H., \& Son, J. Y. (2010). The education of perception. Topics in Cognitive Science, 2(2), 265-284.

Goldstone, R. L., \& Wilensky, U. (2008). Promoting transfer by grounding complex systems principles. The Journal of the Learning Sciences, 17(4), 465-516.

Gómez, C. B., Sanjosé, V., \& Solaz-Portolés, J. J. (2012). Una revisión de los procesos de transferencia para el aprendizaje y enseñanza de las ciencias. Didáctica De Las Ciencias Experimentales y Sociales, (26).

González, A. G., \& Holford, J. (2010). Contribuciones al éxito educativo desde la metodología comunicativa. Revista Educación y Pedagogía, 22(56), 2130.

Goodman, L. A. (1968). The analysis of cross-classified data: Independence, quasi-independence, and interactions in contingency tables with or without missing entries: RA fisher memorial lecture. Journal of the American Statistical Association, 63(324), 1091-1131.

Goodman, L. A., \& Kruskal, W. H. (1979). Measures of association for cross classifications. Springer.

Goodwin, C., \& Duranti, A. (1992). Rethinking context: Language as an interactive phenomenon. Cambridge University Press.

Greene, J. C., \& Caracelli, V. J. (2003). Making paradigmatic sense of mixed methods practice. Handbook of Mixed Methods in Social and Behavioral Research, 91-110.

Greeno, J. G. (1997). On claims that answer the wrong questions. Educational Researcher, 26(1), 5-17. 
Greeno, J., Smith, D., Moore, J., Detterman, D., \& Sternberg, R. (1993). Transfer on trial: Intelligence, cognition and instruction. Norwood NJ, Ablex.

Gunawardena, C. N., Lowe, C. A., \& Anderson, T. (1997). Analysis of a global online debate and the development of an interaction analysis model for examining social construction of knowledge in computer conferencing. Journal of Educational Computing Research, 17(4), 397-431.

Haberman, S. J. (1979). Analysis of qualitative data. vol. 2, new developments Academic Press.

Hair, J., Black, W., Babin, B., \& Anderson, R. (2014). Exploratory factor analysis. Multivariate Data Analysis, 7th Pearson New International Ed.Harlow: Pearson.

Hammer, D., Elby, A., Scherr, R. E., \& Redish, E. F. (2005). Resources, framing, and transfer. Transfer of Learning from a Modern Multidisciplinary Perspective, 89-120.

Harpaz-Itay, Y., Kaniel, S., \& Ben-Amram, E. (2006). Analogy construction versus analogy solution, and their influence on transfer. Learning and Instruction, 16(6), 583-591.

Hartigan, J. A., \& Kleiner, B. (1984). A mosaic of television ratings. The American Statistician, 38(1), 32-35.

Haskell, R. E. (2001). Transfer of learning: Cognition, instruction, and reasoning. San Diego: Academic Press.

Henri, F. (1992). Computer conferencing and content analysis. Springer.

Hernández-Sellés, N., González Sanmamed, M., \& Muñoz Carril, P. C. (2015). El rol docente en las ecologías de aprendizaje: Análisis de una experiencia de aprendizaje colaborativo en entornos virtuales. Profesorado, Revista de Currículum y Formación del Profesorado, 19(2), 147-163. 
Holding, D. (1987). Concepts of training. In G. Salvendy, G (Ed.), Handbook of human factors. New York: Wiley.

Holyoak, K. J., \& Morrison, R. G. (2005). The Cambridge handbook of thinking and reasoning. Cambridge University Press.

Hosmer Jr, D. W., Lemeshow, S., \& Sturdivant, R. X. (2013). Applied logistic regression. John Wiley \& Sons.

Hovelynck, J. (2000). Recognising and exploring action-theories: A reflectionin-action approach to facilitating experiential learning. Journal of Adventure Education \& Outdoor Learning, 1(1), 7-20.

Howe, C., Tolmie, A., Duchak-Tanner, V., \& Rattray, C. (2000). Hypothesis testing in science: Group consensus and the acquisition of conceptual and procedural knowledge. Learning and Instruction, 10(4), 361-391.

Hutchins, E. (1995). Cognition in the wild. MIT press.

Hutchison, P., \& Hammer, D. (2010). Attending to student epistemological framing in a science classroom. Science Education, 94(3), 506-524.

Ingold, T. (2014). That's enough about ethnography! HAU: Journal of Ethnographic Theory, 4(1), 383-395.

Iturra Herrera, C. (2013). Los diálogos construidos y los contenidos elaborados en clases dedicadas a la comprensión de textos, en aulas chilenas. Psicología Educativa, 19(2).

Jain, N., \& Warnes, G. R. (2006). Balloon plot. The Newsletter of the R Project Volume 6/2, may 2006, 35.

Jerlock, M., Falk, K., \& Severinsson, E. (2003). Academic nursing education guidelines: Tool for bridging the gap between theory, research and practice. Nursing \& Health Sciences, 5(3), 219-228. 
Johnson, S. M., \& Bolstad, O. D. (1972). Methodological issues in naturalistic observation: Some problems and solutions for field research. Final report.

Joraisti, L., \& Lizosain, L. (2000). Análisis de correspondencias. cuadernos de estadística. Ediciones La Muralla.

Klausmeier, H. J., \& Davis, J. K. (1969). Transfer of learning. Encyclopedia of Educational Research, 4.

Klausmeier, H. J. (1984). Educational psychology (5th ed.). New York: Harper and Row.

Knoke, D., \& Burke, P. J. (1980). Log-linear models. Sage.

Kok-Auntoh, \& Woolnough, B. E. (1994). Science process skills: Are they generalisable? Research in Science \& Technological Education, 12(1), 31-42.

Kuss, O. (2001). A SAS/IML macro for goodness-of-fit testing in logistic regression models with sparse data. 26th Annual SAS Users Group International Conference.

Lakoff, G., \& Johnson, M. (1999). Philosophy in the flesh: The embodied mind and its challenge to western thought. Basic books.

Lave, J. (1988). Cognition in practice: Mind, mathematics and culture in everyday life. Cambridge University Press.

Lave, J., \& Wenger, E. (1991). Situated learning: Legitimate peripheral participation. Cambridge University Press.

Leberman, S. I., \& Martin, A. J. (2004). Enhancing transfer of learning through post-course reflection. Journal of Adventure Education \& Outdoor Learning, 4(2), 173-184.

Lemke, J. L. (1997). Cognition, context, and learning: A social semiotic perspective. Situated Cognition: Social, Semiotic, and Psychological Perspectives, 37-56. 


\section{Referencias bibliográficas}

Lepper, M. R., \& Greene, D. (2015). The hidden costs of reward: New perspectives on the psychology of human motivation. Psychology Press.

Ley orgánica 2/2006, de 3 de mayo, de educación, (2006).

Lin, H., Hong, Z., \& Huang, T. (2012). The role of emotional factors in building public scientific literacy and engagement with science. International Journal of Science Education, 34(1), 25-42.

Lobato, J. (2006). Alternative perspectives on the transfer of learning: History, issues, and challenges for future research. The Journal of the Learning Sciences, 15(4), 431-449.

Lobato, J. (2012). The actor-oriented transfer perspective and its contributions to educational research and practice. Educational Psychologist, 47(3), 232247.

Lobato, J., Ellis, A. B., \& Munoz, R. (2003). How" focusing phenomena" in the instructional environment support individual students' generalizations. Mathematical Thinking and Learning, 5(1), 1-36.

Lobato, J., Rhodehamel, B., \& Hohensee, C. (2012). "Noticing" as an alternative transfer of learning process. Journal of the Learning Sciences, 21(3), 433-482.

Long, J. S. (1997). Regression models for categorical and limited dependent variables. SAGE.

Losada, J. L., \& López-Feal, R. (2003). Métodos de investigación en ciencias humanas y sociales. Madrid: Thomson.

MacLachlan, G., \& Reid, I. (1994). Framing and interpretation. Melbourne: Melbourne University Press.

Maestre, J. (1990). La investigación en antropología social. Madrid: Akal. 
Malone, T. W. (1981). Toward a theory of intrinsically motivating instruction. Cognitive Science, 5(4), 333-369.

Marton, F. (2006). Sameness and difference in transfer. The Journal of the Learning Sciences, 15(4), 499-535.

Mayer, R. E. (1987). Educational psychology: A cognitive approach. Glenview, IL: Scott, Foresman \& Co.

McCullagh, P., \& Nelder, J. (1989). Generalized linear models. London, UK: Chapman and Hall.

McFadden, D. (1973). Conditional logit analysis of qualitative choice behavior. Frontiers in Econometrics, 105-142.

Menard, S. (2000). Coefficients of determination for multiple logistic regression analysis. The American Statistician, 54(1), 17-24.

Mendelson, A. (2010). Using online forums to scaffold oral participation in foreign language instruction. L2 Journal, 2(1).

Mercer, N. (1995). The guided construction of knowledge: Talk amongst teachers and learners. Clecedon, Avon, England: Multilingual Matters.

Mercer, N. (2008). The seeds of time: Why classroom dialogue needs a temporal analysis. The Journal of the Learning Sciences, 17(1), 33-59.

Mercer, N., Dawes, L., Wegerif, R., \& Sams, C. (2004). Reasoning as a scientist: Ways of helping children to use language to learn science. British Educational Research Journal, 30(3), 359-377.

Mercer, N., Warwick, P., Kershner, R., \& Staarman, J. K. (2010). Can the interactive whiteboard help to provide 'dialogic space'for children's collaborative activity? Language and Education, 24(5), 367-384.

Mestre, A. (2003). Apología y crítica de España en el siglo XVIII. Madrid: Marcial Pons. 


\section{Referencias bibliográficas}

Ming, N. (2009). Analogies vs. contrasts: A comparison of their learning benefits. Proceedings of the Second International Conference on Analogy, 338347.

Mittlböck, M., \& Schemper, M. (1996). Explained variation for logistic regression. Statistics in Medicine, 15(19), 1987-1997.

Molina, E. (2005). Creación y desarrollo de comunicaciones de aprendizaje: Hacia la mejora educativa. Revista De Educación, (337), 235-250.

Moll, L. (1997). Vygotsky, la educación y la cultura en acción. Hacia Un Curriculum Cultural: La Vigencia De Vygotsky En La Educación, 39-53.

Moll, L. C., Amanti, C., Neff, D., \& Gonzalez, N. (1992). Funds of knowledge for teaching: Using a qualitative approach to connect homes and classrooms. Theory into Practice, 31(2), 132-141.

Montero, I., de Dios, M. J., \& Huertas, J. A. (2001). El desarrollo de la motivación en el contexto escolar: Un estudio a través del habla privada. Estudios De Psicología, 22(3), 305-318.

Mood, A., Graybill, F., \& Boes, D. (1974). Introduction to the theory of statistics. (Third ed.). New York (USA): McGraw-Hill.

Morris, C. D., Bransford, J. D., \& Franks, J. J. (1977). Levels of processing versus transfer appropriate processing. Journal of Verbal Learning and Verbal Behavior, 16(5), 519-533.

Nagelkerke, N. J. (1991). A note on a general definition of the coefficient of determination. Biometrika, 78(3), 691-692.

Nesher, P., \& Hershkovitz, S. (1994). The role of schemes in two-step problems: Analysis and research findings. Educational Studies in Mathematics, 26(1), $1-23$. 
Newman, D., Griffin, P., \& Cole, M. (1989). The construction zone: Working for cognitive change in school. Cambridge University Press.

Newstrom, J. (1984). A role-taker/time-differentiated integration of transfer strategies. Working Paper Series, 84(13).

Nokes, T. J. (2009). Mechanisms of knowledge transfer. Thinking \& Reasoning, 15(1), 1-36.

Nokes, T. J., \& Ohlsson, S. (2005). Comparing multiple paths to mastery: What is learned? Cognitive Science, 29(5), 769-796.

Nokes, T., \& Ohlsson, S. (2003). Declarative transfer from a memory task to a problem-solving task. Cognitive Science Quarterly, 3, 259-296.

Nokes-Malach, T. J., \& Mestre, J. P. (2013). Toward a model of transfer as sense-making. Educational Psychologist, 48(3), 184-207.

Novick, L. R. (1988). Analogical transfer, problem similarity, and expertise. Journal of Experimental Psychology: Learning, Memory, and Cognition, 14(3), 510.

Ohlsson, S. (1996). Learning from performance errors. Psychological Review, 103(2), 241.

Oliva, J. M. (2004). El pensamiento analógico desde la investigación educativa y desde la perspectiva del profesor de ciencias. REEC: Revista Electrónica De Enseñanza De Las Ciencias, 3(3), 7.

Olivares, R. A. (2002). Communication, constructivism and transfer of knowledge in the education of bilingual learners. International Journal of Bilingual Education and Bilingualism, 5(1), 4-19.

Orrantia, J., González, L. B., \& Vicente, S. (2005). Un análisis de los problemas aritméticos en los libros de texto de educación primaria. Infancia y Aprendizaje, 28(4), 429-451. 
Payne, H. (1992). Shut in, shut out. H. Payne (Ed.). London: Routledge.

Pea, R. D. (1987). Cognitive technologies for mathematics education. Cognitive Science and Mathematics Education, 89-122.

Peng, C. J., Lee, K. L., \& Ingersoll, G. M. (2002). An introduction to logistic regression analysis and reporting. The Journal of Educational Research, 96(1), 3-14.

Perkins, D. N., \& Salomon, G. (1988). Teaching for transfer. Educational Leadership, 46(1), 22-32.

Perkins, D. N., \& Salomon, G. (2012). Knowledge to go: A motivational and dispositional view of transfer. Educational Psychologist, 47(3), 248-258.

Peters, S., Barbier, M., Faulx, D., \& Hansez, I. (2012). Learning and motivation to transfer after an e-learning programme: Impact of trainees' motivation to train, personal interaction and satisfaction. Innovations in Education and Teaching International, 49(4), 375-387.

Pugh, K. J., Koskey, K. L., \& Linnenbrink-Garcia, L. (2014). High school biology students' transfer of the concept of natural selection: A mixed-methods approach. Journal of Biological Education, 48(1), 23-33.

R Core Team. (2015). R: A language and environment for statistical computing. Vienna, Austria: R Foundation for Statistical Computing.

Racionero, S., \& Padrós, M. (2010). The dialogic turn in educational psychology. Journal of Psychodidactics, 15(2).

Raftery, A. E. (1986). Choosing models for cross-classifications. American Sociological Review, 51(1), 145-146.

Ramachandran, V. S. (2008). Los laberintos del cerebro. Barcelona: La liebre de marzo. 
Rebello, N. S., Cui, L., Bennett, A. G., Zollman, D. A., \& Ozimek, D. J. (2007). Transfer of learning in problem solving in the context of mathematics and physics. Learning to Solve Complex Scientific Problems, 223-246.

Reed, S. K. (2012). Learning by mapping across situations. Journal of the Learning Sciences, 21(3), 353-398.

Reeves, L., \& Weisberg, R. W. (1994). The role of content and abstract information in analogical transfer. Psychological Bulletin, 115(3), 381.

Reznitskaya, A., Glina, M., Carolan, B., Michaud, O., Rogers, J., \& Sequeira, L. (2012). Examining transfer effects from dialogic discussions to new tasks and contexts. Contemporary Educational Psychology, 37(4), 288-306.

Richland, L. E., Stigler, J. W., \& Holyoak, K. J. (2012). Teaching the conceptual structure of mathematics. Educational Psychologist, 47(3), 189-203.

Rittle-Johnson, B., \& Star, J. R. (2007). Does comparing solution methods facilitate conceptual and procedural knowledge? an experimental study on learning to solve equations. Journal of Educational Psychology, 99(3), 561.

Rizzolatti, G. y Sinigaglia, C. (2006). Las neuronas espejo. Barcelona: Paidos

Rogoff, B. (1990). Apprenticeship in thinking: Cognitive development in social context. Oxford University Press.

Rogoff, B., Turkanis, C. G., \& Bartlett, L. (2002). Learning together: Children and adults in a school community. Oxford University Press.

Rois, C. (2014). El proceso de transferencia y de construcción conjunta de conocimiento en entornos comunicativos de aprendizaje (trabajo Fin de Máster). Universidad de Valladolid, Valladolid, España.

Rosalie, S. M., \& Müller, S. (2012). A model for the transfer of perceptual-motor skill learning in human behaviors. Research Quarterly for Exercise and Sport, 83(3), 413-421. 
Ross, B. H. (1984). Remindings and their effects in learning a cognitive skill. Cognitive Psychology, 16(3), 371-416.

Ross, B. H. (1987). This is like that: The use of earlier problems and the separation of similarity effects. Journal of Experimental Psychology: Learning, Memory, and Cognition, 13(4), 629.

Rossett, A. (1997). That was a great class, but... Training \& Development, 51(7), 18-25.

Salmerón, L. (2013). Actividades que promueven la transferencia de los aprendizajes: Una revisión de la literatura. Revista de Educación, 2013, vol. Extra, p. 34-53.

Sánchez, E., García, R., \& Rosales, J. (2010). La lectura en el aula. qué se hace, qué se debe hacer y qué se puede hacer. Barcelona: Graó.

Sanjosé López, V., Valenzuela Escriche, T., Fortes del Valle, M Carmen, \& Solaz-Portolés, J. J. (2007). Dificultades algebraicas en la resolución de problemas por transferencia. Revista Electrónica De Enseñanza De Las Ciencias, 2007, Vol.6, Num.3, P.538-561.

SAS Institute (2015). SAS (Versión 9.4) [Software de computación]. Cary, NC: SAS Institute.

Scherr, R. E., \& Hammer, D. (2009). Student behavior and epistemological framing: Examples from collaborative active-learning activities in physics. Cognition and Instruction, 27(2), 147-174.

Schleicher, A., Zimmer, K., Evans, J., \& Clements, N. (2009). PISA 2009 assessment framework: Key competencies in reading, mathematics and science. OECD Publishing (NJ1).

Schunk, D. H., \& Zimmerman, B. J. (2012). Motivation and self-regulated learning: Theory, research, and applications Routledge. 
Schwartz, D., \& Nasir, N. (2003). Transfer of learning. Encyclopedia of Education, 1449-1452.

Scribner, S. (1986). Thinking in action: Some characteristics of practical thought. Practical Intelligence: Nature and Origins of Competence in the Everyday World, 13, 60.

Searle, J. R. (1995). The construction of social reality. Simon and Schuster.

Seddon, G., \& Waweru, G. (1987). The transferability of scientific concepts between different languages for kenyan students. British Journal of Educational Psychology, 57(2), 244-248.

Sinclair, J. M., \& Coulthard, M. (1975). Towards an analysis ofdiscourse. New York: Oxford, 246.

Singley, M. K., \& Anderson, J. R. (1989). The transfer of cognitive skill. Harvard University Press.

Smedslund, J. (1953). The problem of" what is learned?". Psychological review, 60(3), 157-158.

Smith, S. M., Glenberg, A., \& Bjork, R. A. (1978). Environmental context and human memory. Memory \& Cognition, 6(4), 342-353.

Solaz-Portolés, J. J., \& Sanjosé López, V. (2007). Resolución de problemas, modelos mentales e instrucción. Revista Electrónica De Enseñanza De Las Ciencias, 2007, Vol.6, Num.1, P.70-89.

Solaz-Portolés, J. J., \& Sanjosé López, V. (2008). Conocimiento previo, modelos mentales y resolución de problemas: Un estudio con alumnos de bachillerato. Revista Electrónica De Investigación Educativa, 10(1), 1-16.

Sorensen, D., \& Gianola, D. (2002). Likelihood, bayesian, and MCMC methods in quantitative genetics. Springer Science \& Business Media. 
Spencer, R. M., \& Weisberg, R. W. (1986). Context-dependent effects on analogical transfer. Memory \& Cognition, 14(5), 442-449.

StataCorp. (2015). Stata statistical software: Release 14. college station, TX: StataCorp LP.

Steiger, J. H., \& Fouladi, R. T. (1997). Noncentrality interval estimation and the evaluation of statistical models. What if there were no Significance Tests, 221-257.

Sternberg, R. J. (1982). Handbook of human intelligence. CUP Archive.

Tabachnick, B. G., \& Fidell, L. S. (2012). Using multivariate statistics (6th ed.). New York: Pearson Education.

Tannen, D. (1993). What's in a frame? surface evidence for underlying expectations. Framing in Discourse, 14, 56.

Thorndike, E. L. (1903). Heredity, correlation and sex differences in school abilities: Studies from the Department of Educational Psychology at Teachers College. Columbia University. New York: Macmillan.

Thorndike, E. L. (1924). Mental discipline in high school studies. Journal of Educational Psychology, 15(1), 1.

Thorndike, E. L. (1932). The fundamentals of learning. New York: Teachers college, Columbia University.

Tjur, T. (2009). Coefficients of determination in logistic regression models-A new proposal: The coefficient of discrimination. The American Statistician, 63(4), 366-372.

Tójar, J. C. (2006). Investigación cualitativa: comprender y actuar. Madrid: La Muralla. 
Tomasello, M. (1999). The human adaptation for culture. Annual Review of Anthropology, 509-529.

Tomasello, M., Carpenter, M., Call, J., Behne, T., \& Moll, H. (2005). Understanding and sharing intentions: The origins of cultural cognition. Behavioral and Brain Sciences, 28(05), 675-691.

Valentin, J., \& Chap-Sam, L. (2005). Roles of semantic structure of arithmetic word problems on pupils' ability to identify the correct operation. International Journal for Mathematics Teaching and Learning (Electronic Journal).

Valls, R., \& Kyriakides, L. (2013). The power of interactive groups: How diversity of adults volunteering in classroom groups can promote inclusion and success for children of vulnerable minority ethnic populations. Cambridge Journal of Education, 43(1), 17-33.

Van Lehn, K. (1990). Mind bugs: The origin of arithmetical misconceptions. Cambridge: MIT press

VanderStoep, S. W., \& Seifert, C. M. (1994). Problem solving, transfer, and thinking. Student Motivation, Cognition, and Learning: Essays in Honor of Wilbert J.McKeachie, 27-49.

Verdugo, M., Gómez, L. E., Arias, B., \& Navas, P. (2010). Aplicación del paradigma de calidad de vida: Construcción de escalas de evaluación e investigación. En Verdugo, M., Crespo, M.T., \& Nieto,T (Coords.) Aplicación Del Paradigma De Calidad De Vida. VII Seminario De Actualización Metodológica En Investigación Sobre Discapacidad, 19-37.

Voss, J. F. (1987). Learning and transfer in subject-matter learning: A problemsolving model. International Journal of Educational Research, 11(6), 607622.

Vygotsky, L. S. (1995).Pensamiento y lenguaje. A. Kozulin (Ed.). Barcelona: Paidós. 


\section{Referencias bibliográficas}

Wells, G. S. B. (2001). Indagación dialógicahacia una teoría y una práctica socioculturales de la educación. Barcelona: Paidós.

Wells, G., \& Arauz, R. M. (2006). Dialogue in the classroom. The Journal of the Learning Sciences, 15(3), 379-428.

Wenger, E. (2001). Comunidades de práctica: Aprendizaje, significado e identidad. Barcelona: Paidós.

Wexley, K. N., Latham, G. P., Kettering, M., Rivaldo, O., \& Christensen, J. (1991). Developing and training human resources in organizations. Department of Agriculture, Washington, DC (EUA). Office of International Cooperation and Development. AID, Washington, DC (EUA). Bureau for Science and Technology.

Wilson, J. W. (1967). The role of structure in verbal problem solving. The Arithmetic Teacher, 14(6), 486-497.

Zoller, U., Lubezky, A., Nakhleh, M. B., Tessier, B., \& Dori, Y. J. (1995). Success on algorithmic and LOCS vs. conceptual chemistry exam questions. Journal of Chemical Education, 72(11), 987. 


\section{APÉNDICES}

Apéndice A. Categorías iniciales

Apéndice B. Transcripciones y categorización

Apéndice $\mathrm{C}$. Sintaxis de los análisis exploratorios $(\mathrm{R})$

Apéndice D. Sintaxis del análisis logarítmico-lineal (R)

Apéndice E. Sintaxis del análisis de regresión logística (SAS)

Apéndice F. Código de otros análisis (R)

Apéndice G. Código de otros análisis (STATA) 


\section{Apéndice A: Categorías iniciales}

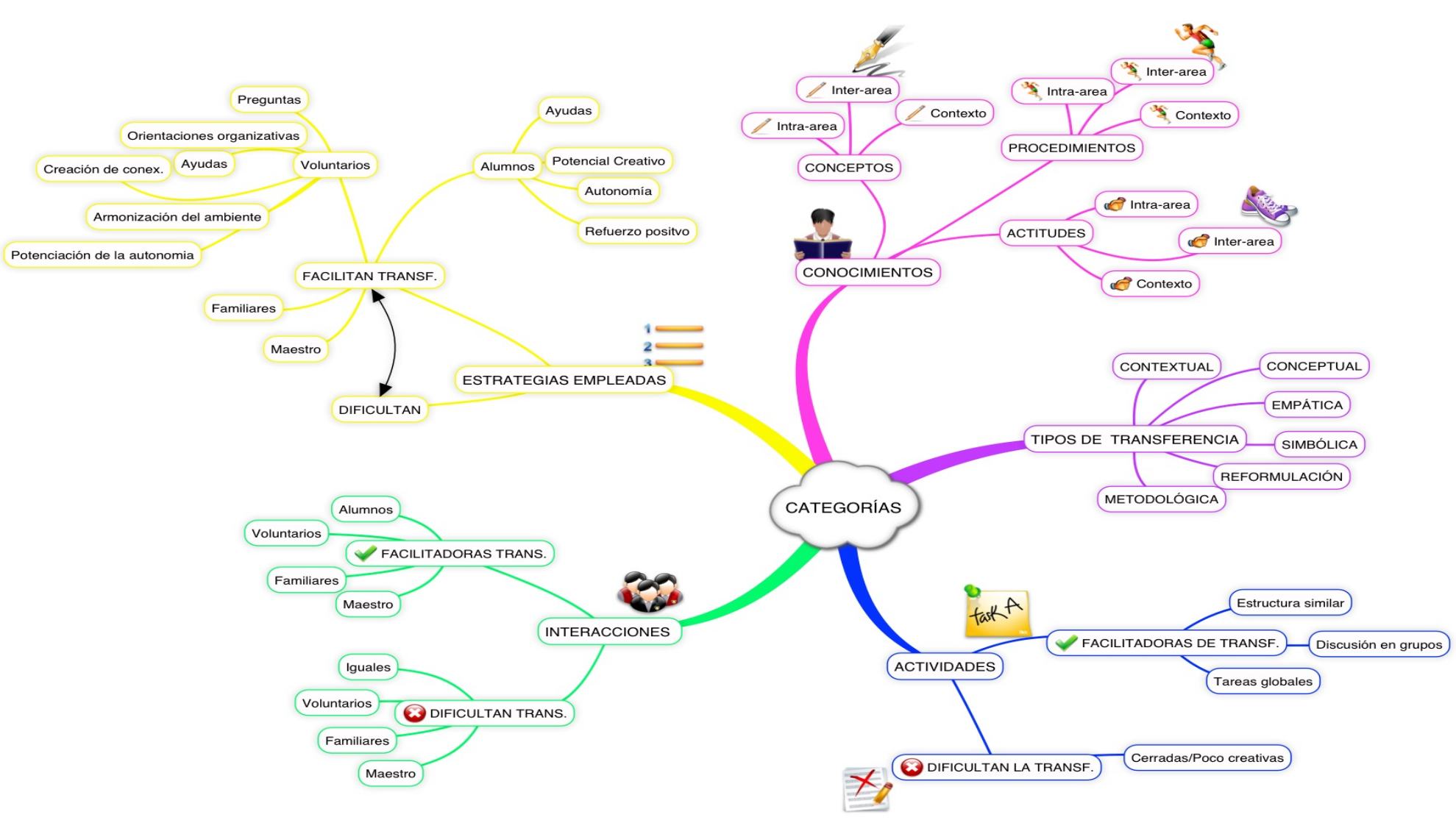




\section{Apéndice B \\ Transcripciones y categorización}

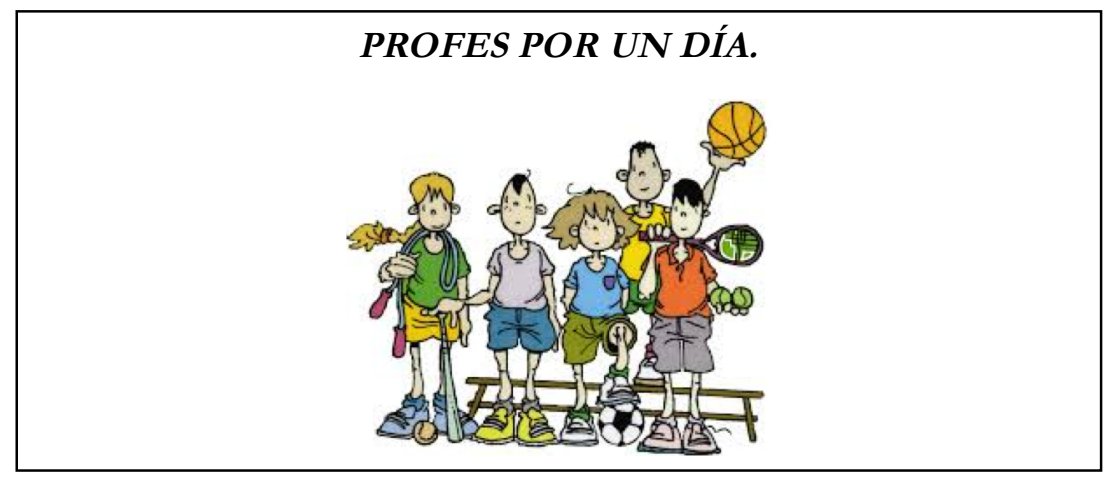

\section{$1^{\circ}$ PENSAMOS}

- Sois los profes de educación física y tenéis que crear una actividad para la clase de hoy. Para ello debéis poneros de acuerdo y redactar una actividad en forma de circuito con todas las habilidades atléticas que hemos practicado durante la unidad: carrera, marcha, relevos, saltos, ...

- Pensad cuántas pruebas vais a hacer y qué material vais a usar antes de ir a por el material. (15-20 minutos)

Número de pruebas:

Material:

Dibujo:

\section{$2^{\circ}$ ACTUAMOS}

Llevamos a cabo la actividad propuesta.

$3^{\circ}$ REVISAMOS Y COMENTAMOS 
Comentamos los posibles fallos de la actividad y la valoramos entre todos:

- ¿Qué es lo que más os ha gustado?

- ¿Qué cambiaríais?

Los apoyos incluidos en la tarea son:

- Explicación de la meta de la actividad, en concreto la creación de un circuito y las partes que debe contener

- Contexto cercano, la tarea los convierte en profesores de E.F, conectando con anteriores actividades de este tipo realizadas en dicha área.

\section{PROFES POR UN DÍA}

26 de marzo de 2014

- Área: Educación Física

- Grupo: $5^{\circ}$

- Hora: 9:30 a.m.

- Grupo: Alumno_1, Alumno_2, Alumno_3, Alumno_4, Alumno_5, Alumno_6

- Adulto: Voluntaria_6, Voluntaria_7, Voluntaria_8, Voluntario_3, Voluntario_4 y Maestra.

\section{EPISODIO LECTURA}

\subsection{1}

Alumno_2: A ver (se dirige a Alumno_3) ¿Qué queréis coger?

Voluntario_4: No, lee en alto que se enteren todos _Voluntaria_7: léelo en alto] Alumno_2: ¿Otra vez, leo esto? Uno, inventar un circuito con todas las habilidades atléticas que hayamos practicado durante la unidad, carrera, marcha, saltos...pensad cuántas pruebas vais a hacer y qué material vais a usar, antes de ir a por el material, quince y veinte minutos. Número de pruebas, material a utilizar y dibujo del circuito.

\subsection{EPISODIO DE NEGOCIACIÓN/REALIZACIÓN}

\subsubsection{Ciclo 1}

Ciclo de tipo DIALÓGICO: negociación en busca de consenso, los propios alumnos plantean interrogantes y llevan a cabo valoraciones del proceso seguido.

Se inicia con una propuesta de un miembro del grupo y continúa con numerosas interacciones entre el alumnado con el fin de llegar a un acuerdo en los materiales necesarios y las pruebas a realizar en el circuito

Finaliza cuando llegan a dicho acuerdo. 


\section{Apéndice $B$}

Alumno_6: Podíamos coger una colchoneta.

Alumno_2: Y ¿vas a ir tú con la colchoneta?

Alumno_6: Sí.

\begin{tabular}{|l|l|l|l|l|l|l|}
\hline 1.1 & 3 & 2 & 1 & 2 & 3 & 2 \\
\hline
\end{tabular}

Voluntario_4: A ver żcuántas pruebas queréis hacer?

Alumno_6: Por lo menos cinco [Alumno_3, Alumno_2 y Alumno_4: tres, tres]

\begin{tabular}{|l|l|l|l|l|l|l|}
\hline $1.1 \mathrm{a}$ & 3 & 2 & 1 & 2 & 3 & 2 \\
\hline
\end{tabular}

Voluntario_3: Pero tres, tenemos que trabajar todo lo que pone carrera, marcha, saltos y relevos.

Alumno_3: Tres.

Alumno_6: Por eso, cuatro, la colchoneta para saltar.

Voluntario_3: Vale.

Alumno_2: Pero ... Y ¿qué hacemos, volteretas?

Alumno_6: Lo que queráis.

Alumno_4: Para saltar.

Alumno_6: Yo voy a hacer un mortal.

\begin{tabular}{|l|l|l|l|l|l|l|}
\hline $1.1 \mathrm{~b}$ & 3 & 2 & 1 & 2 & 3 & 2 \\
\hline
\end{tabular}

Maestra: Es un circuito como el que a veces hago con vosotros, lo que pasa es que hoy lo inventáis vosotros, otro día yo os pongo picas, os pongo ladrillos, os pongo cuerdas... [Alumno_4: las tenemos que saltar] utilizamos las espalderas, ¿vale? Y lo tenemos que saltar o... (Alumno_2 y Alumno_4 empiezan a hablar entre ellas) Alumno_2,

\begin{tabular}{|l|l|l|l|l|l|l|}
\hline $1.1 \mathrm{c}$ & 3 & 4 & 1 & 2 & 3 & 2 \\
\hline
\end{tabular}

...escucha ¿vale? Y ahora habláis vosotros, entonces lo que quiero es que montéis un circuito con el material que usamos normalmente ¿vale?

Alumno_6: Y ¿una colchoneta no podemos coger?

\begin{tabular}{|l|l|l|l|l|l|l|}
\hline 1.d & 3 & 2 & 1 & 2 & 3 & 2 \\
\hline
\end{tabular}

Maestra: Claro que podéis coger una colchoneta, abi tenéis el cuarto del material y todo el material que hay lo podéis utilizar, pero, lo que os decía Voluntario_3 y lo que os dice Voluntario_4. Primero ¿Cuántas pruebas vais a utilizar? [Alumno_3: cuatro] y tenéis que utilizar todas las habilidades, o sea, una tiene que ser marcha, otra tiene que ser salto otra tiene que ser relevos, ¿vale? ¿Cómo nos organizamos eso? Alumno_2 revisa lo que han escrito en la ficha: Carrera, marcha, relevos, saltos y...ya está, cuatro. [Alumno_1: cuatro.]

Maestra: ¿Vale? Pues venga.

Alumno_3 dice a Alumno_2: Venga, vamos a por el material. Alumno_2: Espérate. 


\begin{tabular}{|l|l|l|l|l|l|l|}
\hline $1.1 \mathrm{e}$ & 3 & 1 & 1 & 2 & 3 & 2 \\
\hline
\end{tabular}

Maestra: Pero espera, antes de ir a por el material ¿qué tienes que hacer?

Alumno_4: Saltar ladrillos.

Alumno_6: Saltar la colchoneta.

Alumno_3: O los ladrillos.

Alumno_2: ¿Por qué no empezamos con los ladrillos? Hacemos unas volteretas en la colchoneta y luego salimos corriendo.

Alumno_6: Como queráis.

Alumno_5: Yo no sé hacer volteretas.

Alumno_3: Yo tampoco.

Alumno_6: Pues saltar, bija.

\begin{tabular}{|l|l|l|l|l|l|l|}
\hline $1.1 \mathrm{f}$ & 3 & 4 & 1 & 2 & 3 & 2 \\
\hline
\end{tabular}

Maestra: ¿Vale? ¿Qué alternativa proponéis para que Alumno_5 la pueda hacer, en vez, de hacer una voltereta?

Alumno_4 le propone una alternativa: Haces así (hace el movimiento) y ya está.

Alumno_6: Pero en la colchoneta, la colchoneta.

Alumno_3: $O$ en el banco.

Alumno_2: $A$ ver.

Alumno_3: No Alumno_6, en el banco mejor.

Alumno_2: $Y$; de saltos?

Alumno_3: En el banco.

Alumno_6: Pero es que en el banco no mola.

Alumno_1: El banco yo no sé.

Maestra: Vale de saltos...

\begin{tabular}{|l|l|l|l|l|l|l|}
\hline $1.1 \mathrm{~g}$ & 3 & 3 & 1 & 2 & 3 & 2 \\
\hline
\end{tabular}

Alumno_4 repite el movimiento: Es hacer asi y asi y ya está.

Alumno_6: En la colchoneta era mejor.

\begin{tabular}{|l|l|l|l|l|l|l|}
\hline $1.1 \mathrm{~h}$ & 3 & 2 & 1 & 2 & 3 & 2 \\
\hline
\end{tabular}

Alumno_3 a Alumno_1: Te agarras (apoya las manos en el suelo imitando el movimiento).

\begin{tabular}{|l|l|l|l|l|l|l|}
\hline $1.1 \mathrm{i}$ & 3 & 2 & 1 & 2 & 3 & 2 \\
\hline
\end{tabular}

Maestra: Podéis hacer varias pruebas de salto ¿no? [Alumno_6: sí...por ejemplo.] salto de altura, salto de longitud.

Alumno_4: Como bicimos.

Alumno_6: Salto de lado, profe.

\begin{tabular}{|l|l|l|l|l|l|l|}
\hline $1.1 j$ & 3 & 2 & 1 & 2 & 3 & 2 \\
\hline
\end{tabular}

Maestra: Claro, saltar en zigzag como bicimos en los bancos...

Alumno_4: ¿Quées eso? 


\section{Apéndice $B$}

Alumno_6: Saltar (se levanta y hace el movimiento para que Alumno_4 lo vea) tienes que saltar así.

\begin{tabular}{|l|l|l|l|l|l|l|}
\hline $1.1 \mathrm{k}$ & 3 & 4 & 1 & 2 & 3 & 2 \\
\hline
\end{tabular}

Maestra: ¿Vale? Venga id pensando... y Alumno_5 jestás dentro del grupo verdad?

Alumno_5: Sí.

\begin{tabular}{|l|l|l|l|l|l|l|}
\hline 1.11 & 3 & 4 & 1 & 2 & 3 & 2 \\
\hline
\end{tabular}

Maestra: Pues entonces, no te he visto hablar.

Alumno_6: Yo sí.

\begin{tabular}{|l|l|l|l|l|l|l|}
\hline $1 . \mathrm{m}$ & 3 & 4 & 1 & 2 & 3 & 2 \\
\hline
\end{tabular}

Maestra: Tú sí, pero Alumno_5 no está dentro del grupo, jvenga va!

Alumno_2: De primero ¿cual escogemos?

Alumno_3: El de los ladrillos, rodear los ladillos...agg

Alumno_6: Y podemos coger y hacer como un zigzag asi (gestos con la mano).

Alumno_4: Es verdad, en los bancos.

Alumno_3 dice a Alumno_2: Hacer así (gestos con la mano) ¿sabes?

Alumno_2: Eso es lo de (también hace gestos con la mano imitando el movimiento en rigrag).

Alumno_4 dice a Alumno_2 señalando la ficha: Pon aquí un ladrillo.

Alumno_3 dice a Alumno_6: Poner los ladrillos esos y luego hacer asi (gestos de rigrag)

Alumno_5: Poner los ladrillos y hacer así (imita el gesto de Alumno_3).

\section{CICLO 2}

Ciclo dialógico, ya que continúan las interacciones en busca de consenso, los propios alumnos plantean interrogantes y llevan a cabo valoraciones. Comienza con una nueva fase de la tarea, dibujar el circuito y a su vez se vuelven a replantear las propuestas del ciclo anterior.

Se cierra al finalizar la negociación de qué pruebas incluir en su dibujo

Mientras Alumno_2 va dibujando el circuito en la ficha con la supervisión de Alumno_4.

Alumno_2: Rodeamos esto ¿no? Y luego ¿qué hacemos? ¿pasamos a las colchonetas?

\begin{tabular}{|l|l|l|l|l|l|l|}
\hline 1.2 & 3 & 4 & 1 & 2 & 3 & 2 \\
\hline
\end{tabular}

Maestra: Alumno_5 te repito, parece que estás abi sentada como...puesta por el ayuntamiento.

Alumno_4: Habla.

Maestra: Acércate al papel y habla jvengaaa! 
Transcripciones y categorización

\begin{tabular}{|l|l|l|l|l|l|l|}
\hline $1.2 \mathrm{a}$ & 3 & 4 & 1 & 2 & 3 & 2 \\
\hline
\end{tabular}

Alumno_4 dice a Alumno_2, que es la que tiene la ficha: Acércate, que se entere Alumno_5

Alumno_6: ¿No sabéis saltar en el banco, bija?

\begin{tabular}{|l|l|l|l|l|l|l|l|}
\hline $1.2 \mathrm{~b}$ & 3 & 2 & 1 & 2 & 3 & 2 & 3 \\
\hline
\end{tabular}

Alumno_3: Alumno_2, ¿Puedes saltar en el banco con las manos así (apoya las manos en el suelo) y dar la vuelta?

Alumno_6: Yo sin manos.

Alumno_2: A ver, pero tampoco se salta asi (mueve los pies).

\begin{tabular}{|l|l|l|l|l|l|l|}
\hline $1.2 \mathrm{c}$ & 3 & 2 & 1 & 2 & 3 & 2 \\
\hline
\end{tabular}

Alumno_6: O sin manos podéis hacerlo.

\begin{tabular}{|c|c|c|c|c|c|c|}
\hline \multirow[t]{2}{*}{$1.2 \mathrm{~d}$} & 3 & 2 & 1 & 2 & 3 & 2 \\
\hline & & & & & & es asi. \\
\hline 1.26 & 3 & 2 & 1 & 2 & 3 & 2 \\
\hline
\end{tabular}

Alumno_5: Que baces así (gestos con la mano).

Alumno_3 hace el mismo gesto y dice a Alumno_5: Eso, eso.

\begin{tabular}{|l|l|l|l|l|l|l|}
\hline $1.2 \mathrm{f}$ & 3 & 2 & 1 & 2 & 3 & 2 \\
\hline
\end{tabular}

Alumno_5: Haces así, te agarras con las manos.

Alumno_3: Eso

\begin{tabular}{|l|l|l|l|l|l|l|}
\hline $1.2 \mathrm{~g}$ & 3 & 2 & 1 & 2 & 3 & 2 \\
\hline
\end{tabular}

Voluntario_3: Avísale para que lo ponga el segundo.

Alumno_3: ¿Eh?

Alumno_5: Eso de los bancos.

Alumno_6: O puede ser sin manos.

Alumno_3: Con manos.

Alumno_5: Con manos o sin manos.

Alumno_2: Ese qué es jel de saltar?

Alumno_6: Si

Alumno_3: Venga el del banco, con manos eh.

Alumno_4: Pon...

Alumno_6: Pues pon una raya y ya está.

\begin{tabular}{|l|l|l|l|l|l|l|}
\hline $1.2 \mathrm{~h}$ & 3 & 2 & 1 & 2 & 3 & 2 \\
\hline
\end{tabular}

Alumno_4 ayuda a Alumno_2 a dibujar el circuito en la ficha

Alumno_3: Correr ¿no? (mira a Maestra) ¿Podemos correr?

\begin{tabular}{|l|l|l|l|l|l|l|}
\hline $1.2 \mathrm{i}$ & 3 & 2 & 1 & 2 & 3 & 2 \\
\hline
\end{tabular}

Maestra: ¡Debéis de correr!

Alumno_6: ¿Cuántos somos? Cinco ¿no?

Maestra: No podéis, debéis de correr.

Alumno_6: Unos profes se ponen alli y los niños aqui y hacemos correr.

Alumno_4: Noo, porque así necesitamos ayuda de ellos. 


\section{Apéndice $B$}

Alumno_3: ¿Y hacemos relevos?

Alumno_5: ¿Y cuál es relevo?

\begin{tabular}{|l|l|l|l|l|l|l|}
\hline $1.2 \mathrm{j}$ & 3 & 2 & 1 & 2 & 3 & 2 \\
\hline
\end{tabular}

Alumno_3: ¿No te acuerdas el chisme ese? (gestos con las manos) el palo ese.

\begin{tabular}{|l|l|l|l|l|l|l|}
\hline $1.2 \mathrm{k}$ & 3 & 2 & 1 & 2 & 3 & 2 \\
\hline
\end{tabular}

Maestra: ¿Cómo se llamaba el palo ese?

Alumno_3: jEl relevo!

Alumno_4: ¡Cuál?

\begin{tabular}{|l|l|l|l|l|l|l|}
\hline 1.21 & 3 & 2 & 1 & 2 & 3 & 2 \\
\hline Maestra:(repite) ¿Cómo se llamaba el palo ese? [Alumno_2: ¿Qué palo?] ¿Qué
\end{tabular} palo?

\begin{tabular}{|l|l|l|l|l|l|l|}
\hline $1.2 \mathrm{~m}$ & 3 & 2 & 1 & 2 & 3 & 2 \\
\hline
\end{tabular}

Alumno_6: Alumno_5 ¿Te acuerdas cuando estábamos en el patio que hacíamos asi

(gestos)? ;Eso!

\begin{tabular}{|l|l|l|l|l|l|l|}
\hline $1.2 \mathrm{n}$ & 3 & 2 & 1 & 2 & 3 & 2 \\
\hline
\end{tabular}

Voluntario_3: En la carrera de relevos, que te dan un palo [Alumno_3: sí] ¿Cómo se llama?

Alumno_4: Abh el que babia que coger.

Alumno_2: Eso que pusimos abí...

\begin{tabular}{|l|l|l|l|l|l|l|}
\hline $1.2 \tilde{n}$ & 3 & 2 & 1 & 2 & 3 & 2 \\
\hline
\end{tabular}

Maestra: Lo que hicisteis el otro día con Voluntaria_6 y con Voluntaria_7.

Alumno_3: ¿Cómo se llama?

Alumno_2: Lo que bicimos contigo (señala a Voluntaria_6).

\begin{tabular}{|l|l|l|l|l|l|l|}
\hline $1.2 \mathrm{O}$ & 3 & 2 & 1 & 2 & 3 & 2 \\
\hline
\end{tabular}

Alumno_3: El palo que os pasabais.

Alumno_2: Ainss que no me acuerdo... ese palo.

Alumno_6: Lo tengo en la punta de la lengua.

\begin{tabular}{|l|l|l|l|l|l|l|}
\hline $1.2 \mathrm{p}$ & 3 & 2 & 1 & 2 & 3 & 2 \\
\hline
\end{tabular}

Maestra: ¿Cómo se llama, venga?

Alumno_3: ¿Re-relevo?

\begin{tabular}{|l|l|l|l|l|l|l|}
\hline $1.2 \mathrm{q}$ & 3 & 2 & 1 & 2 & 3 & 2 \\
\hline
\end{tabular}

Maestra: Pista, cuando vais a un juzgado, también lo bay...y no es el juez:

Alumno_3: Abh el que da (gesto con la mano).

\begin{tabular}{|l|l|l|l|l|l|l|}
\hline $1.2 \mathrm{r}$ & 3 & 2 & 1 & 2 & 3 & 2 \\
\hline
\end{tabular}

Maestra: ¿Cómo se llama? Es una persona.

Alumno_6: Acusado.

\begin{tabular}{|l|l|l|l|l|l|l|}
\hline $1.2 \mathrm{~s}$ & 3 & 2 & 1 & 2 & 3 & 2 \\
\hline
\end{tabular}

Maestra: vale el acusado y dice "no yo tengo coartada porque estaba, tengo a un..." Alumno_6: Eljuer. 


\begin{tabular}{|l|l|l|l|l|l|l|}
\hline $1.2 \mathrm{t}$ & 3 & 2 & 1 & 2 & 3 & 2 \\
\hline
\end{tabular}

Maestra: Tengo a una persona que puede.

Alumno_3: El juez.

Alumno_2: ¡Testigos!

Maestra: ;Testigos!

Alumno_3: El testigo

Alumno_2: Vess, lo tenía en la punta de la lengua jtestigos!

\begin{tabular}{|l|l|l|l|l|l|l|}
\hline $1.2 \mathrm{u}$ & 3 & 3 & 1 & 2 & 3 & 2 \\
\hline
\end{tabular}

Maestra: Vale, testigo.

Alumno_3 dice a Alumno_5: El testigo es el que te decia, pos hacemos....

\section{CICLO 3}

Ciclo de nuevo dialógico

Se inicia con una nueva problemática a resolver, en este caso, reflexionar sobre el material necesario según el número de participantes.

Finaliza cuando se aclara el problema

Alumno_3: Es que somos cinco profes.

\begin{tabular}{|l|l|l|l|l|l|l|}
\hline 1.3 & 3 & 2 & 1 & 2 & 3 & 2 \\
\hline
\end{tabular}

Maestra: ¿Sois cinco?

Alumno_6: Profe somos diez:

Alumno_3 Cuenta uno a uno.

Alumno_6 le dice a Alumno_3: Cinco mayores y cinco niños.

Alumno_3: Pues los profesores en un grupo [Alumno_2: zentonces?] y los niños en otro grupo.

Alumno_5 también cuenta uno a uno los miembros del grupo.

Alumno_4: Noo, somos...

\begin{tabular}{|l|l|l|l|l|l|l|}
\hline $1.3 \mathrm{a}$ & 3 & 4 & 1 & 2 & 3 & 2 \\
\hline
\end{tabular}

Voluntario_3 dice a Alumno_5: Dile cuántos somos.

Alumno_3: Somos en total die:.

\begin{tabular}{|l|l|l|l|l|l|l|}
\hline $1.3 \mathrm{~b}$ & 3 & 2 & 1 & 2 & 3 & 2 \\
\hline
\end{tabular}

Voluntario_3: Y iniños?

Alumno_5: Somos cinco de niños.

Alumno_5: Somos diez, de niños somos... (cuenta de nuevo).

Alumno_2: Somos seis, Alumno_3, tres y tres, seis.

Alumno_5: Seis, lo iba a decir yo, seis niños y cinco profesores.

Alumno_2: Entonces ponemos las ... [Alumno_5: un, dos, tres, cuatro, cinco y seis niños.]

Alumno_3: Pero en total somos diez:

Alumno_5: En total diez, pero niños somos seis y profesores cinco. 


\section{Apéndice $B$}

\begin{tabular}{|l|l|l|l|l|l|l|}
\hline $1.3 \mathrm{c}$ & 3 & 2 & 1 & 2 & 3 & 2 \\
\hline
\end{tabular}

Maestra: Pues entonces no somos diez, si sois [Alumno_2: Entonces somos once]

Eso iba a decir...

Alumno_6: Pero Maestra no juega porque está con el iPad.

Maestra: Eso es, también.

\section{CICLO 4}

Ciclo también dialógico por motivos expresados anteriormente.

Se inicia con una nueva cuestión, reformular alguna de las pruebas elegidas y aclarar en qué consiste

Finaliza una vez se solucionan las dudas planteadas

Alumno_2: A ver, una cosa, entonces ¿qué ponemos? Ponemos las cosas azules.

Alumno_4: Sí, pero...pasar la cuerda saltando.

Alumno_3: Mira, como somos seis, tres en un grupo y otros tres en otro grupo [Alumno_2: a ver, el de relevos] y vamos corriendo, cogemos los... ¿cómo se llaman los circulitos esos? Y los ponemos dos o tres y pasamos los [Alumno_6: el testigo]... el testigo.

\begin{tabular}{|l|l|l|l|l|l|l|}
\hline 1.4 & 3 & 3 & 1 & 2 & 3 & 2 \\
\hline
\end{tabular}

Maestra: Espera a ver, ¿Qué pruebas tenéis? Recapitulamos.

\begin{tabular}{|l|l|l|l|l|l|l|}
\hline $1.4 \mathrm{a}$ & 3 & 3 & 1 & 2 & 3 & 2 \\
\hline
\end{tabular}

Voluntario_3: ¿Cuáles lleváis hechas?

Alumno_3: Saltar a la comba.

Alumno_2: Pero ya tenemos otras de saltar.

\begin{tabular}{|l|l|l|l|l|l|l|}
\hline $1.4 \mathrm{~b}$ & 3 & 2 & 1 & 2 & 3 & 2 \\
\hline
\end{tabular}

Voluntario_3: Saltarya le tenemos.

Alumno_2: A ver la...aaaaa...la carrera, ya tenemos hecha la carrera, que es lo de...espera que se ha hecho un pedazo de lio.

\begin{tabular}{|l|l|l|l|l|l|l|}
\hline $1.4 \mathrm{c}$ & 3 & 4 & 1 & 2 & 3 & 2 \\
\hline
\end{tabular}

Maestra: Alumno_6 jüntate que no has visto ni el dibujo, venga...venga a ver.

Alumno_4: $A$ ver las colchonetas.

Alumno_2: La carrera es esto (señala la ficha).

Alumno_3: Lo de las picas que tienes que hacer asi (gestos).

Alumno_2: Saltar es esto y relevos es esto, y falta la marcha (señala la ficha).

Alumno_3: La marcha.

Alumno_6: Un grupo marcha delante y otro grupo marcha atrás y luego lo cambia-

mos.

Alumno_4: Es verdad.

Alumno_3: Noo.

\begin{tabular}{|l|l|l|l|l|l|l|}
\hline $1.4 \mathrm{~d}$ & 3 & 2 & 1 & 2 & 3 & 2 \\
\hline
\end{tabular}


Maestra: ¿Qué era la marcha?

Alumno_3: Ehh pues correr.

Alumno_6: No, correr no (se levanta).

Alumno_3: Andar deprisa.

Alumno_4 también se levanta con la intención de ejemplificar la marcha y dice: Andar deprisa.

Alumno_6: Asi (hace el movimiento de la marcha).

\begin{tabular}{|l|l|l|l|l|l|l|}
\hline $1.4 \mathrm{e}$ & 3 & 3 & 1 & 2 & 3 & 2 \\
\hline
\end{tabular}

Maestra: Vale, vale.

Alumno_2: Venga, pues eso.

Alumno_3: Hacer así.

\section{CICLO 5}

CICLO DIALÓGICO: los propios alumnos piden ayuda, realizan valoraciones y reflexiones (ALUMNO_2 $\rightarrow$ Pero es que carreras ya tenemos / ALUMNO_5

$\rightarrow$ A lo mejor también se podría jugar a la araña peluda / ALUMNO_2 $\rightarrow$

¿Pero y eso qué es?

Comienza con una propuesta de reflexión por parte de la profesora, para que revisen el proceso realizado. Finaliza cuando se llega a un acuerdo de las pruebas que finalmente formarán su circuito.

\begin{tabular}{l|l|l|l|l|l|l|l}
\hline 1.5 & 3 & 2 & 1 & 2 & 3 & 2 \\
\hline
\end{tabular} Maestra: Y tenéis que marcar un circuito para ver de dónde a donde, ¿no? Venga
que estoy hablando demasiado, venga que yo no tenía que bablar nada.

Alumno_2 dice a los voluntarios: Es que no decís nada, estáis callados.

\begin{tabular}{|l|l|l|l|l|l|l|}
\hline $1.5 \mathrm{a}$ & 3 & 4 & 1 & 2 & 3 & 2 \\
\hline
\end{tabular}

Voluntario_4: Eso lo tenéis que hacer vosotros.

\begin{tabular}{|l|l|l|l|l|l|l|}
\hline $1.5 \mathrm{~b}$ & 3 & 4 & 1 & 2 & 3 & 2 \\
\hline
\end{tabular}

Maestra: Lo tenéis que hacer vosotros.

Alumno_2: Pero podéis darnos una idea.

\begin{tabular}{|l|l|l|l|l|l|l|}
\hline $1.5 \mathrm{c}$ & 3 & 2 & 1 & 2 & 3 & 2 \\
\hline
\end{tabular}

Voluntario_3: Sí, para hacer la marcha ¿qué tenéis que hacer? [Alumno_6: Pues unos se ponen abí... ¿ ¿ Un circuito no? pues pensad como podéis dibujar ese circuito.

Alumno_6: O carreras, podíamos hacer de... de marcha.

\begin{tabular}{|l|l|l|l|l|l|l|}
\hline $1.5 \mathrm{~d}$ & 3 & 2 & 1 & 2 & 3 & 2 \\
\hline
\end{tabular}

Voluntario_3: O carreras.

Alumno_2: Pero es que carreras ya tenemos.

Alumno_3: El pilla-pilla en marcha.

Alumno_6: Es verdad, o araña peluda en marcha.

Maestra: Pero tiene que ser... 


\section{Apéndice $B$}

Alumno_4 repite la idea de Alumno_6 para que la escriba Alumno_2 en la ficha: Araña peluda en marcha.

\begin{tabular}{|l|l|l|l|l|l|l|}
\hline $1.5 \mathrm{e}$ & 3 & 2 & 1 & 2 & 3 & 2 \\
\hline
\end{tabular}

Maestra: Pero escucha, ¿Pero valdría? ¿Es un circuito? ¿Es un circuito? Será un juego ¿no? de marcha.

Alumno_2: Pero la araña se podría mover de ese sitio.

\begin{tabular}{|l|l|l|l|l|l|l|}
\hline $1.5 \mathrm{f}$ & 3 & 2 & 1 & 2 & 3 & 2 \\
\hline
\end{tabular}

Maestra: Pero en un circuito no metemos un juego.

Alumno_5: O a lo mejor también se podría jugar a la araña peluda en marcha, pero para que no esté todo el día en la misma línea, que salga a por nosotros y, por ejemplo.

[Alumno_6: al pilla-pilla] si a mi Alumno_6 me pilla yo me voy con él a pillar, como la araña peluda, pero saliendo.

\begin{tabular}{|l|l|l|l|l|l|l|}
\hline $1.5 \mathrm{~g}$ & 3 & 2 & 1 & 2 & 3 & 2 \\
\hline
\end{tabular}

Maestra: ¿Pero eso es un circuito? Vuelvo a hacer la pregunta ¿eso puede estar dentro de un circuito?

Alumno_3: O podemos poner los ladrillos con los palos esos...o las picas [Risas Maestra] ehb cuatro, dos abi y dos abi, y correr, correr no, en marcha.

Alumno_2: Ir en marcha, pero con los talones (mueve los pies).

Alumno_6: Ehb mola.

\begin{tabular}{|l|l|l|l|l|l|l|}
\hline $1.5 \mathrm{~h}$ & 3 & 2 & 1 & 2 & 3 & 2 \\
\hline
\end{tabular}

Maestra: Pero entonces no es ir en marcha, vamos a ver...

Alumno_3: Andar en marcha normal y ponemos las picas con los ladrillos en cuatro lados.

Alumno_6: Y ponerlas en rigzag.

Alumno_3: Por ejemplo, y podemos rodearlos así (gestos con la mano). Zigzag en marcha.

Alumno_6: Ponemos asi las picas (gesto).

Alumno_3: Pero en marcha.

Alumno_2 a Alumno_3: [No se entiende]

Alumno_3: ¿Cómo? pero no, bacemos lo de Alumno_6 y ya está.

\begin{tabular}{|l|l|l|l|l|l|l|}
\hline $1.5 \mathrm{i}$ & 3 & 4 & 1 & 2 & 3 & 2 \\
\hline
\end{tabular}

Maestra: Alumno_1 no ba dicho nada

Alumno_2: Pero y eso ¿qué es?

Alumno_6: Ponemos ladrillos [Alumno_3: ladrillos y...] y picas.

Alumno_4 dice algo a Alumno_3: [No se entiende]

Alumno_5: con... ***

\begin{tabular}{|l|l|l|l|l|l|l|}
\hline $1.5 j$ & 3 & 2 & 1 & 2 & 3 & 2 \\
\hline
\end{tabular}

Voluntario_4: Pero jeso no es la primera actividad que habéis diseñado? Alumno_3: Sí. 
Transcripciones y categorización

\begin{tabular}{|l|l|l|l|l|l|l|}
\hline $1.5 \mathrm{k}$ & 3 & 3 & 1 & 2 & 3 & 2 \\
\hline
\end{tabular}

Voluntario_4: Vale, pues esa ya la tenéis.

Alumno_3: Pues lo que be dicho yo, ponemos cuatro chismas y andamos en marcha.

Alumno_4: ¡Hija! (se incorpora).

Alumno_6: Ponemos una zona de marcha y ya está.

Alumno_2: Lo recorremos, lo tuyo, porque lo del Alumno_6 ya lo tenemos hecho.

Alumno_6: Recorremos todo el gimnasio en marcha.

Alumno_3: Sí, pero con las picas y los...y los ladrillos.

\begin{tabular}{|l|l|l|l|l|l|l|}
\hline 1.51 & 3 & 2 & 1 & 2 & 3 & 2 \\
\hline
\end{tabular}

Maestra: Pero sigo diciendo ieso está dentro de un circuito? O sea, en un circuito tiene que haber una prueba, otra prueba, otra prueba y otra prueba, no puedo dar siete vueltas al gimnasio... tiene que estar organizado.

Alumno_5: Pero profe somos grupos interactivos.

\begin{tabular}{|l|l|l|l|l|l|l|}
\hline $1.5 \mathrm{~m}$ & 3 & 4 & 1 & 2 & 3 & 2 \\
\hline
\end{tabular}

Maestra: Ahh tenéis que organizaros.

Alumno_6: Y ponemos abi ladrillos y los vamos saltando.

Alumno_3: Ponemos colchonetas y unas cuantas picas por alrededor y vamos...vamos...

Alumno_4: Guiándonos en marcha.

Alumno_3: Y vamos andando así en marcha, rodeándolo.

Alumno_6: Pues profe uno se tiene que tapar los ojos y otro no y tiene que guiarlo a la derecha a la izquierda y llevarlo por los ladrillos.

Alumno_4 dice a Alumno_6: jPero de marchaaa!

\begin{tabular}{|l|l|l|l|l|l|l|}
\hline $1.5 n$ & 3 & 2 & 1 & 2 & 3 & 2 \\
\hline
\end{tabular}

Maestra: Que sea una actividad que pueda entrar dentro de un circuito. En un circuito bay varias pruebas ¿No? En un circuito hay varias pruebas, cuando hicimos el circuito el año pasado y este habia varias pruebas.

Alumno_4: Pues ya está como... [Alumno_6: saltar, profe, cuando saltemos...]

\begin{tabular}{|l|l|l|l|l|l|l|}
\hline $1.5 \tilde{n}$ & 3 & 2 & 1 & 2 & 3 & 2 \\
\hline
\end{tabular}

Maestra: Unas veces era de repetíamos la prueba $x$ veces...y otras veces la pasábamos rápido.

Alumno_2 dice a Alumno_3: Cuando bicimos los zancos ite acuerdas?

Alumno_4: Es verdad, en Halloween, lo que bicimos allí (señala una parte del gimnasio).

Alumno_3: El de los zancos.

Alumno_2: El que bicimos alli con los zancos.

\begin{tabular}{|l|l|l|l|l|l|l|}
\hline 1.50 & 3 & 2 & 1 & 2 & 3 & 2 \\
\hline \multicolumn{70}{|c|}{$-220-$} \\
\hline
\end{tabular}




\section{Apéndice $B$}

Maestra: Pero los zancos ¿están dentro del salto, dentro del relevo y dentro de estas actividades que estamos viendo?

Alumno_6: Noo.

Alumno_3: Noo...estamos perdiendo el tiempo eehh niñas.

\begin{tabular}{|l|l|l|l|l|l|l|}
\hline $1.5 \mathrm{p}$ & 3 & 4 & 1 & 2 & 3 & 2 \\
\hline
\end{tabular}

Maestra: Mira uno tumbado, la otra sin abrir la boca y la otra sin abrir la boca.

Alumno_6: Eh yo sí que he abierto la boca.

Alumno_2: Yo si que la he abierto eehh.

\begin{tabular}{|l|l|l|l|l|l|l|}
\hline $1.5 \mathrm{q}$ & 3 & 1 & 1 & 2 & 3 & 2 \\
\hline
\end{tabular}

Maestra: Claro, venga va $\ldots$ a ver ¿cuántas pruebas tenéis?

Alumno_3: Cuatro.

Alumno_2: Tenemos cuatro, ya tenemos la primera, la segunda y la tercera, nos falta la cuarta.

Alumno_6: La marcha podíamos...

Maestra: Para mi es la más fácil la marcha.

Alumno_6: Pues para mi no profe.

Alumno_5: Pues jugar, al pilla-pilla con marcha.

Alumno_3: Pues coger... [Alumno_4: Pues una carrera de marcha] los bancosy ponerlo en

...en (hace gestos con los brazos).

Alumno_6: Profee lo que hacemos con los bancos.

Alumno_3: [Sigue con su idea] Y lo...uno aqui, dos aqui y otros dos aqui y el cuadradito ese (movimiento con los brazos) pos...pillarnos en marcha.

Alumno_6: Y los bancos son casa, si te saltas la línea, te la quedas.

Alumno_2 dice a Maestra: El juego que bicimos el otro día...

\begin{tabular}{|l|l|l|l|l|l|l|}
\hline $1.5 \mathrm{r}$ & 3 & 2 & 1 & 2 & 3 & 2 \\
\hline
\end{tabular}

Maestra: Vale, vuelvo a repetir, vuelvo a repetir por quinta o sexta vez, ¿̇puedo meter un juego dentro de un circuito? [Alumno_6 y Alumno_2: no] porque en un circuito.

[Alumno_3: O pillarnos en marcha, ya está] escucha Alumno_3, en un circuito empiezo aquí, empiezo aqui en esta zona con conos, con picas o lo que sea, voy a la siguiente prueba, hago voltereta o lo que sea, voy a la siguiente prueba, salto encima de banco, voy a la siguiente prueba, subo encima de abi, voy a la siguiente prueba...lo que sea ¿puedo meter un juego? Vuelvo a repetir ¿puedo meter un juego?

Alumno_3 dice a Alumno_2: ¿Sabes a lo que podemos jugar?

\begin{tabular}{|l|l|l|l|l|l|l|}
\hline $1.5 \mathrm{~s}$ & 3 & 2 & 1 & 2 & 3 & 2 \\
\hline
\end{tabular}

Voluntario_4 le hace gestos de negación con la mano, para indicarle que proponer un juego está mal.

Alumno_3 al verlo se autocorrige: $O$ sea no jugar, cuando vinieron los de sexto esto que era correr con los relevos, pero en marcha [Alumno_2: pero es que eso ya lo hemos hecho] con los chismes esos azules. 
Transcripciones y categorización

\begin{tabular}{|l|l|l|l|l|l|l|}
\hline $1.5 \mathrm{t}$ & 3 & 2 & 1 & 2 & 3 & 2 \\
\hline
\end{tabular}

Maestra: Pero ya lo tenéis.

Alumno_2 le señala la ficha: Ya lo tenemos eso.

Maestra: Ya tenéis de relevos, hecho.

Alumno_4: Que lo pusimos en la pizarra.

Alumno_6: Andar en marcha, marcha delante marcha atrás (mueve las piernas).

Alumno_2: Pues ale, pues ya está.

\section{CICLO 6}

CICLO DIALÓGICO

Comienza con una nueva fase: distribuir el espacio para cada prueba. Finaliza cuando acaban de organizar el espacio.

Los alumnos van dando propuestas para colocar las pruebas

\begin{tabular}{|l|l|l|l|l|l|l|}
\hline 1.6 & 3 & 2 & 1 & 2 & 3 & 2 \\
\hline
\end{tabular}

Maestra: Ale, ahora tenéis que distribuir en qué espacio va a estar cada prueba.

Alumno_3: El primero aqui, el segundo abi, el tercero abi, el cuarto ahi (va señalando con la mano puntos del gimnasio).

Maestra: Dibujarlo que para eso tenéis el...

Alumno_6: Mira uno abi, otro alli, otro aqui y otro abi, es más fácil.

\begin{tabular}{|l|l|l|l|l|l|l|}
\hline $1.6 \mathrm{a}$ & 3 & 2 & 1 & 2 & 3 & 2 \\
\hline
\end{tabular}

Maestra pregunta a Alumno_2 y Alumno_3: ¿Lo tenéis dibujado como está repartido [Alumno_3 y Alumno_2: sii] A ver...

\begin{tabular}{|l|l|l|l|l|l|l|}
\hline $1.6 \mathrm{~b}$ & 3 & 2 & 1 & 2 & 3 & 2 \\
\hline
\end{tabular}

Voluntario_4: Pero no has distribuido el espacio, abi has dibujado cada prueba.

\begin{tabular}{|l|l|l|l|l|l|l|}
\hline $1.6 \mathrm{c}$ & 3 & 2 & 1 & 2 & 3 & 2 \\
\hline
\end{tabular}

Maestra: Claro tienes que distribuir...eso es el gimnasio.

Alumno_4 y Alumno_6 siguen dando ideas de colocación

Alumno_2: Aqui la primera [Alumno_3: Abi la segunda, la tercera, la cuartay ya está (van señalando el sitio)].

\section{CICLO 7}

Ciclo dialógico: con aportaciones y valoraciones del alumnado (ALUMNO_2 $\rightarrow$ Espera un momento profe... y va a revisar el espacio en una parte determinada del gimnasio) y un consenso final.

Comienza con una nueva fase, revisar el material necesario, finaliza al terminar de organizar esta parte

\begin{tabular}{|l|l|l|l|l|l|l|}
\hline 1.7 & 3 & 2 & 1 & 2 & 3 & 2 \\
\hline
\end{tabular}

Maestra: Vale ¿qué material necesitáis? ¿Cuántas picas, cuántos...?

Alumno_6: Una colchoneta. 
Apéndice $B$

\begin{tabular}{|l|l|l|l|l|l|l|}
\hline $1.7 \mathrm{a}$ & 3 & 1 & 1 & 2 & 3 & 2 \\
\hline
\end{tabular}

Maestra: Antes de ir a lo bobo, pensamos.

Alumno_2 se levanta y dice: Espera un momento profe (va a comprobar el espacio que bay en la parte del gimnasio en la que van a colocar la primera prueba).

Maestra: Os está costando hoy la leche eh.

Alumno_6: La verdad que si profe.

Alumno_4: A ver la colchoneta, los ladrillos...

\begin{tabular}{|l|l|l|l|l|l|l|}
\hline $1.7 \mathrm{~b}$ & 3 & 2 & 1 & 2 & 3 & 2 \\
\hline
\end{tabular}

Voluntaria Alumno_3: Pero ¿cuántos?

Maestra: ¿Cuántos?

Alumno_6: Cinco o seis.

\begin{tabular}{|l|l|l|l|l|l|l|}
\hline $1.7 \mathrm{c}$ & 3 & 2 & 1 & 2 & 3 & 2 \\
\hline
\end{tabular}

Maestra: jPensaaad!

Alumno_2, Alumno_3, Alumno_4 y Alumno_5 se levantan y hacen un corro mirando la ficha, Alumno_6 se une al grupo, la

\begin{tabular}{|l|l|l|l|l|l|l|}
\hline $1.7 \mathrm{~d}$ & 3 & 4 & 1 & 2 & 3 & 2 \\
\hline
\end{tabular}

Maestra anima a Alumno_1 a unirse también: ;Venga Alumno_1!

Alumno_2: Seis ladrillos.

Alumno_6: Y una colchoneta.

Alumno_3: Y seis picas.

Una vez decidido el material van todos a buscarlo

\section{CICLO 8}

\subsection{EPISODIO 3. PREPARACIÓN MATERIAL}

Ciclo dialógico, ya que continúan las interacciones en busca de consenso, los propios alumnos plantean interrogantes y llevan a cabo valoraciones.

Comienza con una nueva fase de la tarea, dibujar el circuito y a su vez se vuelven a replantear las propuestas del ciclo anterior.

Se cierra al finalizar la negociación de quépruebas incluir en su dibujo

Ciclo de nuevo dialógico

Se inicia con una nueva problemática a resolver, en este caso, reflexionar sobre el material necesario se

Alumno_3 protesta porque no sabe hacer la voltereta: Pero que yo no sé saltar en la colchoneta.

\begin{tabular}{|l|l|l|l|l|l|l|}
\hline 1.8 & 3 & 4 & 1 & 2 & 3 & 2 \\
\hline
\end{tabular}

Alumno_2: Pues te ayudamos, que para eso estamos ; hija!

Alumno_1: Es verdad, yo tampoco sé....

Alumno_4 coge los ladrillos y dice: ayudarme, Alumno_3 lleva estos (le acerca con el pie unos pocos ladrillos) 
Alumno_2: ¿No sabes saltar en la colchoneta?

Alumno_3: Entonces i sólo hay que hacer así? ¡Por mi abuela! (da un pequeño salto lateral y al terminar coge los ladrillos que le ha dejado Alumno_4).

Alumno_2: Un relevo.

Alumno_3: Dos, porque somos dos grupos.

\begin{tabular}{|l|l|l|l|l|l|l|}
\hline $1.8 \mathrm{a}$ & 3 & 2 & 1 & 2 & 3 & 2 \\
\hline
\end{tabular}

Voluntario_3: A ver los relevos ¿Cómo los vais a hacer, por parejas?

Alumno_2: Ahh, pero ¿ha cogido la Alumno_4 de estos? (señala los ladrillos).

Alumno_3: Sí.

Alumno_2: ¿Cuántos?

Alumno_3: Seis.

Alumno_2: Y ¿porqué llevas eso? (señala el ladrillo que tiene Alumno_3).

Alumno_3: Porque ella lleva cinco y con este... Seis.

Alumno_5 después de estar un rato chocando los relevos uno con otro dice: ¡Claves! (establece relación con las claves de música).

\section{CICLO 9}

\subsection{COLOCACIÓN DE MATERIAL}

Finaliza cuando se aclara el problema

Ciclo también dialógico por motivos expresados anteriormente.

Se inicia con una nueva cuestión, reformular alguna de las pruebas elegidas y aclarar en qué consiste

Finaliza una vez, se solucionan las dudas planteadas

CICLO DIALÓGICO: los propios alumnos piden ayuda, realizan valoraciones y reflexiones (ALUMNO_2 $\rightarrow$ Pero es que carreras ya tenemos / ALUMNO_5

$\rightarrow$ A lo mejor también se podría jugar a la araña

Alumno_3: Que era con el banco, no la colchoneta, era con el banco.

Alumno_2: Pero si aqui pusimos con la colchoneta.

Alumno_3: Era con el banco.

Alumno_5: Saltar con la colchoneta adentro y con el banco... (señala otra zona del gimnasio).

Alumno_2: El uno hemos dicho que era con las picas y la colchoneta y el segundo es el del banco.

\begin{tabular}{|l|l|l|l|l|l|l|}
\hline 1.9 & 3 & 2 & 1 & 2 & 3 & 2 \\
\hline
\end{tabular}

Voluntario_3: Venga, babéis decidido que el espacio para el uno es este ¿no?

Cogen la colchoneta y la ponen un poco más alejada, para dejar sitio a los ladrillos y las picas.

\begin{tabular}{|l|l|l|l|l|l|l|}
\hline $1.9 \mathrm{a}$ & 3 & 2 & 1 & 2 & 3 & 2 \\
\hline
\end{tabular}

Voluntaria_6: Faltan las picas 


\section{Apéndice $B$}

Alumno_6: Es verdad no tenemos picas, seis (va corriendo al cuarto de material y Alumno_1

le sigue).

Mientras Alumno_2, Alumno_3 y Alumno_4 negocian cómo colocar los ladrillos

Alumno_4 los coloca a modo muralla delante de la colchoneta, al verlo Alumno_2 pregunta:

¿Por qué pones eso asi?

Alumno_4: Para saltarlo así.

Alumno_5: Pero eso...

Alumno_3: Es que nos están confundiendo, hemos dicho los bancos y ahora las colchonetas.

Alumno_2 coge los ladrillos que ha colocado Alumno_4 delante de la colchoneta y los recoloca: Los teníamos que rodear.

\begin{tabular}{|l|l|l|l|l|l|l|}
\hline $1.9 \mathrm{~b}$ & 3 & 2 & 1 & 2 & 3 & 2 \\
\hline
\end{tabular}

Voluntaria_6 les hace revisar lo que han escrito en la ficha: $A$ ver iqué habria que poner primero? V ais a correr en rigzag, las picas...

Alumno_4: Y hacer volteretas así o saltar (señala la zona de la colchoneta)

Piden ayuda a la maestra.

\begin{tabular}{|l|l|l|l|l|l|l|}
\hline $1.9 \mathrm{c}$ & 3 & 4 & 1 & 2 & 3 & 2 \\
\hline
\end{tabular}

Maestra esta les dice: Profe no. Sois vosotros, sois el grupo.

Alumno_6 y Alumno_1 traen las picas y comienzan a colocarlas

Alumno_3: $¿$ Así? ¿Ponemos todo en fila?

Alumno_2: Pero ¿no tendrás que rodearlos para luego hacer la voltereta?

Alumno_4: A ver itienes que hacer la voltereta o saltar la colchoneta?

Alumno_3: Una voltereta comunitaria.

Alumno_6: Saltando o bacer... [Alumno_5: Una voltereta.]

Alumno_2: Lo que queráis, el que no sabe hacer volteretas.

Continúan debatiendo cómo colocar las picas y los ladrillos, Alumno_2 propone una forma: Luego cuando lleguemos aquí, hacemos asi...

\begin{tabular}{|l|l|l|l|l|l|l|}
\hline $1.9 \mathrm{~d}$ & 3 & 2 & 1 & 2 & 3 & 2 \\
\hline
\end{tabular}

Alumno_6: Hacemos así (atraviesa las picas y ladrillos en rigzag).

Alumno_3: No lo entiendo, de verdad.

\begin{tabular}{|l|l|l|l|l|l|l|}
\hline $1.9 \mathrm{e}$ & 3 & 2 & 1 & 2 & 3 & 2 \\
\hline
\end{tabular}

Alumno_4: Asi bija (atraviesa las picas y ladrillos en rigzag).

Alumno_6: Es más fácil.

\begin{tabular}{|l|l|l|l|l|l|l|}
\hline $1.9 \mathrm{f}$ & 3 & 2 & 1 & 2 & 3 & 2 \\
\hline
\end{tabular}

Voluntario_4: La primera la tenéis clara yo creo, que es pasar las picas haciendo rigzag [Alumno_4: Asi (mueve los brazos imitando el rigzag)]. Yo creo que las 
picas están muy juntas tenéis que separarlas un poco, mirad todo el espacio de clase (señala el gimnasio).

Alumno_2: Pero.

Alumno_4: ¿Asi?

\begin{tabular}{|l|l|l|l|l|l|l|}
\hline $1.9 \mathrm{~g}$ & 3 & 2 & 1 & 2 & 3 & 2 \\
\hline
\end{tabular}

Voluntari_6: ¿No era mejor poner las picas en fila?

Alumno_3 dice a Alumno_5: Lo ves...en fila mejor.

Alumno_4: Pero ¿cómo que en fila?

Alumno_3: Separadas.

\begin{tabular}{|l|l|l|l|l|l|l|}
\hline $1.9 \mathrm{~h}$ & 3 & 2 & 1 & 2 & 3 & 2 \\
\hline
\end{tabular}

Alumno_6: Mira dos cuadros...dos cuadros (le dice a Alumno_3) ponlo ahi.

Alumno_3: Pero Alumno_4 ¿Dónde los vas a juntar? (Coloca más separadas las picas que ba puesto Alumno_4.)

Alumno_6: Dos cuadros y ya está.

\begin{tabular}{|l|l|l|l|l|l|l|}
\hline $1.9 \mathrm{i}$ & 3 & 4 & 1 & 2 & 3 & 2 \\
\hline
\end{tabular}

Maestra: ¿Estáis escuchando a Alumno_6 lo que está diciendo?

Alumno_3: Dos cuadrados.

Maestra asiente

Alumno_4: ;Así! (Recorre esta parte del circuito para que sus compañeros vean cómo se hace.)

Alumno_2: Aquí no hay dos (los recoloca).

Alumno_5 quiere hacer ella el circuito, empieza, pero se para dudosa y pregunta a Alumno_6: ¿Cómo era?

\begin{tabular}{|l|l|l|l|l|l|l|}
\hline $1.9 j$ & 3 & 2 & 1 & 2 & 3 & 2 \\
\hline
\end{tabular}

Alumno_6: ¡Mira! (recorre el circuito de picas) y luego baces asi y así... y un saltó abí.

\begin{tabular}{|l|l|l|l|l|l|l|}
\hline $1.9 \mathrm{k}$ & 3 & 2 & 1 & 2 & 3 & 2 \\
\hline
\end{tabular}

Voluntaria_6: ¿La colchoneta la vais a dejar así o la vais a mover?

Alumno_6: Al revéees.

Alumno_2 y Alumno_4 mueven la colchoneta y la colocan en vertical

Alumno_4: Pero cómo ¿así?

\begin{tabular}{|l|l|l|l|l|l|l|}
\hline 1.91 & 3 & 2 & 1 & 2 & 3 & 2 \\
\hline
\end{tabular}

Alumno_2: Así (hace gesto con los brazos para indicar la dirección del salto o voltereta

que deben realizar en la colchoneta.)

Alumno_1 hace una voltereta en la colchoneta

Alumno_3: Yo no sée

\begin{tabular}{|l|l|l|l|l|l|l|}
\hline $1.9 \mathrm{~m}$ & 3 & 4 & 1 & 2 & 3 & 2 \\
\hline
\end{tabular}

Alumno_2: Pero que para eso te ayudamos.

\begin{tabular}{|l|l|l|l|l|l|l|}
\hline $1.9 \mathrm{n}$ & 3 & 4 & 1 & 2 & 3 & 2 \\
\hline \multicolumn{70}{|c|}{} \\
\hline
\end{tabular}




\section{Apéndice $B$}

Alumno_4: Asi (hace la voltereta a modo de ejemplo para Alumno_3)

Alumno_4: Pero ¿cómo haces la voltereta?

Alumno_2: Asícomo lo has becho tú...

\begin{tabular}{|l|l|l|l|l|l|l|}
\hline $1.9 \tilde{\mathrm{n}}$ & 3 & 4 & 1 & 2 & 3 & 2 \\
\hline
\end{tabular}

Voluntaria_6: Pues los que no sepan decirles cómo hacer la voltereta.

\begin{tabular}{|l|l|l|l|l|l|l|}
\hline 1.90 & 3 & 4 & 1 & 2 & 3 & 2 \\
\hline
\end{tabular}

Alumno_6: Para la voltereta, pones la cabeza y ruedas y ya está.

\begin{tabular}{|l|l|l|l|l|l|l|}
\hline $1.9 \mathrm{p}$ & 3 & 4 & 1 & 2 & 3 & 2 \\
\hline
\end{tabular}

Alumno_2: O los que no sepan le ayudamos, que somos un grupo.

Alumno_4: Vengaa.

\section{CICLO 10}

Comienza con una propuesta de reflexión por parte de la profesora, para que revisen el proceso realizado. Finaliza cuando se llega a un acuerdo de las pruebas que finalmente formarán su circuito.

CICLO DIALÓGICO

Comienza con una nueva fase: distribuir el espacio para cada prueba. Finaliza cuando acaban de organizar el espacio.

Los alumnos van dando propuestas para colocar las pruebas

\begin{tabular}{|l|l|l|l|l|l|l|}
\hline 1.10 & 3 & 1 & 1 & 2 & 3 & 2 \\
\hline
\end{tabular}

Voluntaria_6: Venga ahora la segunda ¿qué habéis preparado en la segunda? Alumno_4 lee la ficha: Saltar el banco.

Voluntaria Alumno_3: Pues venga un banco.

Van todos a buscar el banco

\begin{tabular}{|l|l|l|l|l|l|l|}
\hline $1.10 \mathrm{a}$ & 3 & 2 & 1 & 2 & 3 & 2 \\
\hline
\end{tabular}

Alumno_4: Hacer bija (salta el banco agarrándose con las manos) como hicimos.

Alumno_6: Quita, quita (se dirige a Alumno_3 y Alumno_4 para que le dejen mover y colocar el banco)

Alumno_6 repite: Quita Alumno_2 ... ino sabes hacer esto? (él y Alumno_4 comienzan a saltar el banco, pero esta vez sin agarrarse.)

\begin{tabular}{|l|l|l|l|l|l|l|}
\hline $1.10 \mathrm{~b}$ & 3 & 2 & 1 & 2 & 3 & 2 \\
\hline
\end{tabular}

Alumno_4: Es mejor así (repite el salto, pero con la ayuda del apoyo en el banco). Alumno_2: Los que no sepan que se agarren.

\begin{tabular}{|c|c|c|c|c|c|c|}
\hline $1.10 \mathrm{c}$ & 3 & 4 & 1 & 2 & 3 & 2 \\
\hline \multicolumn{7}{|c|}{ Alumno_2 dice a Alumno_1: Te ayudamos. } \\
\hline $1.10 \mathrm{~d}$ & 3 & 3 & 1 & 2 & 3 & 2 \\
\hline
\end{tabular}

Voluntario_3: Vale, bien, ¿lo tenéis claro no? 
Alumno_2 coge el banco y dice: Vale, pero el dos hemos dicho que era allí (señala una

parte del gimnasio a continuación e la primera prueba que ban colocado).

Colocan en el banco en el sitio que ha indicado Alumno_2

\section{CICLO 11}

$V$ aloraciones del alumnado (ALUMNO_2 $\rightarrow$ Espera un momento profe...y va a revisar el espacio en una parte determinada del gimnasio) y un consenso final.

Comienza con una nueva fase, revisar el material necesario, finaliza al terminar de organizar esta parte.

Alumno_4: Es verdad, ilo que jugamos en el patio que dabas la vuelta y chocabas! Alumno_3: Nosotras tres por ejemplo (se refiere a ella, a Alumno_1 y a Alumno_5) y ellos lo mismo (Alumno_2, Alumno_4 y Alumno_6) una carrera [Alumno_2 le da a Alumno_3 dos conos: colócalo]

Alumno_4: Uno solo, que solo somos un grupo.

Finaliza cuando terminan de colocar la tercera prueba.

Alumno_4: Los relevos ahora... jlos relevos ahora!

Alumno_3: Uno cada uno.

Alumno_2: Es mejor saltar dos.

Alumno_3: ¿Dos?

Alumno_2: Que sí.

\begin{tabular}{|l|l|l|l|l|l|l|}
\hline 1.11 & 3 & 2 & 1 & 2 & 3 & 2 \\
\hline
\end{tabular}

Maestra: ¿Está bien cerca de la pared?

Alumno_3: ¿ehh?

Maestra: ¿Está bien, cerca de la pared, ese banco? (Lo ve demasiado próximo a la Pared.)

Alumno_4: Vamos a saltar dos.

\begin{tabular}{|l|l|l|l|l|l|l|}
\hline $1.11 \mathrm{a}$ & 3 & 2 & 1 & 2 & 3 & 2 \\
\hline
\end{tabular}

Maestra: Vale, pero está muy...

\begin{tabular}{|l|l|l|l|l|l|l|}
\hline $1.11 \mathrm{~b}$ & 3 & 2 & 1 & 2 & 3 & 2 \\
\hline
\end{tabular}

Voluntario_3: Con todo el espacio que tenemos ¿lo tenéis que pegar en la pared...?

\begin{tabular}{|l|l|l|l|l|l|l|}
\hline $1.11 \mathrm{c}$ & 3 & 2 & 1 & 2 & 3 & 2 \\
\hline
\end{tabular}

Maestra: Eso digo yo, ¿no está...?

Alumno_6: Para allá

\begin{tabular}{|l|l|l|l|l|l|l|}
\hline $1.11 \mathrm{~d}$ & 3 & 2 & 1 & 2 & 3 & 2 \\
\hline
\end{tabular}

Maestra: Lo que dice Voluntario_3, tenéis mucho espacio

Lo alejan un poco de la pared y colocan los bancos de forma paralela el uno del otro 


\section{Apéndice $B$}

Alumno_4 dice a Alumno_3: Tan cerca nooo.

\begin{tabular}{|l|l|l|l|l|l|l|}
\hline $1.11 \mathrm{e}$ & 3 & 2 & 1 & 2 & 3 & 2 \\
\hline
\end{tabular}

Voluntaria Alumno_3: Pero si vais a saltar dos hay que ponerlos juntos ¿no? Seguidos

Alumno_4: Noo así, uno así (señala el banco indicando que primero comenzarían saltando

en ese) y luego otro.

\begin{tabular}{|l|l|l|l|l|l|l|}
\hline $1.11 \mathrm{f}$ & 3 & 2 & 1 & 2 & 3 & 2 \\
\hline
\end{tabular}

Voluntaria_6: Y ¿̇por qué no los ponéis así seguidos?

Alumno_6: Cinco aquí en fila y cinco alli en fila.

Alumno_4 y Alumno_6 saltan los bancos a modo de ejemplo de su propuesta.

Alumno_2 trae más material para preparar las siguientes pruebas: el tres

\begin{tabular}{|l|l|l|l|l|l|l|}
\hline $1.11 \mathrm{~g}$ & 3 & 4 & 1 & 2 & 3 & 2 \\
\hline
\end{tabular}

Maestra: Venga, vale, si babéis decidido que así, pues así y ya está.

Alumno_6: Hay que poner aquí cinco y abí otros cinco.

Alumno_3: Noooo pon dos.

Alumno_2: ¡Hija! ¿y cómo haces el relevo?

Alumno_3: Pues pon dos marcos separados y hacemos dos grupos y uno recorre sus conos.

Alumno_4: Es verdad, jlo que jugamos en el patio que dabas la vuelta y chocabas!

Alumno_3: Nosotras tres por ejemplo (se refiere a ella, a Alumno_1 y a Alumno_5) y ellos lo mismo (Alumno_2, Alumno_4 y Alumno_6) una carrera [Alumno_2 le da a Alumno_3 dos conos: colócalo]

Alumno_4: Uno solo, que solo somos un grupo

Alumno_3 coloca los dos conos que le ha dado Alumno_2

Alumno_5: Tenías que venir corriendo desde alli...

Alumno_4: ¿Qué tenemos que hacer asi? (recorre el circuito que han colocado)

Alumno_3: ¡Claro! pero .... inoo!

Alumno_6: iQue noo! rodeamos y vamos para allí.

Alumno_2: Empezamos aqui y ¿Cómo bacemos? ¿Asi?

Alumno_3: iAhi hija! (señala el lado contrario por el que ha empezado Alumno_2) abi, hermana, abí.

Alumno_3: Soy la primera, la primera de un equipo [Alumno_1: ;Alumno_3! Pero sal ... (como Alumno_3 no le hace caso se lo dice en bajo a Alumno_2)] tengo que rodear y paso el relevo a otro compañero.

Siguen hablando por mini grupos, Alumno_1 le insiste a Alumno_3: pero Alumno_3 allí (le propone empezar desde más atrás, ya que dónde habían colocado los conos estaba demasiado cerca de la pared)

Alumno_3: Qué más da, aquí.

Alumno_4 lee la ficha: jMarcha atrás!... jEl cuatro, niñas! 
Alumno_6 dice a Alumno_4: Eyy, pero bay que poner aqui dos, bay que poner aqui algo (se refiere a alguna señal que indique que comienzan desde ese punto).

Las demás recorren la actividad de relevos que han creado a modo de prueba

Alumno_4 dice a Alumno_6: Hasta donde salgan los primeros.

Alumno_6: Aquí, tenía que estar aquí.

Alumno_3 comienza a hacer los grupos: jMira, un, dos, tres...! (señala a Alumno_4 y Alumno_5)

Alumno_2: Pero que no, que uno de vosotros va con ellos (se refiere a los voluntarios,

que también participan en la carrera de relevos).

Alumno_5: Es verdad.

Alumno_3: Claro un grupo...

Alumno_2: Lo que pasa es que un grupo tienen que salir los primeros.

Alumno_5: Voluntario_3 corre mucho.

\section{CICLO 12}

Alumno_2: El cuatro ¿Cuál era el cuatro?

Alumno_4 y Alumno_3 miran la ficha

Alumno_4: Marcha, marcha atrás, primero así y luego para atrás.

Como ya tienen las pruebas colocadas se dirigen todos hacia la primera, para comenzar

a realizar el circuito

\section{CICLO 13}

\section{EPISODIO 5: REALIZACIÓN}

Dialógico: realizan cuestiones y valoraciones sobre el circuito que han creado.

Alumno_3: jesperad! Primero hacia adelante [Alumno_2: perimo hacia adelante] y luego nos ponemos hacia atrás.

Todos empiezan a correr en marcha y dice Alumno_2: ¿por qué no llegamos hasta las azules?

Comienzan a realizar el circuito comprobando las pruebas que han colocado en ciclos anteriores. Finaliza cuando terminan de probar su propuesta.

Alumno_2: ¿Quién se atreve?

Alumno_3: El Alumno_6.

Alumno_6: Yoo (comienza él la prueba)

Alumno_2 al ver que comienza muy despacio le dice: ¡Corriendo, ;Alumno_6, corriendo!

Alumno_6: Mira que fácil ¿̇y ahora que tengo que saltar? 


\section{Apéndice $B$}

Maestra: ¡L L habéis hecho vosotros!!

\begin{tabular}{|l|l|l|l|l|l|l|}
\hline $1.13 \mathrm{a}$ & 3 & 2 & 1 & 2 & 3 & 2 \\
\hline
\end{tabular}

Sus compañeras dicen a Alumno_6: La voltereta.

Continúa Alumno_1, Alumno_4, Alumno_2, Alumno_3 y Alumno_5, estas dos últimas no hacen la voltereta y pasan la prueba dando un pequeño salto.

\begin{tabular}{|l|l|l|l|l|l|l|}
\hline $1.13 \mathrm{~b}$ & 3 & 2 & 1 & 2 & 3 & 2 \\
\hline
\end{tabular}

En la prueba de los bancos Alumno_5 y Alumno_2 se quedan paradas, Alumno_4 va ayudarlas y hace unos saltos de ejemplo. Alumno_2 se anima a saltar, pero Alumno_5 acaba pasando los pies sin saltar.

En los relevos animan a participar a los voluntarios les dicen: iponeros en fila! iponeros en fila india!

Alumno_6: Los niños y las niñas.

\begin{tabular}{|l|l|l|l|l|l|l|}
\hline $1.13 \mathrm{c}$ & 3 & 1 & 1 & 2 & 3 & 2 \\
\hline
\end{tabular}

Voluntario_3: Venga, cuando digáis.

Hacen una carrera de relevos, compitiendo los voluntarios con los alumnos, al cavar pasan a la siguiente prueba, la marcha

\begin{tabular}{|l|l|l|l|l|l|l|}
\hline $1.13 \mathrm{~d}$ & 3 & 2 & 1 & 2 & 3 & 2 \\
\hline
\end{tabular}

Voluntaria Alumno_3: Os falta la marcha.

Alumno_6: La marcha, venga, carreras.

Alumno_4: Noo, carreras noo.

Alumno_3: Aacia atrás y hacia adelante

Maestra: Pero eso de marcha atrás os lo habéis inventado vosotros eebh.

Alumno_5: pero ¿Cómo era?

Maestra: Lo de marcha atrás os lo habéis inventado vosotros.

\begin{tabular}{|l|l|l|l|l|l|l|}
\hline $1.13 \mathrm{e}$ & 3 & 2 & 1 & 2 & 3 & 2 \\
\hline
\end{tabular}

Voluntario_3: la marcha es caminar lo más rápido posible, pero sin correr

Todos se ponen a probar la marcha.

Alumno_6: ¿Así?

\begin{tabular}{|l|l|l|l|l|l|l|}
\hline $1.13 \mathrm{f}$ & 3 & 2 & 1 & 2 & 3 & 2 \\
\hline
\end{tabular}

Voluntario_3: Hasta que no pongáis...

Alumno_4: Venga...

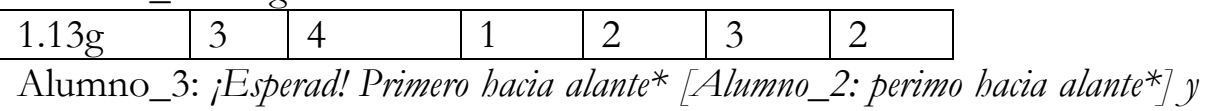
luego nos ponemos hacia atrás.

Todos empiezan a correr en marcha y dice Alumno_2: ippor qué no llegamos basta las azules?

Algunos van corriendo, pero sin ir en marcha, Alumno_2 se queda atrás 
Alumno_6: Ya lo be terminado.

Alumno_3: jOtra vez!

\section{CICLO 14}

\section{EPISODIO 6: EVALUACIÓN}

CICLO DIALÓGICO: los propios alumnos plantean soluciones a su actividad, valorando lo realizado.

Alumno_6: Hay un problema de atasco.

Alumno_2: Ha salido disparados y yo me he quedado...

Alumno_3: Pues...hacemos todos todo esto [Alumno_2 la interrumpe: Pues.] [Alumno_6:

¿cuántas hay seis no?] [Alumno_2: cuando el compañero llegue al último verde, al que está en el ladrillo, sale el otro...]

Alumno_2: asi mientras Alumno_6 hace la voltereta, nosotros ya hemos llegado abi. Cuando Alumno_6 salte los bancos, cuando se llegue ya que vaya a terminar el último que salga el otro, así.

Comienza con una propuesta de reflexión por parte de la profesora, termina cuando se terminan de propuestas para mejorar uno de los fallos planteados.

Maestra: $V$ ale, nos sentamos un segundito, a ver, nos sentamos un segundito, vamos a ver.

Se sientan en el palco que hay en el gimnasio.

\begin{tabular}{|l|l|l|l|l|l|l|}
\hline 1.14 & 2 & 4 & 1 & 2 & 3 & 2 \\
\hline
\end{tabular}

Maestra: Alumno_6 si te acercas un poquito mejor (ya que se babia sentado muy separado del resto de compañeras).

\begin{tabular}{|l|l|l|l|l|l|l|}
\hline $1.14 \mathrm{a}$ & 2 & 2 & 1 & 2 & 3 & 2 \\
\hline
\end{tabular}

Maestra: ¿Habéis organizado bien el espacio?

Dicen: Siii.

\begin{tabular}{|l|l|l|l|l|l|l|}
\hline $1.14 \mathrm{~b}$ & 2 & 2 & 1 & 2 & 3 & 2 \\
\hline
\end{tabular}

Maestra: ¿Habéis acabado todos los circuitos a la vez, o babia abi un problema de atasco?

Voluntario_3 se sienta con ellos.

Alumno_6: Hay un problema de atasco.

Alumno_2: Ha salido disparados y yo me he quedado.

\begin{tabular}{|l|l|l|l|l|l|l|}
\hline $1.13 \mathrm{c}$ & 2 & 2 & 1 & 2 & 3 & 2 \\
\hline
\end{tabular}

Maestra: Vale, yo vi un problema, que tampoco es un problema vaya, que hacéis este circuito todos individual, esto vaya (señala una parte). Vale, entonces Alumno_6 ha cogido lo ha hecho el primero, ha hecho la voltereta, ha hecho el salto y luego le ha 


\section{Apéndice $B$}

tocado esperar a los compañeros para hacer el relevo ¿cómo lo podíamos hacer para solucionar eso?

Alumno_3: Pues...hacemos todos todo esto [Alumno_2 la interrumpe: Pues.] [Alumno_6:

¿cuántas hay seis no?] [Alumno_2: cuando el compañero llegue al último verde, al que está en el ladrillo, sale el otro...]

Maestra: aham

Alumno_2: Asi mientras Alumno_6 hace la voltereta, nosotros ya bemos llegado abí. Cuando

Alumno_6 salte los bancos, cuando se llegue ya que vaya a terminar el último que salga el otro, así.

\begin{tabular}{|l|l|l|l|l|l|l|}
\hline $1.13 \mathrm{~d}$ & 2 & 2 & 1 & 2 & 3 & 2 \\
\hline
\end{tabular}

Maestra: $Y$ isi lo bacéis de dos en dos, se solucionaría el problema? (como se quedan callados, Maestra repite la pregunta) ¿Si lo hacéis de dos en dos, se solucionaría el problema? Estoy preguntando.

Alumno_6: Tres abi y otros tres abi... (***)

\begin{tabular}{|l|l|l|l|l|l|l|}
\hline $1.13 \mathrm{e}$ & 2 & 2 & 1 & 2 & 3 & 2 \\
\hline
\end{tabular}

Maestra: Pensamos iy si lo hiciésemos de dos en dos, se solucionaría el problema?

Todos dicen: Siii

Maestra: ¿Si?

Alumno_3: Sí, porque salimos dos, yo y Alumno_5 [Alumno_6: tendrá que haber dos colchonetas] o yo y Alumno_2, salimos las dos y luego ya cuando lleguemos al... al palo verde, ya salen otros dos]

\begin{tabular}{|l|l|l|l|l|l|l|}
\hline $1.13 \mathrm{f}$ & 2 & 2 & 1 & 2 & 3 & 2 \\
\hline
\end{tabular}

Maestra: Vale, entonces, cuando lleguéis alli podéis hacer vosotros los relevos con tu pareja ¿no? [Alumno_3: vale] Y la marcha la puedo hacer con mi pareja, vuelvo a empezar...entonces estoy todo el rato... haciendo el circuito, no tengo por qué esperar, o eso o pensáis toda una solución para que hagáis todos los circuitos a la vezy que no tengáis que estar esperando.

Alumno_5: No, mira. Por ejemplo, también, uno sale y va hacia eso mmm luego llegas a la voltereta, haces otra cosa, a los bancos sigue así, y ya cuando esté aquí, sale otra persona.

\begin{tabular}{|l|l|l|l|l|l|l|}
\hline $1.13 \mathrm{~g}$ & 2 & 2 & 1 & 2 & 3 & 2 \\
\hline
\end{tabular}

Voluntario_3: Pero entonces espera mucho ¿no?

\begin{tabular}{|l|l|l|l|l|l|l|}
\hline $1.13 \mathrm{~h}$ & 2 & 2 & 1 & 2 & 3 & 2 \\
\hline
\end{tabular}

Maestra: Claro ¿y cómo haces los relevos?

Alumno_6: Pues mira...

Alumno_2: Pues haciendo relevos.

Alumno_5: Cogiendo el palo, dando la vuelta y venir, dejando el palo en el suelo y venir. 
Alumno_2: Pues cuando Alumno_6 llegue al verde que salga el otro, así cuando el otro llegué al verde, que salga el otro.

Alumno_4: Es que, bay muchos verdes.

Alumno_2: Pos... (Ella y Alumno_6 se levantan a señalar el cono verde.)

Maestra: El segundo supongo.

Alumno_2: Ese, al tercero.

Maestra: Ay perdón al tercero.

Alumno_2: En grupo ¿de dos en dos?

\begin{tabular}{|l|l|l|l|l|l|l|}
\hline $1.13 \mathrm{i}$ & 3 & 4 & 1 & 2 & 3 & 2 \\
\hline
\end{tabular}

Maestra: Lo que decidáis, yo digo que he visto ese problema, no sé lo que pensáis vosotros, si no habéis visto ese problema...

Alumno_3: Vamos a jugar...

Maestra: Hay que bacer esto bien, luego jugamos, no os preocupéis.

Alumno_4 pregunta: ¿Cuánto queda?

Maestra: cuarto de hora

Alumno_4 se levanta y tira de Alumno_2: ¡Venga niñas!

\section{CICLO 15}

También dialógico: plantean preguntas, dialogan entre ellos y evaluan sus propuestas Alumno_6: Pues mira, vamos de dos en dos, saltamos ¿no? Y en los relevos esperamos a bacerlo.

Alumno_3 vuelve a preguntar: $Y$ ¿por qué no todos juntos, asi en fila?

Comienza con una nueva pregunta de la profesora, que les hace llegar a una propuesta final y consensuada de mejor y también les permite realizar el circuito de nuevo, para valorar los cambios

\begin{tabular}{|c|c|c|c|c|c|c|}
\hline 1.14 & 3 & 2 & 1 & 2 & 3 & 2 \\
\hline \multicolumn{7}{|c|}{ Maestra: ¡Venga! ¿Cómo lo hacéis para hacerlo bien? } \\
\hline $1.14 \mathrm{a}$ & 3 & 2 & 1 & 2 & 3 & 2 \\
\hline \multicolumn{7}{|c|}{ Voluntario_4: ¿Tenéis que pensarlo todavía? } \\
\hline $1.14 \mathrm{~b}$ & 3 & 2 & 1 & 2 & 3 & 2 \\
\hline
\end{tabular}

Maestra: ¡Pensad!

Alumno_4: ¡De dos en dos! Cuando lleguemos por aqui sale el otro.

Alumno_3: Pero mira, la salida, esto es de prueba, salid las dos.

Alumno_1: Yo no quiero ir con Alumno_6.

Alumno_2 y Alumno_4 llegan al cono que han dicho antes y sale Alumno_5 y Alumno_3

Al llegar a la prueba de las colchonetas Alumno_3 dice: $Y$ ahora ya salen otra ver. ellos.

Alumno_4: Y vamos siguiendo. 


\section{Apéndice $B$}

Alumno_2: Pero es que es mejor que cuando nosotros, en vez. de llegarnos por este (señala una pica amarilla), llegamos por este (señala otra anterior) que salga el siguiente es que, si no, tenemos que esperarlos igual.

Alumno_4: No mira.

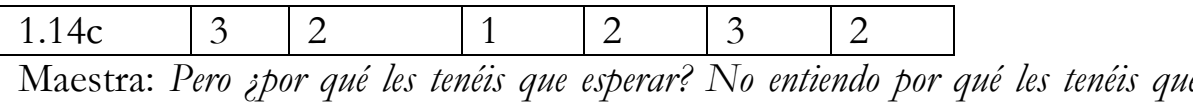
esperar.

Alumno_3: Y ¿por qué no todos?

Maestra: ¿Por qué les tenéis que esperar?

Alumno_6: Pues mira, vamos de dos en dos, saltamos ¿no? Y en los relevos esperamos a bacerlo.

Alumno_3 vuelve a preguntar: $Y$ ipor qué no todos juntos, asi en fila?

\begin{tabular}{|l|l|l|l|l|l|l|}
\hline $1.14 \mathrm{~d}$ & 2 & 2 & 1 & 2 & 3 & 2 \\
\hline
\end{tabular}

Maestra: Yo veo el problema alli (zona de relevos) que hacéis relevos...

Alumno_3: Pero si lo de los relevos es lo que ha estado mejor.

\begin{tabular}{|l|l|l|l|l|l|l|}
\hline $1.14 \mathrm{e}$ & 2 & 4 & 1 & 2 & 3 & 2 \\
\hline
\end{tabular}

Maestra: V ale, hacerlo como queráis, yo no digo más, yo no digo más, como queráis, yo no digo más, jvenga va! ¿Cómo, por parejas, en fila o qué?

Se acaban colocando por parejas

Comienza Alumno_4 y Alumno_2 y al llegar a la tercera pica amarilla dice Alumno_4: jNiñas salid! Salen Alumno_3 y Alumno_5.

En la prueba de relevos vuelven a esperar por los demás, cuando ya están todos forman grupos, de modo que cada miembro de la pareja está en uno, y hacen la carrera. Finalmente hacen la carrera de marcha. 


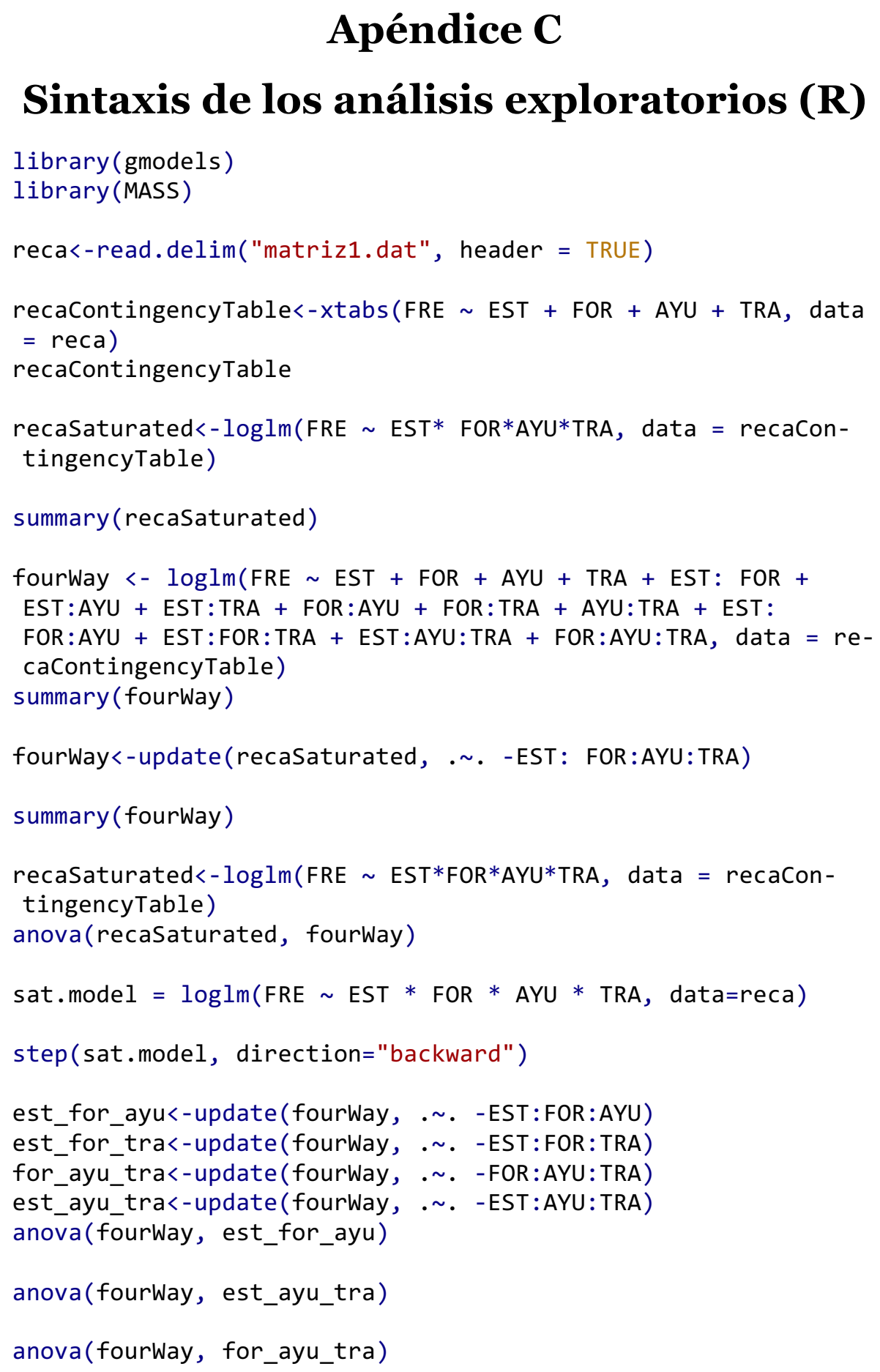


Apéndice $C$

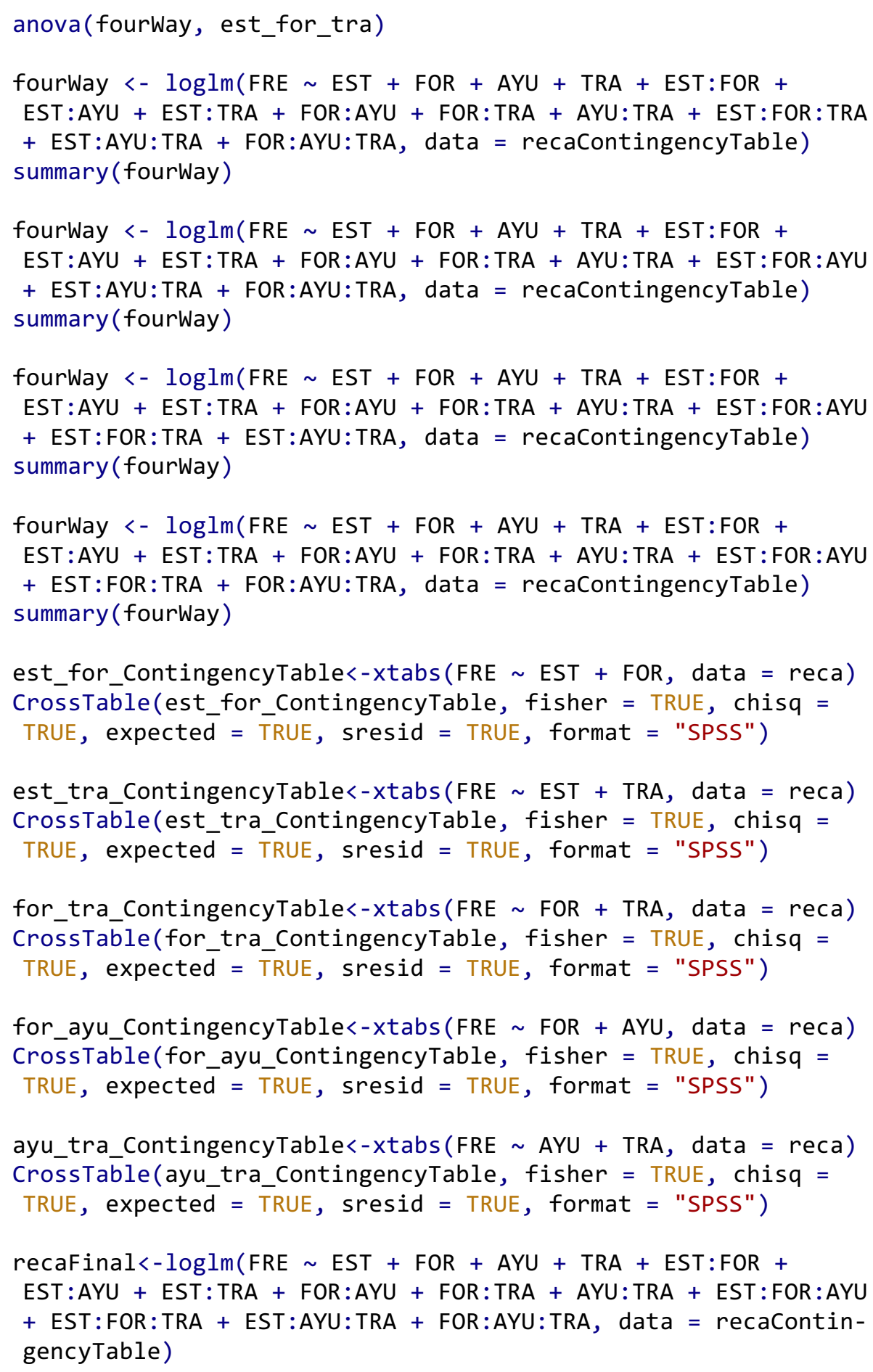




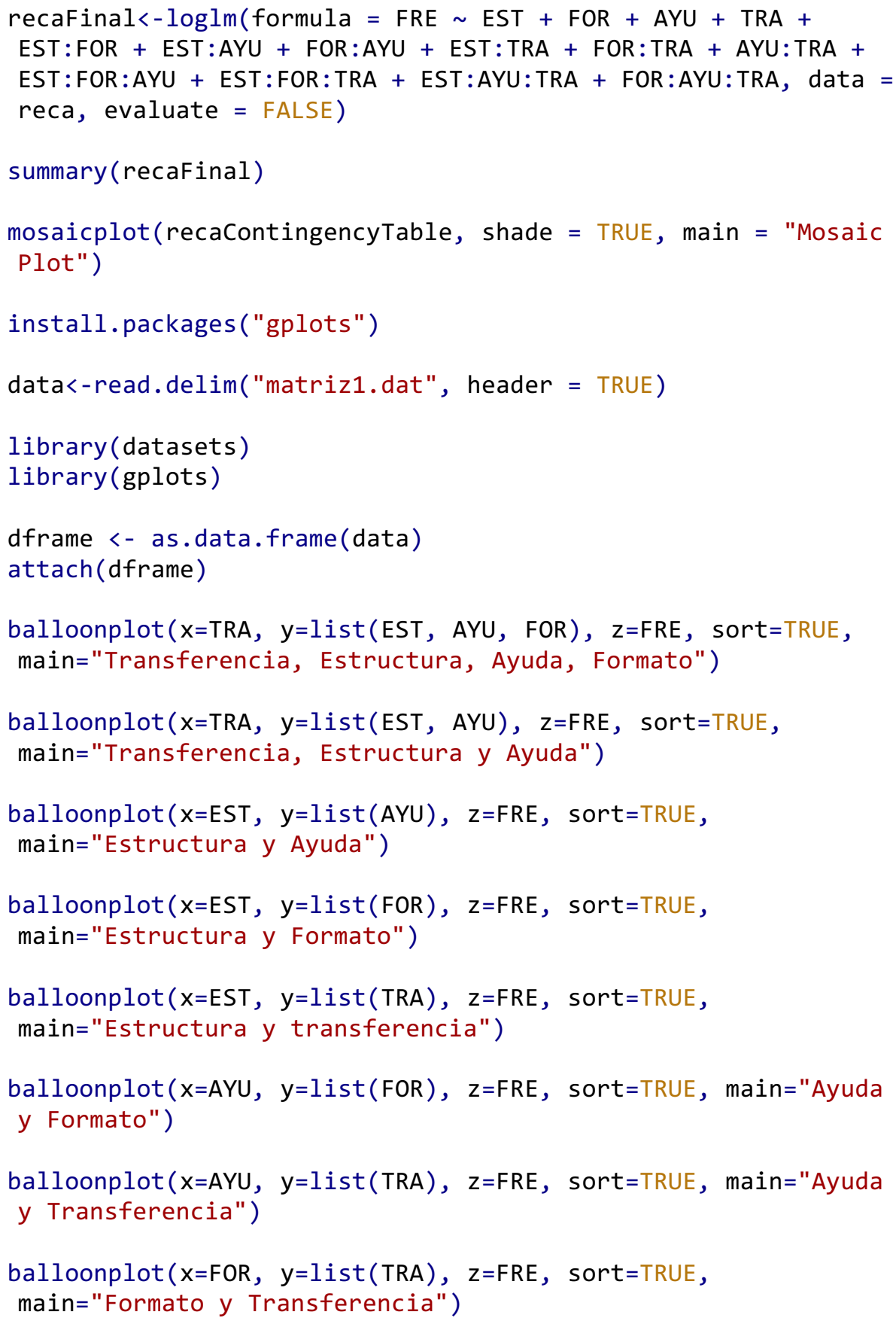




\section{Apéndice D}

\section{Sintaxis del análisis logarítmico-lineal (R)}

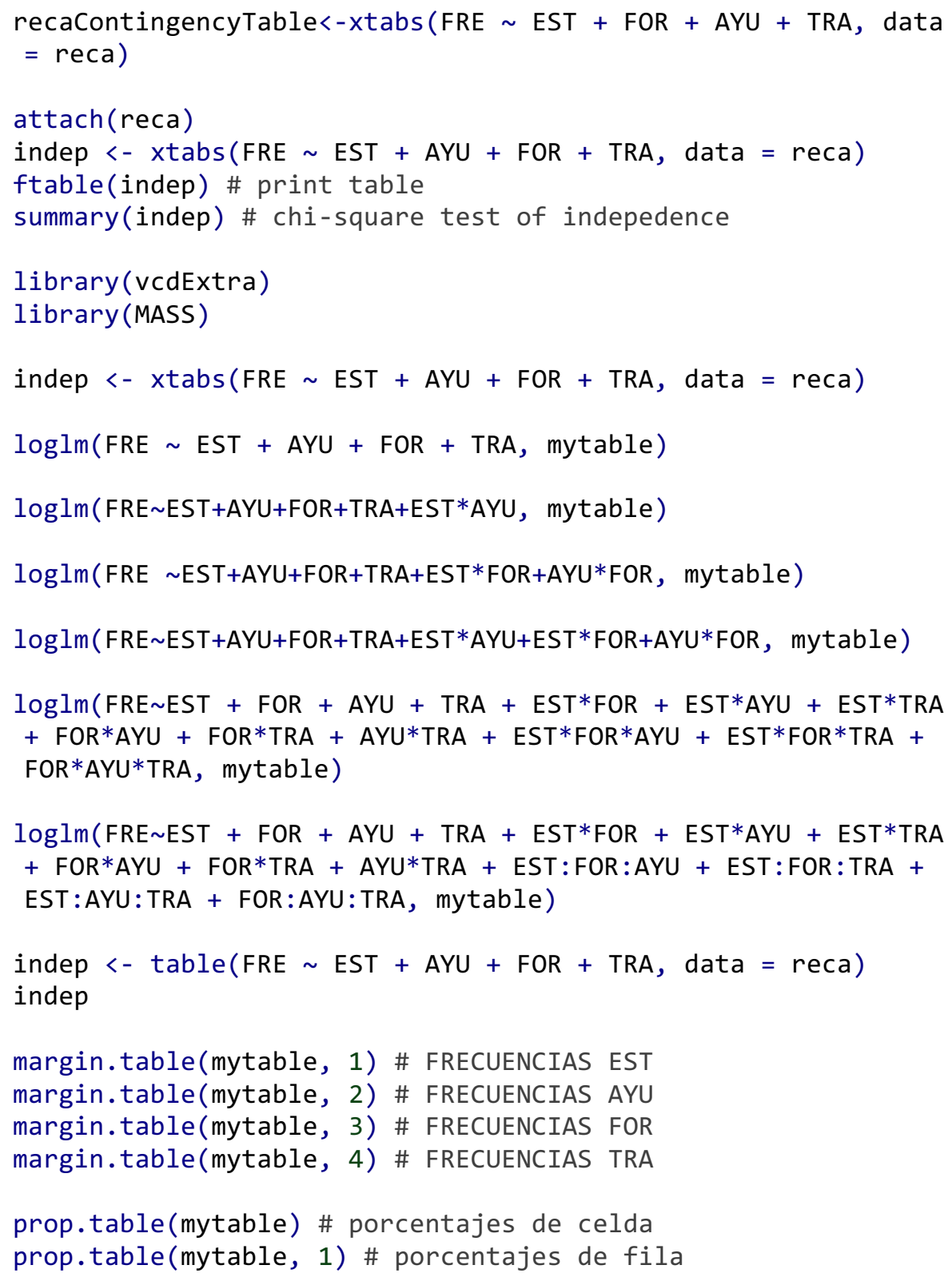




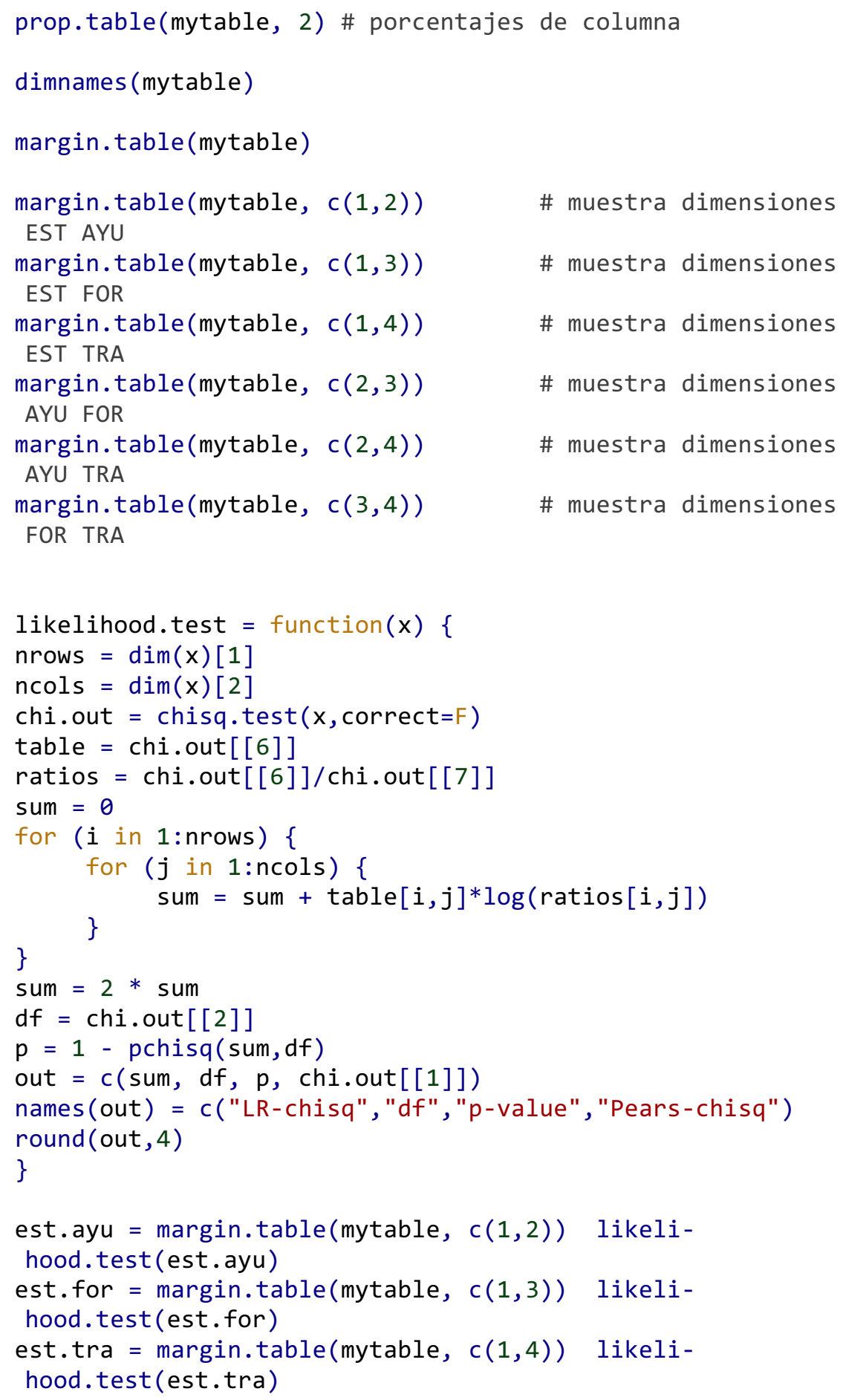


Apéndice $D$

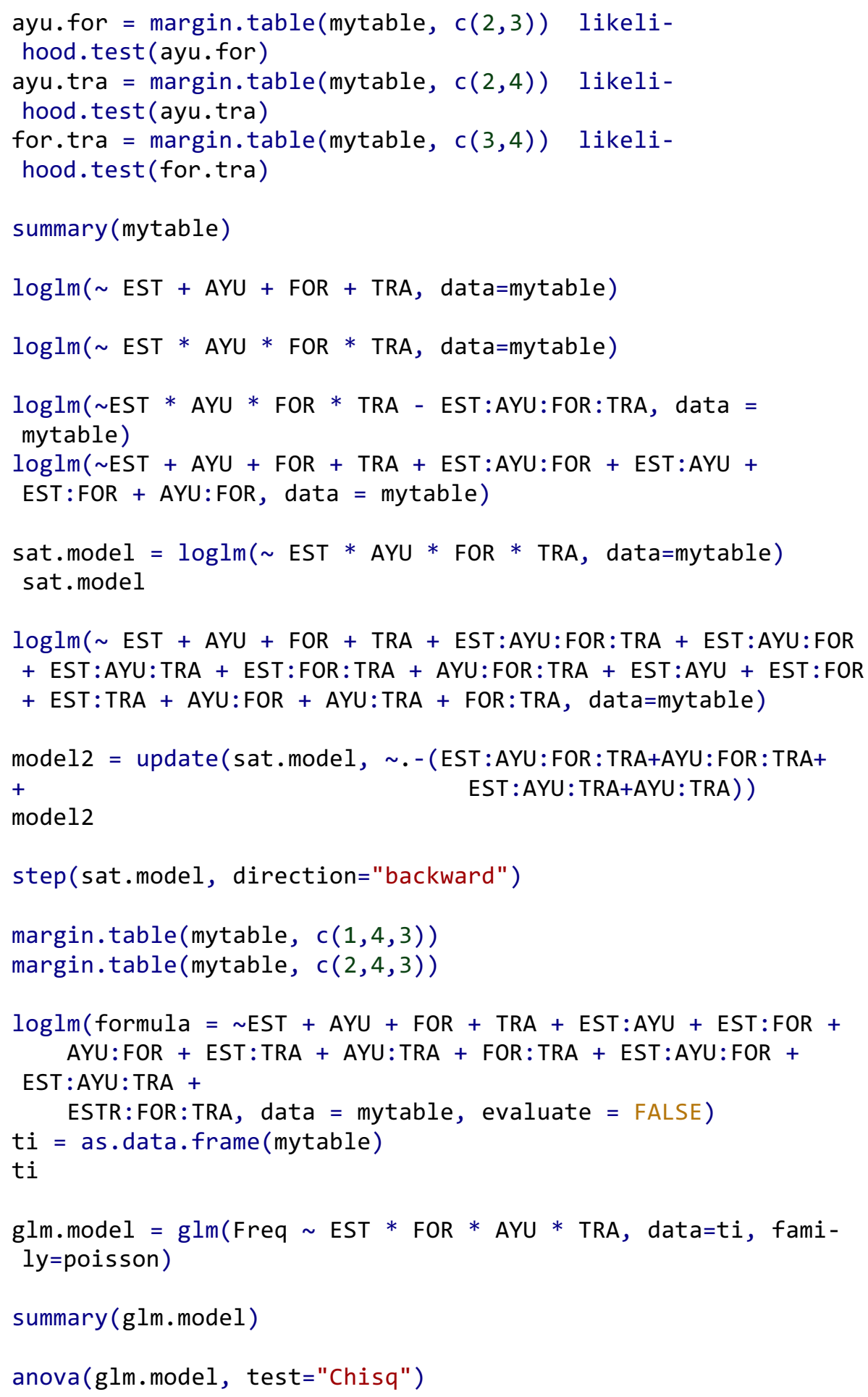




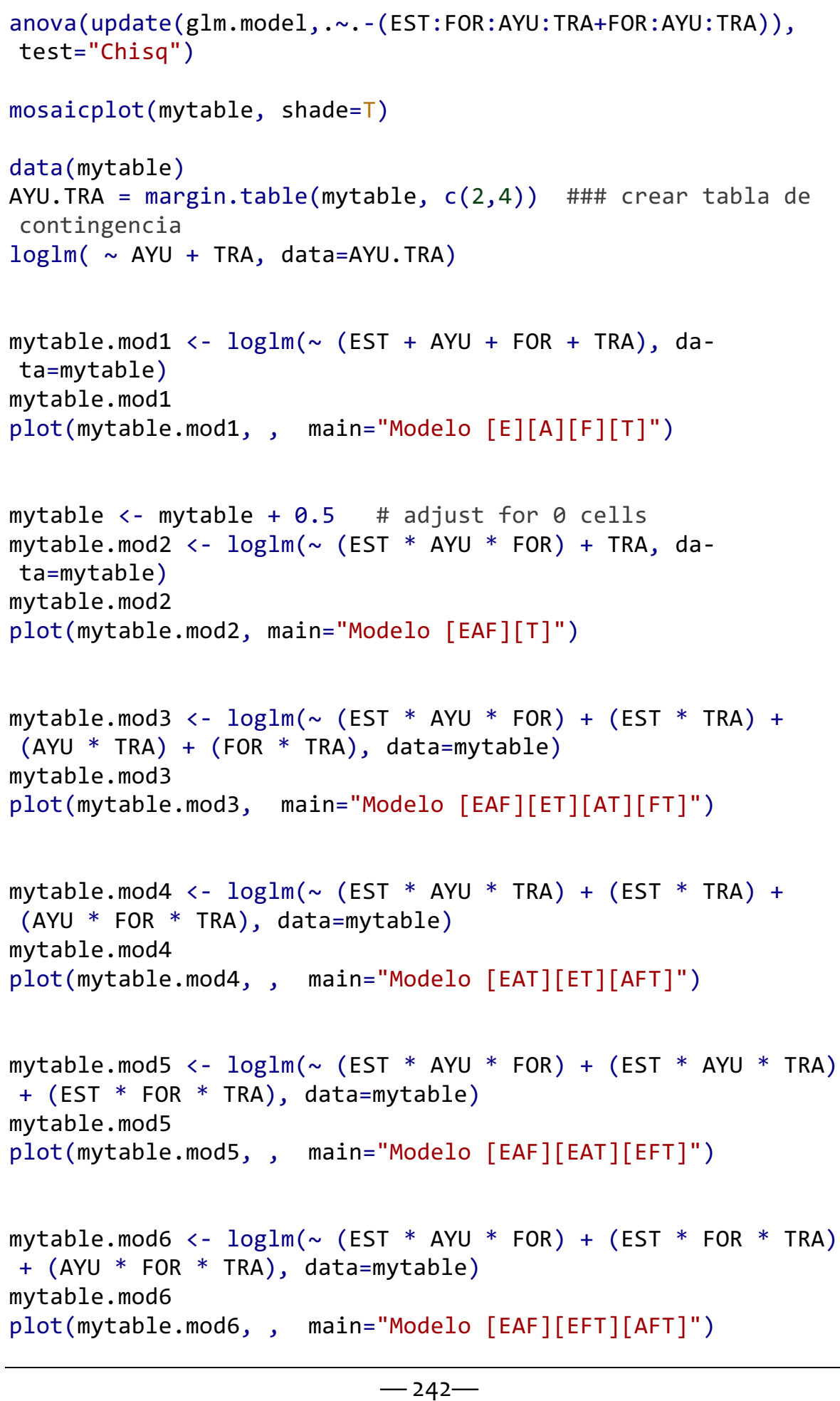


Apéndice $D$

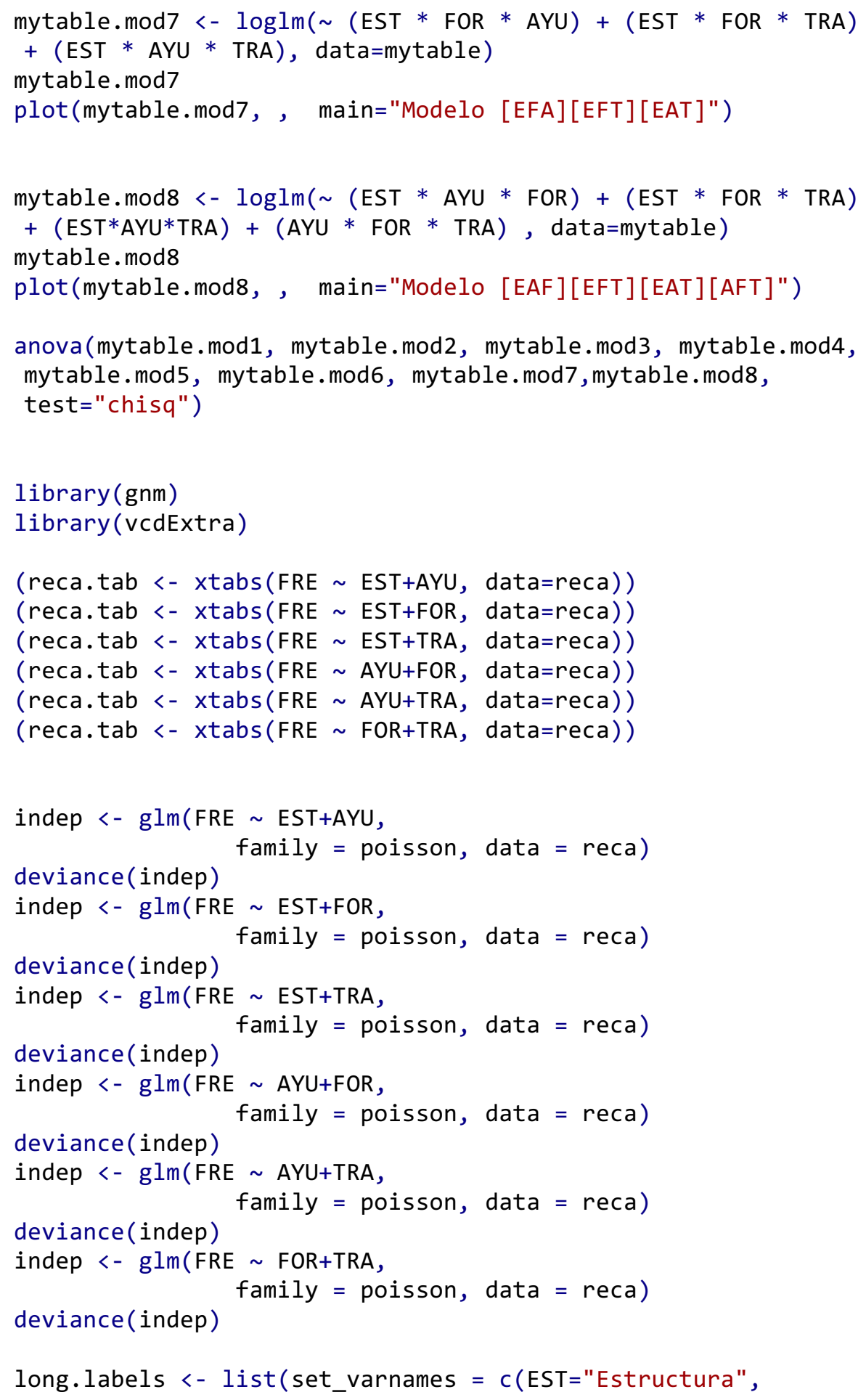




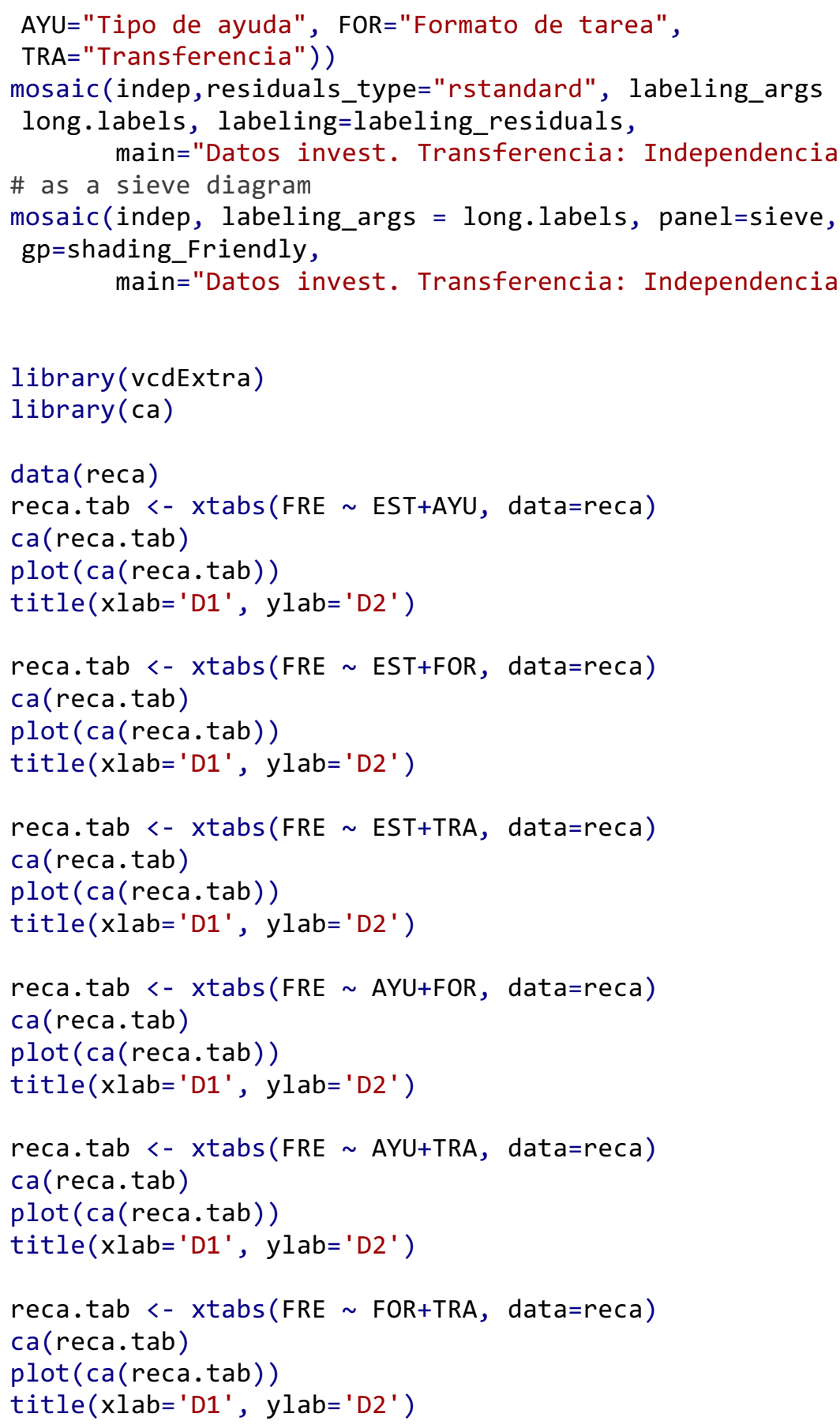




\section{Apéndice E}

\section{Sintaxis del análisis de regresión logísti- ca (SAS)}

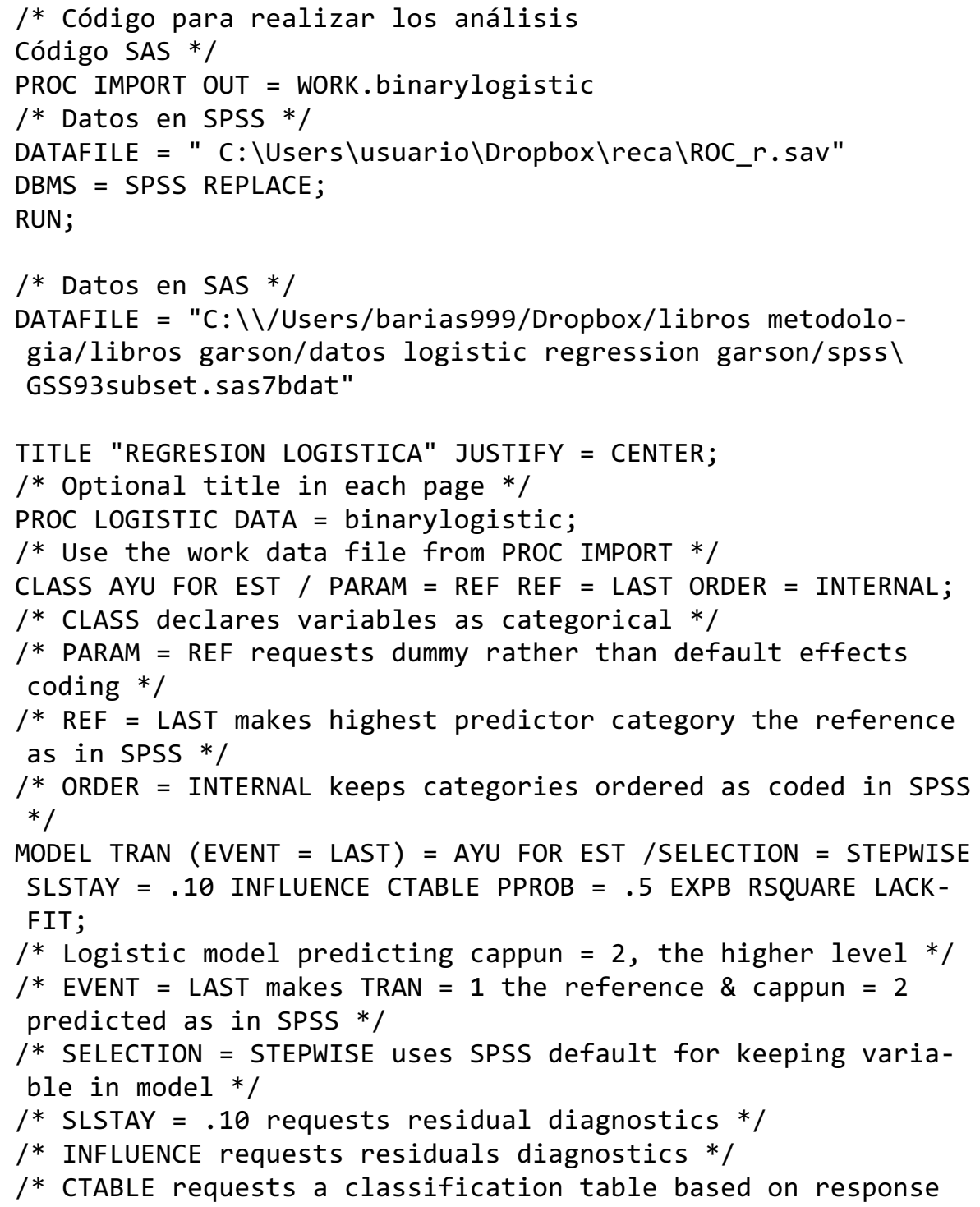




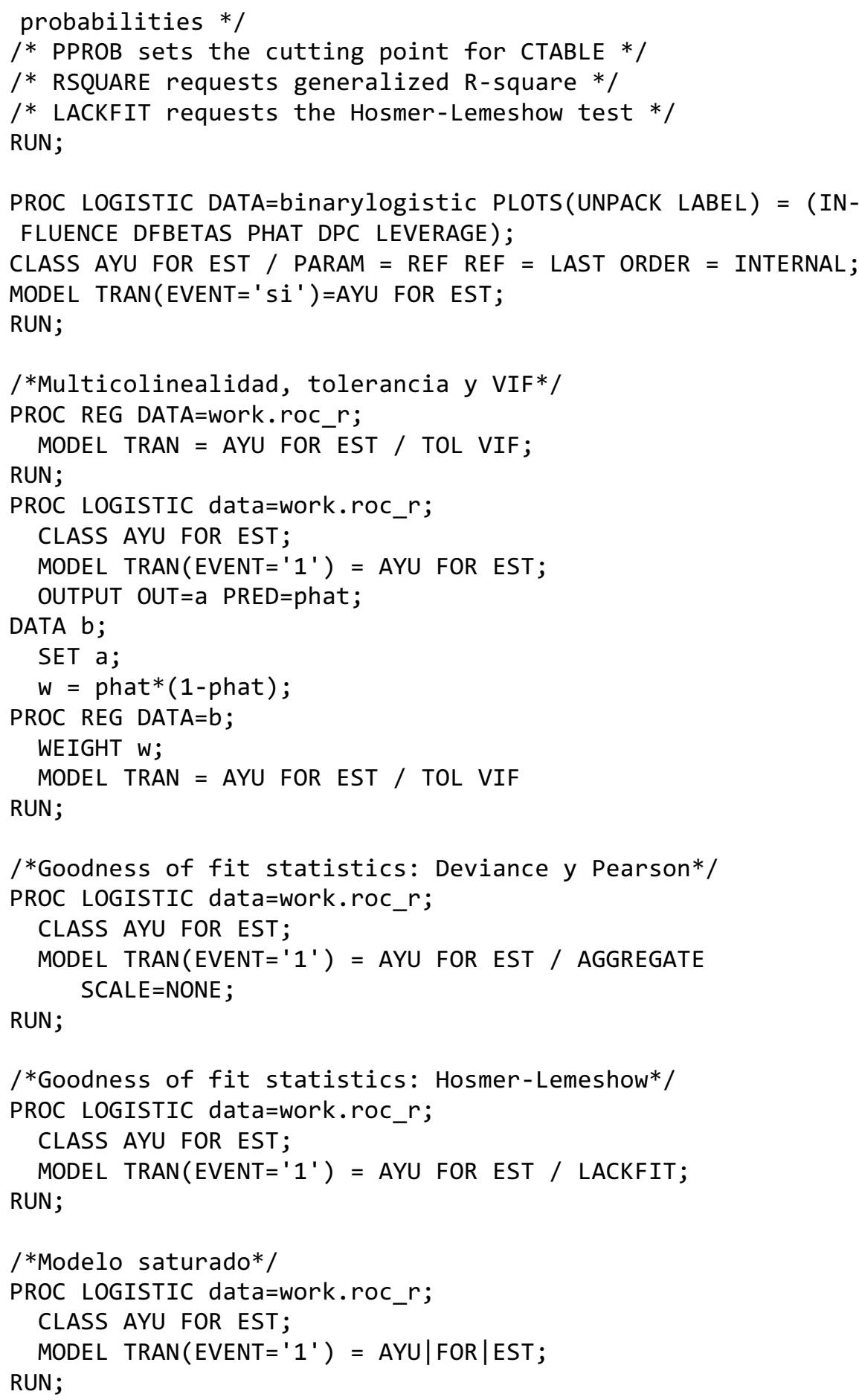


Apéndice $E$

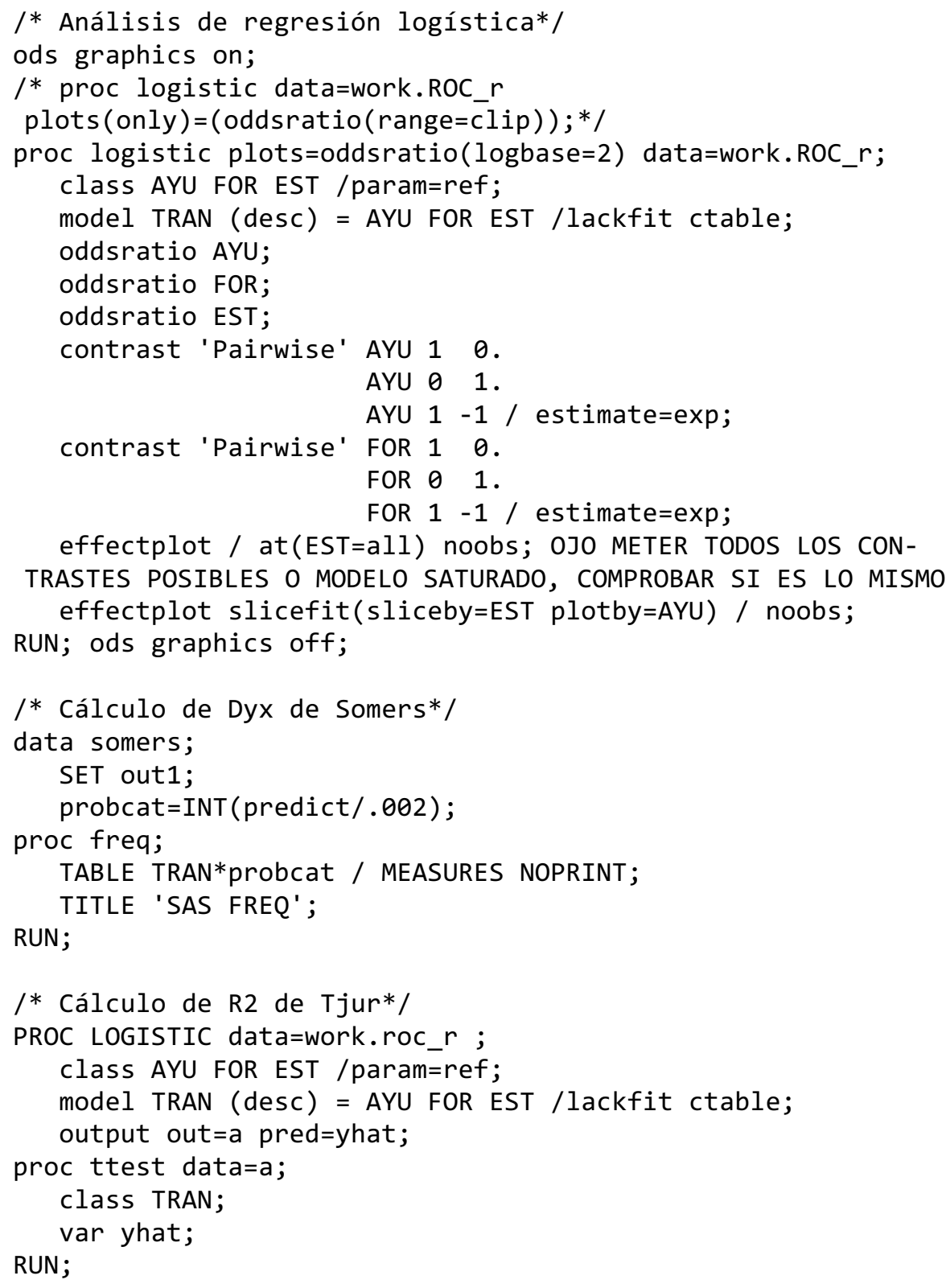




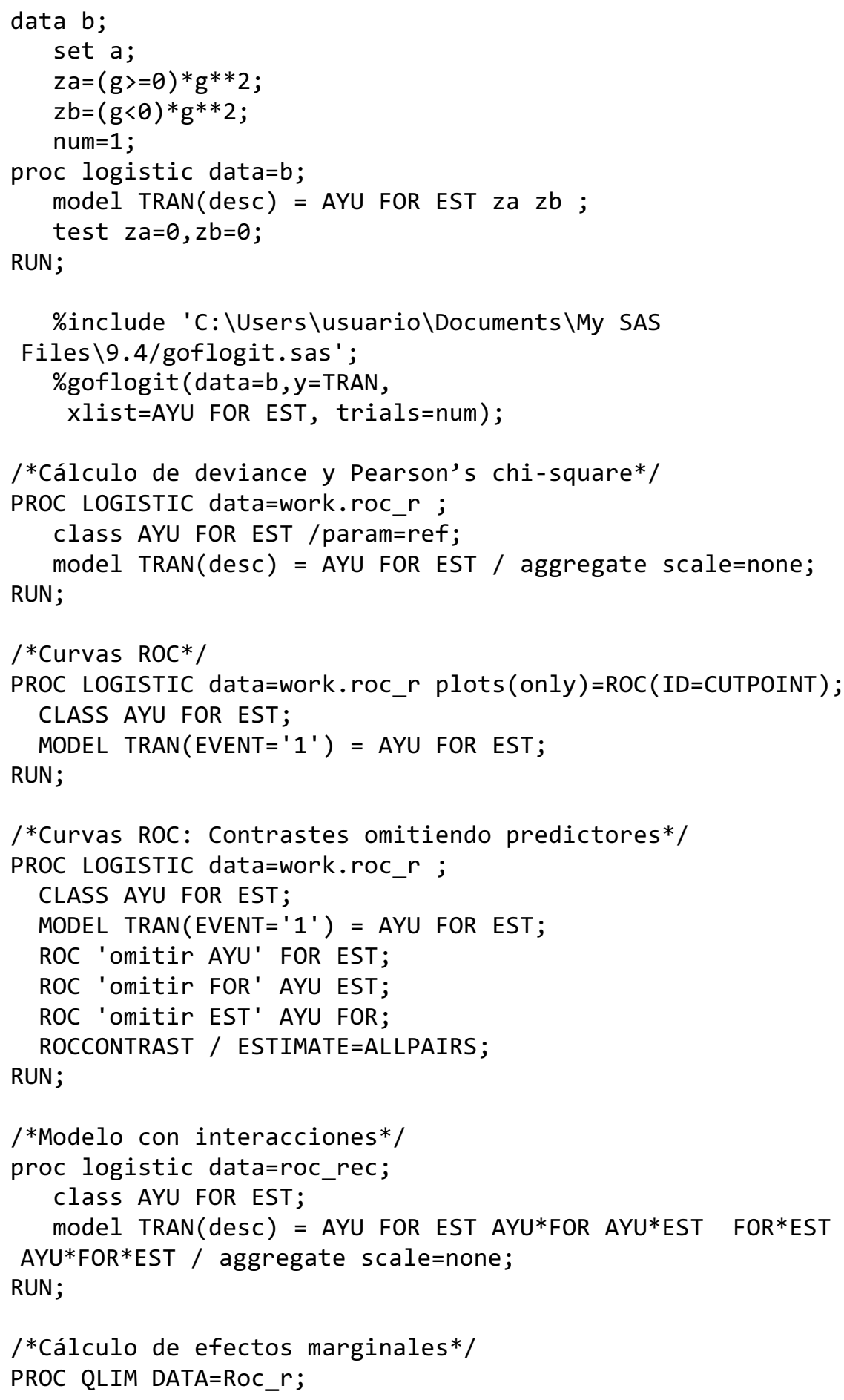


Apéndice $E$

ENDOGENOUS TRAN DISCRETE(DIST=LOGISTIC);

Class AYU FOR EST;

MODEL TRAN = AYU FOR EST;

OUTPUT OUT=a MARGINAL;

PROC PRINT DATA $=a(O B S=10)$;

VAR meff_p2_AYU meff_p2_FOR meff_p2_EST; RUN;

/*Predicted values, residuals, influence statistics, gráficos independientes*/

PROC LOGISTIC data=work.roc_r PLOTS(UNPACK LABEL) =

(INFLUENCE DFBETAS PHAT DPC LEVERAGE);

class AYU FOR EST;

MODEL TRAN $\left(\right.$ EVENT $\left.=1^{\prime} 1^{\prime}\right)$ = AYU FOR EST;

RUN;

/*Predicted values, residuals, influence statistics, gráficos agrupados*/

PROC LOGISTIC data=work. roc $r$ PLOTS $=$

(INFLUENCE DFBETAS PHAT DPC LEVERAGE);

class AYU FOR EST;

MODEL TRAN $\left(\right.$ EVENT $\left.=1^{\prime} 1^{\prime}\right)$ = AYU FOR EST;

RUN; 


\section{Apéndice $\mathbf{F}$}

\section{Código de otros análisis (R)}

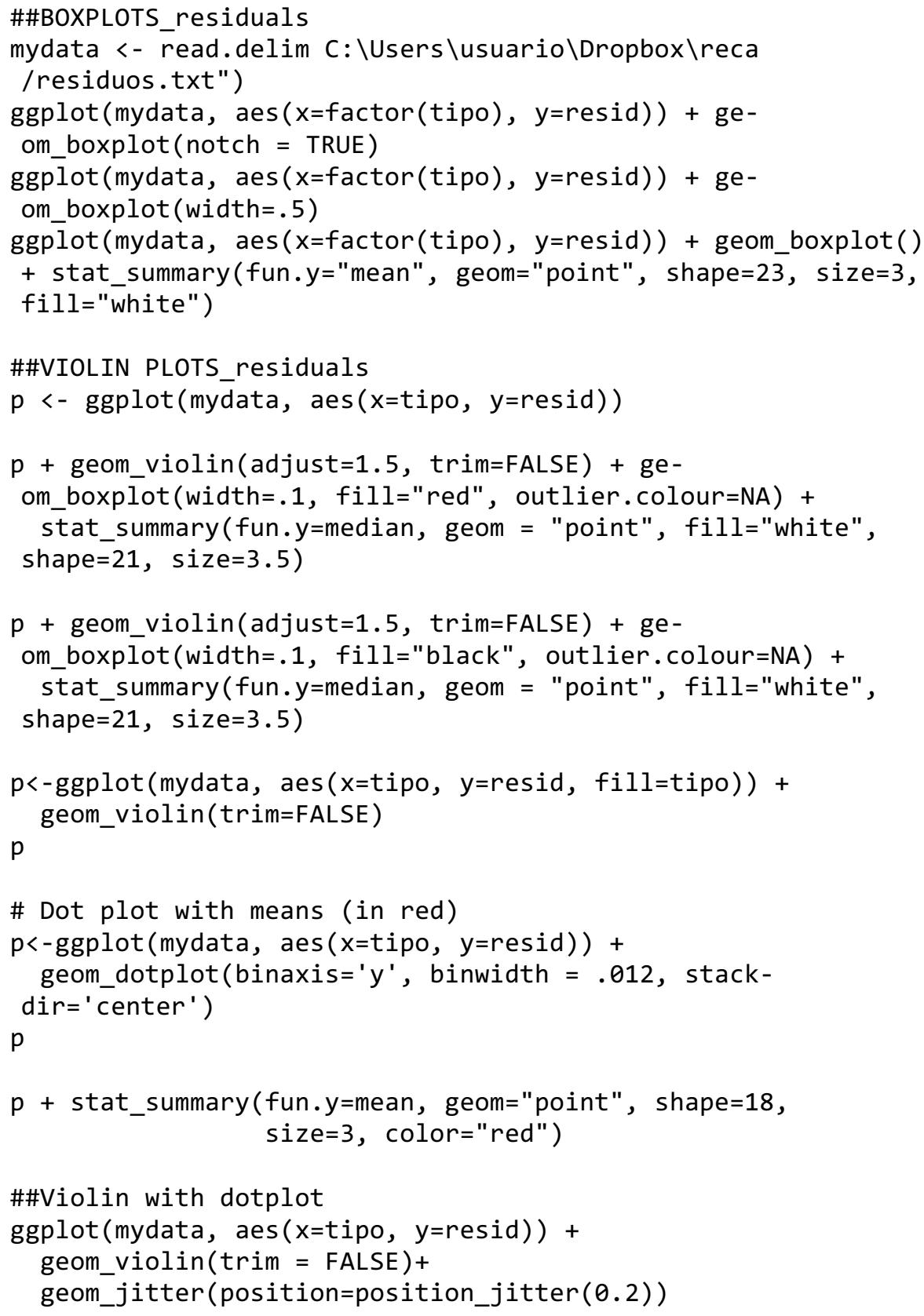




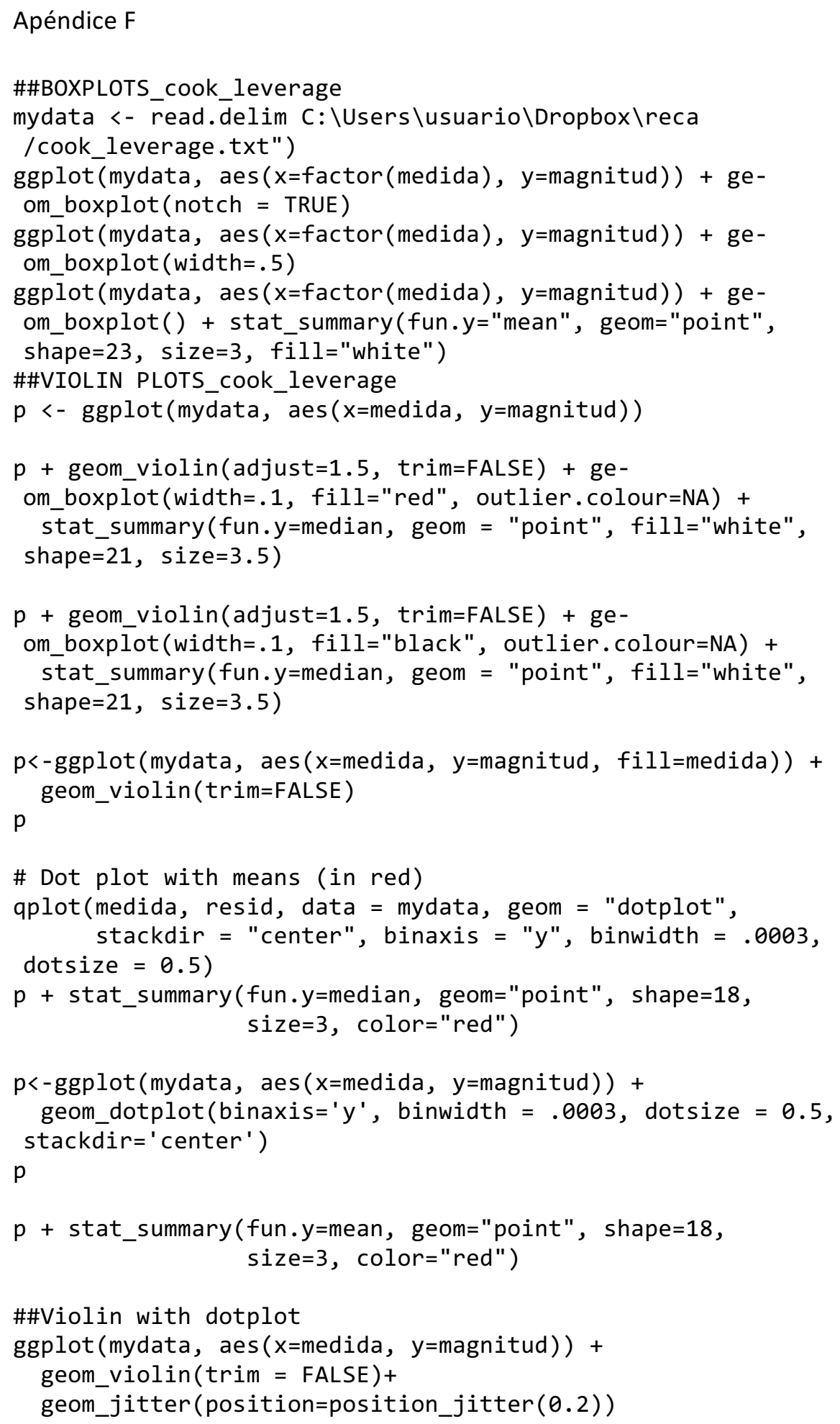




\section{Apéndice G \\ Código de otros análisis (STATA)}

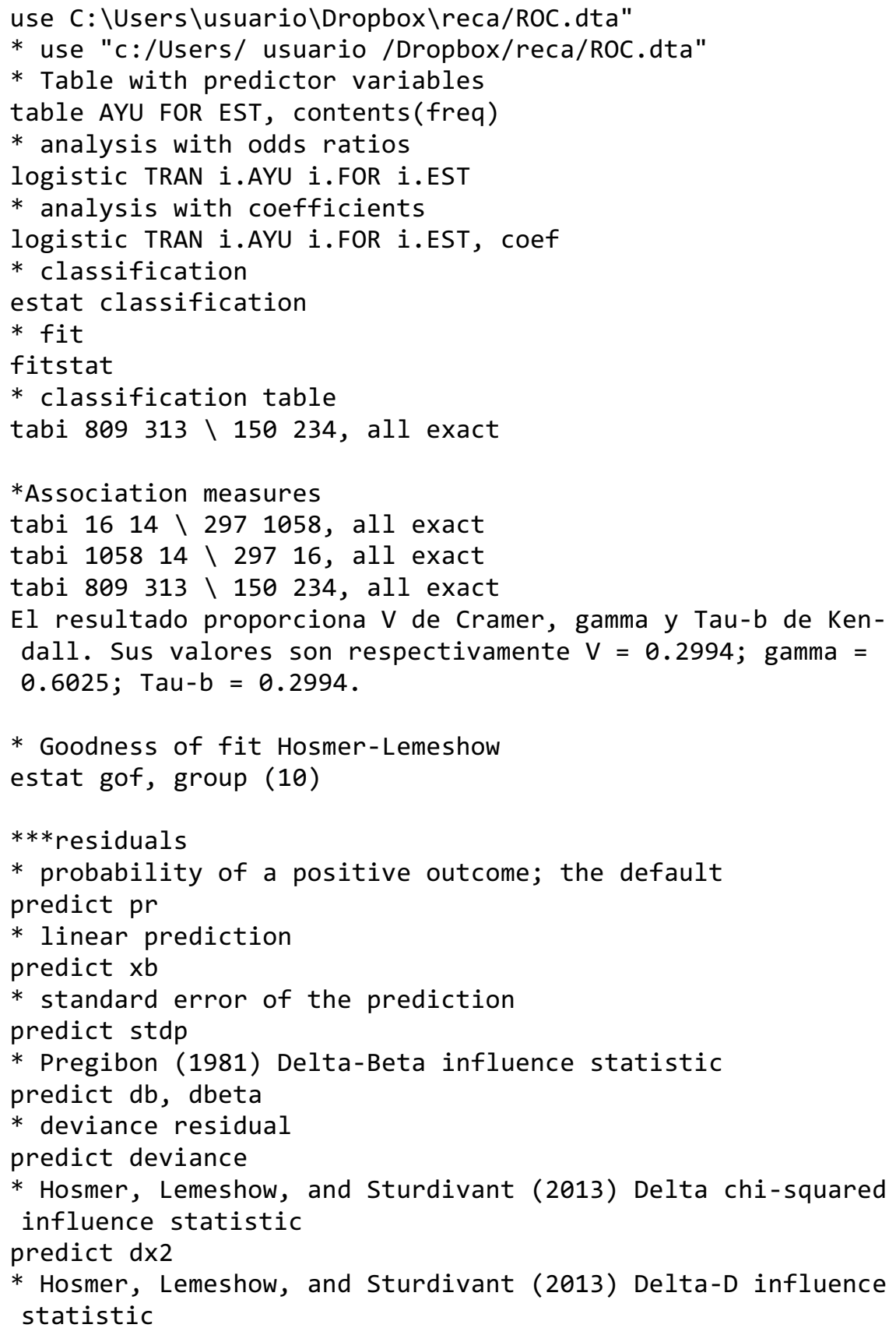


Apéndice $\mathrm{G}$

predict ddeviance

* Pregibon (1981) leverage

predict hat

* sequential number of the covariate pattern predict number

* Pearson residuals; adjusted for number sharing covariate pattern

predict res1, residuals

* standardized Pearson residuals; adjusted for number sharing covariate pattern

predict res2, rstandard

* first derivative of the log likelihood with respect to $\mathrm{xb}$ predict score

* ldfbeta

predict 1 dfbeta

* Plotting

gen casenum $=\_n$

rename casenum id

scatter $\mathrm{db}$ id in $1 / 100, \mathrm{mlab}$ (id)

scatter db id,mlab(id)

* Box Tidwell

boxtid logit TRAN AYU FOR EST

* ROC curve

lroc, nograph

lroc

* ROC curves comparison

use "/Users/usuario/Dropbox/reca/ROC.dta", clear

* ROC curve with AYU

logistic TRAN i.AYU

estat classification

lroc, nograph

predict $x b 1, x b$

* ROC curve with FOR

logistic TRAN i.FOR

estat classification

lroc, nograph

predict $x b 2, x b$

* ROC curve with EST

logistic TRAN i.EST

estat classification

lroc, nograph

predict $x b 3, x b$ 


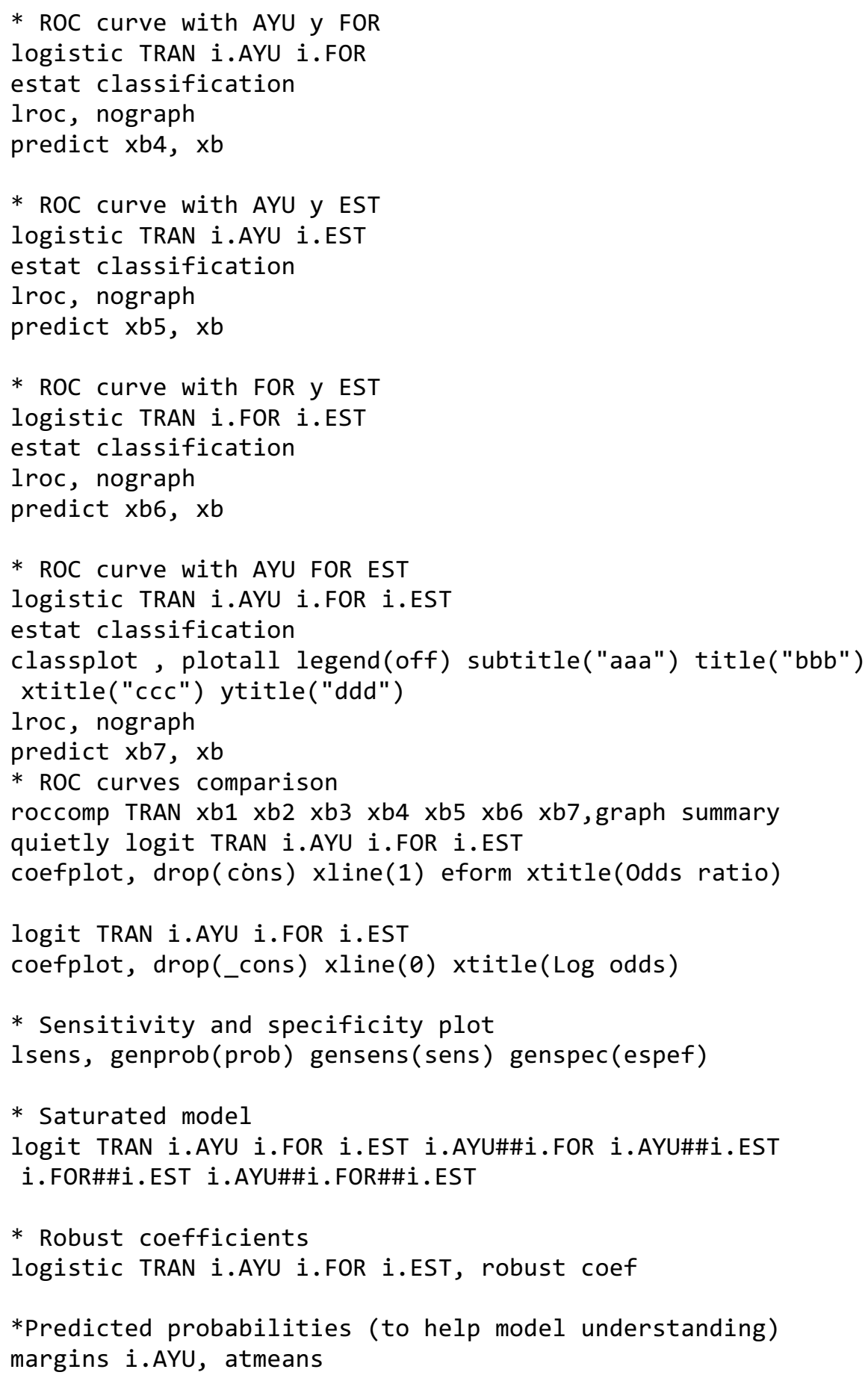




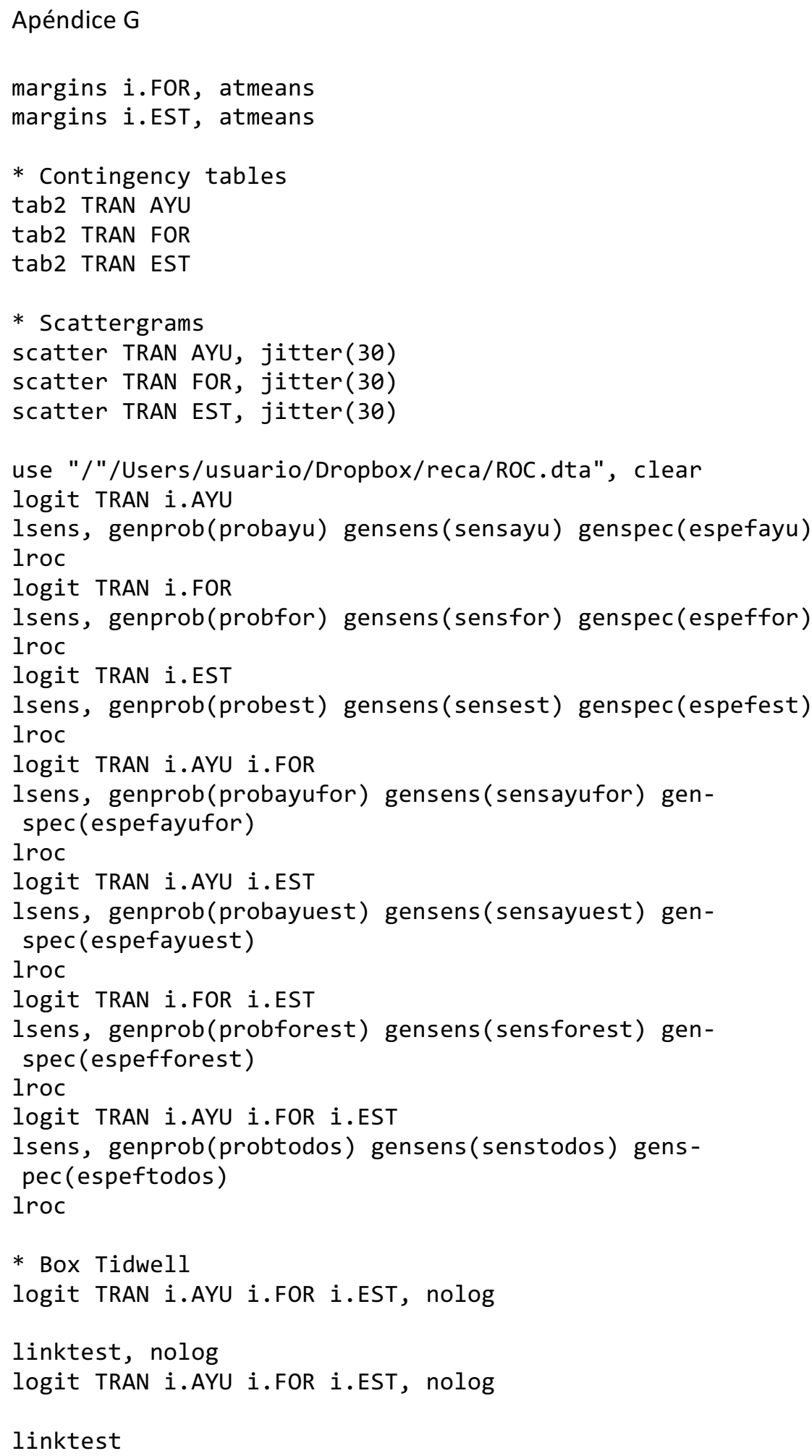


logit TRAN i.AYU i.EST

linktest

logit TRAN i.AYU i.EST i.FOR

linktest

logit TRAN i.AYU i.FOR, nolog

linktest, nolog

boxtid logit TRAN i.AYU i.FOR

logit TRAN i.AYU i.EST, nolog

linktest, nolog

* Diagnóstico de regresión y de residuos (Se generan nuevas variables en base de datos)

ldfbeta

* Prueba de Hosmer Lemeshow

estat gof, group (10) table 


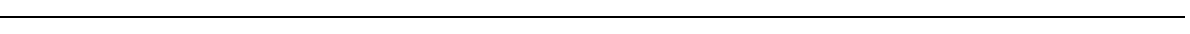

